Structural and functional studies of theYersinia ruckeri inverse autotransporters

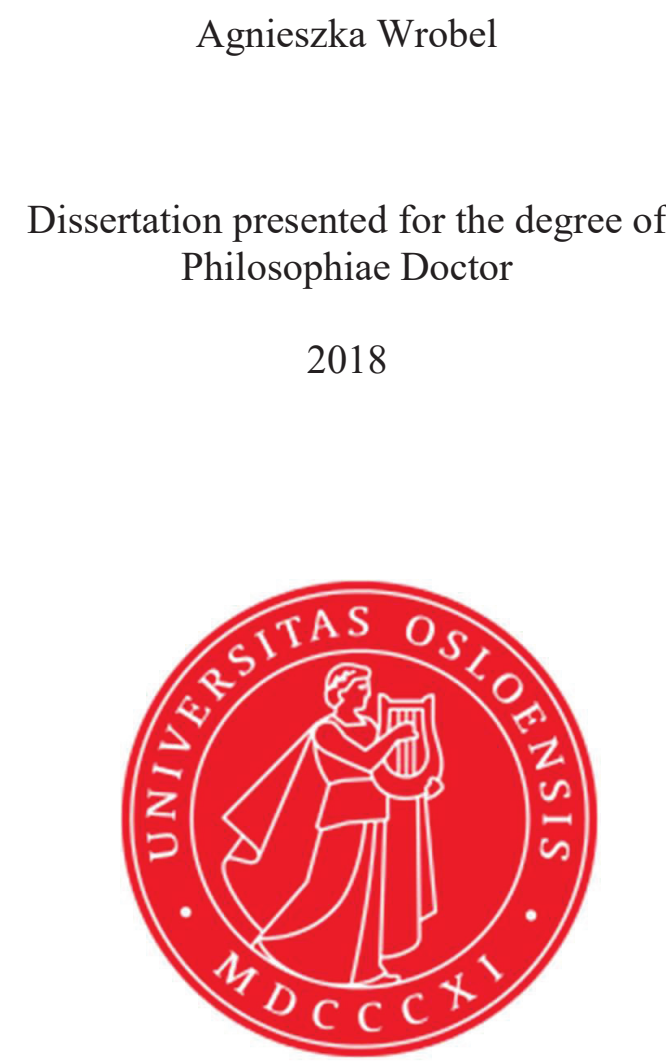

Section for Genetics and Evolutionary Biology

Department of Biosciences

Faculty of Mathematics and Natural Sciences

University of Oslo 
(C) Agnieszka Wrobel, 2019

Series of dissertations submitted to the Faculty of Mathematics and Natural Sciences, University of Oslo No. 2072

ISSN 1501-7710

All rights reserved. No part of this publication may be reproduced or transmitted, in any form or by any means, without permission.

Cover: Hanne Baadsgaard Utigard.

Print production: Reprosentralen, University of Oslo. 
However difficult life may seem, there is always something you can do and succeed at. It matters that you don't just give up.

Stephen Hawking 



\section{Acknowledgments}

$\mathrm{PhD}$ is a journey. It has the start and the end. But every journey is unique. Unique because of all the people you meet on the way. Without them, the journey wouldn't be possible to accomplish. That is what makes the journey so special.

First of all, I would like to thank my supervisors, Prof. Dirk Linke and Prof. Gareth Wyn Griffiths for their guidance throughout the $\mathrm{PhD}$ period. Dirk, I would like to thank you for giving me this great opportunity of being a part of your research group. Thank you for your support, your patience, for believing in my research ideas and for giving me a lot of freedom in research. Thank you for teaching me how to become an independent scientist and for giving me the opportunity to attend international conferences, especially the Gordon Research Conference in the US.

I would also like to thank the University of Oslo for funding this research project.

I would like to thank all Leo and Linke lab members. I would like to direct special thanks to Jack C. Leo for his kindness, wisdom and for all brilliant ideas he gave me. Athanasios Saragliadis, Daniel Hatlem, Kenneth Schneider, Nadeem Joudeh, Marcella Orwick Rydmark, Marcin Michalik, Thomas Trunk, Nandini Chauhan, Krystyna Liskewicz, Hawzeen Salah Khalil, Daniel Hatlem - thank you for being awesome colleagues and friends. Thomas, thank you for patiently listening to our sometimes long conversations in Polish. Marcella, thank you for your advice, support and smile. Krystyna, thank you for baking cakes. Marcin, thank you for being a great friend and for making my $30^{\text {th }}$ birthday so special. Kenneth Schneider, thank you for introducing me into the world of material science. Nadeem Joudeh and Athanasios Saragliadis, thank you for kindness, support and your encouragement that "I can do it”. Thank you all former lab members, Anja Rudd Winther, Dasaradhi B RKG Udatha, Keshav Raj Bhusal, Eric Torgeman for being great colleagues. Thank you all for your encouragement and faith in me. 
Thank you to all people from EVOGENE. Special thanks to Prof. Reidunn Aalen, Roy Falleth, Bård Enger Mathiesen for being a part of my teaching journey. Thank you for all the nice discussions we have had together. Roy and Bård, thank you for helping me in preparation of lab exercises for the courses I was teaching. Thanks to the Koomey group, Nelson Wang and Chris Hadijneophytou for being great friends.

Thank you Prof. Fahri Saatcioglu for giving me the opportunity to teach MBV3020. Thank you to all your present and former lab members for being helpful. Special thanks to Nora Pällmann and Sonja Kistenich for being awesome friends and making my PhD journey pleasant. Nora, thank you for all the nice dinners we have had together, the hiking trips, the long conversations and traveling stories. Sonja, thank you for teaching me joggling and for being supportive throughout my $\mathrm{PhD}$.

Claudio Ottoni, thank you for teaching me bioinformatics and for being helpful and kind. Mads Bengtsen, thank you for your help with qRT-PCR. Frederico Fenaroli, thank you for teaching me how to inject zebrafish embryos.

Thank you to all our collaborators at the UiO and NMBU. Special thanks to Prof. Henning Sørum for giving me the opportunity to work at NMBU. Thank you Stine Braaen for helping with the fish cell lines experiments. Thank you for being kind and helpful whenever I needed it.

Thank you to the lab members at the research group of Prof. Jan Tommassen at the Utrecht University for being fantastic and helpful colleagues during my 3-monthlong visit. Special thanks to Jesús Andrés Arenas Busto for his research guidance, support, discussions, encouragement and for making my stay in Utrecht pleasant and nice. Jesús Pérez-Ortega, thank you for helping me with the confocal microscope and for being a great friend.

Thank you to all my amazing friends, especially to Maryia Khomich, for your support throughout the duration of my PhD.

Tusen takk til Anders Eckhoff og Wenche Kvalstad Eckhoff for å være mine norske foreldre. Tusen takk for at vi kunne feire min bursdag sammen. Tusen takk for 
felles middager, varme rundstykker på morningen, utallige norske samtaler, og varme som dere ga meg.

Specjalne podziękowania dla mojej rodzinki, szczególnie dla moich ukochanych rodziców i siostry. Dziękuje za Wasze wsparcie moralne i emocjonalne w trakcie trwania doktoratu. Nie ma słowa, które mogłoby wyrazić jaka jestem szczęśliwa, że Was mam. Dziękuję za wszystko, co dla mnie zrobiliście. Kocham Was! Specjalne i największe podziękowania chciałabym skierować do mojego ukochanego narzeczonego, Piotrka. Kochanie, dziękuję za Twoje wsparcie, miłość, cierpliwość i wiarę w mnie. Kocham Cię.

Agnieszka Wróbel

Oslo, November 2018 



\section{LIST OF PAPERS}

I. Wrobel A., Ottoni C., Leo JC., Gulla S., Linke D. The repeat structure of two paralogous genes, Yersinia ruckeri invasin (yrInv) and a "Y. ruckeri invasin-like molecule", (yrIlm) sheds light on the evolution of adhesive capacities of a fish pathogen. 2017. Journal of Structural Biology, 201(2): 171-183. DOI: https://doi.org/10 $.1016 /$ j.jsb .2017 .08.008

II. Wrobel A., Liskiewicz K., Saragliadis A., Schneider K., Leo JC., Arenas J., Linke D. Y. ruckeri NVH_3758 inverse autotransporters contribute to biofilm formation. Manuscript

III. Wrobel A., Ottoni C., Leo JC., Linke D. pYR4 from a Norwegian isolate of $Y$. ruckeri is a putative virulence plasmid encoding both a type IV pilus and a type IV secretion system. 2018. Frontiers in Cellular and Infection Microbiology, 8(373): 1-14. DOI: https://doi.org/10 .3389/fcimb .2018 .00373 
Papers not included in the thesis, but written in the course of the $\mathrm{PhD}$ studies:

I. Chauhan N., Wrobel A., Skurnik M., Leo JC. 2016. Yersinia adhesins: An arsenal for infection. Proteomics Clinical Applications, 10 (9-10): 949-963. DOI: https://doi.org/10.1002 /prca.201600012. 


\section{THESIS SUMMARY}

Yersinia ruckeri is the causative agent of Enteric Redmouth Disease (ERM), a serious bacterial infection in marine and freshwater fish. Y. ruckeri was first documented in the 1950s in Hagerman Valley in Idaho, USA. Since its first isolation, the bacterium has spread over the entire globe. The outbreaks have been reported in various European countries and in the USA in intensively cultured fish species such as rainbow trout and Atlantic salmon. Losses of $10-25 \%$ of the fish population are common. If the disease is left untreated, the mortality rate may exceed $75 \%$. To a certain extent, ERM is well-controlled by the use of vaccines and antibiotics. Due to the high effectiveness of the vaccines available on the market, there was little interest in research on pathogenicity of $Y$. ruckeri, and therefore relatively little is known about the virulence factors associated with the pathogen.

Inverse autotransporters (IATs) are virulence-associated proteins widely distributed in Gram-negative bacteria. IATs share a common domain architecture: they are composed of an N-terminal signal peptide, a transmembrane $\beta$-barrel and a $\mathrm{C}$-terminal passenger. IATs are part of the recently identified type $\mathrm{V}$ secretion system (T5SS). They play a role in bacterial adherence to host cells and tissues. Apart from the well-characterized example IAT from enteropathogenic Yersiniae, invasin, little is known about the structure and function of IATs in Yersiniae.

The results presented in the thesis show two IATs: $y r I n v$ (for $Y$. ruckeri invasin) and yrIlm (for Y. ruckeri invasin-like molecule) from the highly

pathogenic Y. ruckeri NVH_3758 (NVH_3758) isolate. Due to the encountered challenges in amplifying the highly repetitive IAT genes and the 
lack of genomic information on NVH_3758, the genome of NVH_3758 was sequenced using single molecule real-time (SMRT) sequencing technology (hereafter just PacBio). PacBio offers some of the longest average length reads compared to second generation (SGS) technology. The new genomic information showed that IATs are variably present in Y.ruckeri strains and that their length also varies. The domain organization of the $y r I n v$ gene is the same among different $Y$. ruckeri strains. The internal repeats of the yrInv gene product are highly diverged, even though they represent similar Ig-like domains as in yrIlm. Y. ruckeri IATs are differentially expressed and their expression is regulated by environmental conditions relevant for pathogenesis. Both IATs, $y r I n v$ and $y r I l m$, are involved in biofilm formation through the exposition at the cell surface. Deleting the IAT genes significantly reduces biofilm formation compared to the wild type strain. The structure and the organization of biofilms differ between the mutant and the wild type strain. The mechanism of biofilm formation involves extracellular DNA, RNA and proteins.

This thesis includes a complete DNA sequence of pYR4, a putative virulence plasmid present in $\mathrm{NVH}_{-} 3758.31 \%$ of the pYR4 sequence is unique compared to other $Y$. ruckeri plasmids. pYR4 encodes for type IV pili (TFP) and for a conjugation system (tra) and contributes to Y. ruckeri virulence.

In summary, the thesis provides a new insight into Y. ruckeri pathogenesis and contributes to better understanding of how Y. ruckeri survives in the aquatic environment by forming a biofilm. 


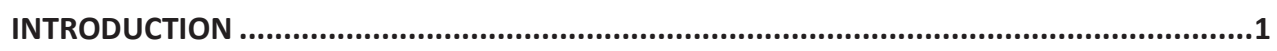

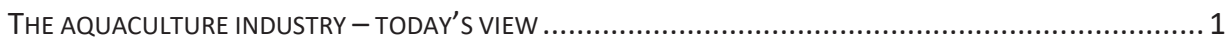

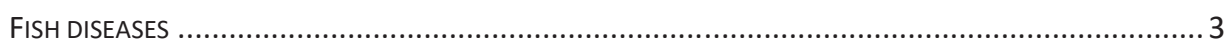

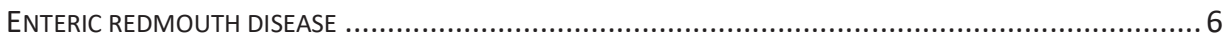

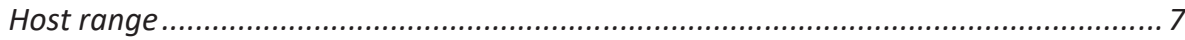

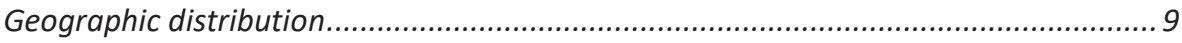

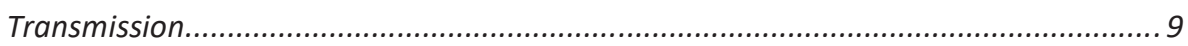

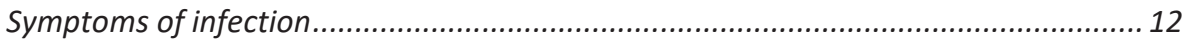

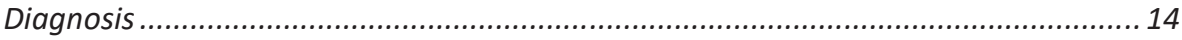

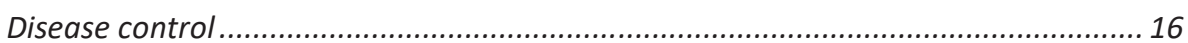

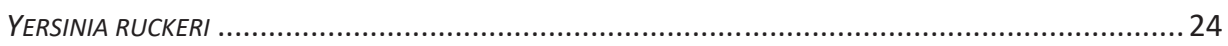

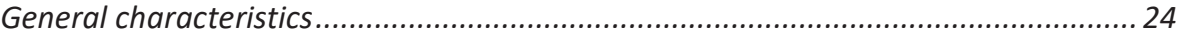

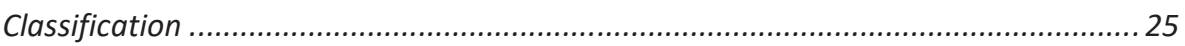

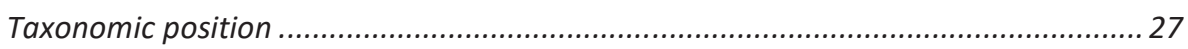

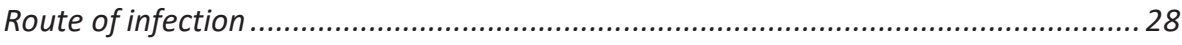

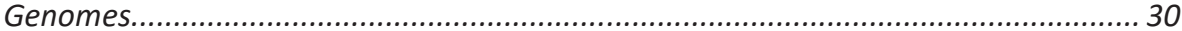

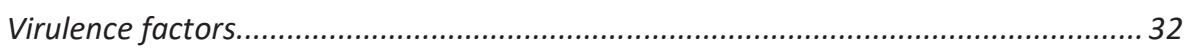

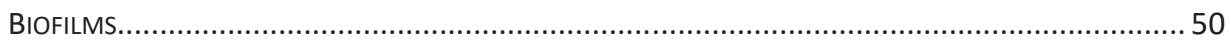

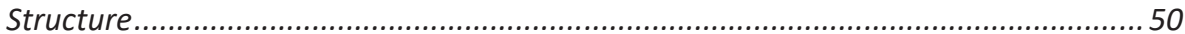

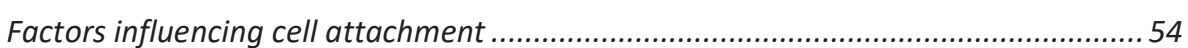

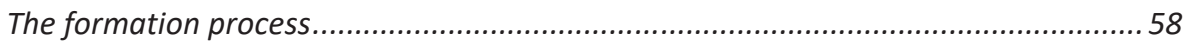

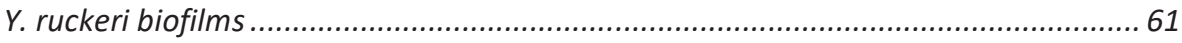

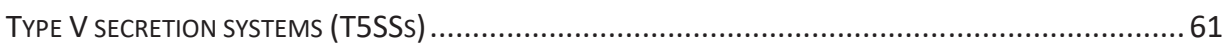

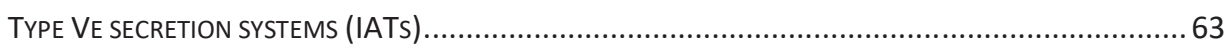

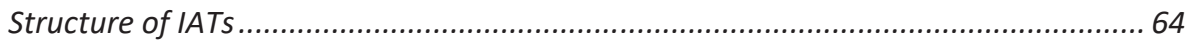

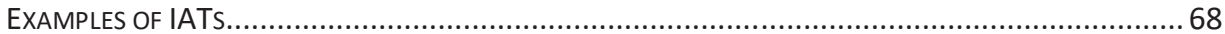

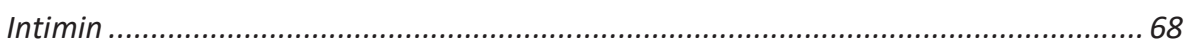

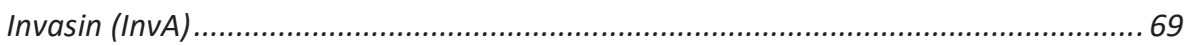

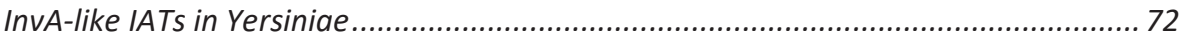




AIMS OF THE THESIS




\section{INTRODUCTION}

\section{The aquaculture industry - today's view}

Fisheries and aquaculture play an important role in today's society. In recent years, both sectors have grown significantly in terms of production, trade and consumption. As a valuable source of food, fisheries and aquaculture are significant contributors to nutritional security. Furthermore, they generate income, contribute to economic growth and give jobs to ca 200 millions of people (FAO, 2018a). A fishery is defined as an area where fish is raised and harvested for commercial use. Fisheries can be divided into wild and farmed. Wild fisheries, often referred to as capture fisheries, exist in both freshwater (inland wild fishery) and saltwater (marine wild fishery). A farmed fishery is a common form of aquaculture which involves raising fish in enclosed systems. In contrast to capture fisheries, aquaculture is defined as "farming of aquatic organisms including fish, molluscs, crustaceans and aquatic plants" under controlled conditions, which involves control of fish stocking, feeding and protection from predators (FAO, 2011).

In 2016, the total production in fisheries and aquaculture hit a new record of about 171 million tonnes. From that, 53\% came from capture fisheries (90.9 million tonnes) while $47 \%$ came from aquaculture ( 80 million tonnes) (FAO, 2018b) (Figure 1).

While capture fisheries have always played an important role in proteinrich food production, there has not been any growth in production in recent years (Figure 1). Contrary to capture fisheries, aquaculture has experienced a 
significant growth over the last decades. In the $1950 \mathrm{~s}$, the total production that came from aquaculture was around 4\%, it reached 19\% during the 1990s and $47 \%$ in 2016. It is estimated that sales value of aquaculture in 2016 was about 232 billion USD (FAO, 2018b). The biggest aquaculture producer is China, accounting for about 49.2 million tonnes, followed by India (5.7 million tonnes), Indonesia (4.9 million tonnes), Vietnam (3.6 million tonnes), Bangladesh (2.2. million tonnes), Egypt (1.4 million tonnes), Norway (1.3. million tonnes), Chile ( 1 million tonnes), Myanmar (1 million tonnes) and Thailand (0.96 million tonnes) (FAO, 2018a).

\section{World fisheries and aquaculture production}

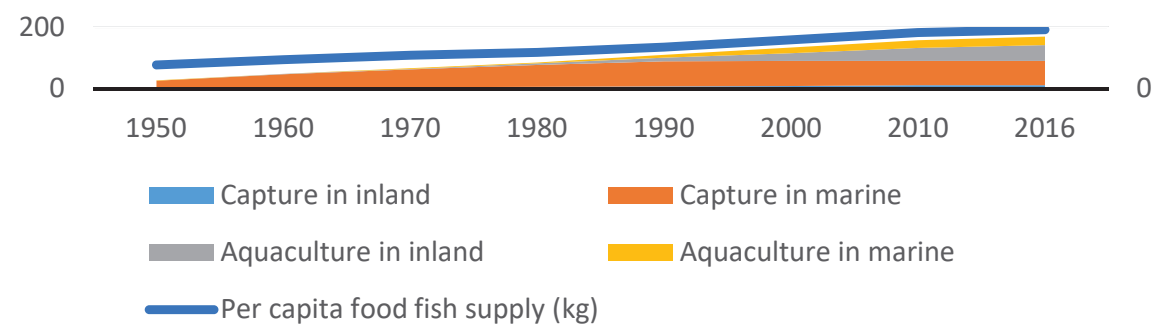

Figure 1. Left axis: production in world fisheries (inland and marine) and aquaculture (inland and marine) in years 1950-2016, in millions of tonnes. Right axis: summarized per capita food fish supply from capture and from aquaculture presented in $\mathrm{kg}$. The presented graph was made based on FAO, 2018 b.

According to FAO, the human population is expected to reach 9.7 billion by 2050 . Taking into account the increasing demand for protein-rich food feeding the growing population might be challenging. As capture fisheries are not able to meet the increasing demand for food supply due to stresses on 
ecosystems (water pollution, overfishing, climate change), the aquaculture industry is placed under a significant pressure to meet the increasing demand for protein-rich food. Aquaculture needs to develop rapidly and has to be sustainable over a longer period of time. However, the industry is often facing serious challenges caused by infectious diseases (FAO, 2018b).

\section{Fish diseases}

Infectious diseases caused by bacterial, viral, parasitic and fungal virulent agents continue to be a major challenge, contributing to significant fish losses in aquaculture. Losses caused by the infectious diseases cost about 6 billion USD per year (Stentiford et al., 2017). Especially, the shrimp industry has suffered enormous losses at the estimated value of 10 billion USD since 1990, and new diseases are emerging every year. One of them is the acute hepatopancreatic necrosis disease that has spread throughout Asian countries and reached Mexico in 2013. This disease has reduced the shrimp production to about $60 \%$ compared to 2012 (Lee et al., 2015). The fact that most of the infectious diseases are occurring in developing countries, where the aquaculture is not well maintained, suggests that the majority of outbreaks are undiagnosed and untreated (Bank, 2014). In this context, infectious diseases remain an important factor that slows down the expansion of aquaculture (Stentiford et al., 2017). The development of an infectious disease depends on the health of the fish and on the environment the fish resides in.

Today, the most important culture species in Norwegian aquaculture are Atlantic salmon (Salmo salar) and rainbow trout (Oncorhynchus mykiss). They account for about $80 \%$ and $10-15 \%$ of the total production, respectively (FAO, 2018c). The most important virulent agents responsible for diseases in rainbow 
trout and Atlantic salmon are summarized in Table 1. The official statistics show that the major virulent agents responsible for most disease outbreaks in Norway are parasites and viruses.

Among the viruses, salmon alpha virus (SAV) remains the most serious agent responsible for recent pancreas disease outbreaks in sea-farmed salmonids. There exist six subtypes of the SAV virus (SAV1 - SAV6) (Jansen et al., 2010). There are two epidemics of the virus in Norway, including SAV2 (Sleeping disease virus) and SAV3 (Norwegian salmon alphavirus) from which SAV3 is responsible for the majority of the outbreaks. To prevent the spread of the infection, vaccination is used as a routine practice (Hjeltnes et al., 2017).

The salmon louse (Lepeophtheirus salmonis) is a major concern of today's aquaculture industry worldwide. This parasite feeds on fish skin, mucus and blood and develops very rapidly in a marine environment. Currently, the most common treatment is a combination of pharmaceutical and nonpharmaceutical (thermal and mechanical) methods. Although the combination of both methods has been fairly effective, pharmaceutical treatments can contribute to reduced appetite and reduced growth of fish. Moreover, sea lice quickly develop drug resistance and therefore new treatments have to be developed. One solution that is already being deployed by some farmers is to introduce cleaner fish that use sea lice as a food source (Hjeltnes et al., 2017).

Bacterial diseases play a minor role in recent fish stock losses thanks to vaccinations. In the recent years, however, the number of outbreaks caused by Y. ruckeri, the causative agent of ERM especially in Atlantic salmon, has substantially increased. 34 fish farms located in the north-west and mid-coastal areas of Norway were shown to be affected by Y. ruckeri in 2015 and 2016. 
There has been a rapid increase in the number of yersiniosis cases in the seawater life stages of Atlantic salmon in contrast to previous years, where the most outbreaks occurred in the freshwater life stage (Hjeltnes et al., 2017).

\begin{tabular}{|c|c|c|}
\hline Bacteria & $\begin{array}{c}\text { Gram negative } \\
\text { Aeromonas salmonicida } \\
\text { Vibrio salmonicida, V. anguillarum } \\
\text { Edwardsiella tarda } \\
\text { Y. ruckeri } \\
\text { Pseudomonas anguilliseptica, P. } \\
\text { fluorescens } \\
\text { Flavobacterium psychrophilum } \\
\text { F. branchiophilum, F. succinicans } \\
\text { Piscirickettsia salmonis } \\
\text { Moritella viscose }\end{array}$ & $\begin{array}{c}\text { Disease } \\
\text { Furunculosis } \\
\text { Vibriosis } \\
\text { Edwardsiellosis } \\
\text { Enteric redmouth disease } \\
\text { Pseudomonasis } \\
\text { Flavobacteriosis } \\
\text { Bacterial gill disease } \\
\text { Salmon Rickettsial Disease } \\
\text { Winter ulcer }\end{array}$ \\
\hline & $\begin{array}{c}\text { Gram-positive } \\
\text { Mycobacterium chelonae, M. } \\
\text { salmoniphilum } \\
\text { Streptococcus iniae, S. phocae } \\
\text { Renibacterium salmoninarum }\end{array}$ & $\begin{array}{c}\text { Mycobacteriosis } \\
\text { Streptococcosis } \\
\text { Bacterial Kidney Disease }\end{array}$ \\
\hline Virus & $\begin{array}{c}\text { Infectious salmon anemia virus } \\
\text { Viral haemorrhagic septicaemia } \\
\text { virus } \\
\text { Salmon pancreas disease virus } \\
\text { Infectious pancreatic necrosis virus } \\
\text { Infectious hematopoietic necrosis } \\
\text { virus }\end{array}$ & $\begin{array}{c}\text { Infectious salmon anaemia } \\
\text { Viral Haemorrhagic } \\
\text { Septicaemia } \\
\text { Pancreas Disease } \\
\text { Infective Pancreatic Necrosis } \\
\text { Infective Haematopoietic } \\
\text { Necrosis }\end{array}$ \\
\hline Fungus & Saprolegnia & Saprolegniasis \\
\hline
\end{tabular}




\begin{tabular}{|c|c|c|}
\hline \multirow{7}{*}{ Parasites } & Lepeophtheirus salmonis & Sea lice \\
& Paramoeba perurans & Amoebic Gill Disease \\
& Ichthyophthirius multifilis & White spot \\
& Myxosoma cerebralis & Whirling disease \\
& Hexamita truttae & Hexamitaisis octomitis \\
\hline
\end{tabular}

Table 1. Selected virulent agents of rainbow trout and Atlantic salmon. The table was made based on the following sources (FAO, 2018c; Hjeltnes et al., 2017).

\section{Enteric redmouth disease}

Enteric redmouth disease (ERM) is a bacterial infection in marine and freshwater fish. It is caused by the Gram-negative bacterium Y. ruckeri. The disease was first documented in 1950 when Y. ruckeri was isolated from the kidney tissues of rainbow trout in the Hagerman Valley in Idaho, USA (Ross et al., 1966; Rucker R, 1966). Until 1975, ERM was referred to as red mouth disease, red vent disease or bacterial septicemia, where the name pertained to clinical signs of the disease rather than the etiological agent itself (Busch, 1978). In 1975, the Fish Health Section of the American Society introduced the universal name ERM, which together with yersinosis continues to be the common names used in literature. Since the first appearance of Y. ruckeri in 1950, the disease was studied in depth by Ross and Rucker (Ross et al., 1966; Rucker R, 1966). Thanks to them, Y. ruckeri was assigned to the family of Enterobacteriaceae, however the taxonomic position is still unclear (Kumar et al., 2015; Reuter et al., 2014). 


\section{Host range}

Y. ruckeri has a broad host range. Since its first isolation in 1950 from rainbow trout, the bacterium was isolated from many fish species, including marine and freshwater fish species (Ross et al., 1966; Rucker R, 1966) (Table 2). Freshwater fish species are most susceptible to Y. ruckeri infections. The mortality rate can reach $25 \%-75 \%$ when the disease is untreated (Busch, 1978). Y. ruckeri has also been found in other animals, such as muskrat (Stevenson and Daly, 1982), the Eurasian otter (Collins et al., 1998), birds (Willumsen, 1987), sea gulls (Willumsen, 1987), turtles (Kumar et al., 2015) and humans (De Keukeleire et al., 2014).

\begin{tabular}{|c|c|c|}
\hline Fish name & Binominal name & Reference \\
\hline Arctic char & Salvelinus alpinus & (Collins et al., 1998) \\
\hline Atlantic cod & Gadus morhua & (Gudmundsdottir et al., 2014) \\
\hline Atlantic salmon & Salmo salar & (Ormsby et al., 2016) \\
& & (Navas et al., 2014) \\
& & (Collins et al., 1998) \\
\hline Bighead carp & Aristichthys nobilis & (Xu et al., 1991) \\
\hline Burbot & Lota lota & (Dwilow et al., 1987) \\
\hline Brook trout & Salvelinus fontinalis & (Cipriano et al., 1986) \\
& & (Stevenson and Daly, 1982) \\
\hline Brown trout & Salmo trutta & (Huang et al., 2015) \\
& & (Valtonen et al., 1992) \\
\hline Coalfish & Pollachius virens & (Michel et al., 1986) \\
\hline Coho salmon & Oncorhynchus kisutch & (Avendaño-Herrer et al., 2016) \\
\hline Common carp & Cyprinus carpio & (Berc et al., 2015) \\
\hline Chinook salmon & Oncorhynchus tshawytscha & (Cipriano et al., 1986) \\
\hline
\end{tabular}




\begin{tabular}{|c|c|c|}
\hline Cisco & Coregonus artedii & (Stevenson and Daly, 1982) \\
\hline Cutthroat trout & Salmo clarkii & (Daly et al., 1986) \\
\hline Eel & Anguilla anguilla & (Fuhrmann et al., 1983) \\
\hline Fathead minnow & Pimephales promelas & (Michel et al., 1986) \\
\hline Goldfish & Carassius auratus auratus & (McArdle and Dooley-Martyn, 1985) \\
\hline Muksun & Coregonus muksun & (Rintamäki et al., 1986) \\
\hline Nile tilapia & Oreochromis niloticus & (Eissa et al., 2008) \\
\hline Perch & Perca fluviatilis & (Valtonen et al., 1992) \\
\hline Peled & Coregonus peled & (Rintamäki et al., 1986) \\
\hline Rainbow trout & Oncorhynchus mykiss & $\begin{array}{c}\text { (Duman et al., 2017) } \\
\text { (Huang et al., 2015) } \\
\text { (Ross et al., 1966) } \\
\text { (Fuhrmann et al., 1983) } \\
\text { (Valtonen et al., 1992) } \\
\text { (Daly et al., 1986) } \\
\text { (Ewing et al., 1978) }\end{array}$ \\
\hline Rudd & Scardinius erythrophthalmus & (Popović et al., 2001) \\
\hline Sockeye salmon & Oncorhynchus nerka & (Ewing et al., 1978) \\
\hline Sole & Solea solea & (Michel et al., 1986) \\
\hline Silver carp & Hypophthalmichthys molitrix & (Xu et al., 1991) \\
\hline Sturgeon & Acipenser baeri & (Vuillaume et al., 1987) \\
\hline Turbot & Scophthalmus maximus & (Michel et al., 1986) \\
\hline Zebrafish & Danio rerio & (Korbut et al., 2016) \\
\hline
\end{tabular}

Table 2. Selected fish species affected by Y. ruckeri. The table was made based on published literature on fish species susceptible to Y. ruckeri infections (Barnes, 2011; Zorriehzahra et al., 2017). 


\section{Geographic distribution}

ERM was first discovered in 1950 in the Hagerman Valley of Idaho. Since then, many researchers have thought that the disease is endemic to that area. However, in the mid-1960s, a large number of asymptomatic carrier fish were shipped to the western states of the US and the disease spread widely from there (Busch, 1978). In 1971, McDaniel documented the presence of the disease in the area of Rocky Mountain in Wyoming (McDaniel, 1971). During the same year, the disease expanded to other states including Alaska, Oregon, Utah and Washington (McDaniel, 1971). In 1978, Bullock et al. reported the presence of ERM in 18 states (Bullock et al., 1978). In 1972, the disease was reported in caged rainbow trout in a southern Saskatchewan lake in Canada (Wobeser, 1973). In the following years, the disease spread to Australia (Llewellyn, 1980) and various European countries such as Denmark (Dalsgaard et al., 1984), France (Lesel et al., 1983), Germany (Fuhrmann et al., 1983), Italy (Giorgetti et al., 1985), Norway (Sparboe et al., 1986), Poland (Grawiński, 1990) and Croatia (Oraić et al., 2002). ERM is also present in Romania (Popescu et al., 2008), New Zealand (Anderson et al., 1994), South Africa (Bragg and Henton, 1986) and Chile (Enríquez and Zamora, 1987). Today the disease is spread over the entire globe with the most recent outbreaks in Australia, Norway and Scotland (Ormsby et al., 2016).

\section{Transmission}

The disease is transmitted through contact between infected and noninfected fish. Carrier fish play an important role in transmission. However, carrier fish are difficult to diagnose due to the lack of clinical signs of ERM 
infection (Busch, 1978). Bush and Lingg (1975) conducted studies where they established the carrier state of ERM in rainbow trout. In order to do that, they monitored the progress of the disease for up to 102 days post-infection. They demonstrated that, 45 days post-infection, $25 \%$ of asymptomatic fish carried Y. ruckeri in the lower intestine. Shedding of the bacterium from the infected fish in the feces occurred in a 30-40 day cycle. The authors suggested that shedding of the bacterium was the cause of recurrent fish infections and that it occurred due to stressful conditions (Busch and Lingg, 1975). Busch (1973) pointed out that the prevalence of bacterial shedding depends on numerous seasonal changes, such water temperature, fish stock density, fish resistance, fish immunity and stress. The water temperature and its quality are particularly important in summer, when water flow is reduced and water temperature can rise up to $15-18^{\circ} \mathrm{C}$ (Busch, 1973). Therefore, summer is the season when most of the ERM outbreaks occur and special care needs to be taken to monitor the water quality and oxygen level (Busch, 1978).

Stress predisposes for ERM infection. Hunter et al. (1980) found that only those carrier fish that were subjected to stress, such as high water temperature, transmitted $Y$. ruckeri to healthy fish. The pathogen was detectable 20 days post-infection in the lower intestine in $20 \%$ of the fish population. After 25 days, the proportion of infected fish increased to $36 \%$ of the fish population. Finally, the bacteria were undetectable 80 days post-infection. Other stressors, such as high fish densities, high ammonia and reduced oxygen levels, have also been shown to lead to significant fish losses if left unaddressed (Hunter et al., 1980).

Early studies have shown that carrier fish are a primary source of ERM infection and that it is mostly transmitted through the shipment of carrier fish 
into disease-free areas (Busch, 1978). However, other evidence has shown that ERM appeared in some regions before the carrier fish were introduced there. Examination of Australian isolates extracted from fish at the National Fish Health Disease Laboratory demonstrated that four of the isolates were $Y$. ruckeri that were isolated in 1960, i.e. before the outbreaks in Australia occurred. This fact could be explained by undocumented fish shipments or presence of the bacterium in that area before (Bullock et al., 1978).

In Norway, the first ERM outbreak was reported in 1985 in Atlantic salmon on the Senja Island and the reason for the outbreak was not fully understood. Subsequently, ERM was documented in various Norwegian fish farms, including hatcheries and fish cages (Sparboe et al., 1986). In 1987, a new study was undertaken that examined the presence of $Y$. ruckeri in the intestines of wild fish and birds living closely to the infected fish farms. The investigations showed that the samples obtained from both the intestines of wild fish and birds were $Y$. ruckeri positive. Thus, birds and wild fish are potential vectors of the disease. Birds that eat the carrier fish can spread the bacterium through feces (Willumsen, 1987).

While horizontal disease transmission, i.e. when the pathogen is transmitted from fish to fish, of $Y$. ruckeri has been widely studied, the vertical transmission, i.e. from parent to progeny, requires further research. Many researchers have thought that the vertical disease transmission is not possible (Bullock, 1989). However, recent studies have shown that Y. ruckeri can be vertically transmitted from parents to its progeny. The prevalence of $Y$. ruckeri was monitored across a single production cycle of Chinook salmon $O$. tshawytscha, using both nested PCR and quantitative PCR. Presence of the pathogen's DNA was detected both in the ovarian fluid of spawning adult 
female fish and in the unfertilized eggs, i.e. the eggs that were removed from ovaries before fertilization happened. This observation confirmed vertical transmission of the pathogen. The reason for presence of the pathogen in the unfertilized eggs was not fully understood. Even though the unfertilized eggs were treated with the disinfectant iodophor to kill external pathogens, $Y$. ruckeri DNA was still detected. The presence of the pathogen's DNA in unfertilized eggs might suggest that $Y$. ruckeri is able to enter the chorion of the eggs from the infected ovarian fluid before fertilization happens. However, the success rate of the egg colonization would depend on the bacteria concentration in the ovarian fluid and the time the egg is exposed to the pathogen before fertilization. The authors pointed out that this is rather unlikely to happen, however it requires further investigation (Glenn et al., 2015).

Water, algae, sewage and dairy products have been also implicated as a source of ERM disease. $Y$. ruckeri was shown to survive in aquatic environments for more than three months outside of the host (Romalde et al., 1994). One of the reasons for the pathogen's survival is its ability to form a biofilm, which it can do on surfaces commonly found in aquaculture (Coquet et al., 2002b).

\section{Symptoms of infection}

The mortality rates with ERM are usually low in the initial phase of the disease and then grow rapidly, resulting in severe fish losses. This is especially true when the fish are exposed to stress, for example caused by poor culture conditions (Kumar et al., 2015). The pathogenesis of ERM varies from preacute, acute, subacute to chronic. Pre-acute to acute infection usually occurs in 
young fish (up to fingerling size) in the summertime, when the water temperature rises and the handling stress is elevated. The mortality rate of ERM is then high and results in severe fish losses reaching up to $70 \%$. Acute to subacute infections mainly occur in yearling fish in the winter, when the water temperature drops. In this case, the mortality level can exceed $10 \%$. Finally, chronic infection usually affects adult fish and results in low fish losses up to $10 \%$ (Busch, 1978). The early clinical signs of ERM usually resemble bacterial septicemia caused by other Gram-negative pathogens such as $A$. salmonicida and $P$. fluorescens (Fuhrmann et al., 1983). The affected fish are darker in color, lose their appetite, become lethargic and swim isolated from the others in slow water flow (Tobback et al., 2007). Other external signs of the disease include reddening of the mouth (which gave the disease its name), oral cavity, throat, anus, the base of the fins and the area around the lateral line, caused by subcutaneous hemorrhages. Exophthalmia, known as pop-eye, usually starts unilaterally, but at later stages both eyes can pop out of their sockets. Eventually, exophthalmia causes the eyes to rupture, which results in fish blindness (Bullock, 1989; Busch, 1978). Internal signs of the infection include petechial hemorrhages in the internal organs such as the liver, pancreas, swim-bladder, stomach and muscles. Hemorrhages and inflammation occur in the intestine, which is filled with a yellowish, opaque fluid. The kidney and the spleen are often swollen and spleen can be black in color (Fuhrmann et al., 1983). Microscopic examination of the infected rainbow trout tissues generally shows septicemia in well-vascularized organs 
such as kidney, spleen, heart, liver and gills (Bruno, 1990; Rucker R, 1966) (Figure 2).

\section{Diagnosis}

ERM is often diagnosed based on the clinical symptoms of the disease.

However, as these symptoms usually resemble the typical signs of septicemia,

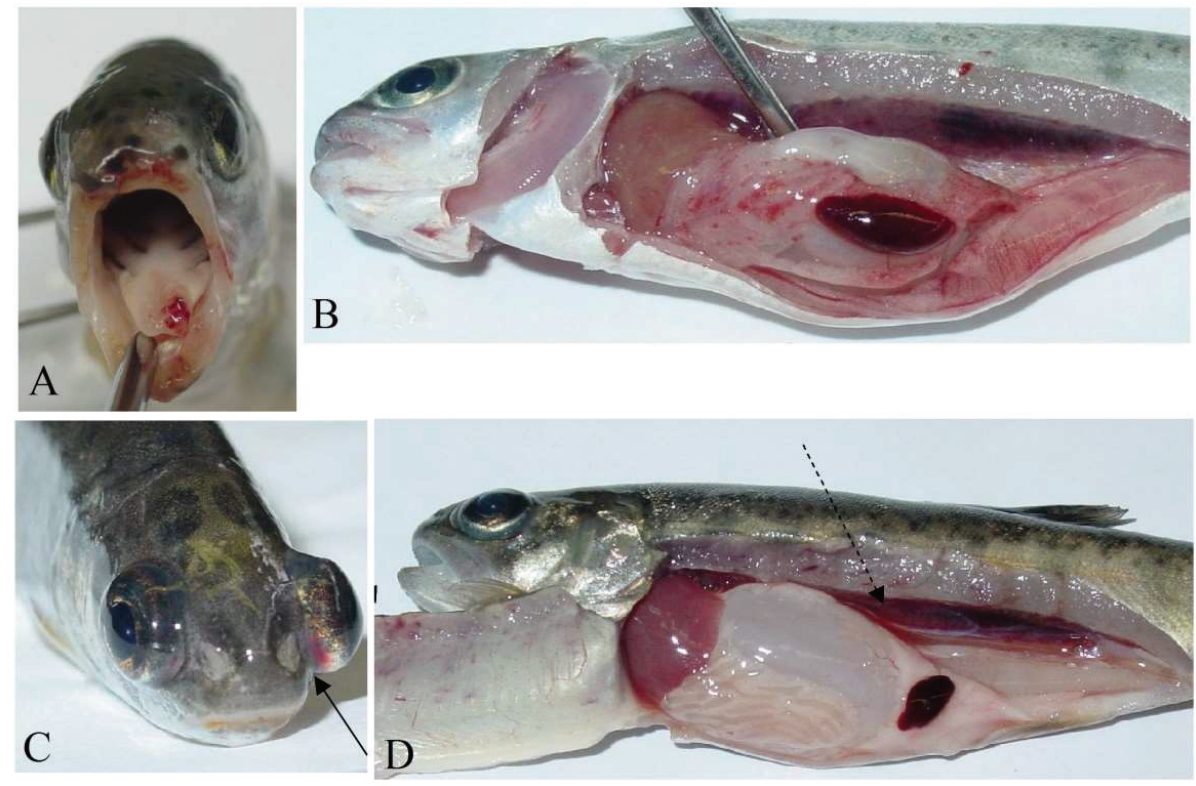

Figure 2. Typical clinical manifestations of enteric redmouth disease of fish infected with

Y. ruckeri. A) haemorrhages around oral cavity, B) haemorrhages in the internal organs

C) exophthalmia (marked with an arrow), D) haemorrhages in swim bladder (marked with an arrow). The figures were adapted from (El-Matbouli et al., 2009).

classical diagnostic methods can be used, such as bacterial culturing and biochemical tests.

Bacterial culturing is typically used to confirm isolation of $Y$.ruckeri from the spleen, heart and kidneys. The pathogen is cultured on different types of 
media, such as Tryptic Soy Agar (TSA), Columbia Blood Agar and MacConkey Agar (Gibello et al., 1999; Kumar et al., 2015). After 48 h incubation at $25^{\circ} \mathrm{C}$, the pathogen forms off-white colonies with diameter of 2 $3 \mathrm{~mm}$

Identification of $Y$. ruckeri can also be done using serological tests including enzyme-linked immunosorbent assay (ELISA) (Cossarini-Dunier, 1985), immunofluorescence antibody technique (IFAT) (Smith et al., 1987) and agglutination test (Kumar et al., 2015). There is a constant need for more efficient, sensitive, specific and cheaper methods to diagnose Y. ruckeri. Recently, a considerable number of molecular diagnostic techniques have been developed, for example restriction fragment length polymorphism (RFLP), polymerase chain reaction (PCR) and loop-mediated isothermal amplification (LAMP) (Glenn et al., 2011; Keeling et al., 2012; Kumar et al., 2015; Saleh et al., 2008; Temprano et al., 2001). A PCR-based amplification method was developed by Gibello et al. to target a specific fragment of 16S rRNA gene of $Y$. ruckeri in infected rainbow trout tissues. This molecular diagnostic method has proven to be sensitive, fast and efficient compared to the traditional microbiological methods (Gibello et al., 1999). Some non-lethal methods developed for Y. ruckeri identification were described by (Altinok et al., 2001; Busch and Lingg, 1975). Altinok et al. developed a PCR method where the blood samples of rainbow trout were tested for the presence of $Y$. ruckeri. The non-lethal method does not involve fish autopsy and facilitates sampling of a single fish several times (Altinok et al., 2001). Noga et al. compared two methods for detecting $Y$. ruckeri infection in rainbow trout: lethal and nonlethal. He pointed out that there was no statistical difference in Y. ruckeri detection between the samples obtained from kidney necropsy and kidney 
biopsy (Noga et al., 1988). A study designed by Bastardo et al. showed a realtime polymerase chain reaction (PCR) based on amplification of the recombination protein $\mathrm{A}$ (recA) to improve detection of $Y$. ruckeri in rainbow trout tissues and blood samples (Bastardo et al., 2012). The most recent study by Ghosh et al. presents a non-invasive, highly sensitive qPCR-based method for amplification of a fragment of $16 \mathrm{~S}$ rRNA of Y. ruckeri in fecal samples from finfish. The method does not require lethal sampling and can be used as a screening tool against asymptomatic Y. ruckeri infections (Ghosh et al., 2018).

\section{Disease control}

\section{Antibiotics}

The use of antibiotics in ERM treatment has been documented by several authors (Calvez et al., 2014; Stock et al., 2002). The most routinely used antibiotics include oxytetracykline, amoxicillin, florfenicol, oxolinic acid, sulfadiazine and trimethoprim (Stock et al., 2002). Antibiotics are commonly used to treat ERM, however Y. ruckeri isolates often display variations in susceptibility to antibiotics (Duman et al., 2017). Oxolinic acid is recommended for prophylactic use against ERM. However, drug resistance can develop when the pathogen is subjected to improper amounts of antibiotics, or when the antibiotic treatment continues over a long time (Rodgers, 2001). One study documented Y. ruckeri isolates that were resistant to both tetracycline and sulphamerazine (De Grandis and Stevenson, 1985). Another study showed that under in vitro conditions, $Y$. ruckeri demonstrates 
increased resistance to oxolinic acid, oxytetracykline and sulphonamide (Rodgers, 2001).

Both oxolinic acid and nalidixic acid are quinolones, which is a large class of antibiotics. Quinolones act by inhibiting DNA gyrase, which in turn prevents DNA replication. DNA gyrase, which functions as topoisomerase, consists of two subunits, $\mathrm{A}$ and $\mathrm{B}$, encoded by two genes, gyrA and gyrB. Resistance to quinolones is usually linked to mutations of serine and asparagine at the position 83 and 87 , respectively, in the subunit A. In fact, $Y$. ruckeri isolates recovered in 2001-2002 in a Spanish fish farm showed highlevel quinolone resistance to both oxolinic and nalidixic acid compared to isolates recovered between 1994 and 1998. The evidence suggests that substitution of serotonin with arginine at the position 83 was the cause of the reduced susceptibility to quinolones (Gibello et al., 2004).

A broad study on presence of antimicrobial resistance genes in the genome of 137 Y. ruckeri strains isolated from Turkish rainbow trout farms was recently published by Duman et al. The authors showed that more than $80 \%$ of the $Y$. ruckeri isolates were susceptible to sulfamethoxazole-trimethoprim, florfenicol and tetracycline. The presence of florfenicol (floR), tetracycline (tetC, tetD and tetE) and sulfamethoxazole resistance genes was reported in the genome of some of the $Y$. ruckeri isolates. Surprisingly, the existence of the antibiotic resistance genes in the $Y$. ruckeri genome was not correlated with phenotypic resistance of the isolates (Duman et al., 2017).

Another two studies have shown that, Y. ruckeri is a natural producer of the broad-spectrum antibiotic holomycin (Qin et al., 2013) and that it might not be sensitive to novobiocin and mupirocin (Kumar et al., 2017). 
The aforementioned studies highlight the growing problem of antibiotic resistance in aquaculture. One way to control this problem is to reduce the usage of antibiotics. Instead, metallic nanoparticles can be applied, for example silver, gold or zinc oxide. These nanoparticles show antimicrobial properties against bacterial pathogens. A new study demonstrates the inhibition of $Y$. ruckeri growth when zinc nanoparticles are used (Shaalan et al., 2017). Another alternative to antibiotics is application of antimicrobial peptides. Antimicrobial peptides (AP) are components of the innate immune response against attacking pathogens. APs are relatively small molecules, composed of 10 to 50 amino acids. It has been demonstrated that APs are effective against a number of Gram-negative and Gram-positive bacteria, fungi, yeast, viruses, protozoa and even to tumor cells (Reddy et al., 2004). One well-known AP is nisin, which is used as a biopreservative in the food industry (Shin et al., 2015). A comparative analysis was performed on 15 APs from different classes in order to determine their effectiveness against a range of pathogenic Gram-positive and Gram-negative bacteria: Staphylococcus. aureus, Enterococcus faecalis, Pseudomonas aeruginosa, Escherichia coli, A. salmonicida, Listeria monocytogenes, Campylobacter jejuni, $F$. psychrophilum, Salmonella typhimurium and Y. ruckeri. Analysis of the selected APs showed that Cap18, obtained from rabbit neutrophils, generated the highest antimicrobial activity against Gram-negative bacteria. Furthermore, Cap18 was shown to be stable and with low level of toxicity, which indicates its potential for further development. However, Cap18 becomes unstable when exposed to proteases (Ebbensgaard et al., 2015). 


\section{Probiotics}

Research interest in probiotics in aquaculture has increased greatly in recent years. The term probiotics was coined in 1974 by Parker, who defined them as "organisms and substances which contribute to intestinal microbial balance" (Parker, 1974). Today, the term "probiotics" generally refers to live microorganisms that can contribute to well-being of the host (Pandiyana et al., 2013).

Enhanced resistance of rainbow trout against $Y$. ruckeri was reported when the fish was orally given the BioPlus2Br that contains two bacterial species, Bacillus subtilis and Bacillus licheniformis. BioPlus2B was also administered to piglets and poultry, with positive results. It is still unclear how BioPlus2B works when administered to rainbow trout infected by $Y$. ruckeri. The authors suggested that the probiotic strains produce antimicrobial substances, which in turn inhibit the growth of $Y$. ruckeri. However, tests conducted in the same laboratory did not show any inhibitory effect of Bacillus spp. on the growth of Y. ruckeri. This indicates involvement of other mechanisms, such as the immunostimulatory effect of the substances produced by the probiotic strain (Raida et al., 2003).

Diet supplemented with Carnobacterium maltaromaticum (B26) and Carnobacterium divergens (B33), which were isolated from the intestine of healthy rainbow trout, had an inhibitory effect against infection by $A$. salmonicida and $Y$. ruckeri. These two carnobacterial cultures were present in the gut up to three weeks after administration, which suggests that they were able to survive passing through the gastrointestinal tract. Carnobacterium spp. provided benefits for the host by influencing its cellular and humoral immune 
response. Particularly, when the fish was fed with B26, the phagocytic activity of the head kidney macrophages increased, whereas after feeding the fish with B33 increased lysozyme activity was observed (Kim and Austin, 2006). Studies performed by Robertson et al. demonstrated a similar role of the Carnobacterium spp. strain, which makes it a promising probiotic (Robertson et al., 2000).

Another study, where Bacillus sp. (JB-1) and A. sobria (GC2) isolates from the gut of rainbow trout were used as probiotics, revealed an inhibitory effect against infection with A. salmonicida, Lactococcus garviea, S. iniae, V. anguillarum, Vibrio ordalii and Y. ruckeri. The data showed reduced mortality of rainbow trout to $0-13 \%$ (JB1) and $0-16 \%$ (GC2) compared to control samples. In agreement with previous studies, both probiotics influenced the cellular and humoral immune response. Moreover, the study showed that GC2 has the ability to produce small compounds, siderophores and enzymes, chitinase. Siderophores were demonstrated to inhibit growth of pathogens by acquiring iron from their environment, whereas chitinase was shown to destroy pathogens with cell wall that contains chitin (Brunt et al., 2007).

Recently, a combination of Enterobacter cloacae and B. mojavensis was used as probiotics to control ERM outbreaks. Supplementing the fish feed with these probiotics led to significantly increased fish growth compared to control samples. The study pointed out that using a particular probiotic concentration is very important in order to control the disease. Using the concentration of $10^{8}$ cells/g led to $99 \%$ fish survival. Interestingly, using different concentrations (both higher and lower) did not have a significant effect on the survival rate (Capkin and Altinok, 2009). 
The probiotic Lactobacillus plantarum is widely used in the aquaculture industry to treat various fish diseases. Lately, oral application of L. plantarum was assessed in rainbow trout that was previously vaccinated against $Y$. ruckeri. The results showed that the fish achieved a better weight gain and cellular and immune response compared to vaccinated fish that was fed normally. The fish that was given the probiotic had also a higher activity of lysozymes. More research, however, is needed as questions regarding probiotic dosage and duration of probiotic administration remain unanswered (Soltani et al., 2017).

\section{Vaccines}

ERM outbreaks are well controlled by vaccines. The ERM vaccine was the first fish vaccine developed and commercialized in the 1970s. It consists of formalin-inactivated whole cells of the serotype 1 Y. ruckeri strain and gives a high level of protection. It can be administered to fish by immersion, injection or by the oral route (Kumar et al., 2015; Plant and Lapatra, 2011). However, outbreaks of $Y$. ruckeri have occurred in previously vaccinated fish at farms located in the USA and throughout Europe, mainly caused by the non-motile biotype 2 (Arias et al., 2007; Calvez et al., 2014; Fouz et al., 2006). A very recent comparative genome analysis of $Y$. ruckeri strains isolated from different geographic locations showed clear genetic variations between $Y$. ruckeri strains, especially between the serotype $\mathrm{O} 1$ and $\mathrm{O} 2$ strains (Cascales et al., 2017). Furthermore, a new Y. ruckeri serotype O8 was recently identified in Atlantic salmon in Scotland (Ormsby et al., 2016). This data suggests that the existing vaccines might not give protection against all Y. ruckeri strains. 
New vaccines have been developed that include live attenuated bacteria and purified protein sub-units (Kumar et al., 2015). The use of attenuated vaccines seems to have many advantages when compared to the traditional inactivated whole-cell vaccines. Live attenuated vaccines provide quicker response and give longer immunity. However, vaccines often receive criticism from the aquaculture industry regarding reversion to virulence (Hanley, 2011). Examples of live attenuated vaccines which confer significant protection to rainbow trout infected with $Y$. ruckeri are the $Y$. ruckeri $\mathrm{O} 1$ aroA mutant and the $Y$. ruckeri $\Delta l p x D$ mutant (Altinok et al., 2016; Temprano et al., 2005). The Y. ruckeri aroA mutant, when injected intraperitoneally into rainbow trout, conferred the relative survival rate of $90 \%$ after exposure to $Y$. ruckeri compared to control samples (Temprano et al., 2005). Rainbow trout immunized with the $Y$. ruckeri $\Delta l p x D$ mutant (LPS deficient mutant), either by immersion or by injection, displayed the relative survival rate of more than $84 \%$ after exposure to $Y$. ruckeri, indicating that the vaccine can effectively protect fish (Altinok et al., 2016).

Sub-unit vaccines are regarded as very safe because only a specific antigen is administrated to the fish. Extracellular protease Yrp1 was the first toxoid that was shown to give protection against the virulence of $Y$. ruckeri (Fernandez et al., 2003). However, further research is needed on duration of the immunity period in fish. Welch and LaPatra (2016) claim that Y. ruckeri lipopolysaccharide (LPS) is sufficient to trigger a protective response in rainbow trout to an experimental challenge, which is in agreement with previous studies (Ispir and Dorucu, 2014; Welch and LaPatra, 2016). This makes LPS a good candidate for a cellular component of a vaccine. 
There has been little success with using monovalent vaccines against $Y$. ruckeri, i.e. vaccines that contain antigens from only one $Y$. ruckeri biotype. Conversely, a bivalent vaccine containing antigens from both Y. ruckeri biotypes (biotype 1 and biotype 2) provides robust protection against both biotypes, where the O-antigen of $Y$. ruckeri has been considered as the dominant immunogenic molecule (Tinsley et al., 2011).

DNA vaccines are one of the most promising approaches that are currently being developed against bacterial, viral and parasitic diseases. Although DNA vaccines provide a high level of protection, their mechanism is not understood well. Moreover, only a few DNA vaccines have been approved for commercial use (Myhr, 2016). So far, there is no DNA vaccine against the ERM disease.

One of the major challenges in developing protective vaccines for fish is the choice of antigen delivery system. It is determined by factors like safety and ability to elicit innate and adaptive immune response in vaccinated fish (Munang'andu et al., 2016). The following antigen delivery systems have been applied for ERM: oral (Ghosh et al., 2016; Jaafar et al., 2017), anal (Villumsen et al., 2014), immersion (Ghosh et al., 2016; Raida and Buchmann, 2008) nasal (LaPatra et al., 2015; Salinas et al., 2015), and an interperitoneal injection (Chetri et al., 2013). Immersion is the preferred method of antigen delivery because it allows for massive and quick fish vaccination in the freshwater stage, when the fish are too small to receive an injection (Villumsen et al., 2014). Immersion vaccines decrease the number of $Y$. ruckeri outbreaks and substantially reduce the use of antibiotics in salmon farming (Chetri et al., 2013). However, immersion vaccines do not confer $100 \%$ protection. For extended protection, it is usually recommended to use booster vaccination (Chetri et al., 2013). 


\section{Yersinia ruckeri}

\section{General characteristics}

Y. ruckeri is a Gram-negative, rod-shaped bacterium belonging to the Enterobacteriaceae family. Y. ruckeri is the causative agent of ERM in fish. The cells of this facultative anaerobe are generally uniform in morphology. They are rounded, with $0.75 \mu \mathrm{m}$ in diameter and $1-3 \mu \mathrm{m}$ in length, although differences in cell size and cell morphology have been reported by some authors (Austin et al., 1982; Bullock et al., 1978; Ross et al., 1966). Y. ruckeri does not form spores or a capsule. Some Y. ruckeri strains are flagellated and consequently exhibit variable motility with peritrichously arranged flagella (Tobback et al., 2007). Y. ruckeri can be recovered from the internal organs of infected fish, and then cultured on bacteriological media such as Tryptone Soya Agar (Stevenson and Daly, 1982), Nutrient Agar (Navais et al., 2014), Brain Heart Infusion Agar (Arias et al., 2007), Columbia Blood Agar (Gibello et al., 2004) and McConkey Agar (Akhlaghi and Sharifi Yazdi, 2008; Gibello et al., 1999). After 24-48 hours of incubation, the bacterium forms smooth, circular, shiny colonies (Busch, 1978). The cells grow fairly rapidly in a wide temperature range from $22^{\circ} \mathrm{C}$ to $37^{\circ} \mathrm{C}$. Best growth is observed between $22^{\circ} \mathrm{C}$ and $25^{\circ} \mathrm{C}$. Y. ruckeri strains are biochemically uniform regardless of geographical location. Y. ruckeri ferments fructose, glucose, glycerol, maltose, mannitol and trehalose contrary to inositol, lactose, rhamnose, raffinose, sorbitol, sucrose, meliobiose, arabinose and salicin. Most $Y$. ruckeri isolates are Voges-Proskauer negative and methyl red and citrate positive. Y. ruckeri strains are positive for $\beta$-galactosidase, lysine, ornithine decarboxylase and 
catalase and negative for indole, hydrogen sulfide, oxidase, cytochrom, phosphatase, urease, phenylalanine deaminase (Ewing et al., 1978).

\section{Classification}

Y. ruckeri can be classified based on biotype, serotype and outer membrane protein profile (OMP) (Kumar et al., 2015). Two different biotypes have been distinguished based on their ability to hydrolyze Tween $20 / 80$ and on the presence or the absence of flagella (Davies and Frerichs, 1989). Biotype 1 is motile and lipase positive while biotype 2 is non-motile and lipase negative (Davies and Frerichs, 1989; Tinsley et al., 2011). Naturally occurring mutations in one of the genes $f l i R, f l h A$, or $f l h B$ of biotype 2, which encode components of the flagellar secretion apparatus, were shown to lead to the loss of both motility and lipase activity in biotype 2 strains that originated from US, UK and Europe (Welch et al., 2011). In addition, UK and US isolates of biotype 2 had mutations in the same mutant allele, which suggests a common origin of biotype 2 (Welch et al., 2011; Wheeler et al., 2009). With the emerging evidence that biotype 2 was responsible for recent yersinosis outbreaks in vaccinated fish in Europe and the US, more attention has been given to the control of the new biotype 2 (Arias et al., 2007; Fouz et al., 2006).

The serotyping scheme of $Y$. ruckeri is rather complex and has been revised many times by different authors (Kumar et al., 2015). The serotyping scheme relies on a serological reaction in which the antisera raised against a certain $Y$. ruckeri serotype in rabbits react with whole-cell or heat-stable Y. ruckeri antigens (Davies, 1990). Stevenson and Airdire grouped Y. ruckeri isolates into six serotypes, ranging from serotype I to serotype VI ( Stevenson and Airdrie, 1984). A while later, serotype IV was excluded from the scheme (DeGrandis 
et al., 1988). Biochemically, the isolate of serotype IV was able to ferment arabinose, rhamnose and xylose, contrary to other serotypes, and showed a low level of DNA hybridization with the DNA of Y. ruckeri. It was proposed that serotype IV may actually be Hafnia alvei, which shows similar biochemical reactions as $Y$.ruckeri, and therefore was wrongly placed in the $Y$. ruckeri species. In 1990, Davies suggested a new serotyping scheme for Y. ruckeri which was based on heat-stable O-antigens (Davies, 1990). He distinguished five different $\mathrm{O}$-serotypes designated as O1 (serotype I and III), O2 (serotype II), O5 (serotype V), O6 (serotype VI) and O7. The serotype III was excluded from the scheme and classified as serotype O1, typical for the Australian and South African Y. ruckeri isolates. In 1993, Romalde et al. revised a serotyping scheme proposed by DeGrandis (Romalde et al., 1993) and proposed a new classification scheme that took into account differences in both the lipopolysaccharide profile and the outer membrane protein profile. Four Oserotypes, from $\mathrm{O} 1$ to $\mathrm{O} 4$, were distinguished, where serotype $\mathrm{O} 1$ and $\mathrm{O} 2$ were further subdivided into subgroups. Serotype O1 was divided into two subgroups, O1a (serotype I) and O1b (serotype III). Serotype O2 (serotype II) was divided into three subgroups $(\mathrm{O} 2 \mathrm{a}, \mathrm{O} 2 \mathrm{~b}$ and $\mathrm{O} 2 \mathrm{c})$. The serotypes $\mathrm{O} 3$ and O4 were equivalent to the serotypes V and VI, respectively (Table 3 ).

Recently, a new serotype designated as serotype 08 was identified in $Y$. ruckeri isolates of rainbow trout and Atlantic salmon in Scotland (Ormsby et al., 2016). Serotypes O8 and O2 of Y. ruckeri isolates recovered from Atlantic salmon were shown to represent distinct and more diverse subpopulation than the isolates from rainbow trout (serotype O1) (Ormsby et al., 2016). 


\begin{tabular}{|c|cc|c|c|c|c|c|}
\hline & \multicolumn{6}{|c|}{ Year } \\
& 1977 & 1978 & 1984 & 1988 & 1990 & 1993 \\
\hline \multirow{3}{*}{ Serotype name } & I & I & I & - & O1 & O1a \\
& II & II & II & II & O2 & O2a,b,c \\
& - & III & III & III & O1 & O1b \\
& - & - & IV & - & - & - \\
& - & - & V & V & O5 & O3 \\
& - & - & - & - & O6 & O4 \\
\hline
\end{tabular}

Table 3. Serotyping scheme for Y. ruckeri between 1977 and 1993.

Some other useful schemes for identification of Y. ruckeri include analyses that are based on outer membrane protein profile or a combination of biotyping, serotyping and outer membrane protein typing (Davies, 1991a, 1991b).

\section{Taxonomic position}

The taxonomic position of $Y$. ruckeri has been a controversial subject since the discovery of the pathogen and still continues to be debated. Y. ruckeri shares $24-30 \%$ of DNA similarity with the Serratia species and $30 \%$ of DNA similarity with the Yersinia species. The final placement of the pathogen in the genus of Yersinia is based on the $\mathrm{G}+\mathrm{C}$ content. The $\mathrm{G}+\mathrm{C}$ content of Y. ruckeri is $47.5-48 \%$ which is closer to the $\mathrm{G}+\mathrm{C}$ value of Yersinia (46-50\%) than of Serratia (52-60\%) (Ewing et al., 1978). Serological cross reactions have shown that antiserum raised against $Y$. ruckeri only reacts with antigens of 
Salmonella enterica subsp. arizonae and H. alvei (Stevenson and Daly, 1982). Biochemical reactions of $Y$. ruckeri showed similarities with Enterobacter liquefaciens, Serratia marcescens subsp. kiliensis and S. enterica subsp. arizonae (Ross et al., 1966). More recently, the phylogenetic tree based on the sequence of 84 housekeeping genes of different Yersinia species showed that Y. ruckeri is the most distinct species within the Yersinia genus (Kotetishvili et al., 2005; Reuter et al., 2014). Several authors proposed to reconsider the taxonomic position of this pathogen and suggested that it should constitute a new genus (Bercovier and Mollaret, 1984; Bottone et al., 2005).

\section{Route of infection}

The first report on the infection route of $Y$. ruckeri was published in 2005 by Welch et al., who constructed a green fluorescent protein-tagged Y. ruckeri strain and visualized its distribution and localization in the infected rainbow trout using epifluorescence microscopy. A small number of $Y$. ruckeri cells was detected in the kidneys, spleen and blood, indicating an extracellular lifestyle of this pathogen (Welch and Wiens, 2005). Tobback et al. researched contact-exposure infection of rainbow trout with four different Y. ruckeri strains, both virulent and non-virulent. The study revealed that the pathogen first adheres to the well vascularized gills, and from there it invades the internal organs. Additionally, the study pointed out that the immune system of rainbow trout is able to clear out the non-virulent strains of Y. ruckeri, but not the virulent ones. This indicates that immune evasion is an important feature of this pathogen (Tobback et al., 2009). Later, the same group studied perfusion models of gills and gut, showing that virulent and non-virulent $Y$. ruckeri strains both adhered to and invaded gills and gut tissues of rainbow trout at the 
same rate. This finding indicated that both gills and gut are the initial targets for the pathogen (Tobback et al., 2010). In another study, a bioluminescent $Y$. ruckeri 150 strain was constructed using the plasmid containing the luxCDABE operon, and then administered to rainbow trout by immersion (Méndez and Guijarro, 2013). Analysis with bioluminescence imaging showed that the gut is the main organ of entry. However, the authors did not exclude other organs such as gills and skin as the initial target of the bacterium. They suggested that the number of bacterial cells during the first 12 hours was too low to detect them on the skin or gill tissues using the above method. Another study, where in situ hybridization and immunohistochemistry were used, demonstrated that beside the gills and gut, the skin acts as the main portal of entry for both live and inactivated Y. ruckeri strains (Khimmakthong et al., 2013).

The aforementioned methods offer many advantages to understand the initial routes of $Y$. ruckeri infection in its natural host, rainbow trout. However, these methods are technically limited. Bioluminescent imaging gives rather a low resolution, whereas immunohistochemistry requires small tissue sections. The fluorescent stereomicroscopy that was used to investigate Y. ruckeri antigen uptake in zebrafish, restricts the optical penetration depth to $1 \mathrm{~mm}$ into the tissue (Korbut et al., 2016). A new technique known as optical projection tomography (OPT) (Ohtani et al., 2014a, 2014b) visualizes the pathogen on the host's mucosal surfaces and shows a 3D spatial distribution of the pathogen in the internal organs without requiring sectioning of the samples. OPT allows accurate localization of $Y$. ruckeri and its route to the internal organs. The initial portal of entry is the secondary lamellae of the gills. Then, at $1 \mathrm{mpi}$ (minute post-infection), the bacterium crosses the gills' pavement cells and reaches the intestine at $30 \mathrm{mpi}$, the kidneys at $3 \mathrm{dpi}$ (days post-infection), and 
finally in the liver, spleen, brain and heart at 7 dpi. The skin surface and the intestine could be secondary portals of entry, as suggested by (Ohtani et al., 2014a, 2014b).

\section{Genomes}

Availability of the whole genome sequence gives an insight into the pathogenic mechanism of a pathogen and allows identification of new virulence determinants. Furthermore, whole genome analysis helps follow dissemination of a pathogen and acquisition of new traits, such as mobile genetic elements or antibiotic genes.

Six whole genome sequences of $Y$. ruckeri strains are available at the moment, sequenced by second generation (Illumina and 454) and the third generation (PacBio) sequencing technology. Four strains were sequenced by PacBio: Big Creek 74 (GenBank accession number: NZ_CP011078.1), CSF007-82 (GenBank accession number: LN681231), QMA0440 (GenBank accession number: NZ_CP017236.1) and NVH_3758 (GenBank accession number: NZ CP023184.1). Two strains were sequenced by Illumina and 454: YRB (GenBank accession number: NZ_CP009539.1) and SC09 (GenBank accession number: NZ_CP025800.1). The genome size of $Y$. ruckeri differs between strains and it is in the range between $3.6-\mathrm{Mb}$ and $3.9-\mathrm{Mb}$. That is around $10-15 \%$ smaller than genomes of other members of the Yersinia genus. The $\mathrm{G}+\mathrm{C}$ content falls in the range between $47.5 \%$ (for $\mathrm{YRB}$ ) and $47.7 \%$ (for QMA0440).

Y. ruckeri $\mathrm{SC} 09$, isolated from a moribut Ictalurus punctatus, possess the largest genome within that species, containing a single chromosome with the length of 3.9-Mb, 3651 CDS (coding DNA sequences), 19 rRNA genes, 79 
tRNA genes and 29sRNA genes. Among the CDS, the Ysa locus was identified that encodes all components of the type III secretion system (T3SS) (Liu et al., 2016). Interestingly, the Ysa locus of SC09 showed similarities in gene content, gene sequence and gene arrangement with the $S$. enterica pathogenicity island 1 and the chromosome-encoded T3SS from Yersinia enterocolitica biotype 1B. Consequently, the intracellular survival of SC09 in fish macrophages might be due to the presence of this T3SS. In addition to the T3SS, other systems have been identified, including the twin arginine transport system, the Sec-dependent transport system, type I secretion system (T1SS), type II secretion system (T2SS) and type IV secretion system (T4SS). Furthermore, the SC09 genome contains prophages and genomic islands (Liu et al., 2016).

A recent comparative genome analysis of the Y. ruckeri strains 150 , CSF007-82, ATCC29473, Big Creek 74 and SC09 representing different serotypes isolated from different hosts showed significant genetic variations between them (Cascales et al., 2017). The serotype O1 (150, ATCC29473, CSF007-82) contained exclusively a set of genes that are involved in the biosynthesis of legionaminic acid (the major component of the $\mathrm{O}$-antigen of LPS) a bacteriocin, as well as virulence-related genes, including a T4SS and an invasin. The serotype O2, represented by Big Creek 74 and presumably by SC09, contained 99 and 261 unique genes, respectively. The presence of these genes was suggested to be host-specific and could explain how the bacterium adapted to the fish environment. Among the unique proteins that are present only in SC09 is thymidylate synthase, which was previously shown to be linked to the intracellular growth of $S$. aureus and $S$. typhimurium (Kriegeskorte et al., 2014). Finally, the fact that the genome of ATCC29473 
(type strain) lacks 21 genes that are involved mostly in virulence, could explain the attenuation of the strain (Cascales et al., 2017; Kriegeskorte et al., 2014).

\section{Virulence factors}

Despite the fact that $Y$. ruckeri causes high stock fish losses in aquaculture, little is known about the virulence determinants of this pathogen. This might be explained by the early success of the ERM vaccine in the 1960s, the complex taxonomy and the limited amount of research on different $Y$. ruckeri serotypes (Barnes, 2011). However, one thing is clear: virulence of Y. ruckeri is influenced by several factors, such as iron availability, temperature, $\mathrm{pH}$ and osmolarity (Guijarro et al., 2018). Furthermore, it is believed that the virulence mechanism and virulence determinants of $Y$. ruckeri are similar to other members of the Enterobacteriaceae family (Fernández et al., 2007a). Therefore, many researchers reused models and techniques that were already applied to study other members of the Yersiniae group. Various approaches have been used to select, identify and further study the virulence-related genes of Y. ruckeri.

Molecular approaches include the in vivo expression approach (IVET) and signature-tagged mutagenesis (STM) (Dahiya and Stevenson, 2010a; Fernández et al., 2004; Mendez et al., 2018). The IVET is based on identification of genes that are expressed in vivo in the host during the infection process. In contrast, STM is used to screen for Y. ruckeri mutants that survive in vitro, but not in vivo, meaning that the inactivated gene is required for survival or infection. Other techniques, especially those developed in recent years, are based on prediction of the role of virulence factors, and they include proteomic, transcriptomic and genomic analyses (Guijarro et al., 2018; Kumar 
et al., 2017, 2016). Although these methods have several limitations, they have helped understand the pathogenesis of $Y$. ruckeri infection (Guijarro et al., 2018).

\section{Genes identified by IVET}

Application of IVET by Fernandez et al. in 2004 allowed for identification of 14 genes, some of which were related to virulence, for example the T4SS, haemolysin (YhlA) and genes involved in iron acquisition (ruckerbactin) and the $c d s A B$ operon (Fernández et al., 2004).

\section{The Type IV secretion system (T4SS)}

\section{Classification of T4SSs}

T4SSs are found in Gram-negative and Gram-positive bacteria, and in some archaea. The T4SSs are used by bacteria to transport macromolecules, such as monomeric and multimeric proteins, protein complexes, protein-DNA complexes or DNA molecules, across the bacterial cell membrane. Three major groups of T4SSs have been identified based on their function (AlvarezMartinez and Christie, 2009). The first group, called conjugative T4SSs, transfers DNA from one cell to another by direct contact, in a process called conjugation. These T4SSs can be found on self-transmissible plasmids. They can also be a part of a chromosome, and then they are known as conjugative transposons. The second group of T4SSs is responsible for the DNA uptake and release into the extracellular milieu. Two examples are the ComB system found in Helicobacter pylori (DNA uptake) and Gonococcal Genetic Island found in N. gonorrhoeae (DNA release). The third group of T4SSs transfers 
virulence proteins and protein complexes into mammalian host cells, and thus plays an important role in virulence. This group is exemplified by important human pathogens, such as H. pylori, Bordetella pertussis and Legionella pneumophila (Alvarez-Martinez and Christie, 2009).

Based on gene organization and evolution, T4SSs can be further divided into subgroups. Originally, T4SSs were divided into the types F, P and I that resemble the IncF, IncP and IncI conjugative plasmids (Lawley et al., 2003). Later on, T4SSs were categorized into type IVA (T4ASS) (counterpart of types F and P) and type IVB (T4BSS) (counterpart of type I) (Christie et al., 2005). The T4ASSs are exemplified by the Ti plasmid of Agrobacterium tumefaciens and pKM101 of E. coli. One example of the T4BSSs is the Dot/Icm (defective in organelle trafficking/intracellular multiplication) of L. pneumophila (Wallden et al., 2010).

\section{Architecture of T4SSs}

Even though T4ASSs and T4BSSs play similar roles in transport of macromolecules, they are composed of different numbers of proteins. The T4ASSs require 12 proteins (termed VirB1 to VirB11 and VirD4) to fulfil its function, while the T4BSSs require 27 proteins (termed Dot/Icm) (Wallden et al., 2010).

The T4ASS is composed of a core complex and an extracellular pilus (Figure 3). The core complex spans both membranes of Gram-negative bacteria and it functions as a secretion channel, through which effector proteins can be translocated. The core complex is composed of three proteins (VirB7, VirB9, VirB10) that provide a scaffold for the secretion channel (Fronzes et al., 2009). The extracellular pilus is made up of a major (VirB2) and a minor 
(VirB5) subunit. Three ATPases (VirB4, VirB11, VirD4), located in the bacterial cytoplasm, provide energy for substrate translocation and help in the assembly of T4ASS (Wallden et al., 2010). Two inner membrane proteins (VirB6 and VirB8) transport macromolecules from the cytoplasm to the periplasm. Finally, proteins located in the inner membrane and in the periplasm, namely VirB3 and VirB1, play a role in pilus assembly (Fronzes et al., 2009; Waksman and Orlova, 2014).

The architecture of the T4BSS is similar to the T4ASS with the exception that T4BSS lack the extracellular pilus (Figure 4). The T4BSS requires 22 structural proteins and 5 chaperones (Segal et al., 1998; Vogel et al., 1998). The secretion channel is made up of five proteins (DotC, DotD, DotF, DotG and DotH) that span both membranes together. It is very likely that these proteins play similar roles to the VirB6-10 proteins in T4ASS (Vincent et al., 2006). The inner membrane consists of twelve proteins that play a stabilization role in the complex (Voth et al., 2013). Six Dot/Icm proteins are positioned in the cytoplasm and are involved in direction and transport of effector proteins through the secretion pore (Voth et al., 2013). DotB acts as ATPase, which is an analogue of VirB11 in T4ASS, while the remaining five proteins play a role in efficient secretion of effectors (Sexton et $a l ., 2005)$. Finally, the function of the periplasmic protein known as IcmX is still unclear (Matthews and Roy, 2000). The Dot/Icm proteins that make up the T4BSS were originally discovered in L. pneumophila (Segal et al., 1998; Vogel et al., 1998). L. pneumophila is a Gram-negative bacterium and the causative agent of the Legionnaire's disease in humans. The Dot/Icm proteins help L. pneumophila survive and multiply inside macrophages. This is done by injecting effector proteins into the host, and thus preventing lysosome- 
phagosome fusion. A large number of Dot/Icm proteins have homologs in the conjugal transfer system (referred to as tra) of self-transmissible IncI plasmids R64 and Colb-P9. Besides L. pneumophila, the Dot/Icm proteins were also shown to be involved in virulence in B. pertussis, H. pylori and L. pneumophila (Sexton and Vogel, 2002). 


\section{T4ASS}

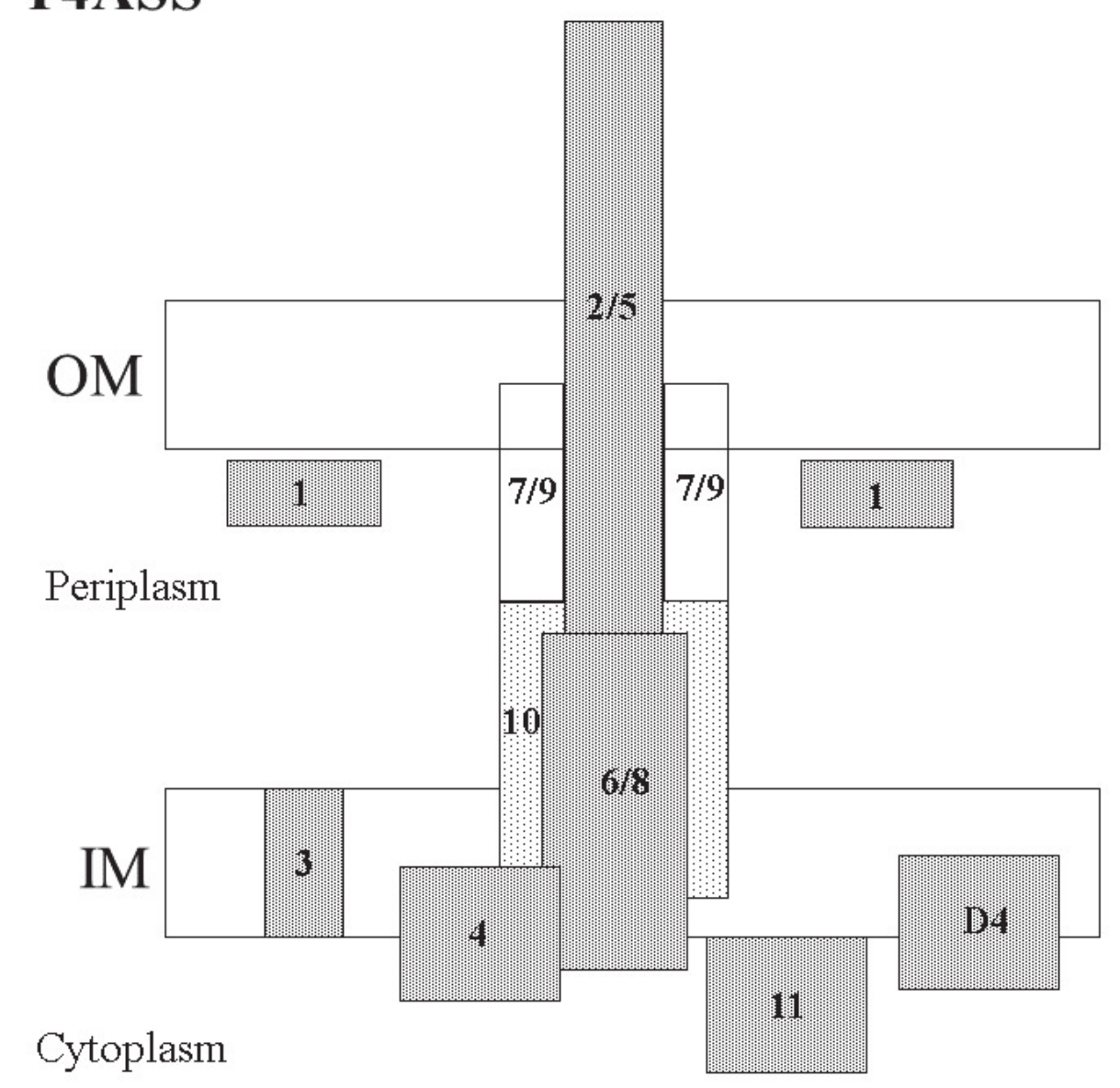

Figure 3. Schematic representation of T4ASS. IM- inner membrane, OM- outer membrane. The T4ASS transports proteins from the bacterial cytoplasm to the eukaryotic host cell. It is made of a core complex and an extracellular pilus. The components of the T4ASS are described in more detail in the text. The VirB proteins are labelled with numbers 1-10 while VirD4 is labelled as D4. The figure was made based on (Voth et al., 2013) 


\section{T4BSS}

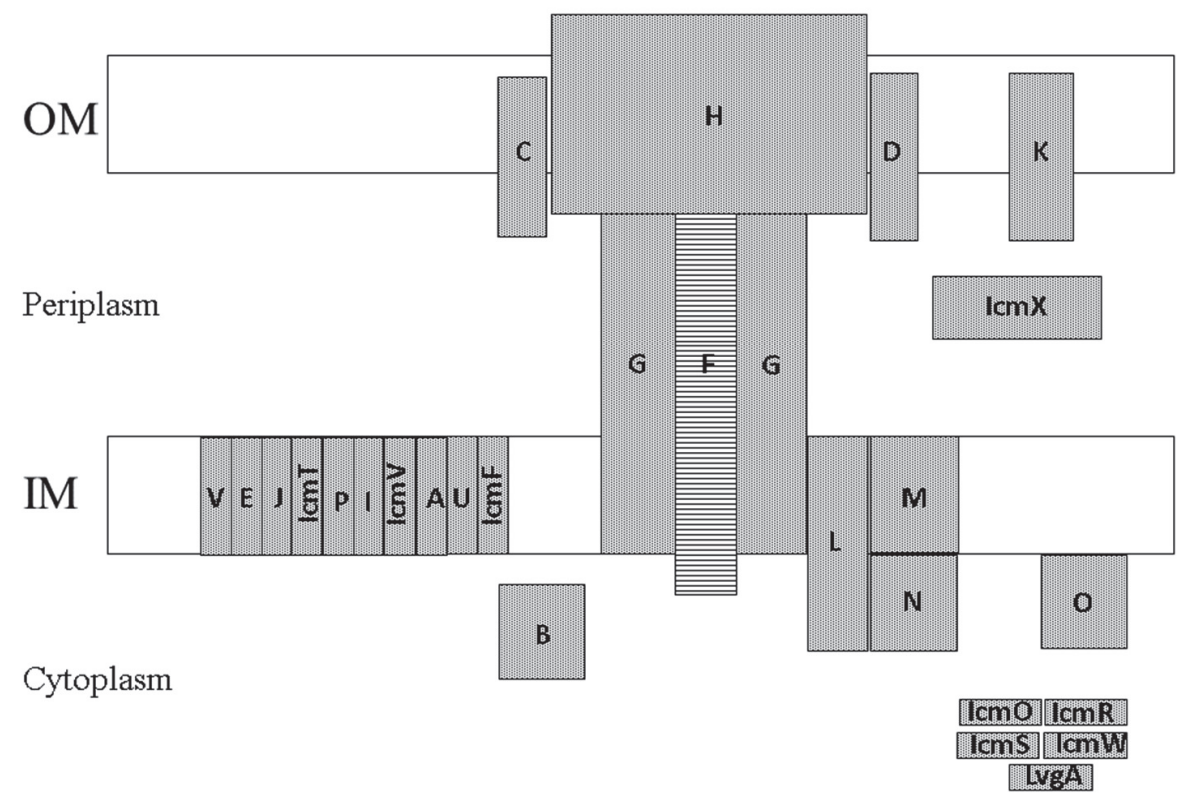

Figure 4. Schematic representation of a T4BSS. IM- inner membrane, OM- outer membrane. The T4BSS transports proteins from the bacterial cytoplasm, through the periplasm, to the eukaryotic host cell. T4BSS lacks an extracellular pilus. The components of the T4BSS are described in more detail in the text. The Dot proteins are labelled with single letters A-V while Icm proteins are labelled with full names. The figure were made based on (Voth et al., 2013). 


\section{T4SSs in Yersiniae}

The presence of T4SSs in Yersiniae is mainly associated with the presence of conjugative plasmids. There exist a few reports describing conjugative plasmids in Yersinia species (Eppinger et al., 2007; Hammerl et al., 2008; Hertwig et al., 2003; Song et al., 2004). Conjugative plasmids in $Y$. enterocolitica and Yersinia pseudotuberculosis confer antibiotic resistance (Kimura et al., 1975). The conjugative plasmids pYcon54 and pYcon966 from $Y$. enterocolitica have been shown to carry two tra regions that are involved in pilus assembly and DNA transfer (Hertwig et al., 2003). Analysis of the complete genome sequence of $Y$. pseudotuberculosis IP31758, the causative agent of the Far East scarlet-like fever in humans, revealed the presence of two novel plasmids, pYspIP31758.1 and pYpsIP31758.2 (Eppinger et al., 2007). The large plasmid pYpsIP31758.1 encodes a T4BSS that is related to the T4BSS of L. pneumophila and could play a role in the pathogenesis of $Y$. pseudotuberculosis and in its intracellular survival. A comparative analysis of the complete nucleotide sequence of the multidrug resistant plasmid pIP1202 from Yersinia pestis strain IP275 revealed a shared region with pSN254 and pYR1, which were isolated from S. enterica and Y. ruckeri. The shared region contained 135 genes that encode, among others, a T4SS (Welch et al., 2007).

The presence of a T4SS was detected in two Y. ruckeri strains, namely 150 and SC09. The tra operon of Y. ruckeri 150 was identified by the IVET (Fernández et al., 2004). The operon was present in the genome of different $Y$. ruckeri strains, but was absent in the genome of the human pathogens. Some genes of the tra operon displayed sequence similarity to the Dot/Icm proteins of L. pneumophila. The expression of the tra operon was regulated by 
temperature and availability of nutrients. The highest expression of the T4SS genes was reported at $18^{\circ} \mathrm{C}$, with limited nutrients. The tra operon was shown to resemble the tra operon of the pADAP plasmid from Serratia entomophila, both in sequence and gene organization. T4SS is likely to play a role in virulence because a mutant of the traI gene of $Y$. ruckeri 150 was reported to be less virulent than the wild type (WT) strain (Méndez et al., 2009). In $Y$. ruckeri SC09, the T4SS was identified by a whole genome analysis. The T4SS of SC09 was reported to be related to the T4ASS of $A$. tumefaciens. It was suggested that the T4SS might be required for the pathogen's survival in fish macrophages (Liu et al., 2016). A recent comparative analysis of genome sequences of $Y$. ruckeri strains (150, CSF007-82, ATCC29473) showed that 268 genes were shared between them, and genes of the T4SS were present among them (Cascales et al., 2017).

\section{Extracellular products: haemolysin YhlA and metalloprotease Yrp1}

The $y h l B A$ cluster, which is also present in human-pathogenic Yersiniae, has been implicated in Y. ruckeri virulence. Both genes, namely $y h l B$ and $y h l A$, identified by IVET have a high sequence similarity to genes encoding haemolysins in Serratia. Both genes exhibit cytolytic and haemolytic properties. They are able to lyse erythrocytes and the BF-2 fish cells. The expression of both genes is regulated by temperature and iron availability. A high level of $y h l B A$ expression was observed under limited iron availability and at $18^{\circ} \mathrm{C}$. The presence of the $y h l B A$ operon in $Y$. ruckeri strains from different geographic areas and sources indicated an important role for this cluster in Y. ruckeri virulence (Fernández et al., 2007b; Guijarro et al., 2018). 
The Yrp1 of Y. ruckeri was identified by Secades and Guijarro in 1999 (Secades and Guijarro, 1999). Yrp1 is a $47-\mathrm{kDa}$ serralysin metalloprotease secreted by a T1SS. Yrp1 is produced by some of the most virulent Y. ruckeri strains, named $\mathrm{Azo}^{+}$strains, at the end of the exponential growth phase (Secades and Guijarro, 1999). Expression of Yrp1 is controlled by osmolarity and temperature: the highest expression occurs at $18^{\circ} \mathrm{C}$ and under low osmotic pressure (Fernandez et al., 2003). Furthermore, Yrp1 protease has been implicated in virulence. Yrp1 has hydrolytic properties. It digests a wide range of matrix and muscle proteins, such as laminin, fibronectin, actin and myosin, causing the typical clinical symptoms of the ERM disease. Finally, inactivated Yrp1 has a protective role against ERM when delivered as an immunogen (Fernandez et al., 2003; Guijarro et al., 2018).

\section{Iron acquisition system}

Iron acquisition systems aid many bacterial pathogens in colonizing and invading host tissues. In Y. ruckeri, the iron acquisition system is called ruckerbactin. Ruckerbactin is a siderophore that belongs to the catecholate group (Tobback et al., 2007). Siderophores are low-molecular-mass and highaffinity iron-chelating molecules (Tobback et al., 2007). They are categorized into four major groups: catecholates (enterobactin), hydroxamates (ferrioxamine), carboxylates (rhizobactin) and a mix of different types (pyoverdine) (Ahmed and Holmström, 2014). During bacterial infection, when iron availability is limited, the siderophores produced by bacteria cells are excreted into the extracellular environment, where they can bind iron molecules. This results in formation of the siderophore- $\mathrm{Fe}^{3+}$ complex, which is then transported back to the bacterial cell and into the cytoplasm through a 
specific bacterial outer membrane receptor. Once inside the bacterial cell, the $\mathrm{Fe}^{3+}$ is reduced to $\mathrm{Fe}^{2+}$ in order to release free iron that can be utilized for metabolic pathways (Tobback et al., 2007).

The genes involved in production of ruckerbactin are upregulated during the infection process and are highly expressed at $18^{\circ} \mathrm{C}$, but not at $28^{\circ} \mathrm{C}$, which is the optimal temperature for the pathogen's growth (Fernández et al., 2004). Ruckerbactin itself has high amino acid sequence similarity with the E. coli enterobactin, and their gene organization is similar. There is also a high degree of similarity between the ruckerbactin receptor and the ferrichrysobactin receptor of E. chrysanthemi, but not the enterobactin receptor of E. coli (Fernández et al., 2004).

\section{cds $A B$ operon}

The $c d s A B$ operon was identified using the IVET (Fernández et al., 2004). The operon is involved in the uptake and degradation of L-cysteine. It consists of two genes, $c d s A$ and $c d s B$, that encode a cysteine permease and an Lcysteine desulfidase, respectively. The $c d s A B$ cluster is found in several groups of Gram-negative bacteria, but not in Y. pseudotuberculosis and Y. pestis (Méndez et al., 2011). It is also present in Y. ruckeri strains from different geographical locations and origins. In vivo assays and $\mathrm{LD}_{50}$ experiments showed that the $c d s A B$ cluster is required to achieve full virulence. The absence of the $c d s A B$ operon leads to $Y$. ruckeri virulence attenuation (Méndez et al., 2011). 


\section{Genes identified by STM}

STM is used to construct $Y$. ruckeri mutants by inactivating random genes, and then inject the mutant pool into a host to observe their survival. If a mutant survives in vitro, but not in vivo, it means that the inactivated gene is required for in-host survival or infection. By using the STM approach, several genes were identified related to bacterial entry and attachment, bacterial colonization of organs, cell signaling and transport (Dahiya and Stevenson, 2010b, 2010c).

\section{$z n u A B C$ and BarA-UvrY}

The znuABC operon is composed of three genes, encoding a zinc binding transporter, a membrane permease, and an ATPase. The genetic organization of the operon is similar to its counterparts found in other Gram-negative bacteria, such as E. coli and S. typhimurium (Campoy et al., 2002; Patzer and Hantke, 1998). The znuABC operon is likely to be involved in the transport of zinc, a molecule required for the pathogen's survival. This is supported by the fact that the growth of E. coli znuABC mutants was restored in a metaldeficient medium when the znuABC operon of $Y$. ruckeri was present on the plasmid. At the same time, the znuABC mutant of $Y$. ruckeri had low virulence and survived poorly in a rainbow trout kidney (Dahiya and Stevenson, 2010b).

The UvrY component of the BarA-UvrY system plays the role of response regulator. It was demonstrated to contribute to $Y$. ruckeri pathogenicity. Mutations in $u v r Y$ led to reduced invasion of EPC epithelial fish cells and increased sensitivity to oxidative stress, which in turn impaired the survival of Y. ruckeri in rainbow trout (Dahiya and Stevenson, 2010c). 


\section{Other virulence factors}

\section{Genes upregulated at $18^{\circ} \mathrm{C}$}

A recent study showed a practical approach for identification of virulence genes upregulated at $18^{\circ} \mathrm{C}$, a temperature at which most $Y$. ruckeri outbreaks occur. A novel Tn5 transposon cassette containing the promoterless lux-lac operon was randomly inserted into the genome of $Y$. ruckeri, causing interruption of genes. As a result of that, 168 clones were identified that had higher $\beta$-galactosidase activity at $18^{\circ} \mathrm{C}$ than at $28^{\circ} \mathrm{C}$. The interrupted genes included, among others, genes there were involved in the synthesis of legionaminic acid (a component of the LPS structure), the yrpl metalloprotease, genes regulated by environmental changes (for example the diguanylate cyclase, a glycosyltransferase, a SAM-dependent methyltransferase), and genes induced under osmotic shock (for example osm Y). All these genes were previously implicated in virulence (Mendez et al., 2018)

\section{Heat-sensitive factor (HSF)}

HSF was identified in 1990 by Furones et al. (Furones et al., 1990). A comparative study of cell extracts between virulent and avirulent $Y$. ruckeri strains exhibited a correlation between production of HSF by virulent strains. Cell extracts of $Y$. ruckeri strains of serotype I, when injected into fish, caused mortalities only in HSF-positive strains. HSF is likely to play a role in virulence. It was proposed that HSF can mask cell surface antigens and thus confer resistance to phagocytic killing. However, a recent study showed that HSF is an alkyl sulphatase, encoded by the $y \mathrm{raS}$ gene. The alkyl sulphatase 
catalyzes the hydrolysis of SDS, but is not directly linked to Y. ruckeri virulence (Navais et al., 2014).

\section{Lipopolysaccharides (LPS)}

LPS is a molecule present in the outer membrane of Gram-negative bacteria and implicated in virulence. $\operatorname{lp} x D$ gene is one of the nine genes involved in biosynthesis of lipid A of LPS (Altinok et al., 2016). In-frame deletion of the $\operatorname{lp} x D$ gene in $Y$. ruckeri leads to a production of an attenuated $Y$. ruckeri strain. The lpxD mutant, when administered by immersion and injection method to rainbow trout, elicited good protection against WT $Y$. ruckeri. The LPS-deficient mutant was suggested to be a good vaccine candidate against $Y$. ruckeri infections in rainbow trout (Altinok et al., 2016; Guijarro et al., 2018)

\section{Antifeeding Prophage 18 (Afp18)}

Afp is a toxin delivery system that shows similarities to the T4SS, Rpyocins of $P$. aeuroginosa and the PVC virulence cassette of Photohabdus luminescens (Heymann et al., 2013). Afp is present in Gram-negative and Gram-positive bacteria as well as in archaea. Afp resemble the tail of T4 bacteriphages that is composed of a central tube covered by a contractile sheath and a baseplate with fibers. Afp, encoded by a pADAP plasmid of $S$. entomophila, was shown to play a role in delivery of a toxin, and thus in virulence. In Y. ruckeri, Afp18 is part of the Afp and it is a toxic unit that contains the glycosyltransferase domain at the C-terminus. The molecular mechanism of the glycosyltransferase domain $\left(\mathrm{Afp} 18^{\mathrm{G}}\right.$ ) was studied in zebrafish embryos. After injection of the $\mathrm{Afp} 18^{\mathrm{G}}$ protein into zebrafish 
embryos, the development of zebrafish stopped, indicating that the glycosyltransferase domain is the major toxic component of Afp18 (Jank et al., 2015).

\section{Flagellar master operon (flhDC)}

The flhDC operon of $Y$. ruckeri is a master regulator of the flagellar secretion apparatus. This operon is essential for flagella production, phospholipase secretion and virulence. Mutation in the $f l h D C$ operon prevents motility and phospholipase activity, whereas its absence results in transcriptional changes. In competition assays, the $f l h \Delta D$ mutant of $Y$. ruckeri was reported to be more virulent than the WT strain. Examination of spleen in rainbow trout revealed an increased density of the $\operatorname{llh} \Delta D$ mutant compared to the WT (Jozwick et al., 2016). This finding indicates that flhD mutation contributes to $Y$. ruckeri virulence.

\section{Plasmids}

The fact that plasmids are involved in virulence of Yersiniae has been known for a long time. One of the most researched species of Yersiniae, $Y$. pestis, carries typically three plasmids. Two of them are species-specific: pPCP1 (also called pPla, pYP and pPst) and pMT1 (pYT, pFra). The third plasmid is the highly conserved pCD1 plasmid. Presence of additional plasmids in $Y$. pestis has been reported, however they are strain-specific and not very well characterized (Rajanna et al., 2010).

The pCD1 plasmid is one of the best characterized plasmids in Yersiniae.

It is shared among the three human pathogenic Yersiniae ( $Y$. pseudotuberculosis, $Y$. enterocolitica and $Y$. pestis) and has different names in 
each of them: pIB1 in Y. pseudotuberculosis, pYVe (YV stands for Yersinia virulence) in $Y$. enterocolitica, and pCD1 (CD stands for calcium-dependent) in $Y$. pestis KIM5. The plasmid is also referred to as pYV, pCad, pLcr, and pVW (Ferber and Brubaker, 1981; Filippov et al., 1990). Removal of this plasmid was shown to result in the loss of virulence. The pCD1 plasmid is a $70 \mathrm{~kb}$ virulence plasmid. It encodes the low-calcium response the T3SS (Ysc) and a protein named YadA (Yersinia adhesin A) (Cornelis et al., 1998; Mühlenkamp et al., 2015). The T3SS, also known as the injectisome, consists of a basal body that spans both inner and outer membrane, and a needle that protrudes out of the cell and makes direct contact between the bacterial cell and a host cell. The T3SS encodes three categories of proteins: structural proteins, chaperones and effector proteins (Puhar, 2014). One example of effector proteins are Yops (Yersinia outer proteins) that are required for extracellular survival of Yersinia. The components of the T3SS can be found in many gram-negative pathogens such as E. coli and $P$. aeuroginosa, and therefore constitute an attractive target for vaccine development (Puhar, 2014). Expression of the T3SS proteins is regulated by temperature and calcium concentration (known as the low calcium response). The T3SS is active when the temperature is rising from $26^{\circ} \mathrm{C}$ to $37^{\circ} \mathrm{C}$. The main purpose of the T3SS is to modulate the function of the host by injecting proteins into the cytosol of immune cells. The Yop proteins protect the bacterial cells against phagocytes, inhibit the production of proinflammatory cytokines, and induce apoptosis of macrophages (Cornelis et al., 1998)

The pMT1 plasmid is unique to the causative agent of plague, $Y$. pestis. It is a $100-\mathrm{kb}$ plasmid; however, the size varies depending on the strain of origin. pMT1 encodes two virulence factors: the Yersinia murine toxin (Ymt) and the 
F1 capsular protein. Ymt is required for survival of $Y$. pestis in the flea vector (Hinnebusch et al., 2002). The activity of Ymt protects Y. pestis from digestion in the flea gut and aids the transmission of $Y$. pestis. The F1 capsular protein, which is encoded by cafl, hampers the uptake of $Y$. pestis by macrophages, and thus prevents phagocytosis (Rajanna et al., 2010).

The pPCP1 plasmid is a $9.6 \mathrm{~kb}$ plasmid, specific for $Y$. pestis strains. It encodes regulatory genes, genes of unknown function, and the plasminogen activator Pla (Bearden et al., 1997). Pla is a surface protease that is required for $Y$. pestis virulence. Pla degrades host fibrin and basement membranes. Its activity is essential for the development of pneumonic plague (Rajanna et al., 2010).

The presence of plasmids in Y. ruckeri has been described by many authors. De Grandis and Stevenson examined the presence of plasmids in Y. ruckeri strains representing serotypes I and II (De Grandis and Stevenson, 1982). Strains of serotype I contained a large and a small plasmid while strains of serotype II contained only small plasmids, regardless of the source of the isolate. These results are in agreement with those obtained by others (Romalde et al., 1993; Stave et al., 1987; Toranzo et al., 1983). As noticed by some authors, the number of plasmids in Y. ruckeri strains can differ depending on the applied plasmid isolation method (Toranzo et al., 1983). The presence of large plasmids was suggested to be related to temperature, as those strains carrying the large plasmids were unable to grow at $37^{\circ} \mathrm{C}$. Y. rukeri strains that carried the large plasmids exhibited distinct colony morphology and serological reactions, indicating that the large plasmid might encode genes related to these features (Stave et al., 1987). Large plasmids have received a lot of attention due to their possible correlation with Yersiniae virulence 
(Garcia et al., 1998). Guilvout et al. examined the plasmid profile of $18 Y$. ruckeri strains isolated from various ERM outbreaks. Strains of serotype II and $\mathrm{V}$ contained 4 plasmids with both high and low molecular weights (72 MDa, $62 \mathrm{MDa}, 32 \mathrm{MDa}, 25 \mathrm{MDa}$ ), while strains of serotype I carried only one plasmid (62 MDa) (Guilvout et al., 1988). Southern hybridization experiments between 62-MDa plasmids of $Y$. ruckeri strains of different origin showed a high level of DNA similarity. However, the 62-MDa plasmid did not show any DNA similarity with the plasmids from other family members of Yersiniae, indicating its different origin and function.

Up to this date, the function of $Y$. ruckeri plasmids is not clear. Large plasmids present in $Y$. ruckeri often carry antibiotic resistance genes. De Grandis and Stevenson tested susceptibility of Y. ruckeri strains to 23 antimicrobial agents (De Grandis and Stevenson, 1985). All tested Y. ruckeri strains showed similar antimicrobial susceptibility pattern with the exception of two strains, which carried a 36-MDa plasmid and a 52-MDa plasmid. Both strains exhibited resistance to sulfonamides and tetracycline. Conjugation experiments showed that one of these two plasmids encoded antibiotic resistance genes that could be transferred to E. coli and Y. ruckeri strains. Furthermore, great variability was reported in polymyxin B susceptibility depending on the tested serotype. Strains of the serotypes II, III and V were polymyxin B resistant while most strains of serotype I were susceptible. Welch et al. showed a comparative DNA sequence analysis between the pIP1202 plasmid of $Y$. pestis strain IP275 and multi-drug resistance plasmids of $Y$. ruckeri YR1(pYR1) and of the S. enterica serotype Newport SL254 (pSN254) (Welch et al., 2007). A comparative study showed almost identical plasmid backbones shared between those pathogens, indicating that the plasmids had a 
common ancestor. The common region contained genes involved in plasmid replication and type IV conjugation transfer.

\section{Biofilms}

For a long time, bacteria were considered as single, freely floating cells. Most of the research during that period was performed on free planktonic cells. In 1684, Antonie van Leeuwenhoek was the first to observe microbial aggregates on tooth surfaces. He defined the aggregates as scurf, which we today know as dental plaque. Since then, many scientists have observed that besides existing in the planktonic state, bacteria could also attach to surfaces. This phenomenon was called "biofilm" for the first time in 1978 (Costerton et al., 1978; Rabin et al., 2015). The authors described the mechanisms and benefits acquired by cells that adhere to materials in form of a biofilm. Since then, the definition of biofilm has been revised several times. Recently, a special interest in biofilm research was given to the group of clinically relevant pathogens called ESKAPE (E. faecalis, S. aureus, Klebsiella pneumoniae, Acetinobacter baumannii, P. aeuroginosa, Enterobacter ssp.) due to their growing antimicrobial resistance (Rabin et al., 2015). Furthermore, there is ongoing research in order to understand the structure of multimicrobial biofilms and the function of the oral microbiome (Xin et al., 2016). Today, biofilm is defined as microbial communities embedded in a self-produced polymeric matrix.

\section{Structure}

A biofilm is composed of microbial cells, embedded in extracellular polymeric substances (EPSs). EPS is a matrix material produced by microbial 
cells, which constitutes for about $90 \%$ of the biofilm dry mass. Synthesis of EPS is highly dependent on the bacterial strain, temperature and availability of nutrients (Flemming and Wingender, 2010). Composition varies greatly between species and even strains: EPS consists of different types of biopolymers, such as nucleic acids, polysaccharides, proteins and lipids (Flemming and Wingender, 2010). EPS gives a biofilm several advantages. First, the fact that EPSs are highly hydrated protects a bacterial biofilm against desiccation. EPSs are mostly hydrophilic, but hydrophobic EPSs exist as well (Donlan, 2002). Another important advantage is that EPSs form the biofilm scaffold by interconnecting bacterial cells. Furthermore, EPSs provide protection against predators, antimicrobials, biocides, antibiotics, ultraviolet radiation and metallic cations. EPSs also participate in signaling, migration and exchange of genetic information by horizontal gene transfer. EPSs trap digestive enzymes for acquisition of nutrients (Dragoš and Kovács, 2017). A significant amount of research has shown that removal of EPS completely stops biofilm formation, which indicates that EPSs are essential for biofilm formation (Dragoš and Kovács, 2017).

One of the components of EPS, exopolysaccharides, are produced extraor intracellularly. They are secreted outside the cell into the environment when produced intracellularly. Exopolysaccharides are natural polymers, linear or branched, with a high molecular mass in the range between $0.5 \times 10^{6}$ Daltons to $2 \times 10^{6}$ Daltons. Exopolysaccharides can be visualized by electron microscopy, where they look like long strands forming complex networks. In biofilms, exopolysaccharides usually interact with other biopolymers, including proteins, lipids, as well as other exopolysaccharides (Sutherland, 2001). Exopolysaccharides can differ between species and even between 
strains of a single species (Sutherland, 2001). One of the most studied exopolysaccharides is alginate, synthesized by the bacterium P. aeruginosa, a causative agent of respiratory infections in cystic fibrosis patients. Alginate is not required in the initial steps of biofilm formation, however it provides mechanical stability for the biofilm and protects the cells from the outside environment (Boyd and Chakrabarty, 1995; Wozniak et al., 2003). Apart from alginate, $P$. aeruginosa produces two other polysaccharides, Pel and Psl, which are required for biofilm formation (Friedman and Kolter, 2004; Jackson et al., 2004). The composition of exopolysaccharides determines their chemical and physical properties. For example, exopolysaccharides become polyanionic if they contain either uronic acids or ketal-linked pyruvate, as well as phosphate or, in some cases, sulphate (Sutherland, 2001). Some examples of polyanionic exopolysaccharides are alginate, xanthan and colonic acid (Flemming and Wingender, 2010). The polyanionic property is used in cation binding. The calcium-binding properties of alginate of $P$. aeruginosa was shown to induce the T3SS upon binding with calcium cations (Horsman et al., 2012). There exist also a few polycationic exopolysaccharides, for example polysaccharide intercellular adhesin from Stapylococcus epidermidis (Mack et al., 1996).

In environmental and sewer biofilms, the amount of extracellular proteins can exceed the polysaccharide content. Extracellular proteins play various roles in the biofilm (Flemming and Wingender, 2010). They act as digestive enzymes that break down high molecular weight polymers into low molecular weight molecules that can be further used by the bacterial cells as a carbon or energy source. Different molecules can serve as substrates for extracellular proteins, including water-soluble biopolymers (proteins), water-insoluble biopolymers (cellulose) and particles trapped in EPS. In some cases, 
extracellular proteins can lead to detachment of bacterial cells from the biofilm. Finally, extracellular proteins serve as virulence factors, especially in medical settings (Flemming and Wingender, 2010). Some examples of extracellular proteins include glucan-binding proteins (Lynch et al., 2007), Fap amyloids (Dueholm et al., 2013), lectins (Diggle et al., 2006) and a biofilmassociated protein family (Bap) (Cucarella et al., 2001). The Bap proteins are high molecular weight proteins, present in many bacterial species, such as $S$. aureus and E. faecalis. They are involved in biofilm formation and the infection processes (Cucarella et al., 2001; Toledo-Arana et al., 2001).

eDNA is another important component of EPS. Initially, it was though that eDNA originates from lysed cells. However, it is now well recognized that eDNA is an integral part of a bacterial biofilm and is produced by secretion or controlled cell lysis (Okshevsky and Meyer, 2015). Although eDNA is found in biofilms of various origin, large amounts of eDNA were found in wastewater biofilms. The localization, the origin and the amount of produced eDNA varies between species (Flemming and Wingender, 2010). eDNA plays several roles in a biofilm. It is involved in biofilm formation (Okshevsky and Meyer, 2015). In close contact with a surface, bacterial eDNA interacts with surface receptors, and thus contributes to bacterial adhesion (Rabin et al., 2015). eDNA is one of the major matrix components in P. aeuroginosa, where it acts as an intercellular connector and provides a scaffold for the biofilm (Flemming and Wingender, 2010). eDNA has also antimicrobial effects because of the ability to bind divalent cations and some positively charged antimicrobial peptides (Flemming and Wingender, 2010). eDNA induces antibiotic resistance. It has been shown that in $P$. aeuroginosa, the ability of eDNA to bind magnesium affects the expression of genes involved in modification of 
cell wall lipopolysaccharides, which leads to changes in the bacterial outer membrane, and thus contributes to enhanced antibiotic resistance (Mulcahy et al., 2008).

\section{Factors influencing cell attachment}

Biofilm can in principle form on almost every surface where nutrients are available. However, there are several factors, such as the environment, the cell surface properties and the material surface characteristics, that can affect biofilm formation (Mortensen, 2014).

\section{Environment}

Certain conditions of the environment in which biofilm is formed, such as temperature, $\mathrm{pH}$, nutrient level, presence of antibiotics, and fluid flow velocity, influence bacterial adhesion (Katsikogianni and Missirlis, 2004). Fletcher et al. investigated the influence of several cations (sodium, calcium, lanthanum, ferric iron) on $P$. fluorescence adhesion to a glass surface. The authors found that that bacteria attached better to the surface when cations were present in the environment. This was probably caused by neutralization of the negative charges on glass surface by the cations, and in turn a decrease of the repulsive force between the bacteria and the surface (Fletcher and Floodgate, 1973). Another study showed that adhesion of Streptococcus faecium to glass is enhanced with increasing temperature, time of exposure and bacterial concentration (An and Friedman, 1998). Fluid flow velocity is also considered as a strong factor that can influence not only bacterial attachment but also their growth, morphology, size and metabolism. The higher the velocity, the higher the shear forces that are applied to the biofilm, and in turn the higher the 
dispersion of single cells from the biofilm. Thus, high shear forces can contribute to a lower growth rate and higher catabolic activity (Katsikogianni and Missirlis, 2004).

\section{Cell wall properties}

Bacterial hydrophobicity and chemical composition of the cell wall components (fimbriae, flagella, LPS, exopolysaccharides, lipoteichoic acid, outer membrane proteins) influence the physicochemical properties of the cell, and therefore determine the extent and the rate of cell attachment (Krasowksa and Sigler, 2014). Generally, bacteria with hydrophilic wall components, such as exopolysaccharides and LPS, will attach stronger to hydrophilic surfaces, while bacteria with hydrophobic wall components, such as fimbriae, prefer to attach to hydrophobic surfaces (Donlan, 2002). In an aqueous environment, hydrophobic interactions between a bacterial cell and a surface are stronger than hydrophilic ones, and are therefore regarded as determinants of microbial attachment to surfaces (Van Loosdrecht et al., 1987). Hydrophobic properties of a cell have been implicated in numerous biological processes, such as bacterial adhesion to phagocytes, host tissues, teeth, plastic, hydrocarbons, and partitioning of bacteria at the water-air interface, as well as partitioning of bacteria at water-oil interfaces (Rosenberg et al., 1980). A number of methods to measure bacterial hydrophobicity have been described in the literature: bacterial adherence to hydrocarbons (Rosenberg et al., 1980), hydrophobic interaction chromatography, salting out aggregation, contact angle measurements, partitioning of bacteria in two-phase systems, and microsphere adhesion to cells (Zita and Hermansson, 1997). 


\section{Surface characteristics}

A number of reports highlight that there is a relation between the surface roughness and bacterial attachment (Gottenbos et al., 1999; Katsikogianni and Missirlis, 2004; Scheuerman et al., 1998; Teughels et al., 2006). Some of them point to surface roughness as the main determinant of bacterial attachment (An and Friedman, 1998), while others indicate that both surface roughness and physiochemical properties (hydrophobicity, charge, and chemical composition) influence the rate and the extent of cell attachment (An and Friedman, 1998; Andreotti et al., 2018).

Bacteria colonize porous, grooved materials better than flat ones (Katsikogianni and Missirlis, 2004) because increased surface roughness means greater area and reduced shear forces (Donlan, 2002). However, some recent studies show that extent of bacterial adhesion is not always in a linear relationship with surface roughness (Andreotti et al., 2018). Wu et al. investigated the relationship between the surface topology of stainless steel with different surface roughness $\left(R_{\mathrm{q}}\right.$ in a range of $\left.217.9-56.6 \mathrm{~nm}\right)$ and bacterial adhesion of $P$. aeruginosa and $S$. aureus. They found that the number of bacterial cells on a rough surface was in general lower than the number of cells on a polished surface. This finding indicates that surface roughness is not the only factor influencing bacterial attachment (Wu et al., 2018). In fact, other factors, such as hydrophobicity, the presence of conditioning film, as well as the size of cell, and the cell surface properties of a microorganism, also play a role in bacteria attachment (Andreotti et al., 2018). Hydrophobic, non-polar surfaces, such as teflon and plastic, are generally more easily colonized by cells than hydrophilic surfaces, such as stainless steel (Donlan, 2002). A surface that 
is in direct contact with the surrounding environment will be almost immediately covered by a thin layer of conditioning agents. Conditioning agents originating from the environment may include organic or inorganic components, cell lysis components, or cellular debris (Moreira et al., 2017). Since the agent molecules are much smaller than the bacterial cells, they migrate faster in the environment, forming a conditioning film. This process is rather fast, taking from a few seconds to a few minutes (Garrido et al., 2014; Moreira et al., 2017). Formation of a conditioning film is essential to biofilm formation, as the conditioning agents can change the chemical properties of the surface. The exact role of the conditioning film is still unclear and many contradictory results have been published. For example, adhesion of $P$. fluorescens AH2 to stainless steel coated with animal extracts was significantly lower than adhesion to an uncoated surface (Bernbom et al., 2009). In contrast to that study, adhesion of Bacillus cereus to stainless steel conditioned with whole milk was higher than adhesion to an unconditioned surface (Ribeiro et al., 2017). Another very recent study evaluated the role of cell extract components used as conditioning agents on E. coli adhesion and initial biofilm formation. Crystal violet staining showed that biofilm formation depended on the concentration of the conditioning agent. Biofilm formation was generally reduced compared to a situation where no conditioning agent was used. Surface conditioning with cell extract components affected the amount and clustering of bacteria and influenced biofilm formation (Moreira et al., 2017). 


\section{The formation process}

Formation of a biofilm is a complex process that involves three steps: attachment of cells to a surface, maturation and dispersion (Figure 5). Attachment can be divided into reversible and irreversible (Bjarnsholt et al., 2013; Rabin et al., 2015). Reversible attachment is sustained via weak forces, such as van der Waals forces or hydrophobic forces, and can be easily removed by applying mechanical forces (Briandet et al., 2001). If not removed, the bacteria can irreversibly attach to the surface. Irreversible attachment is caused by bacterial cell structures such as pili and flagella, and it is more resistant to physical and chemical shear forces than reversible attachment (Rabin et al., 2015). Once the bacteria are irreversibly attached, microcolonies of one or more bacterial species are formed. Then, biofilm grows through a combination of cell divisions and recruitments, to finally form a mushroom-like structure. This structure is composed of a stalk and a cap (Bjarnsholt et al., 2013). The stalk is established by clonal growth, whereas the cap is formed by motile bacteria that can use their TFP to climb over the stalk and form the cap (in case of $P$. aeruginosa). The final step of biofilm formation is dispersal of a single cell or bacterial aggregates from the biofilm. In this step, cells attach to and colonize new surfaces (Donlan, 2002). Dispersal of a single cell from the biofilm is not well understood. It is believed that this process is genetically programmed or it is related to the work of enzymes, such as dispersin B or deoxyribonuclease, which might be responsible for biofilm degradation. In contrast to single cell dispersal, cell aggregates can be dispersed by applying shear forces or by cell death (Bjarnsholt et al., 2013). The final biofilm structure depends on availability of nutrients and environmental factors 
(Mortensen, 2014). The organization of cells in a biofilm is unique according to their metabolism. Anaerobic bacteria reside in deeper layers of the biofilm, in contrast to aerobic bacteria that prefer to be close to the surface, which is an oxygen-rich environment. 


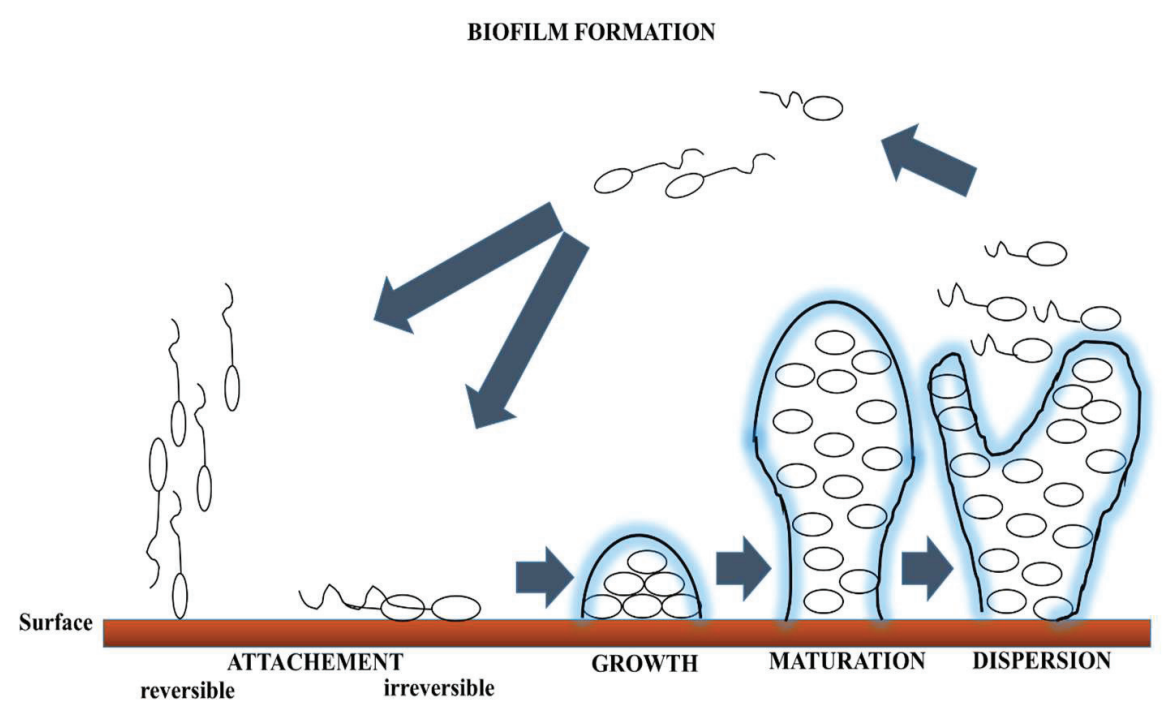

Figure 5. Schematic representation of biofilm formation.

Biofilm formation is a highly complex, multi-step and dynamic process. Formation of a biofilm involves the following steps: attachment, growth, maturation and dispersion. The formation of a biofilm begins when bacterial cells attach irreversibly to a surface. Then, the bacteria form microcolonies. Cell-divisions and further cells recruitment lead to biofilm maturation and formation of a mushroom-like structure. Finally, nutrient and oxygen depletion results in bacterial dispersion. The figure was made based on (Vasudevan, 2014). 


\section{Y. ruckeri biofilms}

Y. ruckeri can form biofilms in an aquatic environment, however knowledge in this regard is rather scarce. Formation of biofilm by $Y$. ruckeri was investigated by Coquet et al. (Coquet et al., 2005, 2002a, 2002b). Y. ruckeri adheres to solid supports such as PVC, fiberglass, concrete and wood, and materials commonly found in fish farms. Surface roughness plays an important role in Y. ruckeri adherence to surfaces. Moreover, with longer incubation times, biofilm formation is more pronounced (Coquet et al., 2002b). Finally, it is suggested that biofilm formation by Y. ruckeri is the source of recurrent infection in rainbow trout (Coquet et al., 2002a).

The efficiency of biofilm formation varies from strain to strain and seems to be correlated with the presence of flagella-mediated motility. Environmental Y. ruckeri isolates exhibit a higher ability to adhere to surfaces than the reference strain, and thus they are more likely to form a biofilm. Surfaceassociated Y. ruckeri cells are more resistant to antibiotics than the planktonic cells (Coquet et al., 2002b). This can be explained by differences between the outer membrane pattern of surface-associated Y. ruckeri strains and planktonic cells (Coquet et al., 2005, 2002a)

\section{Type V secretion systems (T5SSs)}

The cell wall of Gram-negative bacteria consists of two membranes: the inner, also known as periplasmic or cytoplasmic, and the outer membrane. The space between these membranes is called the periplasm. Secretion of proteins can occur via different secretion systems (Leo et al., 2012; Vasudevan, 2014) 
The T5SS is a two-step secretion system that is exemplified by a IgA protease from Neisseria gonorrhea (Mulks and Plaut, 1987). The protein is translocated through the inner membrane in an unfolded state by the Sec system. Once in the periplasm, the chaperones SurA, Skp, DegP prevent protein misfolding and aggregation. Finally, the protein is inserted in the outer membrane with the help of the BAM ( $\beta$-barrel assembly machinery) complex. In T5SSs, the translocated protein is called an autotransporter as no external energy is required for its transport. In fact, all information required for its transport is encoded in a single polypeptide chain (or two chains, in the case of T5bSS). Common features of different classes of autotransporters are the presence of the translocator domain ( $\beta$-barrel domain) and the Sec-dependent protein transport. The translocator domain is necessary for protein secretion and serves as a secretion pore (Leo et al., 2012).

T5SSs are divided into five subtypes, 5a-5e, depending on the organization of the translocator domain and on the protein transport mechanism (Leo et al., 2012). The T5aSS refers to classical autotransporters that are expressed as a single polypeptide chain. The T5bSS are a two-partner secretion systems where the translocator domain and the passenger (the extracellular domain) are encoded by separate polypeptide chains. The translocator domain of the T5bSS contains two periplasmic regions named polypeptide transport associated (POTRA) domains. The T5cSS refers to trimeric autotransporters, where the passenger and the translocator domains are made up of three polypeptide chains. The T5dSS is similar to T5aSS, with the exception that a translocator domain is connected to the passenger via a POTRA domain. T5eSSs are 
inverse autotransporters, as the domain organization is reversed compared to classical autotransporters. The T5eSS will be discussed in more detail as this type constitutes the main focus of the thesis (Figure 6).

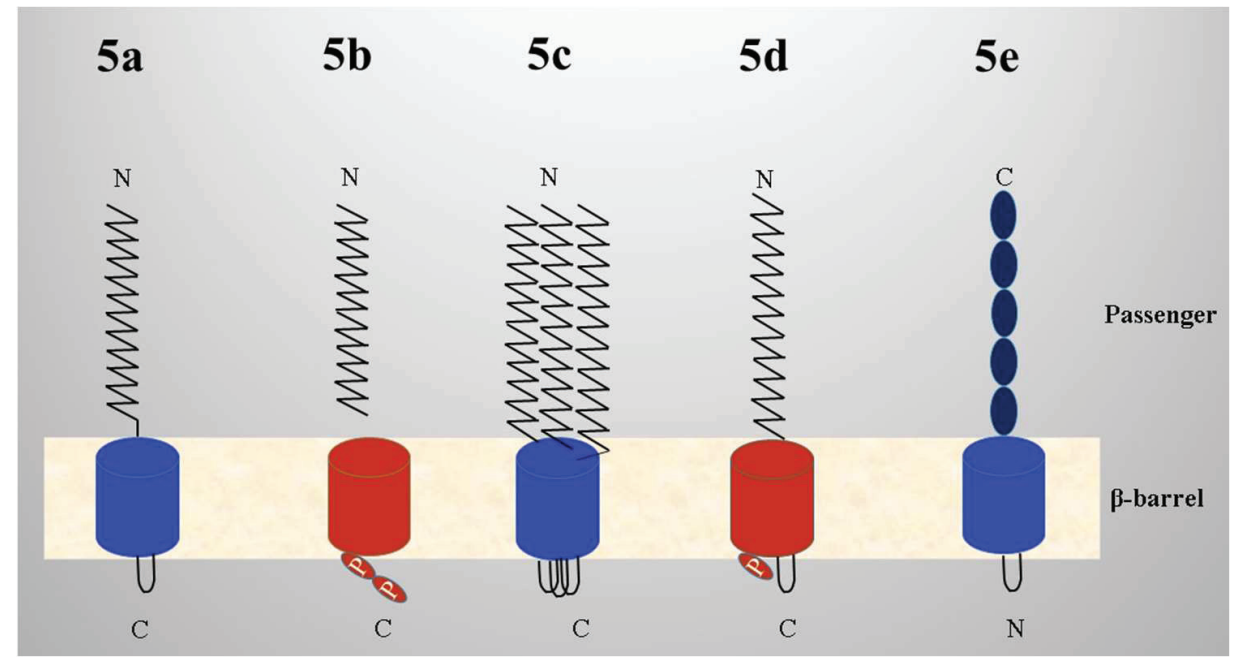

Figure 6. Different T5SS. All T5SS are composed of a translocation domain- $\beta$-barrel (displayed in blue for $5 \mathrm{a}, 5 \mathrm{c}$, and $5 \mathrm{e}$; in dark red for $5 \mathrm{~b}$ and $5 \mathrm{~d}$ ) and a passenger (displayed in black for 5a, 5b, 5c, 5d, in dark blue for 5e). POTRA domains are marked as P. The figure was made based on Leo et al., 2012).

\section{Type Ve secretion systems (IATs)}

The inverse autotransporters (IATs) are virulence-associated adhesins secreted by various pathogens (Leo et al., 2015b). IATs are a large family with a dispersed taxonomic distribution. IATs are present in $\alpha-\gamma-, \beta$ - and $\varepsilon$ Proteobacteria, Chlamydia, Planctomycetes as well as in Cyanobacteria (Heinz et al., 2016; Leo et al., 2015b). They include four sub-families: intimin, invasin, FdeC- type adhesins and two-partner inverse autotranporters (Heinz et al., 2016). Invasin and intimin are the best studied examples of the IATs. 
Both intimin and invasin have similar domain organization and have a similar function. They are composed of an N-terminal signal peptide, a translocation domain and a $\mathrm{C}$-terminal passenger. Both proteins play a role in bacterial adherence to host cells (Leo et al., 2015b).The autotransport mechanism of IATs onto the cell surface is poorly understood. However, it is generally accepted that the translocation domain inserts the protein in the outer membrane and then aids the export of the passenger from $\mathrm{N}$ - to $\mathrm{C}$-terminal direction (Oberhettinger et al., 2012).

\section{Structure of IATs}

\section{The signal peptide}

The N-terminal signal peptide targets proteins for translocation across the inner membrane. This is done via the Sec machinery (Leo et al., 2015b). The components of the Sec machinery are located both in the cytoplasm (SecA) and in the inner membrane (SecYEG). They have been shown to interact with the newly synthetized protein to aid its transport across the inner membrane (Ulsen et al., 2014).

The sequences of signal peptide in IATs are often unusually long, ranging from 18 to 65 amino acid residues in length. The structure of the N-terminal signal peptide shows a tripartite organization: it consists of a charged $\mathrm{N}$ domain, a hydrophobic $\mathrm{H}$-domain and a $\mathrm{C}$-cleavage recognition site domain (Ulsen et al., 2014). Little or no sequence conservation was found in the signal peptides within the IATs family (Tsai et al., 2010). These long signal peptides might play a role in the biogenesis of IATs by keeping proteins in the inner 
membrane, and thus preventing protein misfolding in the periplasm (Szabady et al., 2005) (Figure 7).

\section{The periplasmic region}

The periplasmic region of IATs, also referred to as the $\alpha$-domain, is immediately $\mathrm{N}$-terminal to the translocation domain (Tsai et al., 2010) (Figure 7). It can be short ( $<50$ residues) or long (approx. 160 residues) (Tsai et al., 2010). Both variants contain two conserved $\alpha$-helices. In addition, the long periplasmic region contains a lysin motif (LysM) domain and a spacer sequence, which is located between the LysM and the two $\alpha$-helical stretches (Leo et al., 2015a; Tsai et al., 2010). LysM is a small peptidoglycan binding domain, which is present among enzymes involved in peptidoglycan degradation and in the IATs from $\gamma$-Proteobacteria (Tsai et al., 2010) (Figure 8). LysM has a typical $\beta-\alpha-\alpha-\beta$ fold (Tsai et al., 2010). The presence of LysM can be predicted to some extent depending on the length of the protein sequence (Leo et al., 2015a). The longer the IATs, the higher the probability that LysM is present. Furthermore, a LysM is present in intimin (EaeA), but absent in invasin (InvA). Some LysMs binds to peptidoglycan and chitin by $\mathrm{N}$-acetyloglucosamine moieties. Binding to peptidoglycan could play a role in protein transport by ensuring proper positioning of the protein in the outer membrane (Leo et al., 2015a).

The periplasmic region plays an essential role in protein multimerization, but only a subset of IATs multimerise. There exist two multimerization sites in the periplasmic region of intimin, the spacer sequence and the C-terminal $\alpha$ helix (Touzé et al., 2004). YrInv from Y. ruckeri and ZirT from S. enterica are two well-studied IATs, in which the periplasmic region (for YrInv) or the 
periplasmic region with the translocation domain (for ZirT) were shown to form multimers (Leo et al., 2015a; Prehna et al., 2012).

A)

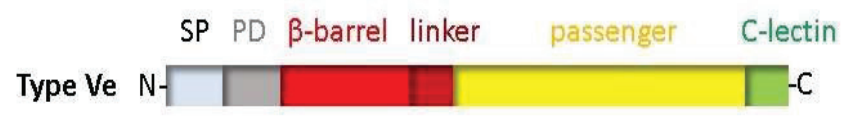

B)

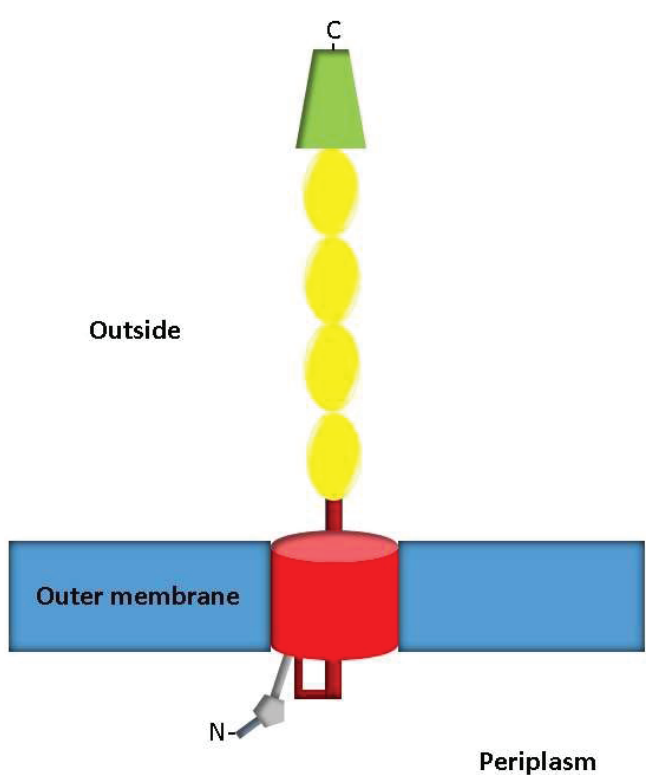

Figure 7. Schematic representation of IATs: A) general view, B) in the bacterial cell membrane. SP- signal peptide, PD- periplasmic region, $\beta$-barrel - translocation domain. The passenger of the IATs consists of the tandemly repeated immunoglobulin-like domains, usually capped with the C-type lectin domain. The periplasmic region may contain a lysin motif, represented by the grey pentagon in the picture. The figure is not to scale. The figure was made based on (Leo et al., 2015b). 


\section{The translocation unit}

There is structural information available for the translocation units of two IATs, namely invasin (InvA) and intimin (EaeA) (Fairman et al., 2012). The translocation unit, also referred to as the $\beta$-domain, is composed of an $\mathrm{N}$ terminal $\beta$-barrel and an C-terminal linker sequence (Oberhettinger et al., 2012) (Figure 7). The translocation unit is the most conserved part of IATs (Fairman et al., 2012). It is composed of 12 antiparallel amphipathic $\beta$-strands (Fairman et al., 2012) (Figure 8). The hydrophilic residues are facing the inside environment, while the hydrophobic residues form the outside of the $\beta$-barrel channel (Fairman et al., 2012). The assembly of the translocation unit in the outer membrane is mediated with the help of the BAM complex (Oberhettinger et al., 2012).

The function of the translocation unit is to anchor the protein in the outer membrane and to serve as a pore for the passenger transport. The linker sequence in the translocation unit plays a role in stabilization of the $\beta$-barrel pore (Fairman et al., 2012).

\section{The passenger (the extracellular domain)}

The IAT passenger is a long and fibrous structure located at the cell surface (Fan et al., 2016) (Figure 7). The passenger consists of tandemly repeated Iglike domains (Immunoglobulin-like domains), referred to as either "Big domains" or "fibronectin domains" (FnIII). There are 11 types of Ig-like domains (referred as D0, D4-D10, D12-D14) in IATs, with low amino acid sequence homology between them (Tsai et al., 2010). The number of Ig-like domains of the passenger differs significantly among IATs and it ranges 
between $0-47$ (Heinz et al., 2016; Tsai et al., 2010). The passenger is usually capped by a C-type lectin domain, which adopts a CLTD fold. The C-type lectin domain is stabilized by disulphide-bonded residues and it functions as an adhesion domain (Hamburger et al., 1999) (Figure 7 and Figure 8).

The passenger plays multiple roles. It provides a scaffold for the adhesion domain and facilitates immune evasion of bacterial pathogens (Tsai et al., 2010).

\section{Examples of IATs}

\section{Intimin}

Intimin was first described by Jerse et al. (Jerse et al., 1990). This 94-kDa outer membrane protein is present in enteropathogenic (EPEC) and enterohemorrhagic (EHEC) E. coli, Citrobacter rodentium and Hafnia alvei. Intimin, originally designated as EaeA (E.coli attaching/effacing protein), is encoded by the eaeA gene which is located within the locus of enterocyte effacement (LEE). LEE is a pathogenicity island encoding a T3SS and various proteins including intimin. A considerable number of allelic variations of intimin have been described based on their structural, immunological and functional properties, including $\alpha, \beta, \gamma$ and $\varepsilon$ (Leo et al., 2015b). Intimin plays a role in bacterial attachment to host cells. The attachment is mediated by the interaction of intimin with the Tir (translocated intimin receptor) receptor. Interestingly, the Tir receptor is not a host protein, but it is a bacterial protein, secreted via the T3SS directly into a host cell membrane. Upon binding with intimin, the host cytoskeleton undergoes rearrangements which results in pedestal formation around the bacterium. It has been postulated that intimin, 
apart from binding to the Tir receptor, can bind to $\beta_{1}$-chain integrins and nucleolin (Frankel et al., 1996; Sinclair and O’Brien, 2002)

\section{Invasin (InvA)}

\section{Structure}

Invasin, also known as InvA, was first characterized by Isberg and coworkers (Isberg and Leong, 1990). This outer membrane protein is present in the human pathogenic Yersinaie. Invasin is encoded by the invA gene that is located on the chromosome. InvA is structurally and functionally related to the intimins from the EPEC (enteropathogenic) and EHEC (enterohemorrhagic) of $E$. coli (Isberg et al., 1987). In Y. enterocolitica, InvA is a 92-kDa protein consisting of 835 residues whereas its homolog in $Y$. pseudotuberculosis is a 103-kDa protein consisting of 986 residues (Palumbo and Wang, 2006). There is $69 \%$ homology between these proteins over the whole protein sequence (Grassl et al., 2003). InvA shares a similar domain architecture as other IATs with the exception that it lacks LysM and spacer sequence found in intimin (Mikula et al., 2012). The crystal structure of the C-terminal passenger (497 amino acids) of InvA from $Y$. pseudotuberculosis shows an $18 \mathrm{~nm}$ rod-like shape and is composed of five domains called D1-D5. Domains D1 to D4 are immunoglobulin-like domains whereas D5 is a C-type lectin-like domain. Domains D1 to D4 consist of $\beta$ sheets, while domain D5 consists of $\beta$ and $\alpha$ helices (Figure 8). The domains D4 and D5 are required for receptor (integrin) binding. The presence of two aspartate residues and a disulphide bond between two cysteines is essential for the integrin binding (Hamburger et al., 1999). Invasin of $Y$. enterocolitica and $Y$. pseudotuberculosis are highly similar in 
domain architecture with the exception of a D2 domain which is only present in $Y$. pseudotuberculosis. Domain D2 plays a role in protein multimerization (Grassl et al., 2003). The presence of the D2 domain was shown to result in more efficient bacterial uptake by the host cells (Dersch and Isberg, 2000).

\section{Function}

Invasin is expressed by two enteropathogenic Yersiniae species, $Y$. pseudotuberculosis and $Y$. enterocolitica. These gastrointestinal pathogens cause a wide range of gastrointestinal diseases from enteritis, lymphadenitis, enterocolitis to more severe conditions such as reactive arthritis, erythema nodosum, uveitis and septicaemia (Grassl et al., 2003). In Y. pestis, InvA production is abolished by a mutation in the invA gene on the IS200 insertion element (Simonet et al., 1996).

Invasin is active in the initial stages of the bacterial infection. It is required to establish a successful colonization and internalization of bacterial cells. Infection starts in the following manner. After the ingestion of contaminated food (lettuce, carrots, undercooked pork), the bacterium traverses the gastrointestinal tract to reach the small intestine. In the small intestine, invasin binds to the $\beta_{1}$-integrin receptors $\left(\alpha_{3} \beta_{1}, \alpha_{4} \beta_{1}, \alpha_{5} \beta_{1}, \alpha_{6} \beta_{1}\right.$ and $\alpha_{v} \beta_{1}$ ) of the microfold cells (M-cells) located over lymphoid patches called Peyer's patches (Isberg and Leong, 1990). Invasin binds to $\beta_{1}$ integrin receptors with 100-fold higher affinity than the integrin's natural ligand, fibronectin (van Nhieu and Isberg, 1991). High concentrations of invasin and $\beta_{1}$ integrins are crucial for bacterial internalization. If the concentration is too low, adhesion will occur instead of internalization (Dersch and Isberg, 1999; Isberg et al., 2000). Integrins are present on the surface of many mammalian 
cells such as B-cells, T-cells, M-cells, and play a role in cell adhesion to extracellular matrix components (fibronectin, laminin, collagen) and cell surface interactions (Palumbo and Wang, 2006). Upon bacterial binding with the host receptor, the bacterium is surrounded by the host's membrane using the zipper mechanism. Then, invasin triggers the signaling cascade which causes rearrangement of the host cytoskeleton and induces the production of various proinflammatory cytokines, including interleukin, tumor necrosis factor- $\alpha$ and others. Next, the vacuole-residing bacteria travel to the basolateral side of M-cells, from where they disseminate to the lymphoid system. The lymphoid system can already be used as a starting point for the infection, but the bacteria can travel further through B-cells, T-cells or macrophages to other lymphatic organs such as the liver, the spleen and the lungs, where they form microabscesses or granulomatous inflammatory lesions (Chauhan et al., 2016).

\section{Regulation}

The expression of invasin is regulated by the following factors: temperature, $\mathrm{pH}$, osmolarity, growth phase, availability of nutrients and activity of the transcriptional regulator (RovA). Invasin is maximally expressed at either $25^{\circ} \mathrm{C}$, pH 8 or $37^{\circ} \mathrm{C}$, pH 5.5 in bacteria in stationary phase. These conditions indicate that invasin is already highly expressed before the host ingests the contaminated food. Small amounts of invasin are also detectable at $37^{\circ} \mathrm{C}$, pH 8 (Chauhan et al., 2016).

RovA is degraded at $37^{\circ} \mathrm{C}$ which results in a lower invasin production (Heroven et al., 2007). Specifically, InvA expression is reduced in $Y$. enterocolitica serotype O:8 and O:9 (Heroven et al., 2004; Trček et al., 2010) This contrasts, however, with the InvA production in Y. enterocolitica serotype 
O:3, where large amounts of InvA are detectable at $37^{\circ} \mathrm{C}$ (Uliczka et al., 2011). This can be explained by the fact that in this serotype, RovA harbors a single amino acid substitution (proline to serine) that increases its thermostability, resulting in efficient invasin production.

RovA expression is repressed by the nucleoid-associated protein H-NS and the LysR-type regulator, RovM. Disruption of the H-NS/RovM complex leads to accumulation of RovA, which then activates the synthesis of invasin (Heroven et al., 2007).

\section{InvA-like IATs in Yersiniae}

Several InvA-like IATs are present in both environment-related and human-related strains of the Yersiniae family. Y. pseudotubeculosis encodes four IATs beside InvA: InvB (also known as Ifp), InvC, InvD and InvE (Chauhan et al., 2016; Pisano et al., 2012; Sadana et al., 2018, 2017). These proteins have a similar domain architecture to InvA. The $\mathrm{C}$-terminal passengers of InvA, InvB and InvC have a high sequence similarity (33-42\%), contrary to InvD (only 17\%) (Sadana et al., 2018). The crystal structures of the C-terminal passengers of InvD and InvE have been recently resolved (Figure 8) (Sadana et al., 2018, 2017). The adhesion domain of InvD adopts a novel Ig-like related fold with diverse modifications and insertions. The adhesion domain of InvD binds specifically to the Fab fragment of the $\operatorname{IgG} / \operatorname{Ig} A$ antibodies, commonly found during the bacterial infection (Sadana et al., 2018). The adhesion domain of InvE adopts the common C-type lectin-like domain, but it lacks motifs required for carbohydrate binding or $\beta_{1}$ integrin binding that are usually present in other IATs (Sadana et al., 2017). 


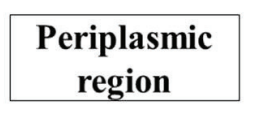

2MPW

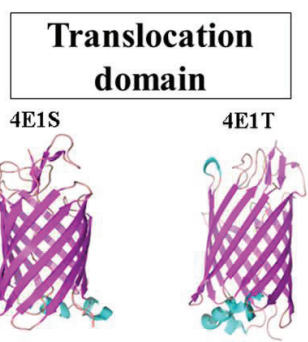

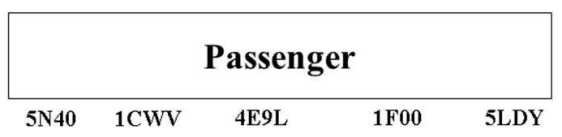
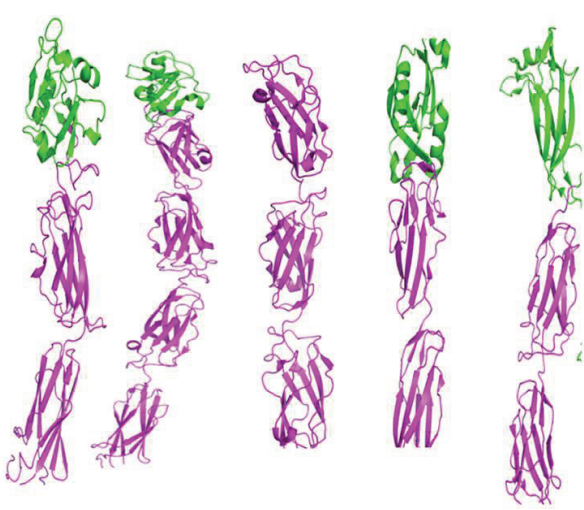

Figure 8. Structures of inverse autotranporters.

Structures of IAT fragments are labeled with their protein database identification numbers: 2MPW (LysM of periplasmic region of intimin from E. coli), 4E1S (the translocation domain of intimin from E.coli), 4E1T (the translocation domain of invasin from $Y$. pseudotuberculosis), 1CWV (the passenger of invasin from Y. pseudotuberculosis, InvA), $5 \mathrm{~N} 40$ (fragments of the passenger of InvE from Y. pseudotuberculosis), 4E9L (fragments of the $E$. coli passenger of the $\mathrm{FdeC}$ ), 1F00 (fragments of the E. coli passenger of intimin) and 5LDY (fragments of the passenger of InvD from Y. pseudotuberculosis). LysM represents the typical $\beta-\alpha-\alpha-\beta$ fold with an extra $\alpha$-helix highlighted in yellow. The passenger of the IATs forms the array of Ig-like domains (depicted in violet) capped with a C-type lectin domain (depicted in green) (with the exception of FdeC which lacks the Ctype lectin domain). The figures are not to scale.

InvA-like IATs play a role in bacterial adhesion and colonization of host cells. InvB was shown to mediate colonization of the lymphatic tissues of the host while InvC was reported to promote bacterial adhesion to intestinal cells. The function of InvD and InvE is still not known (Sadana et al., 2018, 2017). 
Y. pestis contains two IATs: Ilp (intimin/InvA-like protein) and Ifp (intimin family protein). Ilp is an orthologue of InvC while Ifp is an orthologue of InvB. Ifp is non-active in Y. pestis due to an insertion element in the gene (Chauhan et al., 2016; Seo et al., 2012).

Environment-related strains of the Yersiniae family such as $Y$. frederiksenii, Y. intermedia, Y. kristensenii and Y. ruckeri encode IATs in their genome (Tsai et al., 2010). Their roles, however, have not been investigated before. Y. ruckeri encodes two IATs, yrInv (for Y. ruckeri Invasin) and yrIlm (for Y. ruckeri Invasnin-like molecule). The first study on yrInv was described by Leo et al., who showed that the LysM-containing periplasmic region of yrInv mediates multimerization and binds to peptidoglycan (Leo et al., 2015a). 


\section{AIMS OF THE THESIS}

The overall aim of the thesis was to increase the knowledge about the molecular pathogenesis of $Y$. ruckeri. The knowledge on $Y$. ruckeri virulence is very limited, however it is an established fact that the bacterium shares many virulence determinants with other members of the Enterobacteriaceae family, especially with the three well-recognized human pathogens. For this reason, a comparative approach has been a central way to study the virulence factors of $Y$. ruckeri. The virulence of the well-studied human pathogens, $Y$. enterocolitica, $Y$. pseudotuberculosis and $Y$. pestis is dependent on a wide range of adhesins molecules and many of them may play diverse roles in different host organisms, such as in fish. Moreover, the adhesin molecules that are exposed on the cell surface might be expressed at different stages and conditions. Therefore, to increase the understanding of the function and structure of $Y$. ruckeri adhesin molecules, specifically invasins, members of the inverse autotranporters family, the following research questions were addressed:

1) How prevalent are the IATs in the genome of $Y$. ruckeri strains? Do they have the same domain architecture as the IATs found in Yersiniae? (Paper I)

2) What is the genomic context of both IATs in the genome of Y. ruckeri? (Paper I)

3) Is the expression of IATs regulated by environmental conditions such as temperature, nutrients, osmolarity and salt? (Paper I) 
4) What is the role of IATs? Are they involved in $Y$. ruckeri pathogenesis? Do the IATs play a role in $Y$. ruckeri adhesion and internalization of gut tissues in fish? (Paper II)

5) How does $Y$. ruckeri form a biofilm? Are IATs involved in its formation? What is the biofilm structure and organization? What factors play a role in Y. ruckeri attachment? (Paper II)

6) Does Y. ruckeri carry plasmids related to virulence? If yes, how similar or different are they from the plasmids found in other Yersiniae? What factors are encoded on the plasmids? (Paper III) 


\section{SUMMARY OF PAPERS}

\section{Paper-I}

We addresses the problem of analyzing highly repetitive proteins in the laboratory. Application of the PacBio sequencing technology demonstrates its potential in sequencing highly repetitive proteins. PacBio sequencing, a third generation sequencing technology, offers many improvements compared to the SGS technology (such as Illumina). One of the main advantages is its read length. The short read length of SGS technology leads to problems related to analysis of repetitive sequences. Because of much longer read lengths of PacBio sequencing, the repetitive regions can be easily resolved. With the help of PacBio sequencing, we identified and characterized two putative inverse autotransporter genes in the fish pathogen Yersinia ruckeri NVH_3758: yrInv (Y. ruckeri invasin) and yrIlm (Y. ruckeri invasin-like molecule). Using the sequenced genome data, we performed a PCR analysis on five $Y$. ruckeri strains that had not been sequenced before and found that both genes are variably present in the strains. We found that yrInv and yrIlm represent the same Immunoglobulin-like domains in all strains, but the internal repeats of the $y r I n v$ gene product are highly diverged in contrast to yrIlm. Furthermore, our qRT-PCR analysis revealed differences in the expression of yrIlm and $y r I n v$ under conditions relevant for pathogenesis. Finally, when comparing the genomic context of both genes in the newly sequenced reference strain to all available $Y$. ruckeri genomes, we found indications of recent occurrence of horizontal gene transfer. 


\section{Paper-II}

In this paper, we illustrate the role of Y.ruckeri NVH_3758 IATs in biofilm formation, contributing to better understanding of how $Y$. ruckeri survives in the aquatic environment. The results clearly show that IATs are involved in biofilm formation, as deletion of both IATs significantly reduces the biofilm formation compared to the WT strain. Additionally, we show the structure and organization of a biofilm formed by Y. ruckeri using confocal microscopy. We demonstrate the mechanisms by which the pathogen forms a biofilm. We also show the involvement of eDNA, RNA and proteins in biofilm formation.

\section{Paper-III}

The results presented in the paper show the analysis of the nucleotide sequence of the 81-kbp pYR4 plasmid isolated from a highly contagious $Y$. ruckeri strain, NVH_3758. Sequencing of the pYR4 plasmid was performed with the single molecule real-time sequencing. The application of the third generation sequencing in the study allowed us to identify misassembled scaffolds in the previously deposited second generation genomic assemblies. Additionally, the results demonstrate that virulence determinants are often encoded on plasmids and it shows for the first time that the presence of virulence-related plasmids might be a general feature of some of $Y$. ruckeri strains. The results show that pYR4 belongs to the IncFII family, like the welldescribed pYV from the human pathogenic Yersiniae. Analysis of the pYR4 sequence indicates the presence of the TFP and the T4SS and suggest its possible role in virulence. 


\section{DISCUSSION}

\section{ERM is an existing problem in aquaculture}

Y. ruckeri is a Gram-negative bacterium and the causative agent of ERM, a systemic infection commonly occurring in Atlantic salmon and rainbow trout (Kumar et al., 2015). ERM is a global problem which up to date has not been solved. ERM is currently affecting fish populations of many countries, including Europe (mainly Ireland, Scotland and Norway), North and South America, South Africa, Australia and New Zealand (Kumar et al., 2015). ERM is typically detectable in the freshwater life stage of fish. Recently, however, outbreaks in the seawater stage were reported, which makes it clear that $Y$. ruckeri is able to adapt to different environments (Hjeltnes et al., 2017). Furthermore, untreated ERM can lead to fish losses in the range of $25 \%$ to $75 \%$ (Busch, 1978). Due to the aforementioned challenges and the importance of Atlantic salmon and rainbow trout in aquaculture, studying the pathogenicity of $Y$. ruckeri is of high relevance.

\section{Certain IATs are non-fimbrial adhesins}

Bacterial adhesins are surface appendages required for bacterial attachment to either host tissues or abiotic surfaces (Berne et al., 2015). Bacterial adhesins can be classified into several different groups (Berne et al., 2015). The long, fimbrial adhesins are ubiquitous in both Gram-positive and Gram-negative bacteria. They are often made of numerous identical subunits (Berne et al., 2015). They have diverse functions: they are involved in bacterial attachment, biofilm formation, motility, as well as DNA transfer (Piepenbrink 
and Sundberg, 2018). In contrast to fimbrial adhesins, non-fimbrial adhesins are outer-membrane proteins usually shorter than pili that are made of one (monomeric) or three (trimeric) polypeptide chains. Non-fimbrial adhesins are further divided into a group secreted via T1SSs and a group secreted via T5SSs (Berne et al., 2015). One particular class of the T5SS is the intimin/invasin family of proteins called the T5eSSs, or the inverse autotransporters (IATs) (Leo et al., 2015b). Some examples of IATs are the well-studied intimin (EaeA) and invasin (InvA) of the enterohemorrhagic and enteropathogenic $E$. coli and Yersiniae (Leo et al., 2015b). Y. ruckeri IATs were chosen as a starting point for the study presented in the thesis.

\section{PacBio is a powerful technology for sequencing highly repetitive regions}

\section{in bacterial genomes}

PacBio sequencing is a third generation sequencing technology that utilizes a SMRT technology without the need for DNA amplification (Rhoads and Au, 2015). One advantage of PacBio over second generation technologies (SGS) is that PacBio offers longer read lengths (in the range of $20 \mathrm{~kb}-60 \mathrm{~kb}$, as opposed to $100-600 \mathrm{bp}$ in SGS) (Rhoads and Au, 2015). PacBio was successfully used to sequence the genomes of microbial pathogens where interspaced and tandem repeats are common, such as $S$. enterica, S. aureus, $P$. aeruginosa and Clostridium sporogenes (Nakano et al., 2017). Therefore, it was appropriate to use PacBio in this thesis to sequence the genome of $Y$. ruckeri NVH_3758 (referred later as NVH_3758) which also contains highly repetitive regions. Sequencing of the NVH_3758 genome using PacBio yielded two contigs, one representing the $\sim 3.7 \mathrm{Mb}$ chromosomal genome and the other the $\sim 81 \mathrm{~kb}$ pYR4 plasmid (Wrobel et al., 2017). Two IATs of the 
NVH_3758 were identified and characterized: yrInv and yrIlm (Wrobel et al., 2017). The PacBio assembly of NVH_3758 enabled us to identify the accurate number of Ig-like domains in the passenger of yrIlm. We identified 20 Ig-like domains, of which 19 were almost identical in nucleotide sequence. Following this, the number of Ig-like domains was confirmed with a PCR reaction. In the PacBio assembly of CSF00782 sequenced by (Nelson et al., 2015), we identified two copies of $y r I l m$ with a different number of Ig-like domains. Interestingly, the SGS assembly of CSF00782 showed only one incomplete copy of yrIlm with 3 Ig-like domains, demonstrating again the power of PacBio in sequencing of repetitive regions (Wrobel et al., 2017).

$\underline{Y}$. ruckeri IATs share a common domain architecture with other wellknown IATs

Both IATs (YrIlm and YrInv) of Y. ruckeri that were identified in this thesis are composed of a long N-terminal signal peptide (39-45 residues), a periplasmic region, followed by a transmembrane region and a large extracellular region (Wrobel et al., 2017). YrIlm have 53\% amino acid sequence similarity with InvA of the human pathogens $Y$. pseudotuberculosis whereas YrInv have only 40\% similarity. The domain architecture of both IATs shows common features with other IATs. First, the periplasmic region contains a LysM, a motif that is also found in intimin (EaeA) (Leo et al., 2015a). Second, the transmembrane region that anchors proteins in the outer membrane is similar to the one found in enteropathogenic Yersiniae (Hamburger et al., 1999). Secondary structure prediction shows that the transmembrane region consists of a 12-stranded $\beta$-barrel, similarly as in InvA, InvB (Ifp), InvC, InvD, InvE and EaeA (Hamburger et al., 1999; Sadana et al., 
2018, 2017; Strong et al., 2011). Third, the extracellular region of yrIlm and $y r I n v$, known as the passenger, consists of repetitive Ig-like domains capped with a C-type lectin domain. The extracellular region is the most variable region in the IATs of $Y$. ruckeri. The number of Ig-like domains in yrIlm in different $Y$. ruckeri strains varies from 17 to 22 (Wrobel et al., 2017). This finding is in agreement with other studies where the number of Ig-like domains in the passenger can vary between strains and species. InvA, InvB, InvC, InvD and InvE from $Y$. pseudotuberculosis are composed of 4 domains (D1-D4), 5 domains, 47 domains, 13 domains and 21 domains, respectively, while InvA from $Y$. enterocolitica is composed of 3 Ig-like domains (D1, D3, D4) (Figure 9) (Hamburger et al., 1999; Sadana et al., 2018, 2017; Strong et al., 2011). Variations in gene length due to a varying number of repetitive sequences were previously shown in trimeric autotransporters. PCR amplification of badA in various Bartonella henselae strains showed that the gene length differs in size from about 9 to $12 \mathrm{~kb}$ (Riess et al., 2007). The size of the head domain and the anchor domain remains equal among different $B$. henselae strains while the number of stalk repeats varies between strains (Riess et al., 2007). Similarly, the number of stalk repeats in VompA and VompD of Bartonella quintana, an important human pathogen, varied from 6 to 7 (Schulte et al., 2006). The observed differences in the number of repetitive sequences may be caused by recombination events that result in expansion or reduction of the sequences. Whether the number of repetitive sequences have any effect on the function of the proteins is unclear and has to be investigated further. 


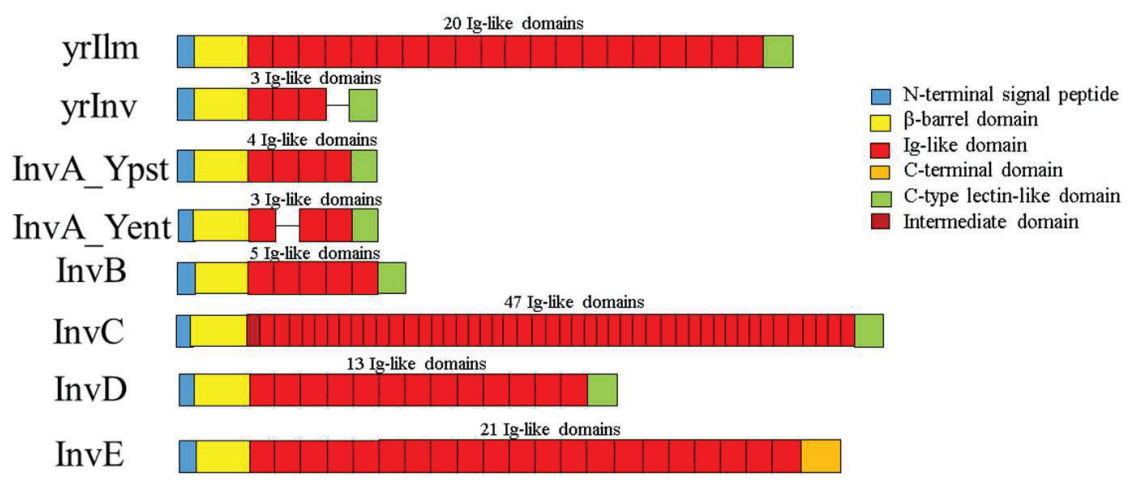

Figure 9. Domain organization of the invasin proteins from Y. ruckeri (yrIlm and yrInv), Y. pseudotuberculosis (InvA_Ypst - InvE) and Y. enterocolitica (InvA_Yent) strains. The figure is not to scale. The figure was modified from (Sadana et al., 2017). Please note the differences in the number of Ig-like domains in the passenger (depicted in red). The Cterminal domain, also referred as adhesion domain, is depicted in green and orange (the orange color indicates low sequence similarity of the C-terminal domain of InvE to the Cterminal domain of the other invasins).

\section{The expression of $Y$. ruckeri IATs is regulated by temperature and}

\section{osmolarity}

The expression of IATs was shown to be regulated by environmental factors including temperature, $\mathrm{pH}$, the presence of iron, osmolarity, growth phase, availability of nutrients. In Y. ruckeri, high expression of IATs was reported at $37^{\circ} \mathrm{C}$ (Wrobel et al., 2017). This is in agreement with some other studies (Chauhan et al., 2016): invasin (InvA) of the enteropathogenic Yersiniae is upregulated at $25^{\circ} \mathrm{C}, \mathrm{pH} 8$ or $37^{\circ} \mathrm{C}, \mathrm{pH} 5.5$ or $\mathrm{pH}$. Similarly, InvD from Y. pseudotuberculosis is highly expressed at $37^{\circ} \mathrm{C}$, but not at $25^{\circ} \mathrm{C}$ (Sadana et al., 2018). YadA, a prototypical trimeric autotranporter and an 
important virulence factor of the human pathogenic Yersiniae, is highly expressed at $37^{\circ} \mathrm{C}$. The same is true about the small $\beta$-barrel protein Ail (attachment and invasion locus) that is found in Yersiniae, and homologues of Ail found in Salmonella and E. coli strains (Chauhan et al., 2016).

The high expression of $Y$. ruckeri IATs at $37^{\circ} \mathrm{C}$ does not correlate with the temperature at which most Y. ruckeri outbreaks occur (Wrobel et al., 2017). Many Y. ruckeri genes related to virulence were reported to be upregulated at $18^{\circ} \mathrm{C}$, similarly as in other fish pathogens (Mendez et al., 2018). These include, among others, genes involved in iron acquisition system, genes involved in the synthesis of LPS, the yrpl metalloprotease and the glycosyltransferase. The high expression of the $Y$. ruckeri IATs at $37^{\circ} \mathrm{C}$ suggests that these IATs might not play any role in pathogenesis in fish. However it is worth mentioning that their expression was only assessed in vitro. Further research is required to analyze the expression level in vivo in fish organs. One approach would be to use bioluminescence by application of the lux operon. The native promoter from the lux operon can be replaced by the yrIlm or yrInv promoter. The fusion of the lux operon with one of the promoters will make it possible to construct an expression vector. Further, this expression vector can be transformed into $Y$. ruckeri and used as a reporter to analyze the gene expression level in vivo via imaging.

Osmolarity is an important factor that can influence the expression of virulence genes. We determined the effect of osmolarity on the expression of both Y. ruckeri IATs (Wrobel et al., 2017).We found a higher expression level of yrIm at $0 \mathrm{mM} \mathrm{NaCl}$ compared to $170 \mathrm{mM} \mathrm{NaCl}$. This result is not surprising: Y. ruckeri is able to survive in water with low salt content $(0-20 \mathrm{ppt})$ for an extended period of time (more than 4 months) (Thorsen et al., 1992). 
Survival in the environment might eventually result in biofilm formation. Biofilm acts as an environmental reservoir that can cause multiple outbreaks, leading to huge stock fish losses.

\section{$\underline{\text { Y. ruckeri IATs are involved in biofilm formation }}$}

The fact that $Y$. ruckeri can survive in an aquatic environment has been known for a long time, however how this happens is still not well understood. Shedding of the bacterium in the feces of carrier fish has been implicated as one of the reasons for the pathogen's survival and it was suggested to contribute to the recurrence of the Y. ruckeri infection (Busch and Lingg, 1975). The ability of $Y$. ruckeri to form a biofilm is regarded as another reason for bacterial survival in the aquatic environment and has not been extensively studied before (Coquet et al., 2005, 2002a, 2002b). The ability of $Y$. ruckeri to form a biofilm on an abiotic and a biotic surface has only been shown in a few studies; however, the mechanism of biofilm formation and the biofilm structure was not understood. The study presented in the thesis shows the role of two $Y$. ruckeri IATs in biofilm formation and their influence on biofilm structure (Wrobel et al., Manuscript). We found that both IATs of the fish pathogen are required for biofilm formation. This finding is in agreement with other studies. Some ATs such as YeeJ, UpaG, Ag43, EhaG, AutA, FdeC and EtInvA have been implicated in biofilm formation before (Arenas et al., 2014, 2012; Chauhan et al., 2016; Dong et al., 2013; Martinez-Gil et al., 2017; Nesta et al., 2012; Valle et al., 2008). Furthermore, we investigated the ability of $Y$. ruckeri to form a biofilm on abiotic and biotic surfaces. PVC, polystyrene, wood, and ceramics are the main surfaces used in aquaculture facilities and therefore these surfaces were used in our studies (Snoussi et al., 2009). We found that 
material colonization depends on the type of material used. Particularly, we observed a greater colonization of $Y$. ruckeri on wood materials compared to other material used. In agreement with other studies, wood is one of the material types where the adhesion is the highest (Coquet et al., 2002a). Surface properties, such as surface roughness, were suggested as the major reasons for it (Coquet et al., 2002a). However, we did not find these correlations. One explanation for the high adhesion could be the type of material used and the type of a method used for quantification of adherent bacterial cells.

Intimin and Invasin of enteropathogenic E. coli and other Yersiniae have previously been shown to be involved in adhesion to and invasion of different types of eukaryotic cells (Leo et al., 2015a). To investigate whether Y. ruckeri IATs are involved in adhesion and invasion of fish cell lines, two different fish cell lines were used. Our in vitro studies, however, did not show significant differences in the adhesion and invasion of fish cell lines between NVH_3758 and the IAT knockout strains.

\section{The $Y$. ruckeri plasmid pYR4 is potentially related to virulence}

The virulence of the human pathogenic Yersiniae is mainly related to the plasmid-encoded virulence determinants. pYV, the $70-\mathrm{kb}$ virulence plasmid of the human pathogenic Yersiniae, encodes the Yop proteins and the T3SS required for extracellular survival of Yersiniae (Cornelis et al., 1998). The plasmids identified so far in Y. ruckeri had not been described in detail and knowledge regarding their involvement in virulence was lacking. The newly identified pYR4 plasmid encodes a T4SS and a TFP that could contribute to $Y$. ruckeri virulence (Wrobel et al., 2018). The involvement of the T4SS and the TFP in virulence has been reported before. Further research is, however, 
required to investigate the role of pYR4 in virulence by knocking out the T4SS and TFP.

\section{Final remarks}

In summary, the results in the thesis show a new insight into the virulence mechanism of $Y$. ruckeri. Our characterization of the IATs shows their potential role in biofilm formation. Further research is, however, required to understand the exact mechanisms of biofilm formation and the involvement of other factors in its formation. 


\section{MAIN CONCLUSIONS}

1) Third generation sequencing is crucial for sequencing highly repetitive proteins.

2) Third generation sequencing is necessary to analyze genomes to get valid biological data.

3) IATs are variably present in Y. ruckeri strains.

4) $y r \operatorname{In} v$ has a similar domain architecture and the same number of Ig-like domains in the passenger in various $Y$. ruckeri strains.

5) yrIlm has a similar domain architecture in various $Y$. ruckeri strains, however the number of Ig-like domains in the passenger differs.

6) IATs are expressed under conditions relevant for pathogenesis.

7) IATs are involved in biofilm formation.

8) eDNA, RNA and proteins play an important role in Y. ruckeri biofilm formation.

9) pYR4 is the Y.ruckeri NVH_3758 plasmid potentially liked to virulence. 


\section{FUTURE PERSPECTIVES}

1) To purify, crystalize, and determine the structure of the C-terminal part of the IATs $y r I n v$ and $y r I l m$ in order to get insight into the architecture of proteins from the invasin-intimin family and to develop antimicrobials that can be directed against $Y$. ruckeri infections.

2) To identify and characterize the $y r I n v$ and $y r I l m$ receptor molecule in fish.

3) To investigate the effect of the IATs yrInv and yrIlm on virulence in vivo in rainbow trout, and to follow the route of infection.

4) To understand the mechanism of biofilm formation in vivo by $Y$. ruckeri in order to design antibiofilm agents and to prevent biofilm formation in the aquatic environment.

5) To understand the role of pYR4 in $Y$. ruckeri virulence by constructing $Y$. ruckeri mutants. 


\section{REFERENCES}

Ahmed, E., Holmström, S., 2014. Siderophores in environmental research: roles and applications. Microb. Biotechnol. 7(3), 196-208.

Akhlaghi, M., Sharifi Yazdi, H., 2008. Detection and identification of virulent Yersinia ruckeri: the causative agent of enteric redmouth disease in rainbow trout (Oncorhynchus mykiss) cultured in Fars province, Iran. Iran. J. Vet. Res. 9(4), 347-352.

Altinok, I., Grizzle, J., Liu, Z., 2001. Detection of Yersinia ruckeri in rainbow trout blood by use of the polymerase chain reaction. Dis. Aquat. Organ. 44(1), 29-34.

Altinok, I., Ozturk, R., Kahraman, U., Capkin, E., 2016. Protection of rainbow trout against yersiniosis by lpxD mutant Yersinia ruckeri. Fish Shellfish Immunol. 55, 21-27.

Alvarez-Martinez, C., Christie, P., 2009. Biological diversity of prokaryotic type IV secretion systems. Microbiol Mol Biol Rev. 775-808.

An, Y., Friedman, R., 1998. Concise review of mechanisms of bacterial adhesion to biomaterial surfaces. J Biomed Mater Res. 43(3), 338-348.

Anderson, C., Knowles, G., de Lisle, G., 1994. A survey for Yersinia ruckeri and Aeromonas salmonicida in farmed and wild fish. Surveill. 2139-40.

Andreotti, A., De Sousa, C., Goiato, M., da Silva, E., Duque, C., Moreno, A., Dos Santos, D., 2018. In vitro evaluation of microbial adhesion on the different surface roughness of acrylic resin specific for ocular prosthesis. Eur J Dent 12(2), 176-183.

Arenas, J., Cano, S., Nijland, R., Dongen, V. van, Rutten, L., Ende, A. van der, Tommassen, J., 2014. The meningococcal autotransporter AutA is implicated in autoaggregation and biofilm formation. Environ. Microbiol. 17(4).

Arenas, J., Nijland, R., Rodriguez, F.J., Bosma, T.N.P., Tommassen, J., 2012. Involvement of three meningococcal surface-exposed proteins, the heparin-binding protein $\mathrm{NhbA}$, the $\alpha$-peptide of $\operatorname{IgA}$ protease and the 
autotransporter protease NalP, in initiation of biofilm formation. Mol. Microbiol. 87(2), 254-268.

Arias, C., Olivares-Fuster, O., Hayden, K., Shoemaker, C., Grizzle, J., Klesius, P., 2007. First Report of Yersinia ruckeri Biotype 2 in the USA. J. Aquat. Anim. Health 19(1), 35-40.

Austin, B., Green, M., Rodgers, C., 1982. Morphological diversity among strains of Yersinia ruckeri. Aquaculture 27(1), 73-78.

Avendaño-Herrer, R., Tapia-Cammas, D., Aedo, A., Saldivia, P., Ortega, C., Irgang, R., 2016. Disease caused by Yersinia ruckeri serotype O2b found in Chilean-farmed coho salmon, Oncorhynchus kisutch (Walbaum, 1792). J. Fish Dis. 40(2), 279-285.

Bank, W., 2014. World Bank. Reducing disease risks in aquaculture. World Bank Report \#88257-GLB.

Barnes, A., 2011. Enteric Redmouth Disease (ERM) (Yersinia ruckeri), in: Fish Diseases and Disorders Volume 3: Viral, Bacterial and Fungal Infections (Eds. P.T.K. Woo and D.W. Bruno), CABI, Walingford, UK. pp. 484-511.

Bastardo, A., Ravelo, C., Romalde, J., 2012. Highly sensitive detection and quantification of the pathogen Yersinia ruckeri in fish tissues by using real-time PCR. Appl. Microbiol. Biotechnol. 96(2), 511-520.

Bearden, S., Fetherston, J., Perry, R., 1997. Genetic organization of the yersiniabactin biosynthetic region and construction of avirulent mutants in Yersinia pestis. Infect. Immun. 65(5), 1659-1668.

Berc, A., Petrinec, Z., Matašin, Ž., Kozarić, Z., 2015. Yersinia ruckeri Septicaemia in Experimentally Infected Carp (Cyprinus Carpio L.) Fingerlings. Acta Vet. Hung. 47(2).

Bercovier, H., Mollaret, H., 1984. Genus. XIV. Yersinia. Krieg, NR (Ed)., Bergey's Man. Syst. Bacteriol. Williams Wilkins 1, 498-506.

Bernbom, N., Ng, Y., Jørgensen, R., Arpanaei, A., Meyer, R., Kingshott, P., Vejborg, R., Klemm, P., Gram, L., 2009. Adhesion of food-borne bacteria to stainless steel is reduced by food conditioning films. J. Appl. Microbiol. 106(4), 1268-1279. 
Berne, C., Ducret, A., Hardy, G., Brun, Y., 2015. Adhesins involved in attachment to abiotic surfaces by Gram-negative bacteria. Microbiol Spectr 3(4), 1-45.

Bjarnsholt, T., Alhede, M., Alhede, M., Eickhardt-Sørensen, S., Moser, C., Kühl, M., Jensen, P., Høiby, N., 2013. The in vivo biofilm. Trends Microbiol. 21(9), 466-474.

Bottone, E., Bercovier, H., Mollaret, H., 2005. Genus. XLI. Yersinia. Garrity, GM (Ed.), Bergey's Man. Syst. Bacteriol. Springer-Verlag 2, 838-848.

Boyd, A., Chakrabarty, A., 1995. Pseudomonas aeruginosa biofilms: role of the alginate exopolysaccharide. J Ind Microbiol 15(3), 162-168.

Bragg, R., Henton, M., 1986. Isolation of Yersinia ruckeri from rainbow trout in South Africa. Bull. Eur. Assoc. Fish Pathol. 6(1), 5-6.

Briandet, R., Herry, J., Bellon-Fontaine, M., 2001. Determination of the van der Waals, electron donor and electron acceptor surface tension components of static Gram-positive microbial biofilms. Colloids and Surfaces B:Biointerfaces 21(4), 299-310.

Bruno, D., 1990. Enteric Redmouth Disease. Aquac. Inf. Ser. 10.

Brunt, J., Newaj-Fyzul, A., Austin, B., 2007. The development of probiotics for the control of multiple bacterial diseases of rainbow trout, Oncorhynchus mykiss (Walbaum). J. Fish Dis. 30(10), 573-579.

Bullock, G., 1989. Enteric Redmouth Disease. Fish Heal. Bull.

Bullock, G., Stuckey, H., Shotts JR, E., 1978. Enteric redmouth bacterium: comparison of isolates from different geographic areas. J. Fish Dis. 1(4), 351-356.

Busch, R., 1978. Enteric redmouth disease. Mar. Fish. Rev. 40(3), 42-51.

Busch, R., 1973. The serological surveillance of salmonid populations for presumptive evidence of specific disease association. Dr. Thesis, Univ. Idaho, Moscow, Idaho 106.

Busch, R., Lingg, A., 1975. Establishment of an Asymptomatic Carrier State Infection of Enteric Redmouth Disease in Rainbow Trout (Salmo gairdneri). J. Fish. Res. Board Canada 32. 
Calvez, S., Gantelet, H., Blanc, G., Douet, D., Daniel, P., 2014. Yersinia ruckeri Biotypes 1 and 2 in France: presence and antibiotic susceptibility. Dis. Aquat. Organ. 109(2), 117-126.

Campoy, S., Jara, M., Busquets, N., de Rozas, A., Badiola, I., Barbe, J., 2002. Role of the high-affinity zinc uptake znuACB system in Salmonella enterica serovar Typhimurium virulence. Infect. Immun. 70, 4721-4725.

Capkin, E., Altinok, I., 2009. Effects of dietary probiotic supplementations on prevention/reatment of yersiniosis disease. J. Appl. Microbiol. 106(4), $1147-1153$.

Cascales, D., Guijarro, J., Garcia-Torrico, A., Méndez, J., 2017. Comparative genome analysis reveals important genetic differences among serotype $\mathrm{O} 1$ and serotype $\mathrm{O} 2$ strains of $Y$. ruckeri and provides insights into host adaptation and virulence. Microbiol. Open 6(4).

Chauhan, N., Wrobel, A., Skurnik, M., Leo, J., 2016. Yersinia adhesins: An arsenal for infection. Proteomics - Clin. Appl.

Chetri, K., Deshmukh, S., Holten-Andersen, L., Jafaar, R., Dalsgaard, I., Buchmann, K., 2013. Comparative evaluation of administration methods for a vaccine protecting rainbow trout against Yersinia ruckeri $\mathrm{O} 1$ biotype 2 infections. Vet. Immunol. Immunopathol. 154(1-2), 42-47.

Christie, P., Atmakuri, K., Krishnamoorthy, V., Jakubowski, S., Cascales, E., 2005. Biogenesis, architecture, and function of bacterial type IV secretion systems. Annu. Rev. Microbiol. 59, 451-485.

Cipriano, R., Schill, W., Pyle, S., Horner, R., 1986. An epizootic in cinook salmon (Oncorhynchus tshawytscha) caused by a sorbitol-positive serovar 2 strain of Yersinia ruckeri. J. Wildl. Dis. 22(4), 488-492.

Collins, R., Foster, G., Ross, H., 1998. Isolation of Yersinia ruckeri from farmed Atlantic Salmon (Salmo salar), and Arctic Char (Salvelinus alpinus) and a European Otter (Lutra lutra) in several water catchment areas in Scotland. Vet. Rec. 139, 169.

Coquet, L., Cosette, P., Dé, E., Galas, L., Vaudry, H., Rihouey, C., Lerouge, P., Junter, G.A., Jouenne, T., 2005. Immobilization induces alterations in the outer membrane protein pattern of Yersinia ruckeri. J. Proteome Res. 4(6), 1988-1998. 
Coquet, L., Cosette, P., Junter, G.-A., Beucher, E., Saiter, J.-M., Jouenne, T., 2002a. Adhesion of Yersinia ruckeri to fish farm materials: influence of cell and material surface properties. Colloids and Surfaces B:Biointerfaces 26(4), 373-378.

Coquet, L., Cosette, P., Quillet, L., Petit, F., Junter, G., Jouenne, T., $2002 b$. Occurrence and Phenotypic Characterization of Yersinia ruckeri Strains with Biofilm-Forming Capacity in a Rainbow Trout Farm. Appl. Environ. Microbiol. 68(2), 470-475.

Cornelis, G., Boland, A., Boyd, A., Geuijen, C., Iriarte, M., Neyt, C., Sory, M., Stainier, I., 1998. The Virulence Plasmid of Yersinia, an Antihost Genome. Microbiol. Mol. Biol. Rev. 62(4), 1315-1352.

Cossarini-Dunier, M., 1985. Indirect enzyme-linked immunosorbent assay (ELISA) to titrate rainbow trout serum antibodies against two pathogens: Yersinia ruckeri and Egtved virus. Aquaculture 49.

Costerton, J., Geesey, G., Cheng, K., 1978. How bacteria stick. Sci. Am. 238(1), 86-95.

Cucarella, C., Solano, C., Valle, J., Amorena, B., Lasa, I., Penadés, J., 2001. Bap, a Staphylococcus aureus surface protein involved in biofilm formation. J. Bacteriol. 183(9), 2888-2896.

Dahiya, I., Stevenson, R., 2010a. Yersinia ruckeri genes that attenuate survival in rainbow trout (Oncorhynchus mykiss) are identified using signaturetagged mutants. Vet. Microbiol. 144(3-4), 399-404.

Dahiya, I., Stevenson, R., 2010b. The ZnuABC operon is important for Yersinia ruckeri infections of rainbow trout, Oncorhynchus mykiss (Walbaum). J. Fish Dis. 33, 331-340.

Dahiya, I., Stevenson, R., 2010c. The UvrY response regulator of the BarA UvrY two-component system contributes to Yersinia ruckeri infection of rainbow trout (Oncorhynchus mykiss). Arch Microbiol 192, 541-547.

Dalsgaard, I., From, J., Hørlyck, V., 1984. First observation of Yersinia ruckeri in Denmark. Bull. Eur. Assoc. Fish Pathol. 4(1).

Daly, J., Lindvik, B., Stevenson, R., 1986. Serological heterogeneity of recent isolates of Yersinia ruckeri from Ontario and British Columbia. Dis. Aquat. Organ. 1, 151-153. 
Davies, R., 1991a. Outer membrane protein profiles of Yersinia ruckeri. Vet. Microbiol. 26, 125-140.

Davies, R., 1991b. Clonal analysis of Yersinia ruckeri based on biotypes, serotypes and outer membrane protein-types. J. Fish Dis. 14, 221-228.

Davies, R., 1990. O-Serotyping of Yersinia ruckeri with Special Emphasis on European Isolates. Vet. Microbiol. 22, 299-307.

Davies, R., Frerichs, G., 1989. Morphological and biochemical differences among isolates of Yersinia ruckeri obtained from wide geographical areas. J. Fish Dis. 357-365.

De Grandis, S., Stevenson, R., 1985. Antimicrobial susceptibility patterns and $\mathrm{R}$ plasmid-mediated resistance of the fish pathogen Yersinia ruckeri. Antimicrob. Agents Chemother. 27(6), 938-942.

De Grandis, S., Stevenson, R., 1982. Variations in plasmid profiles and growth characteristics of Yersinia ruckeri strains. FEMS Microbiol. Lett. 15(3), 199-202.

De Keukeleire, S., De Bel, A., Jansen, Y., Janssens, M., Wauters, G., Piérard, D., 2014. Yersinia ruckeri, an unusual microorganism isolated from a human wound infection. New Microbes New Infect. 2(4), 134-135.

DeGrandis, S., Krell, P., Flett, D., Stevenson, R., 1988. Deoxyribonucleic Acid Relatedness of Serovars of Yersinia ruckeri, the Enteric Redmouth Bacterium. J. Syst. Bacteriol. 38, 49-55.

Dersch, P., Isberg, R., 2000. An immunoglobulin superfamily-like domain unique to the Yersinia pseudotuberculosis invasin protein is required for stimulation of bacterial uptake via integrin receptors. Infect. Immun. 68(5), 2930-8.

Dersch, P., Isberg, R., 1999. A region of the Yersinia pseudotuberculosis invasin protein enhances integrinmediated uptake into mammalian cells and promotes self-association. EMBO 18, 1199-1213.

Diggle, S., Stacey, R., Dodd, C., Cámara, M., Williams, P., Winzer, K., 2006. The galactophilic lectin, LecA, contributes to biofilm development in Pseudomonas aeruginosa. Environ. Microbiol. 8(6), 1095-1104.

Dong, X., Fan, X., Wang, B., Shi, X., Zhang, X.-H., 2013. Invasin of 
Edwardsiella tarda is essential for its haemolytic activity, biofilm formation and virulence towards fish. J. Appl. mMcrobiology 115(1), 1219.

Donlan, R., 2002. Biofilms: Microbial Life on Surfaces. Emerg. Infect. Dis. $8(9), 881-890$.

Dragoš, A., Kovács, Á., 2017. The Peculiar Functions of the Bacterial Extracellular Matrix. Trends Microbiol. 25(4), 257-266.

Dueholm, M., Søndergaard, M., Nilsson, M., Christiansen, G., Stensballe, A., Overgaard, M., Givskov, M., Tolker-Nielsen, T., Otzen, D., Nielsen, P., 2013. Expression of Fap amyloids in Pseudomonas aeruginosa, $P$. fluorescens, and P. putida results in aggregation and increased biofilm formation. Microbiol. Open 2(3), 365-382.

Duman, M., Altun, S., Cengiz, M., Saticioglu, I., Buyukekiz, A., Sahinturk, P., 2017. Genotyping and antimicrobial resistance genes of Yersinia ruckeri isolates from rainbow trout farms. Dis. Aquat. Organ. 125(1), 31-44.

Dwilow, A., Souter, B., Knight, K., 1987. Isolation of Yersinia ruckeri from burbot, Lota lota (L.), from the Mackenzie River, Canada. J. Fish Dis. 10, 315-317.

Ebbensgaard, A., Mordhorst, H., Overgaard, M., Nielsen, C., Aarestrup, F., Hansen, E., 2015. Comparative Evaluation of the Antimicrobial Activity of Different Antimicrobial Peptides against a Range of Pathogenic Bacteria. PLoS One 10(12), 1-18.

Eissa, A., Moustafa, M., Abdelaziz, M., Ezzeldeen, N., 2008. Yersinia ruckeri infection in cultured Nile tilapia, Oreochromis niloticus, at a semiintensive fish farm in lower Egypt. African J. Aquat. Sci. 33(3), 283-286.

El-Matbouli, M., Mattes, M., Soliman, H., 2009. Susceptibility of whirling disease (WD) resistance and WD susceptible strains of rainbow trout Oncorhynchus mykiss to Tetracapsuloides bryosalmonae, Yersinia ruckeri and viral haemorrhagic septicaemia virus. Aquaculture 288(3-4), 299-304.

Enríquez, R., Zamora, J., 1987. Isolation of Yersinia ruckeri from carp (Cyprinus carpio) in Valdivia. Arch. Med. Vet. 19(1), 33-36.

Eppinger, M., Rosovitz, M., Fricke, W., Rasko, D., Kokorina, G., Fayolle, C., 
Lindler, L., Carniel, E., Ravel, J., 2007. The Complete Genome Sequence of Yersinia pseudotuberculosis IP31758, the Causative Agent of Far East Scarlet-Like Fever. Plos Genet. 3(8):e142.

Ewing, W., Ross, A., Brenner, D., Fanning, G., 1978. Yersinia ruckeri sp. nov., the Redmouth (RM) Bacterium. Int. J. Syst. Bcteriology 28(1), 37-44.

Fairman, J., Dautin, N., Wojtowicz, D., Liu, W., Noinaj, N., Barnard, T., Udho, E., Przytycka, T., Cherezov, V., Buchanan, S., 2012. Crystal structures of the outer membrane domain of intimin and invasin from enterohemorrhagic E. coli and enteropathogenic Y. pseudotuberculosis. Structure 20(7), 1233-43.

Fan, E., Chauhan, N., Udatha, D., Leo, J., Linke, D., 2016. Type V Secretion Systems in Bacteria. Microbiol. Spectr. 4(1), 1-24.

FAO, 2018a. FAO Yearbook. Fishery and Aquaculture Statistics. FAO, Rome, Italy.

FAO, 2018b. Impacts of climate change on fisheries and aquaculture. Synthesis of current knowledge, adaptation and mitigation options.

FAO, 2018c. FAO (http://www.fao.org).

FAO, 2011. Global Aquaculture Production Fishery Statistical Collections.

Ferber, D., Brubaker, R., 1981. Plasmids in Yersinia pestis. Infect. Immun. 31 (2), 839-841.

Fernandez, L., Lopez, J., Secades, P., Menendez, A., Marquez, I., Guijarro, J., 2003. In Vitro and In Vivo Studies of the Yrp1 Protease from Yersinia ruckeri and Its Role in Protective Immunity against Enteric Red Mouth Disease of Salmonids. Appl. Environ. Microbiol. 69(12), 7328-7335.

Fernández, L., Marquez, I., Guijarro, J., 2004. Identification of specific in vivoinduced (ivi) genes in Yersinia ruckeri and analysis of ruckerbactin, a catecholate siderophore iron acquisition system. Appl. Environ. Microbiol. 70(9), 5199-5207.

Fernández, L., Méndez, J., Guijarro, J., 2007a. Molecular virulence mechanisms of the fish pathogen Yersinia ruckeri. Vet. Microbiol. 125 (1-2), 1-10. 
Fernández, L., Prieto, M., Guijaro, J., 2007b. The iron- and temperatureregulated haemolysin YhlA is a virulence factor of Yersinia ruckeri. Microbiology 153(2), 483-489.

Filippov, A., Solodovnikov, N., Kookleva, L., Protsenko, O., 1990. Plasmid content in Yersinia pestis strains of different origin. FEMS Microbiol. Lett. 55(1-2), 45-48.

Flemming, H., Wingender, J., 2010. The biofilm matrix. Nat. Rev. Microbiol. $8(9), 623-633$.

Fletcher, M., Floodgate, G., 1973. An electron-microscopic demonstration of as acidic polysaccharide involved in the adhesion of a marine bacterium to solid surfaces. J. Gen. Microbiol. 74, 325-334.

Fouz, B., Zarza, C., Amaro, C., 2006. First description of non-motile Yersinia ruckeri serovar I strains causing disease in rainbow trout, Oncorhynchus mykiss (Walbaum), cultured in Spain. J. Fish Dis. 29(6), 339-346.

Frankel, G., Lider, O., Hershkoviz, R., Mould, A., Candy, D., Cahalon, L., Humphires, M., Dougan, G., 1996. The cell-binding domain of intimin from enteropathogenic Escherichia coli binds to beta1 integrins. J. Biol. Chem. 271, 20359-20364.

Friedman, L., Kolter, R., 2004. Genes involved in matrix formation in Pseudomonas aeruginosa PA14 biofilms. Mol Microbiol 51(3), 675-690.

Fronzes, R., Christie, P., Waksman, G., 2009. The structural biology of type IV secretion systems. Nat. Rev. Microbiol. 7(10).

Fuhrmann, H., Böhm, K., Schlotfeldt, H., 1983. An outbreak of enteric redmouth disease in West Germany. J. Fish Dis. 6, 309-311.

Furones, M., Gilpin, M., Alderman, D., Munn, C., 1990. Virulence of Yersinia ruckeri serotype I strains is associated with a heat sensitive factor (HSF) in cell extracts. FEMS Microbiol. Lett. 66, 339-343.

Garcia, J., Dominguez, L., Larsen, J., Pedersen, K., 1998. Ribotyping and plasmid profiling of Yersinia ruckeri. J. Appl. Microbiol. 85(6), 949-955.

Garrido, K., Palacios, R., Lee, C., Kang, S., 2014. Impact ofconditioning film on the initial adhesion of $\mathrm{E}$. coli onpolysulfone ultrafiltration membrane. J. Ind. Eng. Chem. 20, 1438-1443. 
Ghosh, B., Crosbie, P., Nowak, B., Bridle, A., 2018. A highly sensitive, noninvasive qPCR-based strategy for direct quantification of Yersinia ruckeri in fish faeces. J. Fish Dis. 1-8.

Ghosh, B., Nguyen, T., Crosbie, P., Nowak, B., Bridle, A., 2016. Oral vaccination of first-feeding Atlantic salmon, Salmo salar L., confers greater protection against yersiniosis than immersion vaccination. Vaccine 34(5), 599-608.

Gibello, A., Blanco, M., Moreno, M., Cutuli, M., Domenech, A., Domínguez, L., Fernández -Garayzábal, J., 1999. Development of a PCR Assay for Detection of Yersinia ruckeri in Tissues of Inoculated and Naturally Infected Trout. Appl. Environ. Microbiol. 65(1), 346-350.

Gibello, A., Concepción Porrero, M., Blanco, M., Vela, A., Liébana, P., Moreno, M., Fernández-Garayzábal, J., Domínguez, L., 2004. Analysis of the gyrA Gene of Clinical Yersinia ruckeri Isolates with Reduced Susceptibility to Quinolones. Appl. Environ. Microbiol. 70(1), 599-602.

Giorgetti, G., Ceschia, G., Bovo, G., 1985. First isolation of Yersinia ruckeri in farmed rainbow trout in Italy. Fish Shellfish Pathol. ed. A.E. Ellis, Acad. Press. London 161-166.

Glenn, R., Taylor, P., Hanson, K., 2011. The use of a real-time PCR primer/probe set to observe infectivity of Yersinia ruckeri in Chinook salmon, Oncorhynchus tshawytscha(Walbaum, and steelhead trout, Oncorhynchus mykiss(Walbaum). J. Fish Dis. 34(10), 783-791.

Glenn, R., Taylor, P., Pelton, E., Gutenberger, S., Ahrens, M., Marchant, L., Hanson, K., 2015. Genetic Evidence of Vertical Transmission and Cycling of Yersinia ruckeri in Hatchery-Origin Fall Chinook Salmon Oncorhynchus tshawytscha. J. Fish Wildl. Manag. 6(1).

Gottenbos, B., Van Der Mei, H., Busscher, H., Grijpma, D., Feijen, J., 1999. Initial adhesion and surface growth of Pseudomonas aeruginosa on negatively and positively charged poly (methacrylates). J Mater Sci Mater Med. 10, 853-855.

Grassl, G., Bohn, E., Müller, Y., Bühler, O., Autenrieth, I., 2003. Interaction of Yersinia enterocolitica with epithelial cells: invasin beyond invasion. Int. J. Med. Microbiol. 293(1), 41-54. 
Grawiński, E., 1990. The occurrence of redmouth disease in the rainbow trout (Salmo gairdneri Richardson). Vet. Med. 46, 183-185.

Gudmundsdottir, B., Gudmundsdottir, S., Gudmundsdottir, S., Magnadottir, B., 2014. Yersiniosis in Atlantic cod, Gadus morhua (L.), characterization of the infective strain and host reactions. J. Fish Dis. $37(6), 511-519$.

Guijarro, J., García-Torrico, A., Cascales, D., Méndez, J., 2018. The Infection Process of Yersinia ruckeri: Reviewing the Pieces of the Jigsaw Puzzle. Front. Cell. Infect. Microbiol. 8, 218.

Guilvout, I., Quilici, M., Rabot, S., Lesel, R., Mazigh, D., 1988. BamHI restriction endonuclease analysis of Yersinia ruckeri plasmids and their relatedness to the genus Yersinia 42- to 47-megadalton plasmid. Appl. Environ. Microbiol. 54(10), 2594-2597.

Hamburger, Z., Brown, M., Isberg, R., Bjorkman, P., 1999. Crystal structure of invasin: a bacterial integrin-binding protein. Science (80-. ). 286(5438), 291-295.

Hammerl, J., Klein, I., Lanka, E., Appel, B., Hertwig, S., 2008. Genetic and functional properties of the self-transmissible Yersinia enterocolitica plasmid pYE854, which mobilizes the virulence plasmid pYV. J. Bacteriol. 190, 991-1010.

Hanley, K., 2011. The double-edged sword: How evolution can make or break a live-attenuated virus vaccine. Evolution (N. Y). 4(4), 635-643.

Heinz, E., Stubenrauch, C., Grinter, R., Croft, N., Purcell, A., Strugnell, R., Dougan, G., Lithgow, T., 2016. Conserved features in the structure, mechanism and biogenesis of the inverse autotransporter protein family. Genome Biol. Evol. 8(6), 1690-1705.

Heroven, A., Dersch, P., Tran-Winkler, H., Böhme, K., 2007. Regulatory Elements Implicated in the Environmental Control of Invasin Expression in Enteropathogenic Yersinia, in: In: Perry RD, Fetherston JD (Eds) The Genus Yersinia. Advances In Experimental Medicine and Biology.

Heroven, A., Nagel, G., Tran, H., Parr, S., Dersch, P., 2004. RovA is autoregulated and antagonizes H-NS mediated silencing of invasin and rovA expression in Yersinia pseudotuberculosis. Mol. Microbiol. 53, 
$871-888$.

Hertwig, S., Klein, I., Hammerl, J., Appel, B., 2003. The Genus Yersinia: Characterization of two conjugative Yersinia plasmids mobilizing pYV. Adv. Exp. Med. Biol. 35-8.

Heymann, J., Bartho, J., Rybakova, D., Venugopal, H., Winkler, D., Sen, A., Hurst, M., Mitra, A., 2013. Three-dimensional Structure of the Toxindelivery Particle Antifeeding Prophage of Serratia entomophila. J. Biol. Chem. 288(35), 25276-25284.

Hinnebusch, B., Rudolph, A., Cherepanov, P., Dixon, J., Schwan, T., Forsberg, A., 2002. Role of Yersinia murine toxin in survival of Yersinia pestis in the midgut of the flea vector. Science (80-. ). 296(5568), 733-5.

Hjeltnes, B., Bornø, G., Jansen, M., Haukaas, A., Walde, C., 2017. The Health Situation in Norwegian Aquaculture 2016. Norwegian Veterinary Institute 2017. Veterinærinstituttet.

Horsman, S., Moore, R., Lewenza, S., 2012. Calcium chelation by alginate activates the type III secretion system in mucoid Pseudomonas aeruginosa biofilms. PLoS One 7(10).

Huang, Y., Jung, A., Schäfer, W.-J., Mock, D., Michael, G., Runge, M., Schwarz, S., Steinhagen, D., 2015. Analysis of Yersinia ruckeri strains isolated from trout farms in northwest Germany. Dis. Aquat. Organ. 116, 243-249.

Hunter, V., Knittel, M., Fryey, J., 1980. Stress-induced transmission of Yersinia ruckeri infection from carriers to recipient steelhead trout Salmo gairdneri Richardson. J. Fish Dis. 3(6), 467-472.

Isberg, R., Hamburger, Z., Dersch, P., 2000. Signaling and invasin-promoted uptake via integrin receptors. Microbes Infect. 2, 793-801.

Isberg, R., Leong, J., 1990. Multiple $\beta 1$ chain integrins are receptors for invasin, a protein that promotes bacterial penetration into mammalian cells. Cell 60(5), 861-871.

Isberg, R., Voorhis, D., Falkow, S., 1987. Identification of invasin: a protein that allows enteric bacteria to penetrate cultured mammalian cells. Cell 50, 769-778. 
Ispir, U., Dorucu, M., 2014. Efficacy of lipopolysaccharide antigen of Yersinia ruckeri in rainbow trout by intraperitoneal and bath immersion administration. Reserach Vet. Sci. 97(2), 271-273.

Jaafar, R., Al-Jubury, A., Dalsgaard, I., Mohammadkarami, A., Kania, P., Buchmann, K., 2017. Effect of oral booster vaccination of rainbow trout against Yersinia ruckeri depends on type of primary immunization. Fish Shellfish Immunol.

Jackson, K., Starkey, M., Kremer, S., Parsek, M., Wozniak, D., 2004. Identification of $\mathrm{psl}$, a Locus Encoding a Potential Exopolysaccharide That Is Essential for Pseudomonas aeruginosa PAO1 Biofilm Formation. J. Bacteriol. 186(14), 4466-4475.

Jank, T., Eckerle, S., Steinemann, M., Trillhaase, C., Schimpl, M., Wiese, S., van Aalten, D., Driever, W., Aktories, K., 2015. Tyrosine glycosylation of Rho by Yersinia toxin impairs blastomere cell behaviour in zebrafish embryos. Nat. Commun. 6, 1-16.

Jansen, M., Gjerset, B., Modahl, I., Bohlin, J., 2010. Molecular epidemiology of salmonid alphavirus ( SAV ) subtype 3 in Norway. Virology 7(188), $1-8$.

Jerse, A., Yu, J., Tall, B., Kaper, J., 1990. A genetic locus of enteropathogenic Escherichia coli necessary for the production of attaching and effacing lesions on tissue culture cells. Proc Natl Acad Sci USA 87, 7839-7843.

Jozwick, A., Graf, J., Welch, T., 2016. The flagellar master operon $f l h D C$ is a pleiotropic regulator involved in motility and virulence of the fish pathogen Yersinia ruckeri. J. Appl. Microbiol. 122(3), 578-588.

Katsikogianni, M., Missirlis, Y., 2004. Concise review of mechanisms of bacterial adhesion to biomaterials and of techniques used in estimating bacteria-material interactions. Eur Cell Mater 8, 37-57.

Keeling, S., Johnston, C., Wallis, R., Brosnahan, C., Gudkovs, N., Mcdonald, W., 2012. Development and validation of real-time PCR for the detection of Yersinia ruckeri. J. Fish Dis. 35(2), 119-125.

Khimmakthong, U., Deshmukh, S., Chettri, J., Bojesen, A., Kania, P., Dalsgaard, I., Buchmann, K., 2013. Tissue specific uptake of inactivated and live Yersinia ruckeri in rainbow trout (Oncorhynchus mykiss): 
Visualization by immunohistochemistry and in situ hybridization. Microb. Pathog. 59-60, 33-41.

Kim, D.-H., Austin, B., 2006. Innate immune responses in rainbow trout (Oncorhynchus mykiss, Walbaum) induced by probiotics. Fish Shellfish Immunol. 21(5), 513-524.

Kimura, S., Eda, T., Ikeda, T., Suzuki, M., 1975. Detection of conjugative R plasmids in genus Yersinia. Japan J. Microbiol. 19, 449-451.

Korbut, R., Mehrdana, F., Kania, P., Larsen, M., Frees, D., Dalsgaard, I., Jørgensen, L., 2016. Antigen Uptake during Different Life Stages of Zebrafish (Danio rerio) Using a GFP-Tagged Yersinia ruckeri. PLoS One 11(7), 1-13.

Kotetishvili, M., Kreger, A., Wauters, G., Morris, J., Sulakvelidze, A., Stine, O., 2005. Multilocus sequence typing for studying genetic relationships among Yersinia species. J. Clin. Microbiol. 43(6), 2674-84.

Krasowksa, A., Sigler, K., 2014. How microorganisms use hydrophobicity and what does this mean for human needs? Front. Cell. Infect. Microbiol. $4(112)$.

Kriegeskorte, A., Block, D., Drescher, M., Windmüller, N., Mellmann, A., Baum, C., ....., Kahl, B., 2014. Inactivation of thy A in Staphylococcus aureus attenuates virulence and has a strong impact on metabolism and virulence gene expression. MBio 5:e1447-1.

Kumar, G., Hummel, K., Ahrens, M., Menanteau-Ledouble, S Welch, T., Eisenacher, M., Razzazi-Fazeli, E., El-Matbouli, M., 2016. Shotgun proteomic analysis of Yersinia ruckeri strains under normal and ironlimited conditions. Vet. Res. 47(1):100.

Kumar, G., Hummel, K., Welch, T., Razzazi-Fazeli, E., El-Matbouli, M., 2017. Global proteomic profiling of Yersinia ruckeri strains. Vet. Res. 48(1), 1-11.

Kumar, G., Menanteau-Ledouble, S., Saleh, M., El-Matbouli, M., 2015. Yersinia ruckeri, the causative agent of enteric redmouth disease in fish. Vet. Res. 46(103), 1-10.

LaPatra, S., Kao, S., Erhardt, E., Salinas, I., 2015. Evaluation of dual nasal delivery of infectious hematopoietic necrosis virus and enteric red mouth 
vaccines in rainbow trout (Oncorhynchus mykiss). Vaccine 33(6), 771776.

Lawley, T., Klimke, W., Gubbins, M., Frost, L., 2003. F factor conjugation is a true type IV secretion system. FEMS Microbiol Lett 224, 1-15.

Lee, C., Chen, I., Yang, Y., Ko, T., Huang, Y., Huang, J., Huang, M., Lin, S., Chen, C., Lin, S., Lightner, D., Wang, H., Wang, A., Wang, H., Hor, L., Lo, C., 2015. The opportunistic marine pathogen Vibrio parahaemolyticus becomes virulent by acquiring a plasmid that expresses a deadly toxin. Proc. Natl. Acad. Sci. U. S. A. 112(34), 10798-10803.

Leo, J., Grin, I., Linke, D., 2012. Type V secretion: mechanism(s) of autotransport through the bacterial outer membrane. Philos. Trans. R. Soc. Lond. B. Biol. Sci. 367(1592), 1088-1101.

Leo, J., Oberhettinger, P., Chaubey, M., Schütz, M., Kühner, D., Bertsche, U., Schwarz, H., Götz, F., Autenrieth, I., Coles, M., Linke, D., 2015a. The Intimin periplasmic domain mediates dimerisation and binding to peptidoglycan. Mol. Microbiol. 95(1), 80-100.

Leo, J., Oberhettinger, P., Schütz, M., Linke, D., 2015b. The inverse autotransporter family: Intimin, invasin and related proteins. Int. J. Med. Microbiol.

Lesel, R., Lesel, M., Gavini, F., Vuillaume, A., 1983. Outbreak of enteric redmouth disease, in rainbow trout, Salmo gairdneri Richardson, in France. J. Fish Dis. 6.

Liu, T., Wang, K., Wang, J., Chen, D., Huang, X., Ouyang, P., Geng, Y., He, Y., Zhou, Y., Min, J., 2016. Genome sequence of the fish pathogen Yersinia ruckeri SC09 provides insights into niche adaptation and pathogenic mechanism. Int. J. Mol. Sci. 17(4), 557.

Llewellyn, L., 1980. A bacterium with similarities to the redmouth bacterium and Serratia liquefaciens (Grimes and Hennerty) causing mortalities in hatchery reared salmonids in Australia. J. Fish Dis. 3(1), 29-39.

Lynch, D., Fountain, T., Mazurkiewicz, J., Banas, J., 2007. Glucan-binding proteins are essential for shaping Streptococcus mutans biofilm architecture. FEMS Microbiol. Lett. 268(2), 158-165.

Mack, D., Fischer, W., Krokotsch, A., Leopold, K., Hartmann, R., Egge, H., 
Laufs, R., 1996. The intercellular adhesin involved in biofilm accumulation of Staphylococcus epidermidis is a linear $\beta$ - 1,6-linked glucosaminoglycan: purification and structural analysis. J. Bacteriol. 178(1), 175-183.

Martinez-Gil, M., Goh, K.G., Rackaityte, E., Sakamoto, C., Audrain, B., Moriel, D.G., Totsika, M., Ghigo, J.-M., Schembri, M.A., 2017. YeeJ is an inverse autotransporter from Escherichia coli that binds to peptidoglycan and promotes biofilm formation. Sci. Rep. 7(11326), 1-16.

Matthews, M., Roy, C., 2000. Identification and subcellular localization of the Legionella pneumophila IcmX protein: a factor essential for establishment of a replicative organelle in eukaryotic host cells. Infect. Immun. 68(7), 3971-82.

McArdle, J., Dooley-Martyn, C., 1985. Isolation of Yersinia ruckeri type I (Hagerman strain) from goldfish Carassius auratus (L.). Bull. Eur. Assoc. Fish Pathol. 5(1), 1-2.

McDaniel, D., 1971. Hagerman redmouth. Am. Fish. US Trout News 15, 14 28.

Mendez, J., Cascales, D., Garcia-Torrico, A., Guijarro, J., 2018. TemperatureDependent Gene Expression in Yersinia ruckeri: Tracking Specific Genes by Bioluminescence During in Vivo Colonization. Front. Microbiol. 9 (1098), 1-15.

Méndez, J., Fernández, L., Ménendez, A., Reimundo, P., Pérez-Pascual, D., Navais, R., Guijarro, J., 2009. A chromosomally located traHIJKCLMN operon encoding a putative type IV secretion system is involved in the virulence of Yersinia ruckeri. Appl. Environ. Microbiol. 75(4), 937-945.

Méndez, J., Guijarro, J., 2013. In vivo monitoring of Yersinia ruckeri in fish tissues: progression and virulence gene expression. Environ. Microbiol. Rep. 5(1), 179-185.

Méndez, J., Reimundo, P., Pérez-Pascual, D., Navais, R., Gómez, E., Guijarro, A., 2011. A Novel $c d s A B$ Operon Is Involved in the Uptake of L -Cysteine and Participates in the Pathogenesis of Yersinia ruckeri. J. Bacteriol. 193(4), 944-951.

Michel, C., Fairve, B., De Kinkelin, P., 1986. A clinical case of enteric 
redmouth in minnows (Pimephales promelas) imported in Europe as baitfish. Bull. Eur. Assoc. Fish Pathol. 6(4), 97-99.

Mikula, K., Kolodziejczyk, R., Goldman, A., 2012. Yersinia infection toolscharacterization of structure and function of adhesins. Front. Cell. Infect. Microbiol. 2, 169.

Moreira, J., Gomes, L., Whitehead, K., Lynch, S., Tetlow, L., Mergulhão, F., 2017. Effect of surface conditioning with cellular extracts on Escherichia coli adhesion and initial biofilm formation. Food Bioprod. Process. 104, $1-12$.

Mortensen, B., 2014. Formation and detection of biofilms. Bactoforce Int. A/S $1-5$.

Mühlenkamp, M., Oberhettinger, P., Leo, J., Linke, D., Schütz, M., 2015. Yersinia adhesin A ( YadA ) - Beauty \& beast. Int. J. Med. Microbiol. 305(2), 252-258.

Mulcahy, H., Charron-Mazenod, L., Lewenza, S., 2008. Extracellular DNA chelates cations and induces antibiotic resistance in Pseudomonas aeruginosa biofilms. PLoS Pathog. 4(11).

Mulks, M., Plaut, A., 1987. IgA protease production as a characteristic distinguishing pathogenic from harmless Neisseriaceae. N. Engl. J. Med 299, 973-976.

Munang'andu, H., Paul, J., Evensen, Ø., 2016. An Overview of Vaccination Strategies and Antigen Delivery Systems for Streptococcus agalactiae Vaccines in Nile Tilapia (Oreochromis niloticus). Vaccine 4(4).

Myhr, A., 2016. DNA Vaccines: Regulatory Considerations and Safety Aspects. Curr. Issues Mol. Biol. 22, 79-88.

Nakano, K., Shiroma, A., Shimoji, M., Tamotsu, H., Ashimine, N., Ohki, S., Shinzato, M., Minami, M., Nakanishi, T., Teruya, K., Satou, K., Hirano, T., 2017. Advantages of genome sequencing by long-read sequencer using SMRT technology in medical area. Hum. Cell 30(3), 149-161.

Navais, R., Méndez, J., Cascales, D., Reimundo, P., Guijarro, J., 2014. The heat sensitive factor (HSF) of Yersinia ruckeri is produced by an alkyl sulphatase involved in sodium dodecyl sulphate (SDS) degradation but not in virulence. BMC Microbiol. 14: 221. 
Navas, E., Bohle, H., Henríquez, P., Grothusen, H., Bustamante, F., Bustos, P., Mancilla, M., 2014. Draft Genome Sequence of the Fish Pathogen Yersinia ruckeri Strain 37551, Serotype O1b, Isolated from Diseased, Vaccinated Atlantic Salmon (Salmo salar) in Chile. Genome Announc. 2(4), 10-11.

Nelson, M., Lapatra, S., Welch, T., 2015. Complete genome sequence of Yersinia ruckeri strain CSF007-82, etiologic agent of red mouth disease in salmonid fish. Genome Announc. 3(1), 4-5.

Nesta, B., Spraggon, G., Alteri, C., Moriel, D., Rosini, R., Veggi, D., Smith, S., Bertoldi, I., Pastorello, I., Ferlenghi, I., Fontana, M., Frankel, G., Mobley, H., Rappuoli, R., Pizza, M., Serino, L., Soriani, M., 2012. FdeC, a Novel Broadly Conserved Escherichia coli Adhesin Eliciting Protection against Urinary Tract Infections. MBio 3(2):e0001.

Noga, E., Levine, J., Townsend, K., Bullis, R., Carlson, C., Corbett, W., 1988. Kidney biopsy: a nonlethal method for diagnosing Yersinia ruckeri infection (enteric redmouth disease) in rainbouw trout (Salmo gairdneri). Am. J. Vet. Res. 49.

O'Leary, P., 1977. Enteric redmouth bacterium of salmonids: a biochemical and serological comparison of selected isolates. M.S. thesis, Oregon State Univ. Corvallis 93.

Oberhettinger, P., Schutz, M., Leo, J., Heinz, N., Berger, J., Autenrieth, I., Linke, D., 2012. Intimin and Invasin Export Their C-Terminus to the Bacterial Cell Surface Using an Inverse Mechanism Compared to Classical Autotransport. PLoS One 7(10), e47069.

Ohtani, M., Kasper, R., Koppang, E., Raida, M., 2014a. Global 3D Imaging of Yersinia ruckeri Bacterin Uptake in Rainbow Trout Fry. PLoS One 10(2), $1-19$.

Ohtani, M., Villumsen, K., Strøm, H., Raida, M., 2014b. 3D visualization of the initial Yersinia ruckeri infection route in rainbow trout (Oncorhynchus mykiss) by optical projection tomography. PLoS One 9(2), e89672.

Okshevsky, M., Meyer, R., 2015. The role of extracellular DNA in the establishment, maintenance and perpetuation of bacterial biofilms. Crit. Rev. Microbiol. 41(3), 341-352. 
Oraić, D., Zrnčić, S., Šoštarić, B., Bažulić, D., Lipiej, Z., 2002. Occurence of enteric redmouth disease in rainbow trout (Oncorhynchus mykiss) on farms in Croatia. Acta Vet. Hung. 50(3), x-y.

Ormsby, M., Caws, T., Burchmore, R., Wallis, T., Verner-Jeffreys, D., Davies, R., 2016. Yersinia ruckeri Isolates Recovered from Diseased Atlantic Salmon (Salmo salar) in Scotland Are More Diverse than Those from Rainbow Trout (Oncorhynchus mykiss) and Represent Distinct Subpopulations. Appl. Environ. Microbiol. 82(19), 5785-5794.

Palumbo, R., Wang, C., 2006. Bacterial invasin: structure, function, and implication for targeted oral gene delivery. Curr. Drug Deliv. 3(1), 4753.

Pandiyana, P., Balaramanb, D., Thirunavukkarasua, R., Georgea, E., Subaramaniyana, K., Manikkama, S., Sadayappana, B., 2013. Probiotics in aquaculture. Drug Inention Today 5(1), 55-59.

Parker, R., 1974. Probiotics, the other half of the antibiotics story. Anim Nutr Heal. 4-8.

Patzer, S., Hantke, K., 1998. The ZnuABC high-affinity zinc uptake system and its regulator Zur in Escherichia coli. Mol. Microbiol. 28, 1199-1210.

Piepenbrink, K., Sundberg, E., 2018. Motility and adhesion through type IV pili in Gram-positive bacteria. Biochem Soc Trans. 44(6), 1659-1666.

Pisano, F., Kochut, A., Uliczka, F., Geyer, R., Stolz, T., Thiermann, T., Rohde, M., Dersch, P., 2012. In vivo-induced InvA-like autotransporters Ifp and InvC of Yersinia pseudotuberculosis promote interactions with intestinal epithelial cells and contribute to virulence. Infect. Immun. 80(3), 10501064.

Plant, K., Lapatra, S., 2011. Advances in fish vaccine delivery. Dev. Comp. Immunol. 35(12), 1256-1262.

Popescu, A., Costea, M., Dăscălescu, P., 2008. Characterization of Yersinia ruckeri strains from salmonid populations in Romania. Rev. Rom. Med. $18(2)$.

Popović, N., Hacmanjek, M., Teskeredžić, E., 2001. Health status of rudd (Scardinius erythrophthalmus hesperidicus H.) in Lake Vrana on the Island of Cres, Croatia. J. Appl. Ichthyol. 17(1), 43-45. 
Prehna, G., Li, Y., Stoynov, N., Okon, M., Vuckovic, M., Mcintosh, L., Foster, L., Finlay, B., Strynadka, N., 2012. The Zinc Regulated Antivirulence Pathway of Salmonella Is a Multiprotein Immunoglobulin Adhesion System. J. Biol. Chem. 287(39), 32324-32337.

Puhar, A., 2014. Type III secretion system. Curr. Biol. 24(17), R784-R791.

Qin, Z., Baker, A., Raab, A., Huang, S., Wang, T., Yu, Y., Jaspars, M., Secombes, C., Deng, H., 2013. The Fish Pathogen Yersinia ruckeri Produces Holomycin and Uses an RNA Methyltransferase for Selfresistance. J. Biol. Chem. 288(21), 14688-14697.

Rabin, N., Zheng, Y., Opoku-Temeng, C., Du, Y., Bonsu, E., Sintim, H., 2015. Biofilm formation mechanisms and targets for developing antibiofilm agents. Future Med. Chem. 7(4), 493-512.

Raida, M., Buchmann, K., 2008. Bath vaccination of rainbow trout (Oncorhynchus mykiss Walbaum) against Yersinia ruckeri: Effects of temperature on protection and gene expression. Vaccine 26(8), 10501062 .

Raida, M., Larsen, J., Nielsen, M., Buchmann, K., 2003. Enhanced resistance of rainbow trout, Oncorhynchus mykiss (Walbaum), against Yersinia ruckeri challenge following oral administration of Bacillus subtilis and $B$. licheniformis (BioPlus2B). J. Fish Dis. 26(8), 495-498.

Rajanna, C., Revazishvili, T., Rashid, M., et al., 2010. Characterization of pPCP1 Plasmids in Yersinia pestis Strains Isolated from the Former Soviet Union. Int. J. Microbiol. 2010, 9.

Reddy, K., Yedery, R., Aranha, C., 2004. Antimicrobial peptides: premises and promises. Int. J. Antimicrob. Agents 24(6), 536-547.

Reuter, S., Connor, T., Barquist, L., Walker, D., Feltwell, T., Harris, S., ..... et al., 2014. Parallel independent evolution of pathogenicity within the genus Yersinia. Proc. Natl. Acad. Sci. U. S. A. 111(18), 6768-6773.

Rhoads, A., Au, K., 2015. PacBio Sequencing and Its Applications. Genomics Proteomics Bioinforma. 13(5), 278-289.

Ribeiro, M., da Silva Fernandes, M Yoshiteru Kuaye, A., Jimenez-Flores, R., Gigante, M., 2017. Preconditioning of thestainless steel surface affects the adhesion of Bacillus cereus spores. Int. Dairy J. 66, 108-114. 
Riess, T., Raddatz, G., Linke, D., Schäfer, A., Kempf, V., 2007. Analysis of Bartonella adhesin A expression reveals differences between various $B$. henselae strains. Infect. Immun. 75(1), 35-43.

Rintamäki, P., Valtonen, E., Frerichs, G., 1986. Occurrence of Yersinia ruckeri infection in farmed whitefish, Coregonus peled Gmelin and Coregonus muksun Pallas, and Atlantic salmon, Salmo salar L., in northern Finland. J. Fish Dis. 9(2), 137-140.

Robertson, P., Dowd, C., Burrells, C., Williams, P., Austin, B., 2000. Use of Carnobacterium sp. as a probiotic for Atlantic salmon (Salmo salar L.) and rainbow trout (Oncorhynchus mykiss, Walbaum). Aquaculture 185(34), 235-243.

Rodgers, C., 2001. Resistance of Yersinia ruckeri to antimicrobial agents in vitro. Aquaculture 196(3-4), 325-345.

Romalde, J., Barja, J., Magariños, B., Toranzo, A., 1994. Starvation-Survival Processes of the Bacterial Fish Pathogen Yersinia ruckeri. Syst. Appl. Microbiol. 17(2), 161-168.

Romalde, J., MagariÑos, B., Barja, J., Toranzo, A., 1993. Antigenic and Molecular Characterization of Yersinia ruckeri Proposal for a New Intraspecies Classification. Syst. Appl. Microbiol. 16(3), 411-419.

Rosenberg, M., Gutnick, D., Rosenberg, E., 1980. Adherence of bacteria to hydrocarbons: a simple method for measuring cell-surface hydrophobicity. FEMS Microbiol. Lett. 9, 29-33.

Ross, A., Rucker, R., Ewing, W., 1966. Description of a bacterium associated with redmouth disease of rainbow trout (Salmo gairdneri). Can. J. Microbiol. 12(4), 763-770.

Rucker R, 1966. Redmouth disease of rainbow trout (Salmo gairdneri). Bull Off Int Epizoot . 65(5), 825-30.

Sadana, P., Geyer, R., Pezoldt, J., Helmsing, S., Huehn, J., Hust, M., 2018. The invasin D protein from Yersinia pseudotuberculosis selectively binds the Fab region of host antibodies and affects colonization of the intestine. J. Biol. Chem. 293(22), 8672-8690.

Sadana, P., Monnich, M., Unverzagt, C., Scrima, A., 2017. Structure of the $Y$. pseudotuberculosis adhesin InvasinE. Protein Sci. 26(6), 1182-1195. 
Saleh, M., Soliman, H., El-Matbouli, M., 2008. Loop-mediated isothermal amplification as an emerging technology for detection of Yersinia ruckeri the causative agent of enteric red mouth disease in fish. BMC Vet. Res. 4(31), 1-10.

Salinas, I., LaPatra, S., Erhardt, E., 2015. Nasal vaccination of young rainbow trout (Oncorhynchus mykiss) against infectious hematopoietic necrosis and enteric red mouth disease. Dev. Comp. Immunol. 53(1), 105-111.

Scheuerman, T., Camper, A., Hamilton, M., 1998. Effects of substratum topography on bacterial adhesion. J Colloid Interface Sci 208, 23-33.

Schulte, B., Linke, D., Klumpp, S., Schaller, M., Riess, T., Autenrieth, I., Kempf, V., 2006. Bartonella quintana variably expressed outer membrane proteins mediate vascular endothelial growth factor secretion but not host cell adherence. Infect. Immun. 74, 5003-5013.

Secades, P., Guijarro, J., 1999. Purification and Characterization of an Extracellular Protease from the Fish pathogen Yersinia ruckeri and effect of culture condition on production. Appl. Environ. Microbiol. 65(9), 3969-3975.

Segal, G., Purcell, M., Shuman, H., 1998. Host cell killing and bacterial conjugation require overlapping sets of genes within a 22-kb region of the Legionella pneumophila genome. Proc Natl Acad Sci USA 95(4), 166974.

Seo, K., Kim, J., Park, J., Viall, A., Minnich, S., Rohde, H., Schnider, D., Lim, S., Hong, J., Hinnebusch, B., O’Loughlin, J., Deobald, C., Bohach, G., Hovde, C., Minnich, S., 2012. Role of a new intimin/invasin-like protein in Yersinia pestis virulence. Infect. Immun. 80(10), 3559-3569.

Sexton, J., Vogel, J., 2002. Type IVB secretion by intracellular pathogens. Traffic 3(3), 178-85.

Sexton, J., Yeo, H., Vogel, J., 2005. Genetic analysis of the Legionella pneumophila DotB ATPase reveals a role in type IV secretion system protein export. Mol. Microbiol. 57(1), 70-84.

Shaalan, M., El-Mahdy, M., Theiner, S., El-Matbouli, M., Saleh, M., 2017. In vitro assessment of the antimicrobial activity of silver and zinc oxide nanoparticles against fish pathogens. Acta Vet. Scand. 59(49), 1-11. 
Shin, J., Gwak, J., Kamarajan, P., Fenno, J., Rickard, A., Kapila, Y., 2015. Biomedical applications of nisin. J. Appl. Microbiol. 120(6), 1449-1465.

Simonet, M., Riot, B., Fortineau, N., Berche, P., 1996. Invasin production by Yersinia pestis is abolished by insertion of an IS200-like element within the inv gene. Infect. Immun. 64(1), 375-379.

Sinclair, J., O’Brien, A., 2002. Cell surface-localized nucleolin is a eukaryotic receptor for the adhesin intimin- $\gamma$ enterohemorrhagic Escherichia coli O157:H7. J. Biol. Chem. 277, 2876-2885.

Smith, A., Goldring, O., Dear, G., 1987. The production and methods of use of polyclonal antisera to the pathogenic organisms Aeromonas salmonicida, Yersinia ruckeri and Renibacterium salmoninarum. J. Fish Biol. 31, 225-226.

Snoussi, M., Noumi, E., Hajlaoui, H., Usai, D., Sechi, L.A., Zanetti, S., Bakhrouf, A., 2009. High potential of adhesion to abiotic and biotic materials in fish aquaculture facility by Vibrio alginolyticus strains. J. Appl. Microbiol. 106, 1591-1599.

Soltani, M., Pakzad, K., Taheri-Mirghaed, A., Mirzargar, S., Shekarabi, S., Yosefi, P., Soleymani, N., 2017. Dietary Application of the Probiotic Lactobacillus plantarum 426951 Enhances Immune Status and Growth of Rainbow Trout (Oncorhynchus mykiss) Vaccinated Against Yersinia ruckeri. Probiotics Antimicrob. Proteins.

Song, Y., Tong, Z., Wang, J., Wang, L., Guo, Z., Han, Y., Zhang, J., Pei, D., Zhou, D., Qin, H., Pang, X., Han, Y., Zhai, J., Li, M., Cui, B., Qi, Z., Jin, L., Dai, R., Chen, F., Li, S., Ye, C., Du, Z., Lin, W., Wang, J., Yu, J., Yang, H., Wang, J., Huang, P., Yang, R., 2004. Complete genome sequence of Yersinia pestis strain 91001, an isolate avirulent to humans. DNA Res. 179-97.

Sparboe, O., Koren, C., Hastein, T., Poppe, T., Stenwig, H., 1986. The first isolation of Yersinia ruckeri from farmed Norwegian salmon. Bull. Eur. Assoc. Fish Pathol. 6(2), 41-42.

Stave, J., Cook, T., Roberson, B., 1987. Chemiluminescent responses of striped bass, Morone saxatilis (Walbaum), phagocytes to strains of Yersinia ruckeri. J. Fish Dis. 10, 1-10. 
Stentiford, G., Sritunyalucksana, K., Flegel, T., Williams, B., Withyachumnarnkul, B., Itsathitphaisarn, O., Bass, D., 2017. New Paradigms to Help Solve the Global Aquaculture Disease Crisis. PLoS Pathog. 13(2): e10.

Stevenson, R., Airdrie, R., 1984. Serological variation among Yersinia ruckeri strains. J. Fish Dis. 7(4), 247-254.

Stevenson, R.M.W., Daly, J.G., 1982. Biochemical and Serological Characteristics of Ontario Isolates of Yersinia ruckeri. Can. J. Fish. Aquat. Sci. 39(6), 870-876.

Stock, I., Henrichfreise, B., Wiedemann, B., 2002. Natural antibiotic susceptibility and biochemical profiles of Yersinia enterocolitica -like strains: $Y$. bercovieri, $Y$. mollaretii, $Y$. aldovae and $Y$. ruckeri. Antimicrob. Agents 51(1), 56-69.

Strong, P., Hinchliffe, S., Patrick, H., Atkinson, S., Champion, O., Wren, B., 2011. Identification and characterisation of a novel adhesin Ifp in Yersinia pseudotuberculosis. BMC Microbiol. 11, 85.

Sutherland, I., 2001. Biofilm exopolysaccharides: a strong and sticky framework. Microbiology 147, 3-9.

Szabady, R., Peterson, J., Skillman, K., Bernstein, H., 2005. An unusual signal peptide facilitates late steps in the biogenesis of a bacterial autotransporter. Proc. Natl. Acad. Sci. U. S. A. 102, 221-226.

Temprano, A., Riaño, J., Yugueros, J., González, P., de Castro, L., Villena, A., Luengo, J., Naharro, G., 2005. Potential use of a Yersinia ruckeri O1 auxotrophic aroA mutant as a live attenuated vaccine. J. Fish Dis. 28(7), 419-27.

Temprano, A., Yugueros, J., Hernanz, C., Sánchez, M., Berzal, B., Luengo, J., Naharro, G., 2001. Rapid identification of Yersinia ruckeri by PCR amplification of yruI-yruR quorum sensing. J. Fish Dis. 24(5), 253-261.

Teughels, W., Van Assche, N., Sliepen, I., Quirynen, M., 2006. Effect of material characteristics and/or surface topography on biofilm development. Clin Oral Implant. Res 17, 68-81.

Thorsen, B., Enger, Ø., Norland, S., Hoff, A., 1992. Long-Term Starvation Survival of Yersinia ruckeri at Different Salinities Studied by 
Microscopical and Flow Cytometric Methods. Appl. Environ. Microbiol. 58(5), 1624-1628.

Tinsley, J., Lyndon, A., Austin, B., 2011. Antigenic and cross-protection studies of biotype 1 and biotype 2 isolates of Yersinia ruckeri in rainbow trout, Oncorhynchus mykiss ( Walbaum ). J. Appl. Microbiol. 111(1), 816.

Tobback, E., Decostere, A., Hermans, K., Haesebrouck, F., Chiers, K., 2007. Yersinia ruckeri infections in salmonid fish. J. Fish 30(5), 257-268.

Tobback, E., Decostere, A., Hermans, K., Ryckaert, J., Duchateau, L., Haesebrouck, F., Chiers, K., 2009. Route of entry and tissue distribution of Yersinia ruckeri in experimentally infected rainbow trout Oncorhynchus mykiss. Dis. Aquat. Organ. 84, 219-228.

Tobback, E., Hermans, K., Decostere, A., Broeck, W., Haesebrouck, F., Chiers, K., 2010. Interactions of virulent and avirulent Yersinia ruckeri strains with isolated gill arches and intestinal explants of rainbow trout Oncorhynchus mykiss. Dis. Aquat. Organ. 90, 175-179.

Toledo-Arana, A., Valle, J., Solano, C., Arrizubieta, M., Cucarella, C., Lamata, M., Amorena, B., Leiva, J., Penadés, J., Lasa, I., 2001. The enterococcal surface protein, Esp, is involved in Enterococcus faecalis biofilm formation. Appl. Environ. Microbiol. 67(10), 4538-4545.

Toranzo, A., Barja, J., Colwell, R., Hetrick, F., 1983. Characterization of Plasmids in Bacterial Fish Pathogens. Infect. Immun. 39(1), 184-192.

Touzé, T., Hayward, R., Eswaran, J., Leong, J., Koronakis, V., 2004. Selfassociation of EPEC intimin mediated by the $\beta$-barrel-containing anchor domain: a role in clustering of the Tir receptor. Mol. Microbiol. 51(1), $73-87$.

Trček, J., Fuchs, T., Trülzsch, K., 2010. Analysis of Yersinia enterocolitica invasin expression in vitro and in vivo using a novel luxCDABE reporter system. Microbiology 156(9), 2734-2745.

Tsai, J., Yen, M., Castillo, R., Leyton, D., Henderson, I., Saier, M., 2010. The bacterial intimins and invasins: A large and novel family of secreted proteins. PLoS One 5(12), e14403.

Uliczka, F., Pisano, F., Schaake, J., Stolz, T., Rohde, M., Fruth, A., Strauch, 
E., Skurnik, M., Batzilla, J., Rakin, A., Heesemann, J., Dersch, P., 2011. Unique cell adhesion and invasion properties of Yersinia enterocolitica O:3, the most frequent cause of human yersiniosis. PLoS Pathog. 7(7).

Ulsen, P., Rahman, S., Jong, W., Daleke-Schermerhorn, M., Luirink, J., 2014. Type V secretion: From biogenesis to biotechnology. Biochim. Biophys. Acta 1843(8), 1592-1611.

Valle, J., Mabbett, A., Ulett, G., Toledo-Arana, A., Wecker, K., Totsika, M., Schembri, M., Ghigo, J., Beloin, C., 2008. UpaG, a New Member of the Trimeric Autotransporter Family of Adhesins in Uropathogenic Escherichia coli. J. Bacteriol. 190(12), 4147-4161.

Valtonen, E., Rintamaki, P., Koskivaara, M., 1992. Occurence and pathogenicity of Yersinia ruckeri at fish farms in northern and central Finland. J. Fish Dis. 15(2), 163-171.

Van Loosdrecht, M., Lyklema, J., Norde, W., Schraa, G., Zehnder, A., 1987. The role of bacterial cell wall hydrophobicity in adhesion. Appl Env. Microbiol 53, 1893-1897.

van Nhieu, G., Isberg, R., 1991. The Yersinia pseudotuberculosis invasin protein and human fibronectin bind to mutually exclusive sites on the interin $\alpha 5 \beta 1$ receptor. J. Biol. Chem. 266, 24367-24375.

Vasudevan, R., 2014. Biofilms: Microbial Cities of Scientific Significance. J. Microbiol. Exp. 1(3), 1-16.

Villumsen, K., Neumann, L., Ohtani, M., Strøm, H., Raida, M., 2014. Oral and Anal Vaccination Confers Full Protection against Enteric Redmouth Disease (ERM) in Rainbow Trout. PLoS One 9(4):e9384.

Vincent, C., Friedman, J., Jeong, K., Buford, E., Miller, J., Vogel, J., 2006. Identification of the core transmembrane complex of the Legionella Dot/Icm type IV secretion system. Mol. Microbiol. 62(5), 1278-91.

Vogel, J., Andrews, H., Wong, S., Isberg, R., 1998. Conjugative transfer by the virulence system of Legionella pneumophila. Science (80-. ). 279(5352), 873-6.

Voth, D., Broederdorf, L., Graham, J., 2013. Bacterial Type IV Secretion Systems: Versatile Virulence Machines. Future Microbiol. 7(2), 241-257. 
Vuillaume, A., Brun, R., Chene, P., Sochon, E., Lesel, R., 1987. First isolation of Yersinia ruckeri from sturgeon, Acipenser baeri Brandt, in South West of France. Bull. Eur. Assoc. Fish Pathol. 7(1), 18-19.

Waksman, G., Orlova, E., 2014. Structural organisation of the type IV secretion systems. Curr. Opin. Microbiol. 17(100), 24-31.

Wallden, K., Rivera-Calzada, A., Waksman, G., 2010. Type IV secretion systems: versatility and diversity in function. Cell. Microbiol. 12 (9), $1203-1212$.

Welch, T., Fricke, W., Mcdermott, P., White, D., Rosso, M., Rasko, D., Mammel, M., Rosovitz, M., Wagner, D., Rahalison, L., Leclerc, J., Hinshaw, J., Lindler, L., Cebula, T., 2007. Multiple Antimicrobial Resistance in Plague: An Emerging Public Health Risk. PLoS One 2(3):e309.

Welch, T., LaPatra, S., 2016. Yersinia ruckeri lipopolysaccharide is necessary and sufficient for eliciting a protective immune response in rainbow trout (Oncorhynchus mykiss, Walbaum). Fish Shellfish Immunol. 49, 420-426.

Welch, T., Verner-Jeffreys, D., Dalsgaard, I., Wiklund, T., Evenhuis, J., Cabrera, J., Hinshaw, J., Drennan, J., LaPatra, S., 2011. Independent Emergence of Yersinia Ruckeri Biotype 2 in the United States and Europe. Appl. Environ. Microbiol. 77(10), 3493-3499.

Welch, T., Wiens, G., 2005. Construction of a virulent, green fluorescent protein- tagged Yersinia ruckeri and detection in trout tissues after intraperitoneal and immersion challenge. Dis. Aquat. Organ. 67, 267272.

Wheeler, R., Davies, R., Dalsgaard, I., Garcia, J., Welch, T., Wagley, S., Bateman, K., Verner-Jeffreys, D., 2009. Yersinia ruckeri biotype 2 isolates from mainland Europe and the UK likely represent different clonal groups. Dis. Aquat. Organ. 84(1), 25-33.

Willumsen, B., 1987. Birds and wild fish as potential vectors of Yersinia ruckeri. J. Fish Dis. Dis. 40(12), 275-277.

Wobeser, G., 1973. An outbreak of redmouth disease in rainbow trout (Salmo gairdneri) in Saskatchewan. J. Fish. Res. Board Canada 30(4), 571-575.

Wozniak, D., Wyckoff, T., Starkey, M., Keyser, R., Azadi, P., O’Toole, G., 
Parsek, M., 2003. Alginate is not a significant component of the extracellular polysaccharide matrix of PA14 and PAO1 Pseudomonas aeruginosa biofilms. Proc. Natl. Acad. Sci. U. S. A. 100(13), 7907-7912.

Wrobel, A., Ottoni, C., Leo, J., Linke, D., 2018. pYR4 From a Norwegian Isolate of Yersinia ruckeri Is a Putative Virulence Plasmid Encoding Both a Type IV Pilus and a Type IV Secretion System. Front. Cell. Infect. Microbiol. 8(373), 1-14.

Wrobel, A., Ottoni, C., Leo, J.C., Gulla, S., Linke, D., 2017. The repeat structure of two paralogous genes, Yersinia ruckeri Invasin (yrInv) and a "Y. ruckeri Invasin-like molecule", (yrIlm) sheds light on the evolution of adhesive capacities of a fish pathogen. J. Struct. Biol. 201(2), 171-183.

Wu, S., Altenried, Zogg, A., Zuber, F., Maniura-Weber, Ren, K., 2018. Role of the Surface Nanoscale Roughness of Stainless Steel on Bacterial Adhesion and Microcolony Formation. ACS Omega 3(6), 6456-6464.

Xin, X., Yuan, Z., Wenyuan, S., Yaling, L., Xuedong, Z., 2016. Biofilm and Dental Caries 27-58.

Xu, B., Yin, Z., Chen, Y., Wu, Y., 1991. An outbreak of a new epi- zootic in Silver Carp and Bighead Carp: Yersinia ruckeri, a new pathogen of Silver Carp and Bighead Carp. Chinese Sci. Bull. 36, 1825-1825.

Zita, A., Hermansson, M., 1997. Determination of bacterial cell surface hydrophobicity of single cells in cultures and in wastewater in situ. FEMS Microbiol. Lett. 152, 299-306.

Zorriehzahra, M., Adel, M., Torabi Delshad, S., 2017. Enteric redmouth disease: Past, present and future: A review. Iran. J. Fish. Sci. 16(4), 11351156. 
PAPER I 

This article is part of a Special Issue on Proteins with Tandem Repeats

\title{
The repeat structure of two paralogous genes, Yersinia ruckeri invasin (yrInv) and a "Y. ruckeri invasin-like molecule", (yrllm) sheds light on the evolution of adhesive capacities of a fish pathogen ${ }^{\text {th }}$
}

\author{
Agnieszka Wrobel $^{\mathrm{a}}$, Claudio Ottoni ${ }^{\mathrm{a}, \mathrm{b}}$, Jack C. Leo ${ }^{\mathrm{a}}$, Snorre Gulla ${ }^{\mathrm{c}}$, Dirk Linke ${ }^{\mathrm{a}, *}$ \\ a Department of Biosciences, University of Oslo, 0316 Oslo, Norway \\ ${ }^{\mathrm{b}}$ Centre for Ecological and Evolutionary Synthesis, University of Oslo, 0316, Norway \\ ${ }^{\mathrm{c}}$ Norwegian Veterinary Institute, 0454 Oslo, Norway
}

\section{A R T I C L E I N F O}

\section{Keywords:}

Inverse autotransporters

Invasin

Yersinia ruckeri

PacBio sequencing

Bacterial Ig-like domains

\begin{abstract}
A B S T R A C T
Inverse autotransporters comprise the recently identified type Ve secretion system and are exemplified by in timin from enterohaemorrhagic Escherichia coli and invasin from enteropathogenic Yersiniae. These proteins share a common domain architecture and promote bacterial adhesion to host cells. Here, we identified and characterized two putative inverse autotransporter genes in the fish pathogen Yersinia ruckeri NVH_3758, namely yrInv (for Y. ruckeri invasin) and yrIlm (for Y. ruckeri invasin-like molecule). When trying to clone the highly repetitive genes for structural and functional studies, we experienced problems in obtaining PCR products. PCR failures and the highly repetitive nature of inverse autotransporters prompted us to sequence the genome of $Y$. ruckeri NVH_3758 using PacBio sequencing, which produces some of the longest average read lengths available in the industry at this moment. According to our sequencing data, YrIlm is composed of 2603 amino acids (7812 bp) and has a molecular mass of $256.4 \mathrm{kDa}$. Based on the new genome information, we performed PCR analysis on four non-sequenced $Y$. ruckeri strains as well as the sequenced. Y. ruckeri type strain. We found that the genes are variably present in the strains, and that the length of yrIlm, when present, also varies. In addition, the length of the gene product for all strains, including the type strain, was much longer than expected based on deposited sequences. The internal repeats of the yrInv gene product are highly diverged, but represent the same bacterial immunoglobulin-like domains as in yrIlm. Using QRT-PCR, we found that yrIlm and yrInv are differentially expressed under conditions relevant for pathogenesis. In addition, we compared the genomic context of both genes in the newly sequenced Y. ruckeri strain to all available PacBio-sequenced Y. ruckeri genomes, and found indications of recent events of horizontal gene transfer. Taken together, this study demonstrates and highlights the power of Single Molecule Real-Time technology for sequencing highly repetitive proteins, and sheds light on the genetic events that gave rise to these highly repetitive genes in a commercially important fish pathogen.
\end{abstract}

\section{Introduction}

Yersiniae are Gram-negative, rod-shaped, facultative anaerobes in the Enterobacteriaceae family. Eighteen different species have been described so far (Savin et al., 2014; Reuter et al., 2014). Some members of the Yersiniae are pathogenic to humans and animals, in particular Yersinia pestis, the causative agent of plague (Rasmussen et al., 2015). Y. ruckeri, a fish pathogen, was initially isolated from rainbow trout in the Hagerman Valley of Idaho, USA in the 1950s (Rucker, 1966). Since then, the bacterium has been found all over the world, including
Canada, China, India, Australia, and Europe (Furones et al., 1993; Shaowu et al., 2013). The bacterium has also been associated with a broad range of non-fish hosts including muskrat (Stevenson and Daly, 1982), sea gulls and other birds (Willumsen, 1989), and humans (de Keukeleire et al., 2014).

Y. ruckeri is the causative agent of enteric redmouth disease (ERM), affecting mostly salmonids. ERM can lead to $70 \%$ mortality in infected fish farms. The typical features of the disease include hemorrhages of the mouth or tongue, exophthalmia, darkening of the skin and inflammation of the gut (Bullock, 1984; Busch, 1978). Exophthalmia,

\footnotetext{
tr This Special Issue is edited by Andrey V. Kajava and Silvio C.E Tosatto, and is published as a companion to the COST Action BM1405 meeting on non-globular proteins in molecular physiopathology at Belgrade, Serbia, September 15-17, 2016.

* Corresponding author.

E-mail address: dirk.linke@ibv.uio.no (D. Linke).
} 
known as 'pop-eye', is an intraocular accumulation of fluid which can result in rupture of the fish eye (Busch, 1978). The bacterium enters the host via the secondary gill lamellae and from there can spread to the blood and internal organs (Ohtani et al., 2014). Very little research has been done to investigate the virulence mechanisms of this pathogen. Several virulence factors have been identified, including the ruckerbactin iron uptake system, adhesins, a type III secretion system and exoproteins (Romalde and Toranzo, 1993). It is especially these extracellular proteins, including the iron-regulated haemolysin YhlA (Fernández et al., 2007) and the metalloprotease Yrp1 (Fernandez et al., 2003; Secades and Guijarro, 1999), that have been reported to be toxic to fish, causing the typical clinical signs of ERM disease (Romalde and Toranzo, 1993).

Only a few studies have tried to identify potential adhesins in $Y$. ruckeri (Kawula et al., 1996). In contrast, many adhesins of the human pathogenic Yersiniae have been studied in detail (Chauhan et al., 2016). To address this issue, we searched the Y. ruckeri genome for proteins belonging to the intimin-invasin family of adhesins. Invasin (InvA), expressed by $Y$. enterocolitica and $Y$. pseudotuberculosis, plays a crucial role during the first stage of infection. InvA binds to $\beta 1$ integrins (Isberg and Leong, 1990) and is responsible for initial colonization and bacterial attachment (Simonet and Falkow, 1992). In addition to invasin, several others InvA-like autotrasporters have been identified, including InvB (also called intimin family protein Ifp), InvC, InvD and the recently identified InvE in $Y$. pseudotuberculosis. Interestingly, Y. pestis possess an orthologue of InvC known as Ilp (intimin/InvA-like protein), whereas Ifp is disrupted by an IS285 insertion element (Chauhan et al., 2016; Pisano et al., 2012; Sadana et al., 2017; Strong et al., 2011). These proteins belong to the recently described type Ve secretion system or inverse autotransporter family (Leo et al., 2012). The common feature of the inverse autotransporter family is the domain architecture. These proteins are composed of an N-terminal signal peptide, followed by a short periplasmic region, a $\beta$-barrel domain and a C-terminal passenger (Leo et al., 2015b). The C-terminal passenger, also referred to as the extracellular domain, includes multiple repetitions of Ig-like domains, and is usually capped with a lectin domain that is presumed to host the adhesin function (Hamburger et al., 1999; Heinz et al., 2016; Tsai et al., 2010). Interestingly, the number of Ig-like domains, and thus the size of the passenger, is highly variable in inverse autotransporters (Heinz et al., 2016; Leo et al., 2012). In the current model of inverse autotransport, the protein is first transported into the periplasm by the Sec machinery via its $\mathrm{N}$-terminal signal peptide (Leo et al., 2015b). Inverse autotransporters contain a transmembrane $\beta$ barrel domain through which the C-terminal passenger is secreted into the extracellular space. According to this autotransport model, the outer membrane $\beta$-barrel insertion depends on the BAM ( $\beta$-barrel assembly machinery) complex and the periplasmic chaperones SurA and Skp, whereas the chaperone/protease DegP plays a role in protein quality control (Leo et al., 2012; Oberhettinger et al., 2015, 2012). We identified two putative inverse autotransporter genes in the $Y$. ruckeri genome. We named the corresponding proteins YrInv (for Y. ruckeri invasin) (Leo et al., 2015a) and YrIlm (for Y. ruckeri invasin-like molecule)(this study). When trying to clone these genes from Y. ruckeri NVH_3758, we experienced problems in obtaining PCR products, particularly regarding yrIlm. Our first attempts failed completely; only when we increased the extension times significantly did we obtain products. However, even with longer extension times, we observed multiple products that ran in a ladder-like fashion in agarose gels (Fig. S1). This suggested to us that the yrIlm gene was much longer than suggested by deposited sequences, and that the gene contains many repeated sequence elements that give rise to the observed ladder patterns by strand slippage or similar effects during the amplification reaction. Indeed, we had similar problems when amplifying yrlm from DNA of the type strain Y. ruckeri ATCC29743. These observations, in combination with a lack of genomic information about $Y$. ruckeri NVH_3758, prompted us to sequence the genome. We employed the third-generation Single Molecule Real-Time (SMRT) sequencing technology of Pacific Biosciences (PacBio; Menlo Park CA), which produces some of the longest average read lengths ( $>10,000 \mathrm{bp}$ ) available in the industry at this moment. This sequencing technology allowed us to analyze the repetitive structure of the two inverse autotransporters of NVH_3758. Here, we accurately characterize the genes, yrInv and yrIlm, and describe their expression under various conditions, and compare them to their orthologues across various Y. ruckeri strains.

\section{Materials and methods}

\subsection{Bacterial strains and growth conditions}

Y. ruckeri NVH_3758 as well as $Y$. ruckeri 1435-94 and 1006-94 were kindly provided by the Norwegian Veterinary Institute in Oslo, Norway. Y. ruckeri NVH_3758 was recovered from an outbreak of clinical yersiniosis in farmed Atlantic salmon in Norway in 1987 (Wasteson U, Hvaal AB, Sørum H, Myhr E, 1989). Molecular characterization of the isolate by multilocus sequence typing showed that NVH_3758 belongs to sequence type 3 (clonal complex 1) (Bastardo et al., 2012). Y. ruckeri OMBL4 and RS41 were provided by the University of Helsinki (Table 1). The Escherichia coli TOP10 strain was obtained from Invitrogen. All strains were grown in lysogeny broth (LB) containing $10 \mathrm{~g} / 1$ salt or LB agar plates (Bertani, 1951) at $28^{\circ} \mathrm{C}$ (for Y. ruckeri) or $37^{\circ} \mathrm{C}$ (for E. coli).

\subsection{DNA sequencing and assembly}

Initial database searches for invasin homologues were performed using pBLAST with the protein sequence of $Y$. pseudotuberculosis invasin (GenBank accession number: AAA27632.1) as a search model.

After failing to amplify and clone the identified genes for structural and functional analyses using standard molecular biology procedures, we decided to sequence the genome of $\mathrm{NVH}_{-} 3758$. Genomic DNA was isolated from $10 \mathrm{ml}$ overnight culture of Y. ruckeri NVH_3758 using a large genomic DNA extraction protocol (Sun et al., 2015). Genome sequencing was performed by the Norwegian Sequencing Centre (Oslo, Norway) using the Pacific Biosciences RS II platform. A DNA library was prepared following the Pacific Biosciences $20 \mathrm{~kb}$ library preparation protocol. The final library was selected based on a $8 \mathrm{~kb}$ cut-off using BluePippin (Sage Science). The library was sequenced using P6C4 chemistry with 360 min movie time (time of fluorescent nucleotides incorporation). The generated reads were assembled using the Hierarchical Genome Assembly Process (HGAP) v3 (Pacific Biosciences, SMRT Analysis Software v2.3.0) comprising preassembly, assembly and consensus polishing.

Table 1

Y. ruckeri strains used in this study.

\begin{tabular}{llll}
\hline Strain & Host/Provenance & References & Source \\
\hline NVH_3758 & Atlantic salmon (Norway) & (Wasteson et al., 1989) & Duncan Colquhoun, Norwegian Veterinary Institute, Oslo \\
ATCC29473 (DSMZ18506) & Rainbow trout (Idaho, USA) & (Ross et al., 1966) & Leibniz Institute DSMZ-German Collection of Microorganisms and Cell Cultures \\
$1006-94$ & Fish (Oslo, Norway) & (Mammeri et al., 2006) & Duncan Colquhoun, Norwegian Veterinary Institute, Oslo \\
1435-94 & Fish (Oslo, Norway) & Unpublished & Duncan Colquhoun, Norwegian Veterinary Institute, Oslo \\
OMBL4 & Whitefish (Finland) & (Reuter et al., 2014) & Mikael Skurnik, Haartman Institute, University of Helsinki \\
RS41 & Rainbow trout (USA) & (Reuter et al., 2014) & Mikael Skurnik, Haartman Institute, University of Helsinki \\
\hline
\end{tabular}




\subsection{Sequence analysis and annotation}

The FASTA consensus sequence of the $Y$. ruckeri NVH_3758 chromosomal genome generated through SMRT sequencing was uploaded into RAST (Rapid Annotation using Subsystem Technology) for automatic annotation of genomic features (Aziz et al., 2008). Visualization of annotations and translation of coding DNA sequences (CDSs) into proteins was done with Geneious (Kearse et al., 2012). The translated CDSs were screened for the presence of integral $\beta$-barrel domains with BOMP (' $\beta$-barrel Outer Membrane protein Predictor') (Berven et al., 2004) and all CDSs containing a $\beta$-barrel were in turn screened for the presence of Ig-like domains with InterProScan (Quevillon et al., 2005). Repetitive regions were identified with RepeatScout (Price et al., 2005) and Tandem Repeat Finder (Benson, 1999), and annotated with RepeatMasker (http://www.repeatmasker.org). Thereafter, Bedtools (Quinlan and Hall, 2010) was used to calculate the density of the repetitive regions within 500 bp-long genomic windows.

We compared the genome of Y. ruckeri NVH_3758 (hereafter just NVH_3758) with the genomes deposited in Genbank of Y. ruckeri Big Creek 74 (Big Creek 74) and Y. ruckeri CSF007-82 (CSF007-82) strains sequenced with PacBio SMRT technology, and of Y. ruckeri YRB (YRB) sequenced with Illumina and 454 platforms. The Illumina assembly of YRB, in contrast to the Illumina assembly of ATCC29473, was included in the genome comparison analysis due to the fact that YRB lacks both inverse autotransporters. This allowed us to make a proper genome comparison analysis despite the poor genome assembly. To be consistent with the annotation performed in NVH_3758, the GenBank PacBio genomes of $Y$. ruckeri strains were re-annotated with RAST. Genome comparison was also done with three human pathogenic Yersinia strains, Y. enterocolitica 8081, Y. pestis CO92 and Y. pseudotuberculosis YPIII. Accession numbers and platforms used to sequence the genomes used in the comparative analysis are in Table 2. Locally collinear genomic blocks (LCBs) were identified by aligning the genomes of the three $Y$. ruckeri strains and of the three human pathogenic strains used in the comparative analysis to that of $\mathrm{NVH}_{3} 3758$ with Progressive Mauve (Darling et al., 2010), using default options and using the 'seed family' option to increase sensitivity. The output backbone file was then used to plot the LCBs in eight different Circos representations (Fig. 1, Fig. S2 and 3), where the genome of each strain in the comparative analysis to all others was used as reference.

\subsection{Analysis of Yersinia ruckeri NVH_3758 adhesins}

2.4.1. In silico analysis of invasin (YrInv) and invasin-like molecule (YrIlm) $\mathrm{N}$-terminal signal sequence predictions were made using Phobius (Käll et al., 2004). The domain prediction obtained with InterProScan was further revised and improved using HHpred (Homology detection

Table 2

Type of sequencing technology used for genome sequencing in Yersniae.

\begin{tabular}{|c|c|c|}
\hline Species/Strain & $\begin{array}{l}\text { Sequencing } \\
\text { technology }\end{array}$ & GenBank \\
\hline Yersinia ruckeri NVH_3758 & PacBio & $\begin{array}{l}\text { This study (Accession to } \\
\text { add) }\end{array}$ \\
\hline Yersinia ruckeri ATCC29473 & Illumina & GCA_000834255.1 \\
\hline Yersinia ruckeri 150 & Illumina & GCF_001750505.1 \\
\hline Yersinia ruckeri CSF007-82 & Illumina & GCF_000824965.1 \\
\hline Yersinia ruckeri CSF007-82 & PacBio & LN681231 \\
\hline Yersinia ruckeri RS41 & Illumina & GCF_001166725.1 \\
\hline Yersinia ruckeri OMBL4 & Illumina & GCF_001172905.1 \\
\hline Yersinia ruckeri Big Creek 74 & PacBio & NZ_CP011078.1 \\
\hline Yersinia ruckeri YRB & Illumina, 454 & NZ_CP009539.1 \\
\hline Yersinia enterocolitica 8081 & Sanger & NC_008800.1 \\
\hline $\begin{array}{l}\text { Yersinia pseudotuberculosis } \\
\quad \text { ATCC6904 }\end{array}$ & Illumina, 454 & NZ_CP008943.1 \\
\hline Yersinia pestis $\mathrm{CO} 2$ & Illumina & AL590842 \\
\hline
\end{tabular}

\& structure prediction by HMM-HMM comparison), available at the Max Planck Institute for Developmental Biology Toolkit (Söding et al., 2005), and Clustal Omega (Sievers et al., 2011; Thompson et al., 1994) (Fig. 2A, Fig. S4-6).

\subsubsection{Alignments of yrInv and yrIlm genomic regions}

In order to investigate the degree of similarity and of structural variation of the larger genomic regions containing the two yrInv and yrIlm genes, we constructed an alignment of the genomic regions containing the identified adhesins and including up to six flanking open reading frames from the different $Y$. ruckeri strains sequenced and deposited in Genbank (Table 2), namely, sequences of NVH_3758, Big Creek 74 and CSF007-82, ATCC29743, CSF, 150, YRB, RS41 and OMBL4 (the latter two available only for the inv genomic region) (Table 2.) The alignment was done with Geneious and refined manually, using CSF007-82 as reference for yrIlm and NVH_3758 for yrInv (Fig. 2B-C).

\subsection{PCR detection of Yersinia ruckeri inverse autotransporter adhesins}

Bacterial genomic DNA was isolated from all available Y. ruckeri strains (Table 1) according to a large genomic DNA extraction protocol (Sun et al., 2015). Purified genomic DNA was used as the template in each PCR reaction ( $120 \mathrm{ng}$ per $50 \mu \mathrm{l}$ reaction). It is important to note that the genomic DNA used in the PCR reactions was pure, intact, double stranded and of a high quality. This was a prerequisite for a successful and reliable PCR reaction. PCRs of full-length yrInv and fulllength yrIlm were carried out according to our optimized protocol with Taq polymerase purchased from New England Biolabs (NEB). The cycling conditions were the following: initial denaturation at $95{ }^{\circ} \mathrm{C}$ for $30 \mathrm{~s}$, denaturation at $95{ }^{\circ} \mathrm{C}$ for $10 \mathrm{~s}$, annealing at $62^{\circ} \mathrm{C}$ for $30 \mathrm{~s}$, extension at $68{ }^{\circ} \mathrm{C}$ for $10 \mathrm{~min}$, final extension at $68^{\circ} \mathrm{C}$ for $5 \mathrm{~min}$. PCR analysis of the translocation domain ( $\beta$-barrel) for both yrInv and yrIlm were performed according to standard protocol with Taq polymerase (NEB). The cycling conditions were as follows: initial denaturation at $94{ }^{\circ} \mathrm{C}$ for $3 \mathrm{~min}$, denaturation at $94{ }^{\circ} \mathrm{C}$ for $30 \mathrm{~s}$, annealing at $52{ }^{\circ} \mathrm{C}$ for $30 \mathrm{~s}$, extension at $72{ }^{\circ} \mathrm{C}$ for $60 \mathrm{~s}$, final extension $72{ }^{\circ} \mathrm{C}$ for $5 \mathrm{~min}$. PCR products were analyzed using $0.7 \%$ and $1.2 \%$ agarose gels for full-length PCR products and translocation domains, respectively. As a positive control for PCR reactions, 16S rDNA was amplified using universal primers unique for Y. ruckeri (Fig. 3) (LeJeune and Rurangirwa, 2000). Primers used in this study are listed in Table 3.

\subsection{Quantitative reverse transcription PCR}

For quantitative reverse transcription (qRT) PCR experiments, we tested the effect on adhesin gene expression of the following environmental factors: temperature $\left(8{ }^{\circ} \mathrm{C}, 28^{\circ} \mathrm{C}, 37^{\circ} \mathrm{C}\right), \mathrm{NaCl}$ concentration (0 mM, $170 \mathrm{mM}, 300 \mathrm{mM}$ ), oxygen availability (aerobic/anaerobic conditions), different media (Dulbecco's Modified Eagle Medium (DMEM), LB, minimal medium M9) and iron availability. For the iron availability analysis, we included 3 types of samples, containing $100 \mu \mathrm{M}$ iron chelator (2, 2'-bipyridyl), $200 \mu \mathrm{M} \mathrm{FeCl}_{2}$, or both. Y. ruckeri $\mathrm{NVH} 3758$ was grown in $\mathrm{LB}$ medium at $28^{\circ} \mathrm{C}$ and an optical density $\left(\mathrm{OD}_{550}\right)$ of the culture was adjusted to 1 . Total RNA was extracted from three biological replicates using RiboPure ${ }^{\mathrm{TM}}$ RNA Purification Kit, yeast (ThermoFisher Scientific). Residual DNA was removed by DNase I treatment. RNA quality and concentration was measured by a Nandrop N-1000 spectrophotometer (ThermoFisher Scientific). First-strand cDNA reaction was performed using $1 \mu \mathrm{g}$ of total RNA with the help of Moloney Murine Leukemia Virus reverse transcriptase (NEB) and random hexamer primers (ThermoFisher Scientific). In addition, a control reaction without reverse transcriptase was also included to check for genomic DNA contamination. After the reverse transcriptase reaction, cDNA was diluted tenfold in diethyl pyrocarbonate water and prepared for qRT-PCR reactions. Primers used in qRT-PCR reactions 
Table 3

PCR Primers and expected amplicon sizes for Yersinia ruckeri NVH_3758.

\begin{tabular}{|c|c|c|c|}
\hline Target gene & Forward primer $\left(5^{\prime}-3^{\prime}\right)$ & Reverse primer $\left(5^{\prime}-3^{\prime}\right)$ & product size (bp) \\
\hline yrInv & ATGGTAGGTCTCGAATGATGAATGAAAATATCATCAGGTCTTTTTTT & ATGGTAGGTCTCAGCGCTTTATAATTGTTTTATACAAGTAACATGGC & 2564 \\
\hline yrIlm & TAACGAGGGCAAAAAATGTCTACCTCCTTTACCCGAC & CGGGTGGCTCCAAGCGCTAAGACCCTGCCGACACACAAC & 7842 \\
\hline$\beta$-barrel yrIlm & TTGAGCCAGTTCGGGAC & CTGATAATCCAACACTAAATTGTTG & 735 \\
\hline$\beta$-barrel yrInv & ATGGTAGGTCTCAGCGCTGTTGTTACGATCAACCAAGTTATAAC & ATGGTAGGTCTCAGGCCACGGCTCAAGTGCGGCTAAAT & 734 \\
\hline 16S rDNA & CAGCGGAAAGTAGCTTG & TGTTCAGTGCTATTAACACTTAA & 409 \\
\hline
\end{tabular}

Table 4

Primers used for qRT-PCR.

\begin{tabular}{lll}
\hline Target gene & Forward primer $\left(5^{\prime}-3^{\prime}\right)$ & Reverse primer $\left(5^{\prime}-3^{\prime}\right)$ \\
\hline$y r I n v$ & GTTACCGGTCTTACCTCAGTTAG & Amplicon size (bp) \\
yrlm & CGTCAATGAGGACTTCCATCT & GAGGGTATTATAGGTTATCCCCG \\
gyrA & ACCAGTAGCCGATCAATAAAGTC & AGGAAGATGTGGTTGTGACG \\
polA & TCCAACTCGGTCAAACGTATC & GATTGAAATCCGTTACTGCC \\
\hline
\end{tabular}

were designed using free online software from Integrated DNA Technologies. The primers used in the study are listed in the table below (Table 4). The amplification efficiency of primers was evaluated using a tenfold dilution series of the cDNA in the qRT-PCR reaction. The choice of reference genes (gyrase A, DNA polymerase I) used in this study was based on literature (Brudal et al., 2013; Rocha et al., 2015). qRT-PCR reactions were performed using SYBR Green Master mix (Roche, Basel, Switzerland) in a LightCycler ${ }^{\circledR} 96$ Real Time PCR System (Roche, Basel, Switzerland). Each reaction was performed in a $10 \mu \mathrm{l}$ volume containing $2 \mu \mathrm{l}$ of cDNA, $5 \mu \mathrm{l}$ of SYBR Green I Master mix, $1 \mu \mathrm{l}$ of primer mix including forward and reverse primers $(5 \mu \mathrm{M})$. The qRTPCR reaction was performed according to the manufacturer's instructions. At the end of each run, melting-curve analysis was also performed using the software provided with the machine to assess specificity of the assay. Controls lacking template cDNA or RNA that had not been reverse transcribed were included in each run. All reactions included three technical and three biological replicates (Fig. 4).

\section{Results}

\subsection{An overview of the genome sequence of $Y$. ruckeri NVH_3758}

Here, we present the complete sequenced chromosomal genome of NVH_3758. The sequenced $\mathrm{NVH}_{-} 3758$ genome contains a 3,7-Mb chromosome with a G + C content of $47.6 \%$. The chromosome encodes 3480 CDSs, 81 tRNA genes and 22 rRNA genes. The chromosomal genome of $Y$. ruckeri ATCC29473 type strain (NZ_KN150747.1) sequenced by Illumina appears to be shorter, with a lower number of rRNA and tRNA genes and CDSs. This suggests multiple issues with completeness, gene annotation, and repeat detection. The general features of the four genomes annotated with RAST are summarized in the table below (Table 5). In addition to the chromosomal genome, we also noticed the presence of plasmids in the strain $\mathrm{NVH}_{-} 3758$. As our genes of interest are encoded on the chromosome, we ignored them for the purpose of the study. The presence of plasmids in Y. ruckeri ATCC29473 has been described by other authors (Garcia et al., 1998; Guilvout et al., 1988; Romalde et al., 1993). A large plasmid of approximately 75 MDa has received a lot of attention due to the fact that this plasmid might be correlated with the virulence of the pathogen. However, more research needs to be conducted in order to confirm this hypothesis.

\subsection{Whole-genome comparative analysis of Y. ruckeri strains}

The initial screening with BOMP resulted in 65 CDSs containing a predicted $\beta$-barrel domain. The following prediction of domains with Interpro showed that only two of them contained Ig-like domains, the 'invasin' and 'putative invasin precursor', as reported in the RAST automatic annotation, corresponding respectively to yrInv and yrIlm. The de novo identification of repeat regions across the genome with RepeatScout showed a high density of repeats at the yrIlm locus. The analysis with Tandem Repeat Finder showed that yrIlm is characterized by 19 repeat units of $300 \mathrm{bp}$, each corresponding to a bacterial Ig-like domain (namely D1-D19). The DNA repeat units are characterized by a high GC content and are almost identical in sequence (97\% identity across the 19 DNA repeat units). Interestingly, yrIlm is flanked by two transposases genes (Fig. 1, Fig. 2C). Such a highly homogeneous and repetitive structure was not observed for the yrInv gene, the product of which is characterized by three Ig-like domains, as revealed by the InterPro screening and manual revision (Figs. 1 and 2A-B).

The comparative analysis of LCBs through Mauve between the chromosomes of Big Creek 74, CSF007-82 and YRB showed that yrInv is not present in either Big Creek 74 or YRB, whereas yrIlm is absent only in YRB (Fig. 1). In CSF007-82, the yrIlm gene is duplicated (Fig. S2). yrInv and yrIlm are both absent in Yersinia spp. human pathogenic strains (Fig. S3).

Table 5

Summary of genomic features of selected Y. ruckeri strains.

\begin{tabular}{llll}
\hline Feature & NVH_3758 Pac Bio (this study) & ATCC29473 NZ_KN150747.1* & BigCreek 74* \\
\hline Genome size (bp) & $3,766,700$ & $3,672,847$ & $3,699,725$ \\
GC content (\%) & 47.6 & 47,4 & 47,6 \\
CDS number & 3480 & 3420 & 3387 \\
CDS total length (bp) & $2,958,357$ & $2,907,687$ & 47,5 \\
CDS average length (bp) & 850 & 850 & 3515 \\
CDS length/Genome (\%) & 79 & 79 & $3,107,346$ \\
tRNA & 81 & 72 & 917 \\
rRNA 5S-16S-23S & $8-7-7$ & $6-4-4$ & 84 \\
& & 84 & 81 \\
\end{tabular}

* For the purpose of our study, the genomes deposited in Genbank were re-annotated in RAST in order to use the same annotations of the Y. ruckeri genome sequenced in this study. 


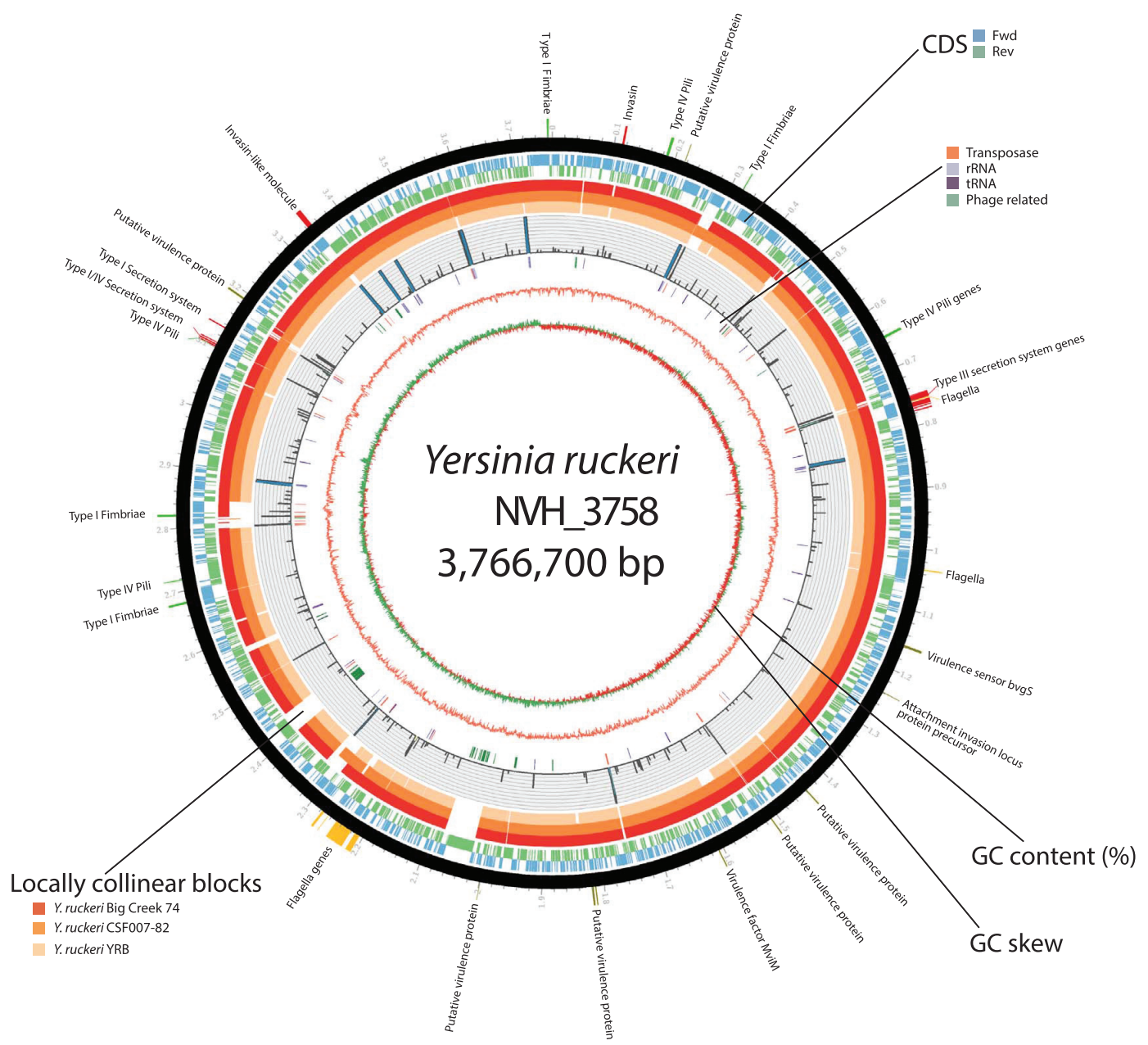

Fig. 1. Circular representation of the main features of the chromosomal genome of $Y$. ruckeri NVH_3758 sequenced in this study. From the inner ring, each track represents 1) GC-skew, 2) GC content, 3) RNA, mobile elements and phage features as reported in colour legend, 4) DNA repeats content percentage, 5-6-7) Mauve locally collinear blocks (LCBs) shared with other Y. ruckeri strains as reported in colour legend, 8-9) Coding sequences in the forward and reverse strand, 10) other features related to flagella (yellow), secretion systems (red), pili and fimbriae (green), and other virulence factors (olive green).

\subsubsection{Invasin-like fragment of Y. ruckeri YRB (YrbIlf)}

Taking a closer look at the genome of YRB, we could identify a genomic region not present in Big Creek and NVH_3758 that contains the coding sequences for a 257 amino- acid long 'fibronectin type III repeat' (an Ig-like fold) protein and a 276 amino-acid long 'invasin-like element", which we named Ig protein and invasin protein, respectively. The region is flanked by two transposases (Fig. 2D). InterPro screening, supported by homology prediction, showed that the invasin protein contains a N-terminal signal sequence (29 aa), followed by a short periplasmic region (77 aa) and a $\beta$-barrel domain (154 aa). Blast analysis found a 50\% identical invasin protein in Hafnia paralvei (Gen Bank: WP_064573282.1, a potential human and animal pathogen within the Enterobacteriaceae family). Alignment analysis of YrInv from NVH_3758 to the YRB invasin-like fragment showed only $12 \%$ identity, suggesting that the YRB fragment is not a product of a translocation event, but that the two regions and the contained genes are significantly different. The Ig protein also carries a short $\mathrm{N}$-terminal signal peptide, and 2 Ig-like domains, 93 and 98 amino-acid long. This genomic region of YRB that contains the two genes could in principle be non-functional remnants of an inverse autotransporter gene, disrupted by mutations. However, the domain orientation is the opposite of what one would expect for an inverted autotransporter (i.e. the Ig-like domains precede the $\beta$-barrel domain), and both genes encode a signal peptide, suggesting that rather than being the decay products of a parental inverse autotransporter, these might be independent (and functional) genes. A possible explanation might be that these two genes constitute an inverse autotransporter 'two-partner secretion system' similar to ZirTS of Salmonella (Gal-Mor et al., 2008) (Fig. 2D).

\subsection{Analysis of Y. ruckeri adhesins}

\subsubsection{Invasin (YrInv)}

The YrInv protein consists of 842 amino acids with a molecular mass of $93.2 \mathrm{kDa}$ and a pI of 5.44. Presence of a signal peptide confirmed that YrInv is an outer membrane protein like its well-studied homologues from other Yersinia species. YrInv consists of an N-terminal signal peptide, a periplasmic region, a transmembrane $\beta$-barrel domain and an extracellular region (Fig. 2A, Fig. S5). The signal peptide has a length of 49 amino acids, making it unusually long; note that long signal peptides may have an important function in autotransporters in general 
(Bernstein, 2014). In the case of classical autotransporters, such long signal peptides function not only as a targeting signal, but also prevent misfolding of the passenger in the periplasm (Szabady et al., 2005). We assume extended signal peptides play a similar role in the biogenesis of inverse autotransporters, but this has not been experimentally verified. The periplasmic region of YrInv contains a lysin motif (LysM)

A.

A.

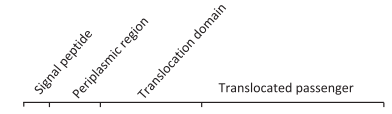

yrlnv
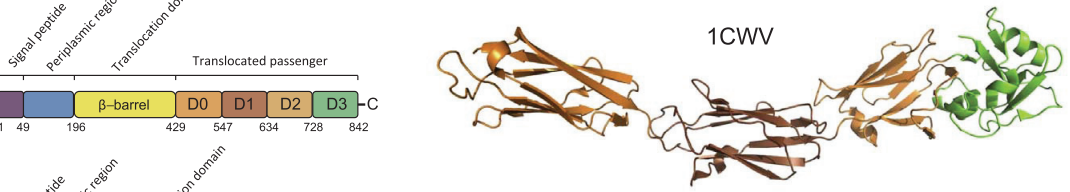

Translocated passenger
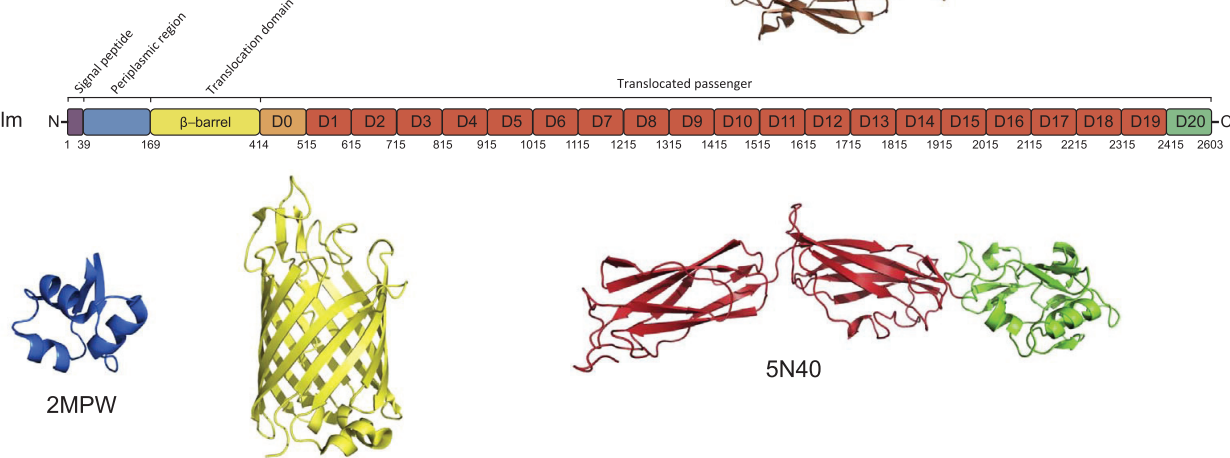

4E1T

B.

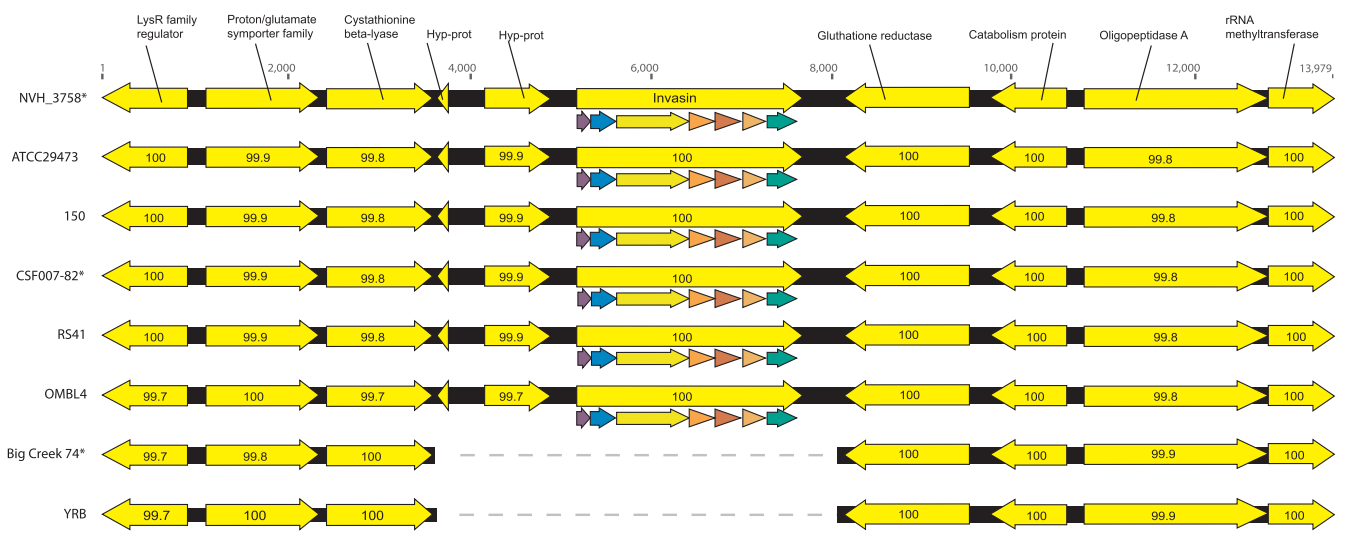

C.

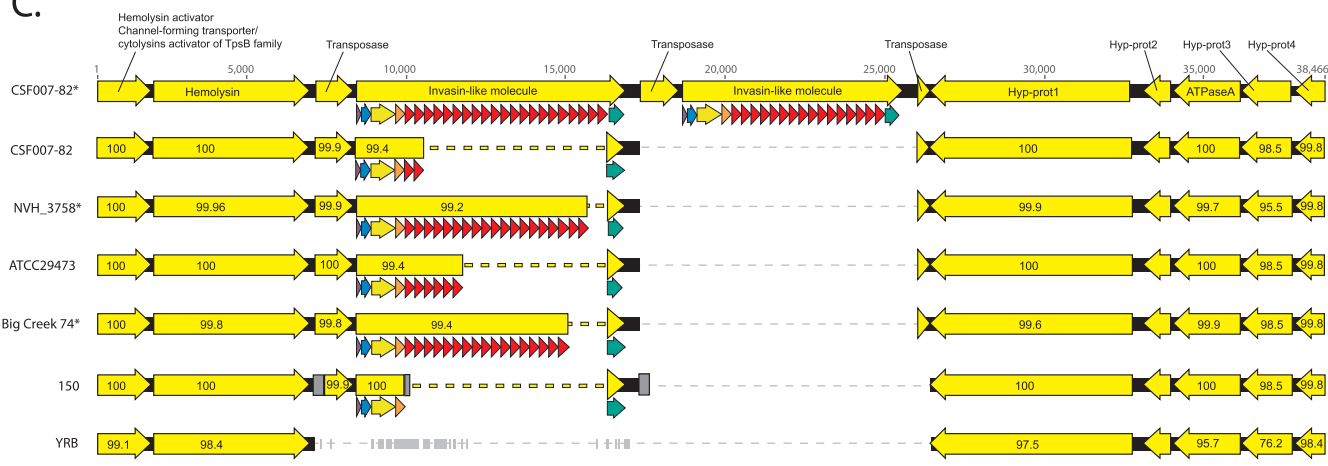

D.

YRB

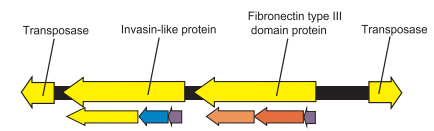


Fig. 2. a) Domain structure of Yrllm and YrInv of Y. ruckeri NVH_3758. All domains of YrIlm and YrInv are depicted by different colouring. The N-terminal signal peptide is shown in purple. The periplasmic region is shown in blue, the translocation domain is shown in yellow and the passenger or extracellular domain is shown in different shadows of red. The passenger consists of an array of tandemly repeated Ig-like domains (in red) or with Ig-like domains of low pairwise sequence similarity (in orange). The passenger is usually capped by a C-type lectin domain (CTLD, in green). The numbers indicated in the figure show the amino acid positions in the protein sequence. Representative experimental structures from homologous proteins (with PDB identifier) are shown in colours matching the domains in the schematics. b) DNA alignment of a $\sim 14 \mathrm{~kb}$-long DNA region containing yrInv and flanking CDS in Y. ruckeri strains sequenced and deposited in Genbank (Table 2). Each CDS is indicated by a yellow arrow, with the percentage of sequence identity to NVH_3758 reported inside the arrow. Regions corresponding to the structural domains of YrInv reported as arrows coloured as in a). c) DNA alignment of $\sim 39 \mathrm{~kb}-$ long DNA region containing yrIlm and flanking CDS in Y. ruckeri strains sequenced and deposited in Genbank. Each CDS is indicated by a yellow arrow, with the percentage of sequence identity to CSF007-82 reported inside the arrow. Regions corresponding to the predicted structural domains in YrIlm are reported as in a). The dashed lines indicate gaps in the DNA alignment. The asterisk (*) in b) and c) indicates assemblies generated through PacBio SMRT sequencing. In strain 150 the grey box indicates a contig break in the assembly. d) Schematic representation of the DNA region in Y. ruckeri YRB containing an invasin-like fragment. Each CDS as predicted in RAST is indicated by a yellow arrow. Region corresponding to the predicted structural domains in invasin-like fragment are reported as in a).

minidomain, which we have previously shown to be involved in peptidoglycan binding and oligomerization (Leo et al., 2015). The translocation unit, based on secondary structure and topology prediction, is highly similar to that of other inverse autotransporters. In Y. pseudotuberculosis InvA, it comprises a 12-stranded $\beta$-barrel and a short intrabarrel linker region (Fairman et al., 2012). The passenger consists of Ig-like domains capped by a C-type lectin like domain (CLTD). Three Iglike domains were identified based on homology predictions and on comparison with $Y$. enterocolitica InvA, and designated as D0, D1 and D2 (Fig. S5). At the sequence level these three domains are highly diverged (Fig. S5). The remaining CLTD was named D3. Interestingly, a BLAST search using the YrInv sequence showed that it shares $43 \%$ identity over the whole sequence with a predicted inverse autotransporter from Edwardsiella piscicida C07-087 (GenBank: WP_069579258.1), an important, recently described fish pathogen. Invasin from E. piscicida C07-087, similarly to YrInv, consists of a $\beta$ barrel domain (56.2\% sequence identity to YrInv $\beta$-barrel) (residue 18262 ) and 3 Ig-like domains (45.9\% sequence identity to YrInv Ig-like domains) (residues 272-557) capped by a CLTD (46.7\% sequence identity to YrInv CLTD) (residues 558-673) (Fig. S7).

\subsubsection{Invasin-like molecule (YrIlm)}

The sequence of YrIlm is composed of 2603 amino acids (Fig. 2A.). It has a molecular mass of $256.4 \mathrm{kDa}$ with a pI of 4.65 . Subcellular localization prediction suggested that YrIlm is an outer membrane protein. Based on our secondary structure prediction, YrIlm, similarly to YrInv, consists of an N-terminal signal sequence (residues 1-39), a periplasmic domain, a transmembrane inverse autotransporter $\beta$-barrel domain (residues 169-413) and a large extracellular region (residues 413-2603) (Fig. 2A). Like YrInv, the periplasmic region of YrIlm contains a LysM minidomain (Leo et al., 2015a). The large extracellular region consists of an array of 20 Ig-like domains capped with a predicted CLTD. 19 of the Ig-like domains are almost identical in sequence, suggesting recent expansion of this autotransporter passenger by duplication events (Fig. S4). Each Ig-like domain contains 100 amino acids with the exception of D0, which contains 101 amino acids. A BLAST search showed that YrIlm shares 59\%, 53\% and 51\% identity over the whole sequence with orthologues from Enterobacter cloacae (Gen Bank: WP_023310354.1) and from human pathogens Y. pseudotuberculosis (Gen Bank: WP_042593065.1) and Y. pestis (Gen Bank: WP_011906434.1), respectively. E. cloacae is a member of Enterobacteriaceae family and it is an important opportunistic pathogen for humans. The invasin-like molecule from E. cloacae contains a transmembrane region, $69 \%$ identical in sequence to YrInv, whereas the extracellular region shares $58.8 \%$ identity. The extracellular region is composed of 18 Ig-like domains which vary in size from 70 residues to 104 residues and it is capped by CLTD (Fig. S8).

\subsubsection{Genomic context of yrInv and yrIlm}

By focusing our comparative analysis more specifically to the genomic regions containing yrInv and yrIlm, we could also include assemblies and contigs from other, less complete $Y$. ruckeri strain genomes generated with either third generation- (SMRT, PacBio) or second generation (Illumina, 454) sequencing technologies, and investigate more thoroughly the structural variations within the targeted genomic regions. For yrInv, we aligned eight sequences spanning about $14 \mathrm{~kb}$ and containing up to ten CDSs from eight different strains. Overall, we observed very high similarity in the CDSs. yrInv and an upstream CDS are not present in Big Creek 74 and YRB (Fig. 2B). For yrIlm, we aligned seven sequences spanning almost $39 \mathrm{~kb}$, containing up to $12 \mathrm{CDSs}$ from six different $Y$. ruckeri strains. The region showed a high degree of structural variation and a variable number of DNA repeat units coding for the Ig-like domains in all the sequences analysed, regardless of the strain of origin and of the sequencing technology adopted (Fig. 2C). In the PacBio assembly of CSF00782 two copies of yrIlm were found, each flanked by transposases. The two copies of yrlm contained a different number of Ig-like domains, 22 and 17, respectively. In stark contrast to the PacBio assembly, the Illumina-based assembly of the CSF00782 genome (Nelson et al., 2015) showed a single copy of yrIlm with only three Ig-like domains. The PacBio-based assembly of NVH_3758 showed one copy of $y r I l m$, though with a higher number of Ig-like domains (20). Further variability was observed in the PacBio-assembly of Big Creek 74, which possesses 18 Ig-like domains. The Illumina assembly of ATCC29473 showed 7 Ig-like domains, in contrast to that of YRB which lacks yrIm entirely, including the flanking transposases. In the strain 150 only one repeated Ig-like domain was identified in yrIlm.

\subsection{Presence and absence of the adhesin genes yrIm and yrInv in different} Yersinia ruckeri strains

We wished to investigate the presence of the two inverse autotransporter genes in a collection of available Y. ruckeri strains (Table 1). The presence of a full-length yrIlm and a full-length yrInv was tested by PCR. High quality and purity of genomic DNA was a key point for reliable and repetitive PCR reactions. The genome sequence of NVH_3758 was used as a reference sequence for primer design. The regions used to design the primers were $100 \%$ conserved when compared to all sequenced $Y$. ruckeri strains. $y r I n v$ is present in all the tested strains, apart from Y. ruckeri 1435-94, which did not give a PCR product. We did not detect any differences in yrInv size in different $Y$. ruckeri strains, suggesting identical repeat numbers (Fig. 3B). In addition, we obtained similar results when amplifying the yrInv translocation domain ( $\beta$ barrel), which is the most conserved region in inverse autotransporters. All the tested Y. ruckeri isolates gave a $0.7 \mathrm{~kb}$ product, corresponding to the $\beta$-barrel sequence. The only exception was Y. ruckeri 1435-94, which did not give any product, confirming the complete absence of the gene (Fig. 3D). We continued to experience some problems with amplifying the yrIlm gene, probably due to a combination of gene length and repetitiveness. However, we were able to get a weak but reproducible product for five of the strains (Fig. 3A). Only Y. ruckeri 1006-94 failed to produce a product. Interestingly, the yrIlm PCR products differ in size, ranging from about 6 to $8 \mathrm{~kb}$. We assume that the difference in the length of the yrlm products in different strains is due to a different number of repeated Ig-like domains; similarly dramatic repeat variations have been shown in other classes of autotransporter adhesins, e.g. for Bartonella BadA (Riess et al., 2007). This is supported 

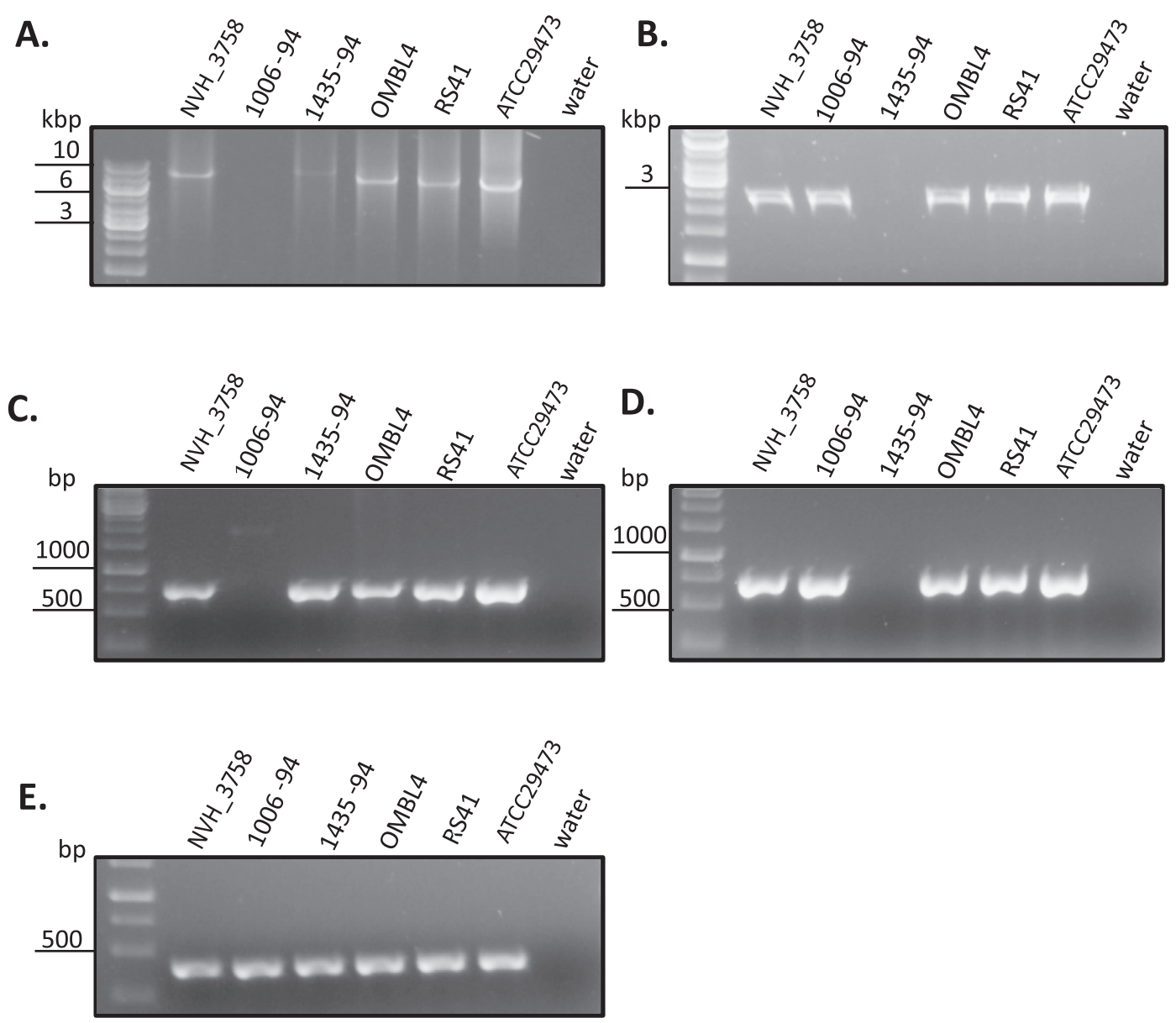

Fig. 3. Analysis of presence and length of yrIlm and yrInv in different Yersinia ruckeri strains. PCR products of full-length yrIlm (A), full-length yrInv (B), translocation domains (C - yrIlm, D - yrInv) and 16S rDNA (E). All Y. ruckeri isolates harbor a full-length yrIlm except Y. ruckeri 1006-94 (A - Note that the length of the PCR bands differ in size). All Y. ruckeri strains harbor yrInv with the exception of $Y$. ruckeri 1435-94 (B - with no observable size differences). Detection of the $\beta$-barrel of $y r I l m$ (735 bp) (C) and the $\beta$-barrel of $y$ rInv (734 bp) (D) confirms the presence or absence of the full-length genes.

by our analysis of sequenced $Y$. ruckeri genomes, where the number of Ig-like domains varies considerably. The length of the yrIlm PCR product of ATCC29473 differs from the length of the yrIm sequence deposited in the NCBI database. This suggests that Illumina assembly has limitations when analysing repetitive gene sequences. With its short read lengths ranging from 100 to $600 \mathrm{bp}$, this is prone to happen especially with long tandem repeats, as in the case of yrIlm. Therefore, we recommend aiming for PacBio sequencing when analysing genes with many internal repeats. Analysis of the yrIlm translocation domain by PCR showed no variability in PCR product length, except for $Y$. ruckeri 1006-94, which produced a fragment approximately twice the expected size (Fig. 3C). To determine what causes the discrepancy, we sequenced this PCR product. The resulting sequence corresponded to the gene for glycerol-3-phosphate acetyl-O-transferase (LN681231.1), suggesting that the unexpected PCR band was due to mispriming. Together with the finding that we could not amplify the full-length yrIlm from this strain, this suggests that 1006-94 does not contain yrIlm. As a positive control to make sure all strains represent $Y$. ruckeri, we amplified and sequenced 16S rDNA from genomic DNA of all Y. ruckeri isolates (Fig. 3E).

\subsection{Gene expression analysis of yrIlm and yrInv under different conditions}

The virulence of all three human Yersinia pathogens relies on number of adhesin molecules expressed on their surface. Some of them, such as Yersinia adhesin A (YadA), invasin (InvA), pH6 antigen (PsaA) of $Y$. pestis have been extensively studied (Chauhan et al., 2016). The expression levels of these virulence factors are modulated by environmental factors such as temperature (Isberg et al., 1988), osmolarity, oxygen presence or absence, and by various nutrients (Pepe et al., 1994). In order to investigate the effect of environmental factors on the expression levels of the two inverse autotransporters from Y. ruckeri, we performed qRT-PCR analysis. These studies can provide a valuable insight into their role in pathogenicity.

\subsubsection{Effect of temperature}

The expression of the invA gene from the human pathogenic Yersiniae is regulated by temperature (Isberg et al., 1988). Therefore, we analyzed the effect of temperature on yrInv and yrIlm expression. Three different temperatures were selected for the analysis: $8{ }^{\circ} \mathrm{C}, 28^{\circ} \mathrm{C}$, and $37^{\circ} \mathrm{C}$. These reflect the temperatures that the fish pathogen would encounter in the environment or in different hosts - which in extreme cases can include zoonotic infections of humans (de Keukeleire et al., 2014). Being psychrophilic, $Y$. ruckeri can easily adapt to and replicate at low temperatures, but grows optimally at $26^{\circ} \mathrm{C}$ to $28{ }^{\circ} \mathrm{C}$. According to our analysis, temperature does have a significant impact on yrIlm or yrInv expression (Fig. 4A). The transcription of both inverse autotransporters is upregulated at $37^{\circ} \mathrm{C}$. However, the effect is stronger for yrIlm, with an increase of about threefold compared with $28{ }^{\circ} \mathrm{C}$ when we use gyrase as the reference gene. The expression level of both genes is unaffected at $8{ }^{\circ} \mathrm{C}$. 


\subsubsection{Effect of salt concentration}

Like temperature, osmolarity is another environmental factor that can alter the transcription of virulence genes (Brzostek et al., 1999; Porter and Dorman, 1994) Changes in osmolarity affects virulence in several bacterial pathogens including Vibro cholerae (Miller and Mekalanos, 1988), Salmonella typhimurium (Galant and Iii, 1990), Escherichia coli (Mouriño et al., 1996), and Pseudomonas aeruginosa (Mittal et al., 2009). We analyzed the effect of salt concentration on the expression on yrIlm and yrInv. Osmolarity has an effect on the transcription of $y r I l m$, whereas expression of yrInv at hyperosmotic and hypoosmotic conditions does not show noticeable changes (Fig. 4B). The expression of yrIlm is upregulated 2.5-fold at $0 \mathrm{mM} \mathrm{NaCl}$ in comparison with $170 \mathrm{mM} \mathrm{NaCl}$ when we used gyrase as the reference gene.

\subsubsection{Effect of oxygen}

Oxygen availability is another environmental factor that can influence the expression of virulence genes (Marteyn et al., 2010). We cultivated bacteria in LB medium with full aeration or oxygen limitation, provided by an anaerobic jar filled with Anaerocult ${ }^{\circledR}$ system and anaerobic indicator, at $28{ }^{\circ} \mathrm{C}$. The growth conditions used in this study aimed to compare the condtions encounter in the $Y$. ruckeri life cycle such as in sediments or inside the host gut, where the condtions are anaerobic. Both genes are upregulated under anaerobic conditions, with yrIlm showing the larger effect (Fig. 4C). However, in our experiments, the stablity of housekepping genes (gyrase A, DNA polymerase I) varied between all biological replicates. To gain a full picture of the influence of oxygen on inverse autotransporter gene expression, more reference genes should be included.

\subsubsection{Effect of the growth medium}

The choice of growth medium is an important consideration when performing gene expression experiments; many medium ingredients can influence the expression of virulence genes. As an example, in Salmonella typhimurium, 287 genes were upregulated when culturing the bacteria in MOPS-based minimal medium compared to LB medium. The hypothesis is that the minimal medium mimics an environment where the genes in question are expressed in nature (Blair et al., 2013).

In order to understand the effect of the growth medium on the transcription of yrInv and yrIlm we performed qRT-PCR analysis. We cultured our bacterial cells in 3 different types of media: rich (but undefined) LB medium, DMEM and the minimal medium M9. We reasoned that DMEM would resemble conditions that the pathogen encounters when infecting a fish, whereas M9 would be more similar to the aqueous (freshwater) environment of fish. Our results showed an increase in the transcription level of both yrIm and yrInv in DMEM medium compared to transcription seen in LB medium. Transcription of yrIlm showed a 14-fold increase in DMEM, whereas a more dramatic a 34-fold increase was seen for the transcritpion of yrInv when we used gyrase as a reference gene. When bacterial cells were grown in M9 medium, we found evidence for a 4-fold overproduction for yrIlm

\section{A. Effect of temperature}

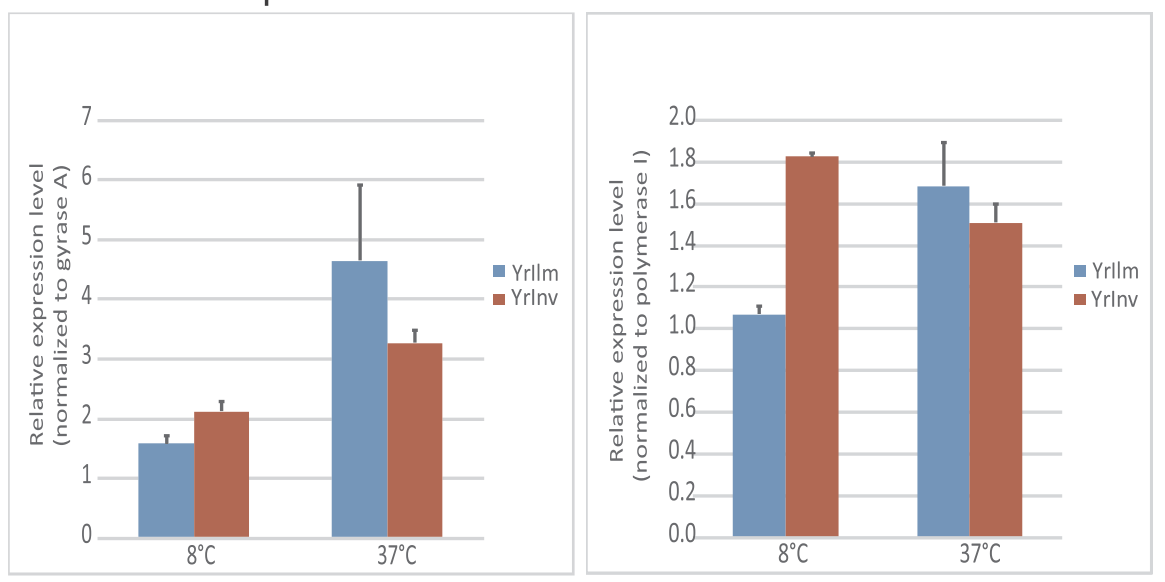

\section{B. Effect of salt concentration}

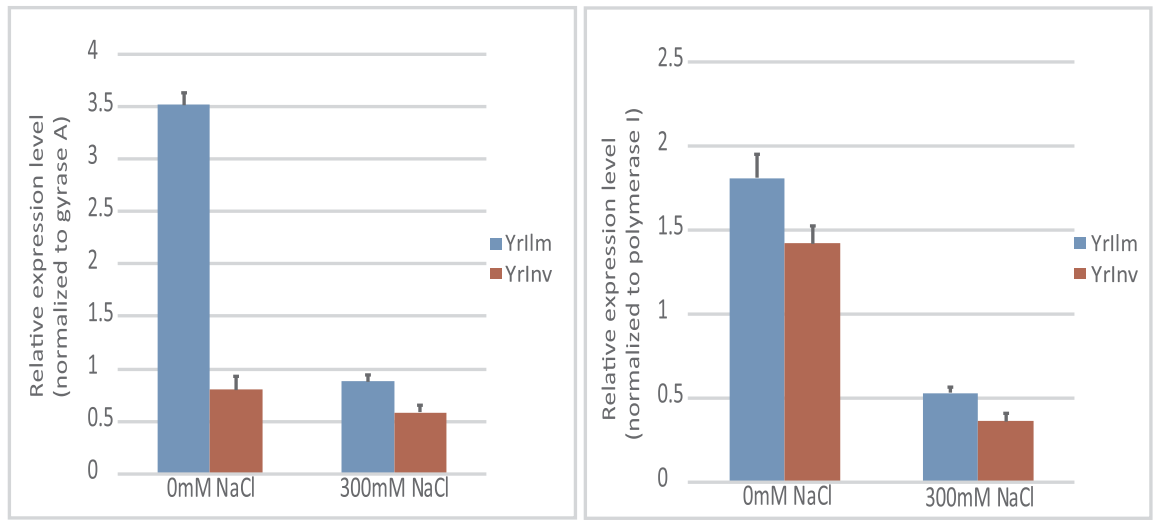

Fig. 4. qRT-PCR analysis of yrInv and yrIlm. Effect of temperature (A), salt concentration (B), oxygen availability (C), medium selection (D) and iron availability (E) on the transcription of yrInv and yrIlm compared to gyrase A and DNA polymerase I. Histograms shows the relative expression levels represented as fold change. Relative transcription was evaluated by using $28{ }^{\circ} \mathrm{C} \mathrm{(A),} 170 \mathrm{mM} \mathrm{NaCl}$ (B), aerobic conditions (C), LB medium (D, E) as the reference. Columns show the data caluclated from the average of three biological replicates, each performed in triplicate with the exception of panel c), where five biological replicates were used for calculations. Error bars indicate the standard error of the mean. 


\section{Effect of oxygen availability}

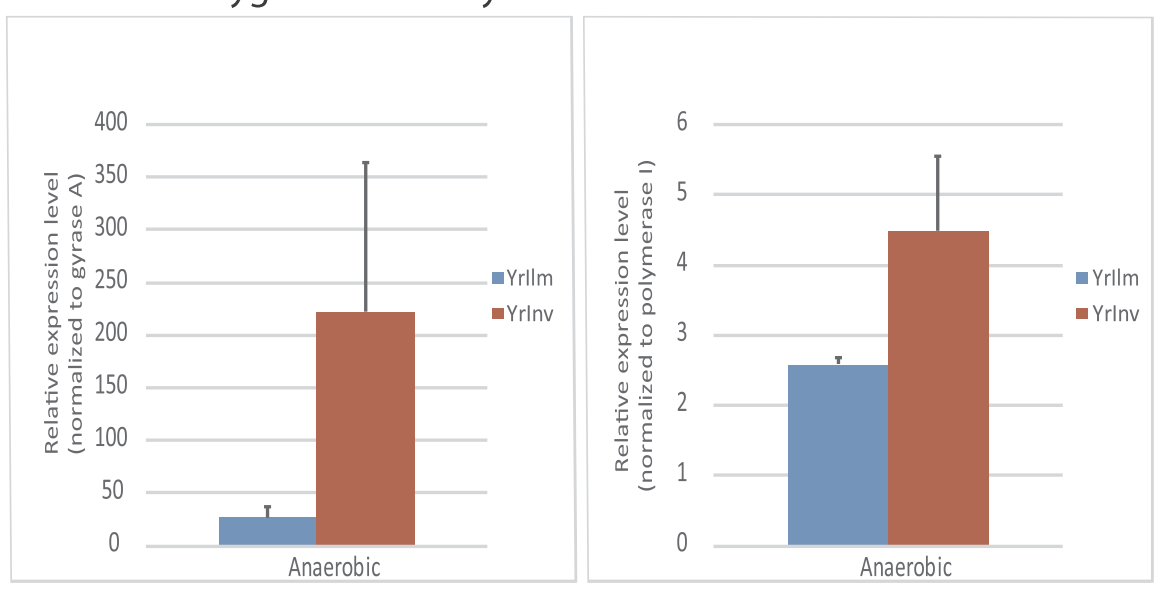

\section{Effect of medium selection}

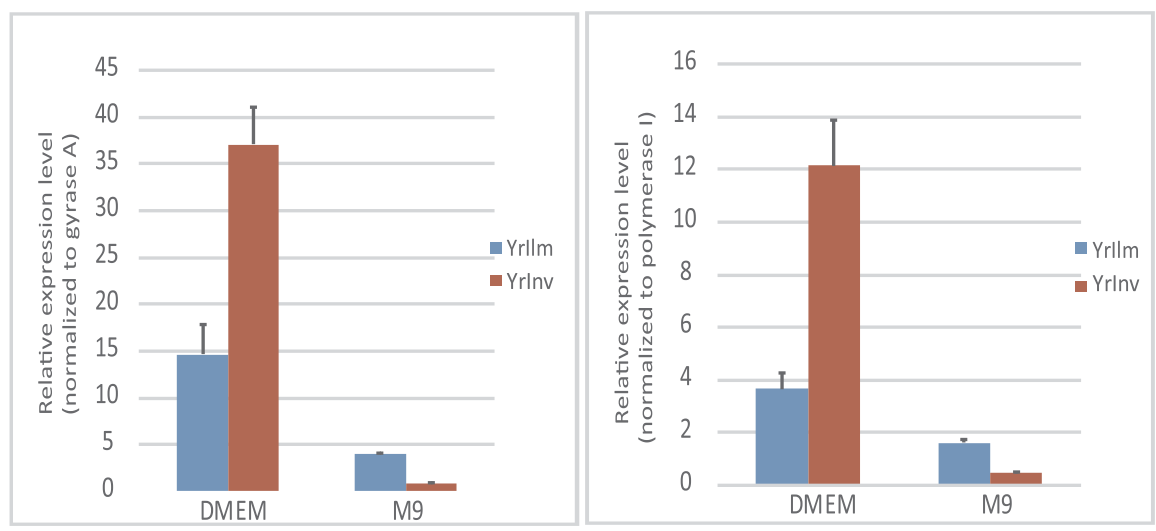

\section{E. Effect of iron availability}

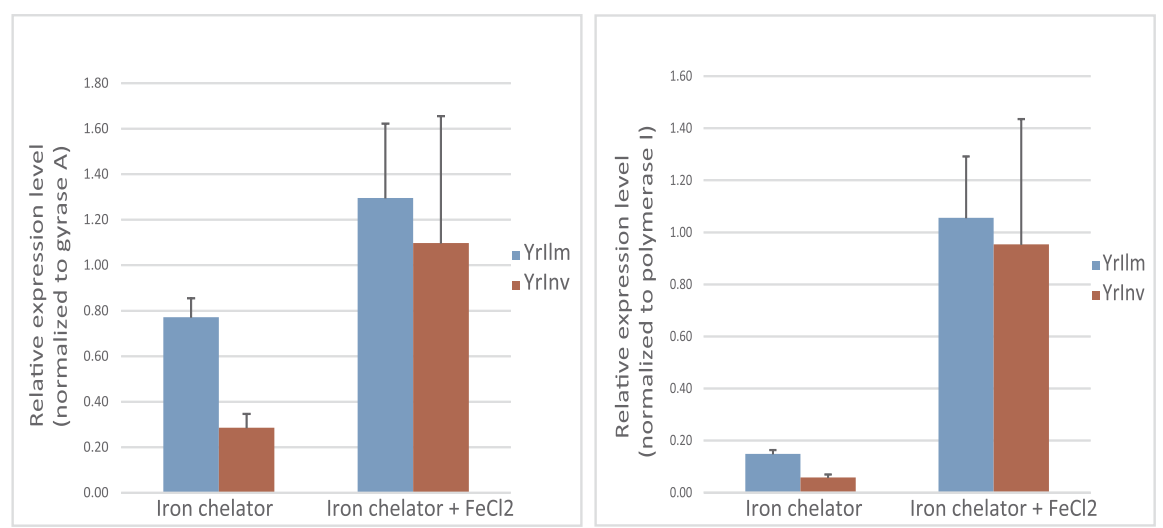

Fig. 4. (continued)

compared to LB medium, while yrInv expression was not significantly affected by these conditions when compared to gyrase as the reference gene (Fig. 4D)

\subsubsection{Effect of iron availability}

Iron is an essential nutrient and a limiting factor in bacterial infections. Iron influences bacterial metabolism, enzyme activity and host-pathogen interactions (Litwin and Calderwood, 1993; Trivier and Courcol, 1996). Therefore, the acquisition of iron by bacterial cells is important for their pathogenicity, and the absence of free iron is an important signal for the bacteria, signalling that they are inside the host (Messenger and Barclay, 1983). In order to investigate the effect of iron limitation on the transcription of yrIlm and yrInv, NVH_3758 was grown in LB medium supplemented with the iron chelator 2,2'-dipyridyl to ensure a lack of free iron in the medium. As controls in our analysis, we used 2 samples including only LB medium and LB supplemented with $100 \mu \mathrm{M}$ of $2,2^{\prime}$-dipyridyl and $200 \mu \mathrm{M}$ of $\mathrm{FeCl}_{3}$ in the medium. Iron availability had an effect on yrInv expression, where lack of iron showed 
a marked reduction in mRNA levels (Fig. 4E). For yrIlm, the effect was not significant when comparing to both reference genes (Fig. 4E).

\section{Discussion}

Inverse autotransporters are prominent virulence factors of many organisms, including enterohaemorrhagic E. coli and the Yersiniae (Leo et al., 2015b). In the human pathogenic Yersiniae, InvA has been studied extensively, but several additional inverse autotransporters, including InvC, Ilp and InvD/E have been identified (Chauhan et al., 2016; Strong et al., 2011). Based on the available genome sequences of Y. ruckeri, we tried to amplify the genes of interest for structural and functional studies. However, despite a significant effort, our PCR attempts failed. Therefore, the whole genome of the NVH_3758 strain was sequenced using PacBio technology. This helped us to identify two inverse autotransporter genes, which we named yrInv and yrIlm. In addition to yrInv and yrIm, we identified a third gene, an invasin-like fragment, and suggested that it is a non-functional inverse autotransporter gene that was disrupted. However, it is worth mentioning that the domain orientation has an opposite topology form the one that we would expect for an invasin homologue. Thus, the two genes could in principle also constitute a variant of a two-partner secretion system; these systems have received much attention in recent years due to their role in virulence of many Gram-negative bacteria (Gal-Mor et al., 2008; Henderson et al., 2000; Leo et al., 2012).

Our study highlights the problems associated with repetitive DNA sequences when using second generation sequencing technologies. Due to their short read length (ranging 100-600 bp), second-generation sequencing platforms often fail to assemble genomic regions characterized by a large number of repeat units, thus resulting in incorrectly assembled genomes. Though problematic for any repeated sequences, this is particularly prominent in the case of tandemly repeated protein domains with high sequence similarity, where the length of the repeated DNA sequences exceed that of the second generation sequencing read lengths. Third-generation sequencing platforms, such as the PacBio platform, offer a large improvement over second-generation platforms, including single-molecule templates, faster run time, lower cost per base and last but not least, significantly longer reads. These are key factors in overcoming challenges in assembling highly repetitive DNA regions.

Sequencing the NVH_3758 genome using the PacBio platform, we were able to determine the correct number of repeated Ig-like domains in $y r I l m$. The number was verified by amplifying the full-length yrIlm gene by PCR, which gave a product size consistent with 20 repeated Iglike domains.

The number of Ig-like domains in YrIlm differs between different strains. In strains sequenced by third-generation techniques, the number of Ig-like domains varies from 17 to 22 . In the strain ATCC29473, the protein is shorter based on the obtained PCR product (6kb). However, according to the NCBI database, the deposited protein sequence of ATCC29473 should give a product corresponding to only 3909 bp. This discrepancy clearly illustrates the problem with using Illumina sequencing for analyzing repetitive sequences, and strongly suggests that multiple repeats are missing in the deposited genome. Moreover, these findings demonstrate that the yrIlm locus is genetically unstable, and that the number of Ig repeats can change relatively rapidly, presumably due to recombination between the near identical, repeated Ig-like domain sequences. Changes in protein length due to insertions or deletions of repeated elements has been observed in some autotransporters before, particularly in some trimeric (type Vc) autotransporters such as BadA from Bartonella henselae (Riess et al., 2004). The length of YadA from $Y$. enterocolitica also varies from strain to strain; here, the length of YadA correlates with the size of other surface structures, and thus the length variation plays a functional role (Mota et al., 2005). This may also be the case in Y. ruckeri. yrIlm appears to be the product of horizontal gene transfer. The GC content of yrIm is
$62.3 \%$, much higher than for the rest of the chromosome $(47.6 \%)$ - the insertion is thus readily visible in the map of the NVH_3758 GC content (Fig. 1). The gene is flanked on both sides by transposase sequences, indicating that it can be readily mobilized. This is further demonstrated by the fact that some strains (YRB, 1006-94) appear to lack the gene entirely, whereas in CSF002-82, the yrIlm gene is duplicated. YrIlm is $59 \%$ identical with an inverse autotransporter of Enterobacter cloacae (EbIlm), an important nosocomial human pathogen. E. cloacae belongs to the Enterobacteriaceae family with the overall $54.79 \%$ of GC content of the chromosome (Ren et al., 2010). We assume that YrIlm and EbIlm are orthologous and hypothesize that $E$. cloacae could be the donor strain. The acquisition of yrIlm thus appears to be recent, and lack of selection pressure allows the locus to remain in flux, leading to variation in both the length of the protein and its presence in different strains.

In contrast, the yrInv locus seems to be more stable. There are no signs of recent genome changes at this locus, and most of the surrounding genes have housekeeping functions (Fig. 2B). Furthermore, in all the sequenced strains that contain $y r I n v$, the structure of the gene is the same. This suggests that (if present) yrInv is under selection pressure. However, as this gene is absent from some strains, it is presumably not an essential virulence factor. Most described inverse autotransporters are virulence factors. A very similar gene to $y r I n v$ is present in E. piscicida. YrInv shares $43 \%$ identity over the whole sequence with invasin from E. piscicida, slightly more than with invasin from the human pathogen $Y$. pseudotuberculosis (40\% identity). As both E. piscicida and Y. ruckeri infect fish, presumably these orthologous proteins play a similar role in the infection process of both pathogens.

Interestingly, both YrIlm and YrInv are upregulated in DMEM medium. We assume this cell culture medium represents an environment similar to what $Y$. ruckeri would encounter in the fish host. As both proteins are presumed adhesins or invasins, they may play an important role in colonization of fish tissues. We are currently investigating the role that these proteins play in $Y$. ruckeri virulence.

\section{Nucleotide sequence accession number}

The genomic sequence presented in this study is deposited in GenBank with the accession number CP023184.

\section{Funding sources}

This work by supported by Research Council of Norway Young Researcher grant 249793 (to JCL), and by Research Council of Norway FriMedBio grant 240483 (to DL).

\section{Acknowledgements}

We would like to thank the qRT-PCR facility at the Department of Biosciences, UiO, especially Dr. Mads Bengtsen, for helping in the execution and analysis of the qRT-PCR experiments. The sequencing service which was provided by the Norwegian Sequencing Centre (www.sequencing.uio.no), a national technology platform hosted by the University of Oslo and supported by the "Functional Genomics" and "Infrastructure" programs of the Research Council of Norway and the Southeastern Regional Health Authorities. We wish to thank Prof Duncan Colquhoun (Norwegian Veterinary Institute) and Prof Mikael Skurnik (University of Helsinki) for providing Y. ruckeri strains. We also wish to thank Prof Henning Sørum (Norwegian University of Life Sciences) for his assistance with $Y$. ruckeri isolates.

\section{Appendix A. Supplementary data}

Supplementary data associated with this article can be found, in the online version, at http://dx.doi.org/10.1016/j.jsb.2017.08.008. 


\section{References}

Aziz, R.K., Bartels, D., Best, A.A., DeJongh, M., Disz, T., Edwards, R.A., Formsma, K., Gerdes, S., Glass, E.M., Kubal, M., Meyer, F., Olsen, G.J., Olson, R., Osterman, A.L., Overbeek, R.A., McNeil, L.K., Paarmann, D., Paczian, T., Parrello, B., Pusch, G.D., Reich, C., Stevens, R., Vassieva, O., Vonstein, V., Wilke, A., Zagnitko, O., 2008. The RAST Server: rapid annotations using subsystems technology. BMC Genomics 9, 75 http://dx.doi.org/10.1186/1471-2164-9-75

Bastardo, A., Ravelo, C., Romalde, J.L., 2012. Multilocus sequence typing reveals high genetic diversity and epidemic population structure for the fish pathogen Yersinia ruckeri. Environ Microbiol. 14, 1888-1897. http://dx.doi.org/10.1111/j.1462-2920. 2012.02735.x.

Benson, G., 1999. Tandem repeats finder: A program to analyze DNA sequences. Nucl. Acids Res. 27, 573-580. http://dx.doi.org/10.1093/nar/27.2.573.

Bernstein, H.D., 2014. NIH Public Access 4, 1-30. http://dx.doi.org/10.1128/ecosalplus. 4.3.6.Type.

Bertani, G., 1951. Studies on lysogenesis. I. The mode of phage liberation by lysogenic Escherichia coli. J. Bacteriol. 62, 293-300 doi:citeulike-article-id:149214.

Berven, F.S., Flikka, K., Jensen, H.B., Eidhammer, I., 2004. BOMP: a program to predict integral beta-barrel outer membrane proteins encoded within genomes of Gram-negative bacteria. Nucleic Acids Res. 32, W394-W399. http://dx.doi.org/10.1093/nar/ gkh351.

Blair, J.M.A., Richmond, G.E., Bailey, A.M., Ivens, A., Piddock, L.J.V., 2013. Choice of bacterial growth medium alters the transcriptome and phenotype of Salmonella enterica serovar typhimurium. PLoS One 8. http://dx.doi.org/10.1371/journal.pone. 0063912

Brudal, E., Winther-Larsen, H.C., Colquhoun, D.J., Duodu, S., 2013. Evaluation of reference genes for reverse transcription quantitative PCR analyses of fish-pathogenic Francisella strains exposed to different growth conditions. BMC Res. Notes 6, 76. http://dx.doi.org/10.1186/1756-0500-6-76.

Brzostek, K., Stencel, I., Hrebenda, J., 1999. Osmoregulation-dependent expression of Yersinia enterocolitica virulence factors. Acta Microbiol Pol 48, 31-37.

Bullock, G.L., 1984. Enteric Redmouth Disease of Salmonids. US Fish Wildl. Publ.

Busch, R.A., 1978. Enteric red mouth disease. Mar. Fish. Rev. 40, 42-51.

Chauhan, N., Wrobel, A., Skurnik, M., Leo, J.C., 2016. Yersinia adhesins: an arsenal for infection. Appl. Proteomics Clin. http://dx.doi.org/10.1002/prca.201600012.

Darling, A.E., Mau, B., Perna, N.T., 2010. Progressivemauve: Multiple genome alignment with gene gain, loss and rearrangement. PLoS One 5. http://dx.doi.org/10.1371/ journal.pone.0011147.

de Keukeleire, S., de Bel, A., Jansen, Y., Janssens, M., Wauters, G., Piérard, D., 2014. Yersinia ruckeri, an unusual microorganism isolated from a human wound infection. New Microbes New Infect. 2, 134-135. http://dx.doi.org/10.1002/nmi2.56.

Fairman, J.W., Dautin, N., Wojtowicz, D., Liu, W., Noinaj, N., Barnard, T.J., Udho, E., Przytycka, T.M., Cherezov, V., Buchanan, S.K., 2012. Crystal structures of the oute membrane domain of intimin and invasin from enterohemorrhagic $E$. coli and enteropathogenic Y. pseudotuberculosis. Structure 20, 1233-1243. http://dx.doi.org/10. 1016/j.str.2012.04.011

Fernandez, L., Fernandez, L., Lopez, J.R., Lopez, J.R., Secades, P., Secades, P., Menendez, A., Menendez, A., Marquez, I., Marquez, I., Guijarro, J.A., Guijarro, J.A., 2003. In vitro and in vivo studies of the Yrp1 protease from Yersinia ruckeri and its role in protective immunity against enteric red mouth disease of salmonids. Society 69 , 7328-7335. http://dx.doi.org/10.1128/AEM.69.12.7328.

Fernández, L., Prieto, M., Guijaro, J.A., 2007. The iron- and temperature-regulated haemolysin YhlA is a virulence factor of Yersinia ruckeri. Microbiology 153, 483-489. http://dx.doi.org/10.1099/mic.0.29284-0.

Furones, M.D., Rodgers, C.J., Munn, C.B., 1993. Yersinia ruckeri, the causal agent of enteric redmouth disease (ERM) in fish. Annu. Rev. Fish Dis. 3, 105-125. http://dx.doi org/10.1016/0959-8030(93)90031-6.

Gal-Mor, O., Gibson, D.L., Baluta, D., Vallance, B.A., Finlay, B.B., 2008. A novel secretion pathway of Salmonella enterica acts as an antivirulence modulator during salmonellosis. PLoS Pathog. 4. http://dx.doi.org/10.1371/journal.ppat.1000036.

Galant, J.E., Iii, R.O.Y.C., 1990. Expression of Salmonella typhimurium Genes Required for Invasion Is Regulated by Changes in DNA Supercoiling. Infect Immun. 58 1879-1885.

Garcia, J.A., Dominguez, L., Larsen, J.L., Pedersen, K., 1998. Ribotyping and plasmid profiling of Yersinia ruckeri. J. Appl. mMcrobiology 85, 949-955.

Guilvout, I., Quilici, M.L., Rabot, S., Lesel, R., Mazigh, D., 1988. BamHI restriction endonuclease analysis of Yersinia ruckeri plasmids and their relatedness to the genus Yersinia 42- to 47-megadalton plasmid. Appl. Environ. Microbiol. 54, 2594-2597.

Hamburger, Z.A., Brown, M.S., Isberg, R.R., Bjorkman, P.J., 1999. Integrin-Binding Protein Crystal Structure of Invasin: A Bacterial Crystal Structure of Invasin: A Bacterial Integrin-Binding Protein. Science 80. http://dx.doi.org/10.1126/science. 286.5438.291.

Heinz, E., Stubenrauch, C.J., Grinter, R., Croft, N.P., Purcell, A.W., Strugnell, R.A., Dougan, G., Lithgow, T., 2016. Conserved features in the structure, mechanism and biogenesis of the inverse autotransporter protein family. Genome Biol. Evol. 8, evw112. http://dx.doi.org/10.1093/gbe/evw112.

Henderson, I.R., Cappello, R., Nataro, J.P., 2000. Autotransporter proteins, evolution and redefining protein secretion: Response. Trends Microbiol. 8, 534-535. http://dx.doi. org/10.1016/S0966-842X(00)01884-9.

http://www.repeatmasker.org [WWW Document], n.d. URL http://www.repeatmasker. org.

Isberg, R.R., Leong, J.M., 1990. Multiple $\beta 1$ chain integrins are receptors for invasin, a protein that promotes bacterial penetration into mammalian cells. Cell 60, 861-871. http://dx.doi.org/10.1016/0092-8674(90)90099-Z.
Isberg, R.R., Swain, A., Falkow, S., 1988. Analysis of expression and thermoregulation of the Yersinia pseudotuberculosis inv gene with hybrid proteins. Infect. Immun. 56, 2133-2138.

Käll, L., Krogh, A., Sonnhammer, E.L.L., 2004. A combined transmembrane topology and signal peptide prediction method. J. Mol. Biol. 338, 1027-1036. http://dx.doi.org/ 10.1016/j.jmb.2004.03.016.

Kawula, T.H., Lelivelt, M.J., Orndorff, P.E., 1996. Using a new inbred fish model and cultured fish tissue cells to study Aeromonas hydrophila and Yersinia ruckeri pathogenesis. Microb. Pathog. 20, 119-125. http://dx.doi.org/10.1006/mpat.1996.0011.

Kearse, M., Moir, R., Wilson, A., Stones-Havas, S., Cheung, M., Sturrock, S., Buxton, S., Cooper, A., Markowitz, S., Duran, C., Thierer, T., Ashton, B., Meintjes, P., Drummond, A.A., Heled, J., 2012. Geneious. Bioinformatics. http://dx.doi.org/10.1093/ bioinformatics/bts199.

LeJeune, J.T., Rurangirwa, F.R., 2000. Polymerase chain reaction for definitive identification of Yersinia ruckeri. J. Vet. Diagn. Invest. 12, 558-561. http://dx.doi.org/10. $1177 / 104063870001200611$.

Leo, J.C., Grin, I., Linke, D., 2012. Type V secretion: mechanism(s) of autotransport through the bacterial outer membrane. Philos. Trans. R. Soc. Lond. B. Biol. Sci. 367, 1088-1101. http://dx.doi.org/10.1098/rstb.2011.0208.

Leo, J.C., Oberhettinger, P., Chaubey, M., Schütz, M., Kühner, D., Bertsche, U., Schwarz H., Götz, F., Autenrieth, I.B., Coles, M., Linke, D., 2015a. The Intimin periplasmic domain mediates dimerisation and binding to peptidoglycan. Mol. Microbiol. 95, 80-100. http://dx.doi.org/10.1111/mmi.12840.

Leo, J.C., Oberhettinger, P., Schütz, M., Linke, D., 2015b. The inverse autotransporter family: Intimin, invasin and related proteins. J. Med. Microbiol Int. http://dx.doi org/10.1016/j.ijmm.2014.12.011.

Litwin, C.M., Calderwood, S.B., 1993. Role of iron in regulation of virulence genes. Clin. Microbiol. Rev. 6, 137-149. http://dx.doi.org/10.1128/CMR.6.2.137.Updated.

Mammeri, H., Poirel, L., Nazik, H., Nordmann, P., 2006. Cloning and functional characterization of the ambler class $\mathrm{C}$ beta-lactamase of Yersinia ruckeri. FEMS Microbiol. Lett. 257, 57-62. http://dx.doi.org/10.1111/j.1574-6968.2006.00148.x.

Marteyn, B., West, N.P., Browning, D.F., Cole, J.A., Shaw, J.G., Palm, F., Mounier, J., Prévost, M.-C., Sansonetti, P., Tang, C.M., 2010. Modulation of Shigella virulence in response to available oxygen in vivo. Nature $465,355-358$. http://dx.doi.org/10. 1038/nature08970.

Messenger, A.J., Barclay, R., 1983. Bacteria, iron and pathogenicity. Biochem. Educ. 11, 54-63. http://dx.doi.org/10.1016/0307-4412(83)90043-2.

Miller, V.L., Mekalanos, J.J., 1988. A novel suicide vector and its use in construction of insertion mutations: Osmoregulation of outer membrane proteins and virulence determinants in Vibrio cholerae requires toxR. J. Bacteriol. 170, 2575-2583.

Mittal, R., Sharma, S., Chhibber, S., Harjai, K., 2009. Effect of Osmolarity on Virulence of Uropathogenic Pseudomonas Aeruginosa. Am. J. Biomed. Sci. 1, 12-26. http://dx.doi. org/10.5099/aj090100012.

Mota, L.J., Journet, L., Sorg, I., Agrain, C., Cornelis, G.R., 2005. Bacterial injectisomes: needle length does matter. Science 307, 1278. http://dx.doi.org/10.1126/science. 1107679 .

Mouriño, M., Madrid, C., Balsalobre, C., Prenafeta, A., Muñoa, F., Blanco, J., Blanco, M., Blanco, J.E., Juarez, A., 1996. The Hha protein as a modulator of expression of virulence factors in Escherichia coli. Infect. Immun. 64, 2881-2884.

Nelson, M.C., Lapatra, S.E., Welch, T.J., 2015. Complete genome sequence of Yersinia ruckeri strain CSF007-82, etiologic agent of red mouth disease in salmonid fish Genome Announc. 3, 4-5. http://dx.doi.org/10.1128/genomeA.01491-14.Copyright.

Oberhettinger, P., Leo, J.C., Linke, D., Autenrieth, I.B., Schütz, M.S., 2015. The inverse autotransporter intimin exports its passenger domain via a hairpin intermediate. J. Biol. Chem. 290, 1837-1849. http://dx.doi.org/10.1074/jbc.M114.604769.

Oberhettinger, P., Schütz, M., Leo, J.C., Heinz, N., Berger, J., Autenrieth, I.B., Linke, D., 2012. Intimin and invasin export their c-terminus to the bacterial cell surface using an inverse mechanism compared to classical autotransport. PLoS One 7. http://dx. doi.org/10.1371/journal.pone.0047069.

Ohtani, M., Villumsen, K.R., Strøm, H.K., Raida, M.K., 2014. 3D visualization of the initia Yersinia ruckeri infection route in rainbow trout (Oncorhynchus mykiss) by optical projection tomography. PLoS One 9. http://dx.doi.org/10.1371/journal.pone. 0089672.

Pepe, J.C., Badger, J.L., Miller, V.L., 1994. Growth phase and low pH affect the therma regulation of the Yersinia enterocolitica inv gene. Mol. Microbiol. 11, 123-135. http:// dx.doi.org/10.1111/j.1365-2958.1994.tb00295.x.

Pisano, F., Kochut, A., Uliczka, F., Geyer, R., Stolz, T., Thiermann, T., Rohde, M., Dersch, P., 2012. In vivo-induced inva-like autotransporters Ifp and invc of Yersinia pseudotuberculosis promote interactions with intestinal epithelial cells and contribute to virulence. Infect. Immun. 80, 1050-1064. http://dx.doi.org/10.1128/IAI.05715-11.

Porter, M.E., Dorman, C.J., 1994. A role for H-NS in the thermo-osmotic regulation of virulence gene expression in Shigella flexneri. J. Bacteriol.

Price, A.L., Jones, N.C., Pevzner, P.A., 2005. De novo identification of repeat families in large genomes. Bioinformatics 21. http://dx.doi.org/10.1093/bioinformatics/ bti1018.

Quevillon, E., Silventoinen, V., Pillai, S., Harte, N., Mulder, N., Apweiler, R., Lopez, R., 2005. InterProScan: Protein domains identifier. Nucleic Acids Res. 33. http://dx.doi. org/10.1093/nar/gki442.

Quinlan, A.R., Hall, I.M., 2010. BEDTools: A flexible suite of utilities for comparing genomic features. Bioinformatics 26, 841-842. http://dx.doi.org/10.1093/ bioinformatics/btq033.

Rasmussen, S., Allentoft, M.E., Nielsen, K., Orlando, L., Sikora, M., Sjögren, K.G., Pedersen, A.G., Schubert, M., Van Dam, A., Kapel, C.M.O., Nielsen, H.B., Brunak, S., Avetisyan, P., Epimakhov, A., Khalyapin, M.V., Gnuni, A., Kriiska, A., Lasak, I., Metspalu, M., Moiseyev, V., Gromov, A., Pokutta, D., Saag, L., Varul, L., Yepiskoposyan, L., Sicheritz-Pontén, T., Foley, R.A., Lahr, M.M., Nielsen, R., 
Kristiansen, K., Willerslev, E., 2015. Early Divergent Strains of Yersinia pestis in Eurasia 5,000 Years Ago. Cell 163, 571-582. http://dx.doi.org/10.1016/j.cell.2015. 10.009 .

Ren, Y., Ren, Y., Zhou, Z., Guo, X., Li, Y., Feng, L., Wang, L., 2010. Complete genome sequence of Enterobacter cloacae subsp. cloacae type strain ATCC 13047. J. Bacteriol. 192, 2463-2464. http://dx.doi.org/10.1128/JB.00067-10.

Reuter, S., Connor, T.R., Barquist, L., Walker, D., Feltwell, T., Harris, S.R., Fookes, M., Hall, M.E., Petty, N.K., Fuchs, T.M., Corander, J., Dufour, M., Ringwood, T., Savin, C., Bouchier, C., Martin, L., Miettinen, M., Shubin, M., Riehm, J.M., Laukkanen-Ninios, R., Sihvonen, L.M., Siitonen, A., Skurnik, M., Falcão, J.P., Fukushima, H., Scholz, H.C., Prentice, M.B., Wren, B.W., Parkhill, J., Carniel, E., Achtman, M., McNally, A., Thomson, N.R., 2014. Parallel independent evolution of pathogenicity within the genus Yersinia. Proc. Natl. Acad. Sci. 111, 6768-6773. http://dx.doi.org/10.1073 pnas.1317161111.

Riess, T., Andersson, S.G.E., Lupas, A., Schaller, M., Schäfer, A., Kyme, P., Martin, J., Wälzlein, J.-H., Ehehalt, U., Lindroos, H., Schirle, M., Nordheim, A., Autenrieth, I.B. Kempf, V.A.J., 2004. Bartonella adhesin a mediates a proangiogenic host cell response. J. Exp. Med. 200, 1267-1278. http://dx.doi.org/10.1084/jem.20040500.

Riess, T., Raddatz, G., Linke, D., Schäfer, A., Kempf, V.A.J., 2007. Analysis of Bartonella adhesin A expression reveals differences between various $B$. henselae strains. Infect. Immun. 75, 35-43. http://dx.doi.org/10.1128/IAI.00963-06.

Rocha, D.J.P., Santos, C.S., Pacheco, L.G.C., 2015. Bacterial reference genes for gene expression studies by RT-qPCR: survey and analysis. Antonie Van Leeuwenhoek 108, 685-693. http://dx.doi.org/10.1007/s10482-015-0524-1.

Romalde, J.L., Magarinos, B., Barja, J.L., Toranzo, A.E., 1993. Antigenic and molecular characterization of Yersinia ruckeri proposal for a new intraspecies classification. Syst. Appl Microbiol. 16.

Romalde, J.L., Toranzo, A.E., 1993. Pathological activities of Yersinia ruckeri, the enteric redmouth (ERM) bacterium. FEMS Microbiol. Lett. 112, 291-299.

Ross, A.J., Rucker, R.R., Ewing, W.H., 1966. Description of a Bacterium Associated with Redmouth Disease of Rainbow Trout (Salmo gairdneri). Can. J. Microbiol. 12, 763-770. http://dx.doi.org/10.1139/m66-103.

Rucker, R., 1966. Redmouth disease of rainbow trout (Salmo gairdneri). Bull Off Int Epizoot. 825-830.

Sadana, P., Mönnich, M., Unverzagt, C., Scrima, A., 2017. Structure of the Y. pseudotuberculosis adhesin InvasinE. Protein Sci. http://dx.doi.org/10.1002/pro.3171.

Savin, C., Martin, L., Bouchier, C., Filali, S., Chenau, J.Ô., Zhou, Z., Becher, F., Fukushima, H., Thomson, N.R., Scholz, H.C., Carniel, E., 2014. The Yersinia pseudotuberculosis complex: Characterization and delineation of a new species, Yersinia wautersii. Int. J. Med. Microbiol. 304, 452-463. http://dx.doi.org/10.1016/j.ijmm. 2014.02.002.

Secades, P., Guijarro, J.A., 1999. Purification and Characterization of an Extracellular Protease from the Fish pathogen Yersinia ruckeri and effect of culture condition on production. Appl. Environ. Microbiol. 65, 3969-3975.
Shaowu, L., Di, W., Hongbai, L., Tongyan, L., 2013. Isolation of Yersinia ruckeri strain H01 from farm-raised Amur Sturgeon Acipenser schrencki in China. J. Aquat. Anim. Health 25, 9-14. http://dx.doi.org/10.1080/08997659.2012.728169.

Sievers, F., Wilm, A., Dineen, D., Gibson, T.J., Karplus, K., Li, W., Lopez, R., McWilliam, H., Remmert, M., Söding, J., Thompson, J.D., Higgins, D.G., 2011. Fast, scalable generation of high-quality protein multiple sequence alignments using Clustal Omega. Mol. Syst. Biol. 7, 539. http://dx.doi.org/10.1038/msb.2011.75.

Simonet, M., Falkow, S., 1992. Invasin expression in Yersinia pseudotuberculosis. Infect, Immun.

Söding, J., Biegert, A., Lupas, A.N., 2005. The HHpred interactive server for protein homology detection and structure prediction. Nucleic Acids Res. 33. http://dx.doi. org/10.1093/nar/gki408.

Stevenson, R.M.W., Daly, J.G., 1982. Biochemical AND serological characteristics of ontario isolates of Yersinia ruckeri. Can. J. Fish. Aquat. Sci. 39, 870-876. http://dx. doi.org/10.1139/f82-118.

Strong, P.C.R., Hinchliffe, S.J., Patrick, H., Atkinson, S., Champion, O.L., Wren, B.W., 2011. Identification and characterisation of a novel adhesin Ifp in Yersinia pseudotuberculosis. BMC Microbiol. 11, 85. http://dx.doi.org/10.1186/1471-2180-11-85.

Sun, Z., Harris, H.M.B., McCann, A., Guo, C., Argimón, S., Zhang, W., Yang, X., Jeffery, I.B., Cooney, J.C., Kagawa, T.F., Liu, W., Song, Y., Salvetti, E., Wrobel, A., Rasinkangas, P., Parkhill, J., Rea, M.C., O'Sullivan, O., Ritari, J., Douillard, F.P., Paul Ross, R., Yang, R., Briner, A.E., Felis, G.E., de Vos, W.M., Barrangou, R. Klaenhammer, T.R., Caufield, P.W., Cui, Y., Zhang, H., O’Toole, P.W., 2015. Expanding the biotechnology potential of lactobacilli through comparative genomic of 213 strains and associated genera. Nat. Commun. 6, 8322. http://dx.doi.org/10. 1038/ncomms9322.

Szabady, R.L., Peterson, J.H., Skillman, K.M., Bernstein, H.D., 2005. An unusual signal peptide facilitates late steps in the biogenesis of a bacterial autotransporter. Proc. Natl. Acad. Sci. U. S. A. 102, 221-226. http://dx.doi.org/10.1073/pnas.0406055102.

Thompson, J.D., Higgins, D.G., Gibson, T.J., 1994. CLUSTAL W: Improving the sensitivity of progressive multiple sequence alignment through sequence weighting, positionspecific gap penalties and weight matrix choice. Nucleic Acids Res. 22, 4673-4680. http://dx.doi.org/10.1093/nar/22.22.4673.

Trivier, D., Courcol, R.J., 1996. Iron depletion and virulence in Staphylococcus aureus. Lett, FEMS Microbiol doi:10.1016/0378-1097(96)00233-9.

Tsai, J.C., Yen, M.R., Castillo, R., Leyton, D.L., Henderson, I.R., Saier, M.H., 2010. The bacterial intimins and invasins: A large and novel family of secreted proteins. PLoS One 5. http://dx.doi.org/10.1371/journal.pone.0014403.

Wasteson, U., Hvaal, A.B., Sørum, H., Myhr, E.FK., 1989. Antibacterial Spectrum and some other Characteristics of an Antimicrobial Factor produced by Yersinia ruckeri. Acta vet. scand. 30, 253-257.

Willumsen, B., 1989. Birds and wild fish as potential vectors of Yersinia ruckeri. J. Fish Dis. 12, 275-277. http://dx.doi.org/10.1111/j.1365-2761.1989.tb00313.x. 


\section{Supplementary Figures}

Figure S1. Non-optimized PCR reaction of a full-length yrIlm in Y. ruckeri ATCC29473. Note the ladder effect on the agarose gel. This suggests that the gene contains many repeated elements that can run in a ladder-like fashion. $10 \mathrm{ul}$ sample was loaded on a $0.8 \%$ agarose gel. The reaction was run for $40 \mathrm{~min}$ at $70 \mathrm{~V}$.

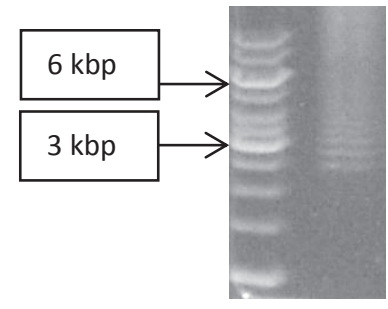


Figure S2. Circular representation of the main features of the chromosomal genomes of the Y. ruckeri strains used in the comparative analysis. In each circular plot, a different $Y$. ruckeri strain is used as the reference, namely NVH_3758, Big Creek 74, CSF007-82. From the inner ring, each track is represented as given in the legend. The outer track represents pathogenicity features related to flagella (yellow), secretion systems (red), pili and fimbriae (green), and virulence factors (olive green). 


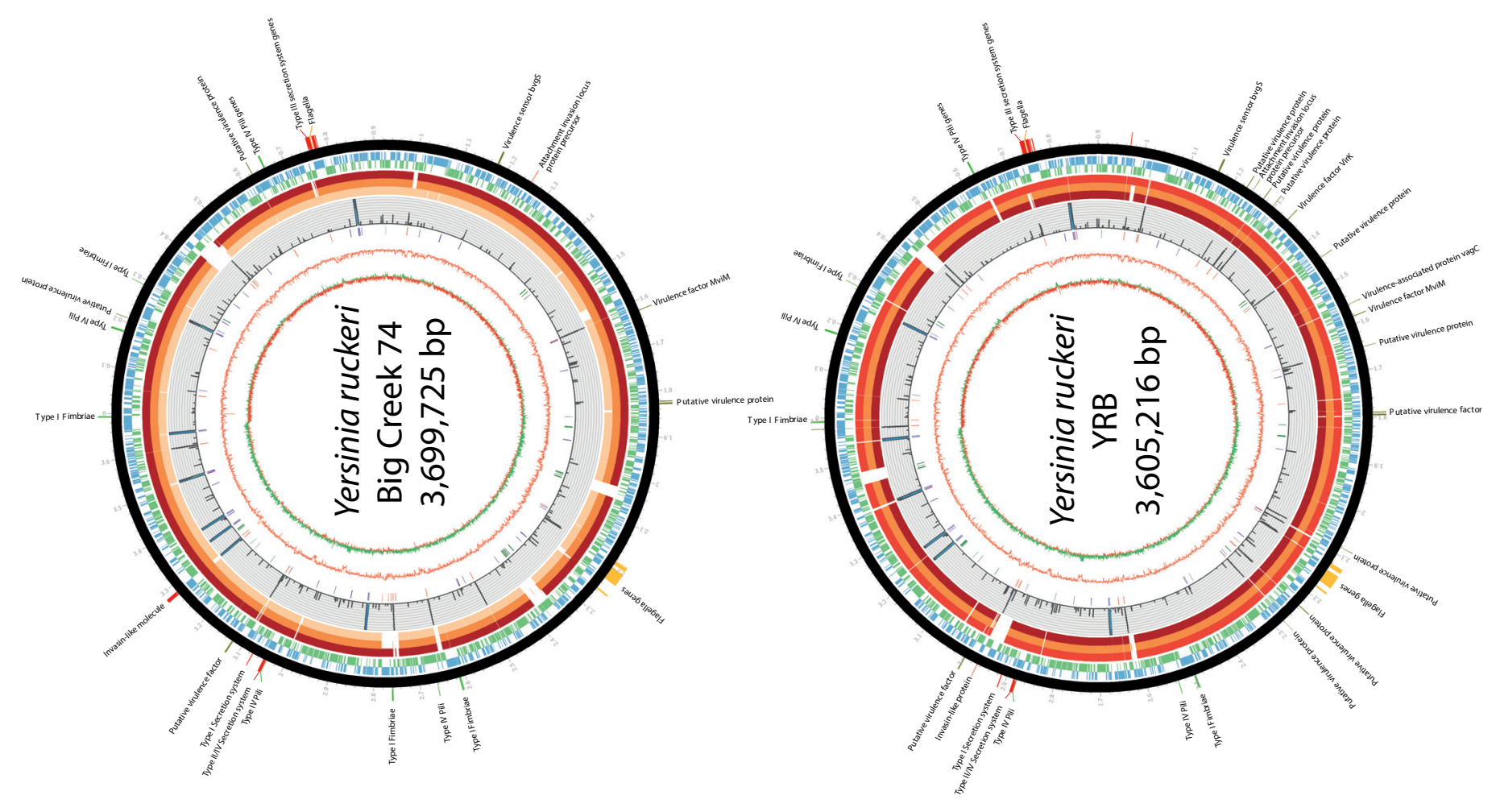

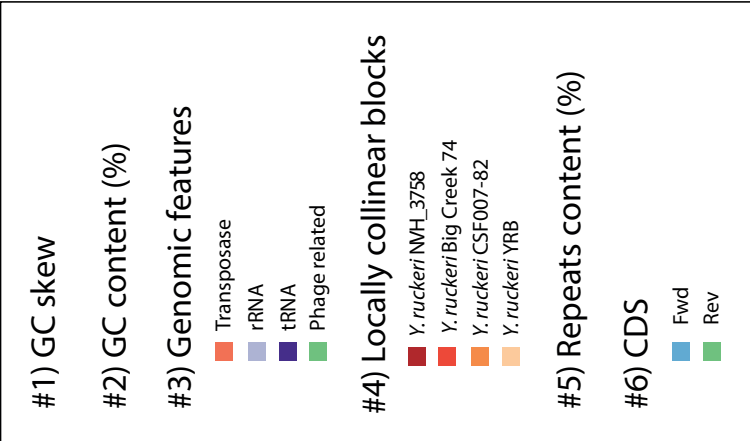

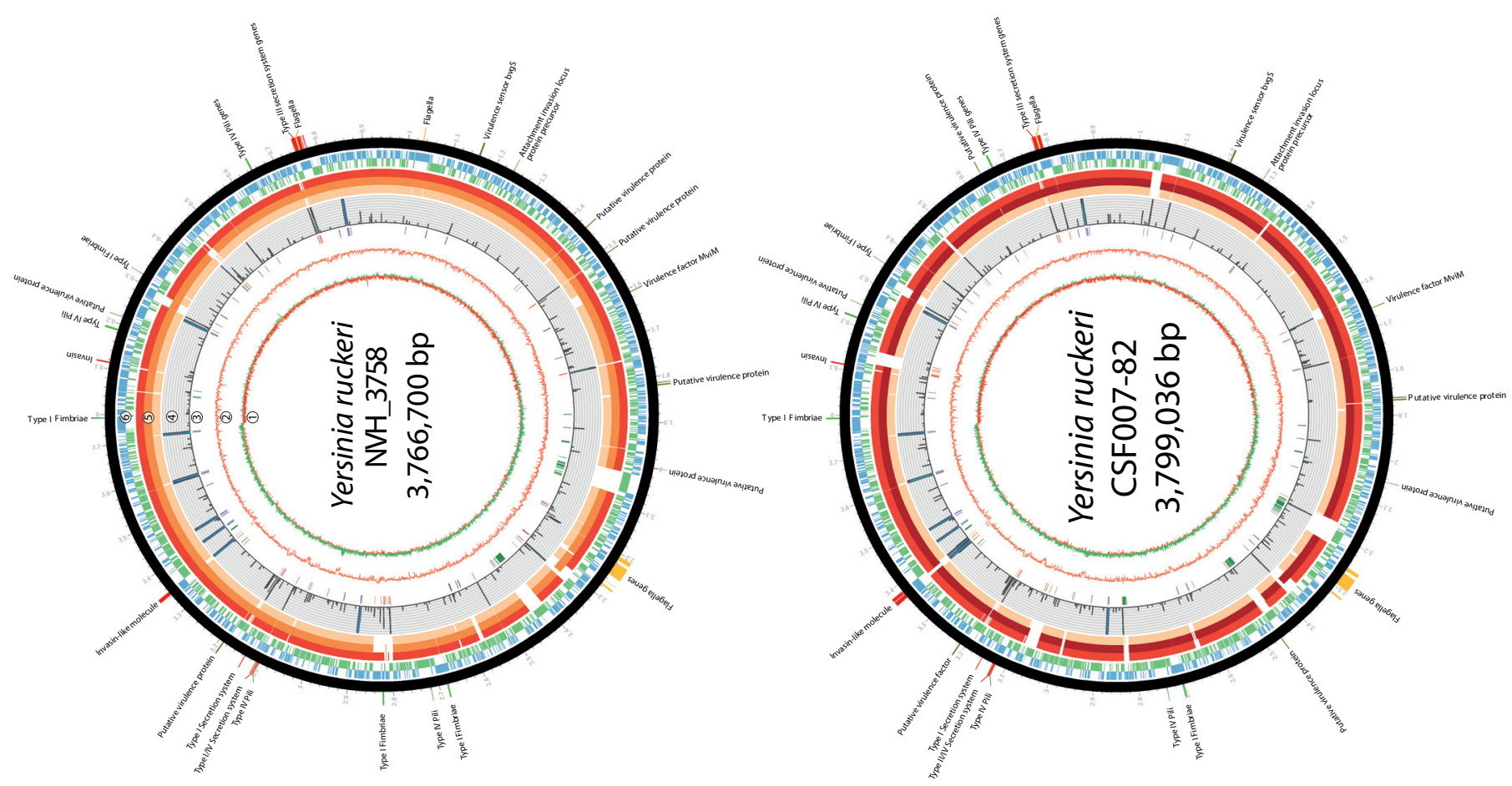


Figure S3. Circular representation of the main features of the chromosomal genomes of the Yersiniae spp. strains used in the comparative analysis. In each circular plot, a different Yersinia pathogenic species is used as reference, namely $Y$. ruckeri NVH_3758, $Y$. enterocolitica 8081, $Y$. pseudotuberculosis ATCC6904, Y. pestis CO92. From the inner ring, each track is represented as given in the legend. The outer track represents pathogenicity features related to flagella (yellow), secretion systems (red), pili and fimbriae (green), and virulence factors (olive green). 

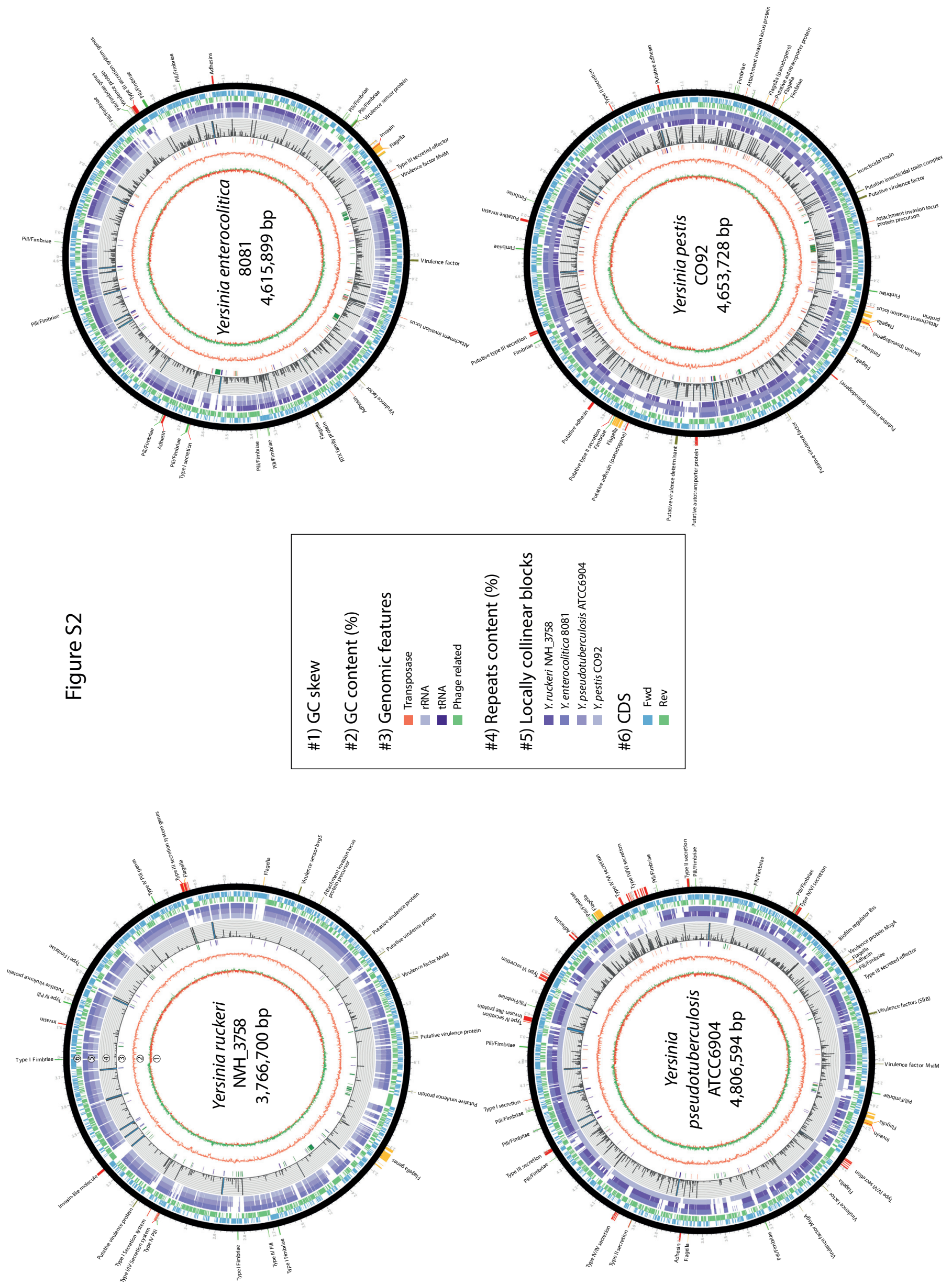
Figure S4. Sequence alignment of the 2 Ig-like domains of Yrllm from Y. ruckeri NVH_3758. The alignment has been generated with Clustal Omega (Thompson et al., 1994). Secondary structure prediction for Ig-like domains was performed with Ali2D and the alignment was further manually edited (Biegert et al., 2006). Secondary structure elements are represented by blue arrows ( $\beta$-strands) located above the alignment. The Ig-like domains are labelled as Ig0 to Ig19 Conserved amino acids are depicted in red. The numbers indicated in the figure show the amino acids positions in the protein sequence. Note that 19 out of the 20 domains are practically identical ( $>90 \%$ up to $100 \%$ ). 


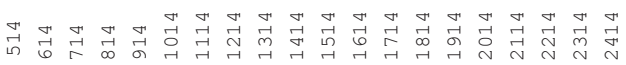

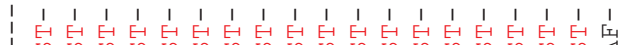

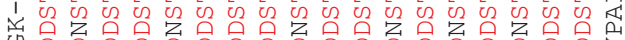

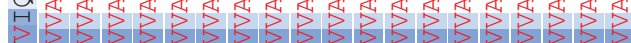

2

空

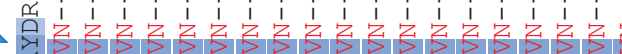

1.

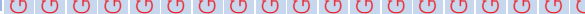

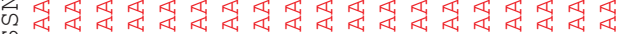
舁

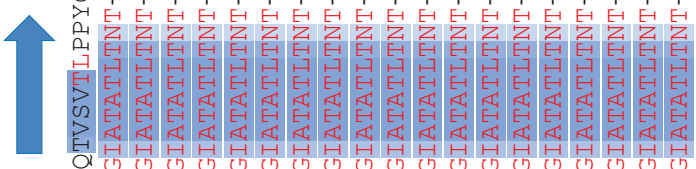

(1)

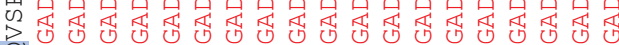
D

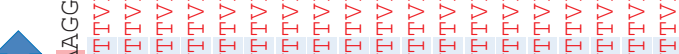

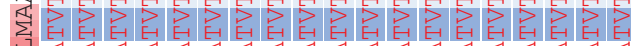

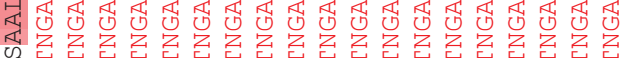

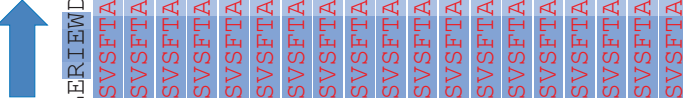

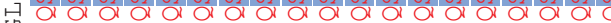

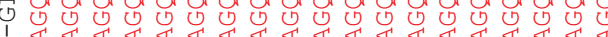

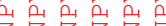

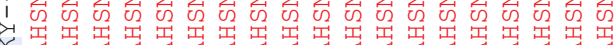

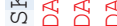

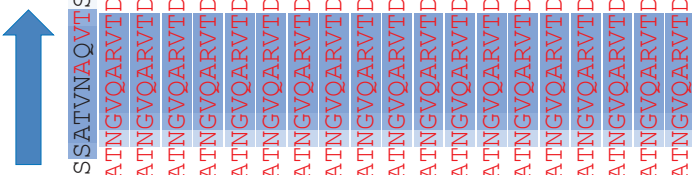

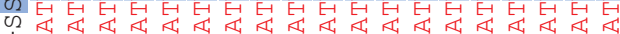

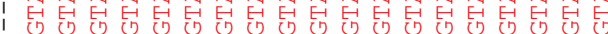

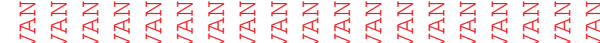

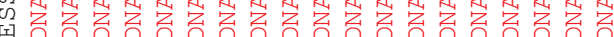

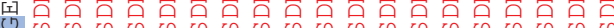

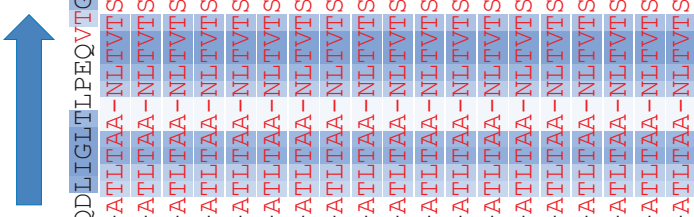

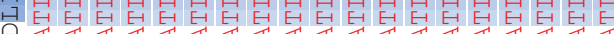

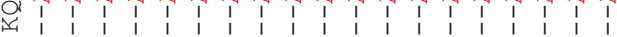

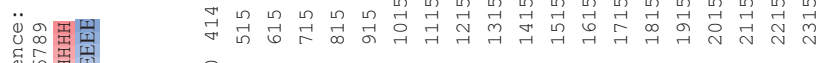

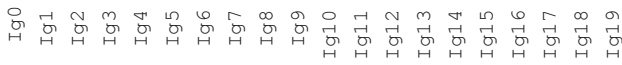


Figure S5. Domain prediction of YrInv. YrInv is composed of N-terminal signal sequence (shown in blue), LysM (shown in brown), a transmembrane region (shown in red) and an extracellular region. The extracellular region is shown in different colors. Ig-like domains are highly divergent in sequence, here depicted in grey (D0), in blue (D1) and in green (D2).The size of Ig-like domains varies from 70 amino acids to 114 amino acids. The extracellular domain is capped by a C-type lectin like domain, depicted in yellow (D3).

MNENIIRSFFKTNHRTSLFFSAKNKLQRQYFCLAIFLFQALFLISPSFSSELASTQKERKADKTHMVTKSYVLGEGETVSSVAKKLGLTLAQLE

QINQFRTFPQGFEQVSSGEEIDIPVPI IAEQGATKVSVVTPNEVNCPVGIENNPQTKEYVKRVSALLASSDPTTVATDVVRSEVSSTANKEIQK WLGQYGTAQVRLNVDDKFSLRESSLDWLFSFYDSSSAI IFTQLGIRNKDHRNTANLGLGGRISMGNWILGANTFYDNDLTGINSRLGFGAEAWT DYLQLSANSYMRLNNWHQSRDFIDHDERPANGFDIRTNAWLPVLPQLGGKLMYEQYSGDSVALFGKDKLQKNPYAVTAGITYTPFPLLTFGIDE RRGKAGKSDTQFNIQLSYHLGESWLSLTDPSAVAGTRQLAEARYNLVDRNNNIVLEYQKODILNITSTEQLRGYSGDNGI ILTKIVSKHNVERV EWINISALLAAGGNSVELPGRKLAITYPPYQIDGNNTYHVDVVAYDSRGNRSNISTTAITVLQKENTPSTVNAVISELITVTNNAWANGVATNS VKATVTDEQGSRLIDQVVNFSADNDAIISATGTTDSNGEVLITLTNNTVGEAIVTASINNTELTTPTIFLPIDIITGINVNNYRFAANEGFPST GFVGAYFOFEINTTTTLNSNYNWTSSOPDWVAVDNNGSVKFLAEPSNKSPVTITATSKSGNGVELSYTFTIDNWFIHNDSNYMTGSAADKWCAS 
Figure S6. Sequence alignment of YrIlm from various Y. ruckeri strains sequenced with different methods, including NVH_3758_PacBio (this study), ATCC29473_Ilumina (Gen Bank: KGA43736.1), Big Creek 74_PacBio (Gen Bank: WP_052690332.1), CSF007-82_copy Yrllm1_PacBio (Gen Bank: CEK29001.1), CFS007-82_copy YrIlm2_PacBio (Gen Bank: CEK29003.1), CFs007-82_Ilumina (Ilm was reconstructed from scaffolds NZ_CCYO01000050, NZ_CCYO01000048) and 150_Ilumina (Ilm was reconstructed from scaffold NZ_MKFJ01000023). Alignments were generated with Clustal Omega (Thompson et al., 1994), and shaded with BoxShade (http://sourceforge.net/projects/boxshade). Ig-like domains are depicted in colors (in yellow (D0) 101 amino acids; in green and in blue (D1-D22) almost identical in amino acid sequence, composed of 100 amino acids, in orange- C-type-lectin domain - 189 amino acids ).

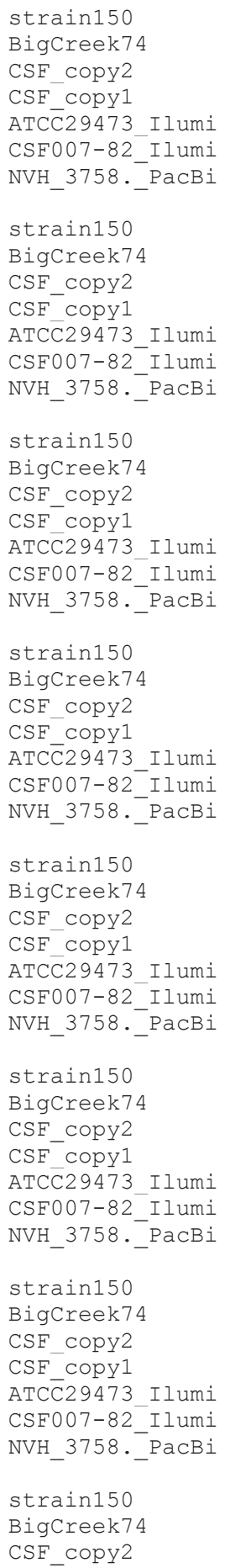

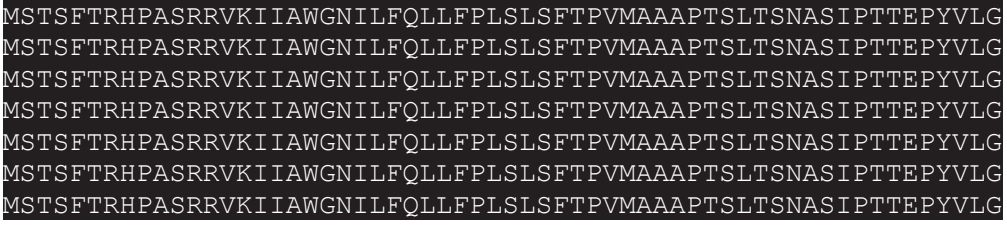
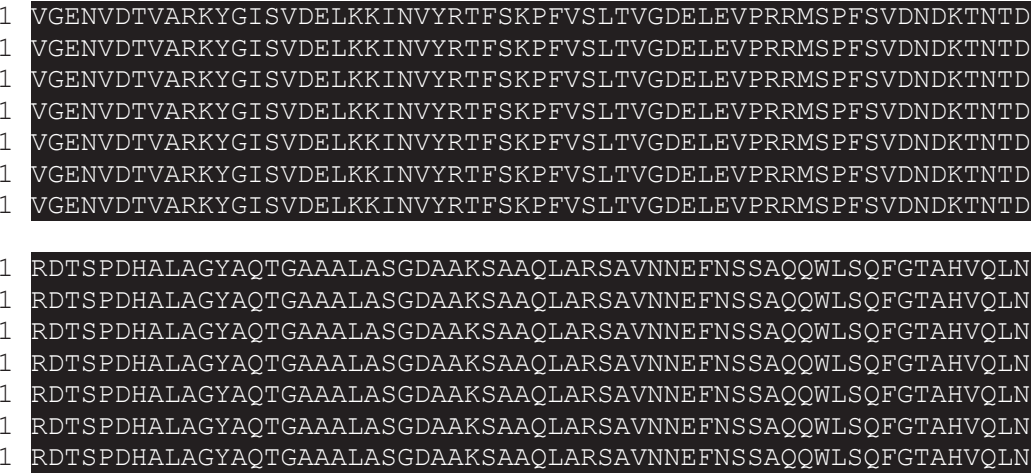

181
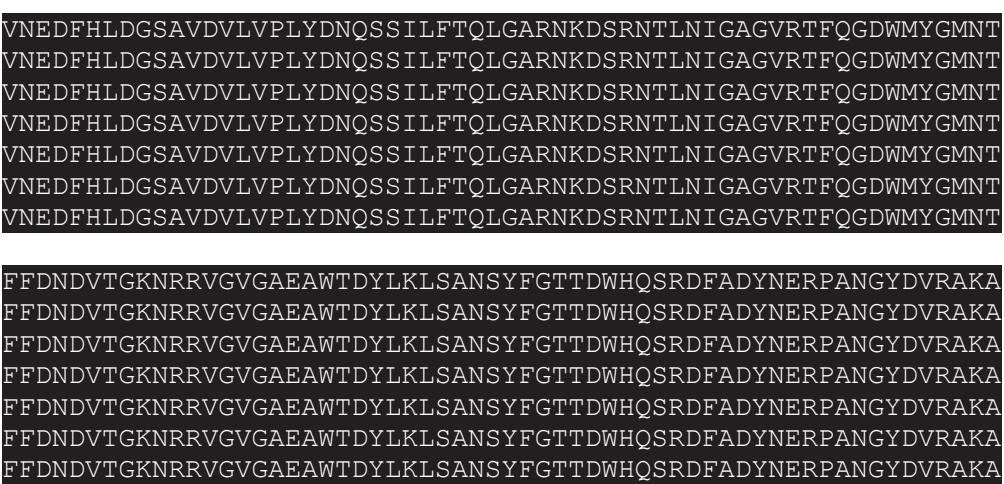

YLPAYPQLGGKLMYEQYQGDEVALFGKDDRQKNPHVITAGINYTPVPLFTVGAEHRAGNG YLPAYPQLGGKLMYEQYQGDEVALFGKDDRQKNPHVITAGINYTPVPLFTVGAEHRAGNG YLPAYPQLGGKLMYEQYQGDEVALFGKDDRQKNPHVITAGINYTPVPLFTVGAEHRAGNG YLPAYPQLGGKLMYEQYQGDEVALFGKDDRQKNPHVITAGINYTPVPLFTVGAEHRAGNG YLPAYPQLGGKLMYEQYQGDEVALFGKDDRQKNPHVITAGINYTPVPLFTVGAEHRAGNG YLPAYPQLGGKLMYEQYQGDEVALFGKDDRQKNPHVITAGINYTPVPLFTVGAEHRAGNG YLPAYPQLGGKLMYEQYQGDEVALFGKDDRQKNPHVITAGINYTPVPLFTVGAEHRAGNG

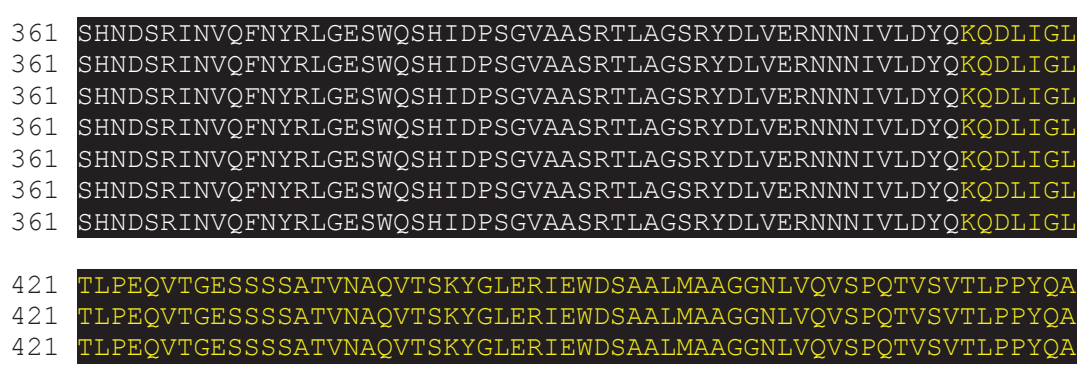


CSF copy 1

ATCC 29473 Ilumi CSF007-82_Ilumi NVH 3758. PacBi strāin150

BigCreek 74

CSF_copy2

CSF Copy 1

ATCC29473 Ilumi

CSF007-82 Ilumi

NVH 3758. $\mathrm{PaCBi}$

strain 150

BigCreek74

CSF_copy2

CSF Copy 1

ATCC29473 Ilumi

CSF007-82 Ilumi

NVH_3758._PaCBi

strain150

BigCreek74

CSF_copy2

CSF ${ }^{-}$copy 1

ATCC29473 Ilumi

CSF007-82 Ilumi

NVH 3758.-PacBi

strain 150

BigCreek74

CSF copy2

CSF ${ }^{-}$copy 1

ATCC29473 Ilumi

CSF007-82 Ilumi

NVH_3758._PaCBi

strain 150

BigCreek74

CSF_copy2

CSF ${ }^{-}$Copy 1

ATCC29473 Ilumi

CSF007-82 Ilumi

NVH 3758._PaCBi

strain 150

BigCreek74

CSF copy2

CSF Copy 1

ATCC29473 Ilumi

CSF007-82 Ilumi

NVH_3758._PacBi

strain 150

BigCreek74

CSF_copy2

CSF Copy 1

ATCC29473 Ilumi

CSF007-82-Ilumi

NVH 3758. $\mathrm{PaCBi}$

strain150

BigCreek74

CSF_copy2

CSF Copy 1

ATCC29473 Ilumi

CSF007-82_Ilumi

NVH 3758. PacBi
TLPEQVTGESSSSATVNAOVTSKYGLERIEWDSAALMAAGGNLVOVSPOTVSVTLPPYOA

TLPEQVTGESSSSATVNAQVTSKYGLERIEWDSAALMAAGGNLVQVSPQTVSVTLPPYQI

TLPEQVTGESSSSATVNAQVTSKYGLERIEWDSAALMAAGGNLVQVSPQTVSVTLPPYQA

TLPEQVTGESSSSATVNAQVTSKYGLERIEWDSAALMAAGGNLVQVSPQTVSVTLPPYQA

TRSSNTHTLSAVAYDRQGNASXXXX-----------------------------------

TRSSNTHTLSAVAYDRQGNASPRATMQIVVIQGKATLTAANLTVTS DNAVANGTATNGV
TRSSNTHTLSAVAYDRQGNASPRATMQIVVIQGKATLTAANLTVTSDNAVANGTATNGV

TRSSNTHTLSAVAY DRQGNAS PRATMQIVVIQGKATLTAANLTVIS DNAVANG IATNG
TRSSNTHTLSAVAYDRQGNASPRATMQIVVIQGKATLTAANLTVTS DNAVANGTATNGV

TRSSNTHTLSAVAYDRQGNASPRATMQIVVIQGKATLTAANLTVTSDNAVANGTATNG

TRSSNTHTLSAVAYDRQGNASPRATMQIVVIQGKATLTAANLTVTS DNAVANGTATNGV
TRSSNTHTLSAVAYDROGNASPRATMOIVVIOGKATLTAANLTVTS DNAVANGTATNGV
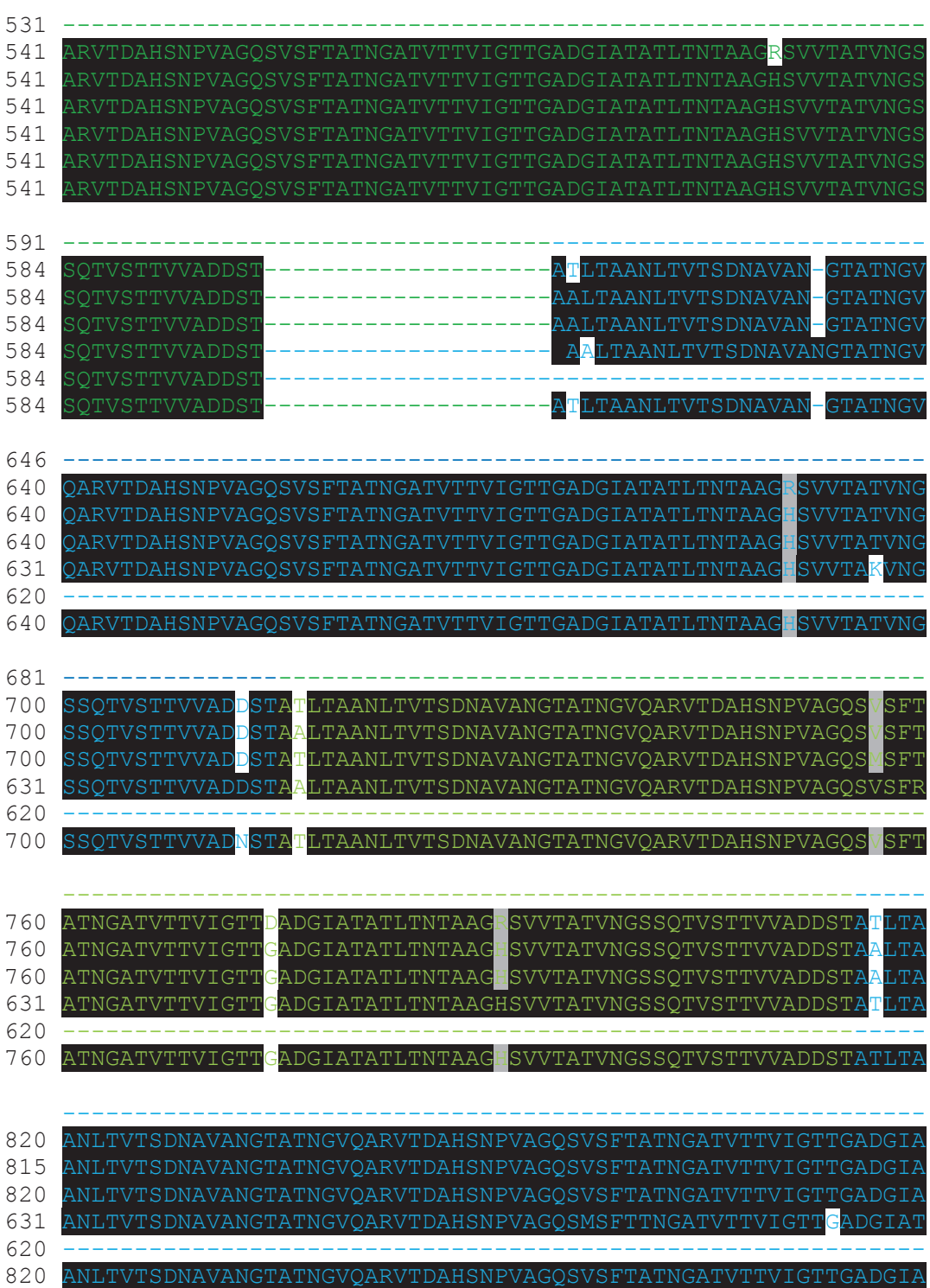

820 ANLTVTSDNAVANGTATNGVQARVTDAHSNPVAGQSVSFTATNGATVTTVIGTTGADGIA

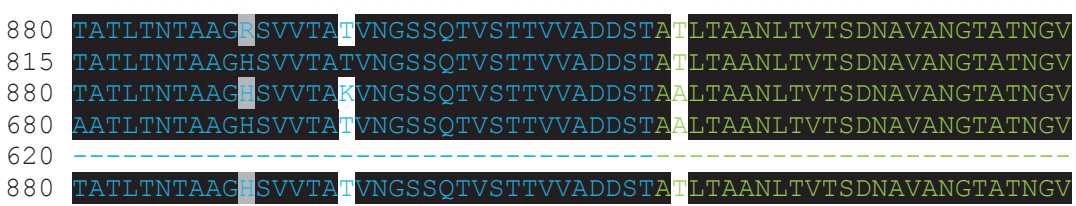


strain150

BigCreek74

CSF copy2

CSF Copy 1

ATC 29473 Ilumi

CSF007-82 Ilumi

NVH_3758._PacBi

strain150

BigCreek74

CSF copy2

CSF Copy1

ATCC̄29473_Ilumi

CSF007-82 Ilum

NVH 3758 . $\mathrm{PaCB}$

strain150

BigCreek74

CSF_copy2

CSF copy 1

ATCC 29473 Ilumi

CSF007-82 Ilum

NVH 3758. PacBi

strain150

BigCreek74

CSF copy2

CSF copy1

ATCC̄ 29473_Ilumi

CSF007-82 Ilumi

NVH_3758. ${ }^{-} \mathrm{PacB}$

strain150

BigCreek74

CSF_copy2

CSF copy

ATCC̄ 29473 Ilumi

CSF007-82 Ilumi

strain150

BigCreek74

CSF_copy2

CSF Copy

ATCC̄ 29473_Ilumi

CSF007-82 Ilumi

NVH_3758._PacB

strain150

BigCreek74

CSF_copy2

CSF COPy 1

ATC $\bar{C} 29473$ Ilumi

CSF007-82 Ilumi

NVH_3758. - PacB

strain150

BigCreek74

CSF Copy2

$\mathrm{CSF}^{-} \mathrm{COPy}$

ATCC̄29473 Ilumi

CSF007-82 Ilumi

NVH 3758. $-\mathrm{PaCB}$

strain150

BigCreek74

CSF copy2

$\mathrm{CSF}^{-} \mathrm{COPy}$

ATCC̄ 29473 Ilumi

CSF007-82 Ilumi

NVH 3758. $\mathrm{PaCBi}$

\section{QARVTDAHSNPVAGQSVSE
OARVTDAHSNPVAGOS SH \\ QARVTDAHSNPVAGQSVS H}

ATNGATVTTVIGTTGADGIATATLTNTAAGHSVVTA TVN QARVTDAHSNPVAGQSVSFTATNGATVTTVI GTIGADGIATATLTNTAAG HSVTATVNG

QARVTDAHSNPVAGQSVSE ATNGATVTTVIGTTGADGIATATLTNTAAGHSVVTATVNG

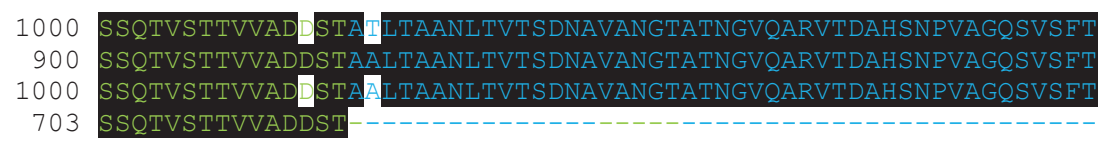

SSQTVSTTVVAD STAA LTAANLTVTSDNAVANGTATNGVQARVTDAHSNPVAGQS SETI

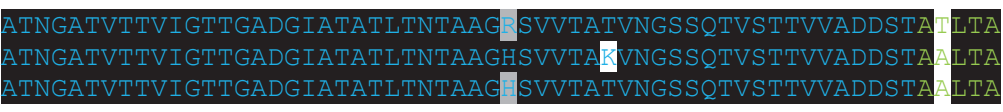

ATNGATVTTVIGTTGADGIATATLTNTAAG SVVTATVNGSSQTVSTTVVADDSTAILTA

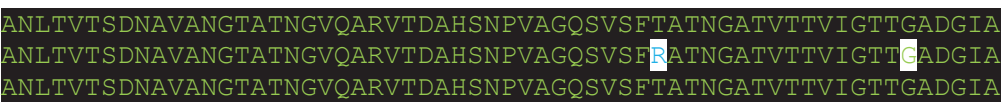

ANLTVTSDNAVANGTATNGVQARVTDAHSNPVAGQSVSFTATNGATVTTVIGTTGADGIA

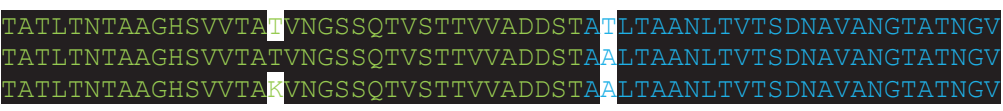

TATLTNTAAGHSVVTA VNGSSQTVSTTVVADDSTATLTAANLTVTSDNAVANGTATNGV

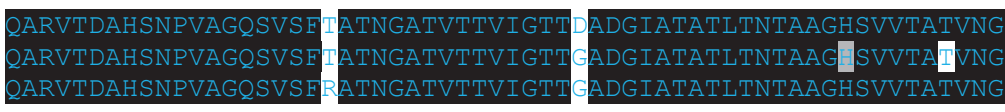

QARVTDAHSNPVAGQSVSHTATNGATVTTVIGTTGADGIATATLTNTAAGHSVVTATVNG

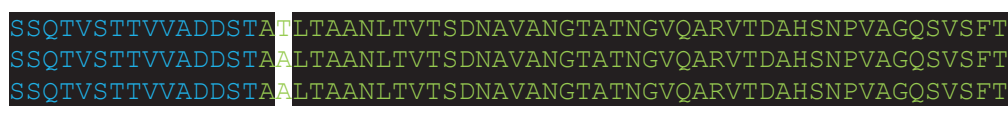

SSQTVSTTVVADDSTA LTAANLTVTSDNAVANGTATNGVQARVTDAHSNPVAGQSVSFT

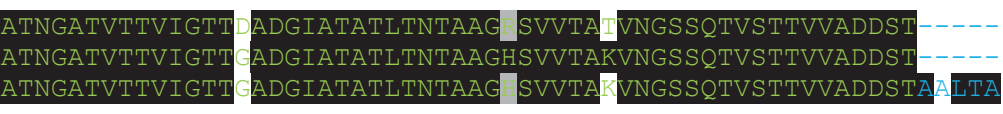

ATNGATVTTVIGTT ADGIATATLTNTAAG SVVTA VNGSSQTVSTTVVADNSTALTA

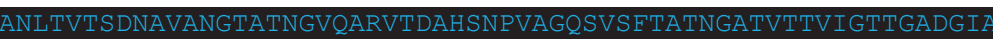

ANLTVTSDNAVANGTATNGVQARVTDAHSNPVAGQSVSFTATNGATVTTVIGTTGADGIA 
strain150

BigCreek74

CSF_copy2

CSF COpy 1

CSF007-82 Ilumi 620

NVH 3758. PacBi 1480

TATLTNTAAGHSVVTATVNGSSQTVSTTVVADDST

strain150

BigCreek74

CSF copy2

CSF_COPY1

strain150

BigCreek74

CSF copy2

$\mathrm{CSF}^{-} \mathrm{COpy} 1$

strain150

BigCreek74

CSF copy2

1397

CSF ${ }^{-}$COPY 1

1295

ATCC29473 Ilumi 860

CSF007-82 Ilumi 620

NVH 3758. PacBi 1480

TATLTNTAAGHSVVTAKVNGSSOTVSTIVVADDST

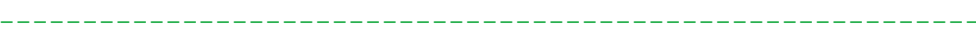
$-$ SSQTVSTTVVADDSTATLTAANLTVTSDNAVANGTATNGVQARVTDAHSNPVAGQSMSET 作

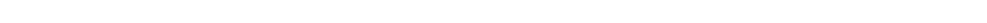

strain150

BigCreek74

CSF copy2

CSF_copy1

ATCC29473 Ilumi 907

CSF007-82 Ilumi 620

NVH 3758. PacBi 1520

strain150

BigCreek74

CSF COpy2

1480

$\mathrm{CSF}^{-} \mathrm{COPY} 1$

ATCC29473 Ilumi 907

CSF007-82 Ilumi 620

NVH_3758. PacBi 1580

strain150

BigCreek74

CSF COPY2

CSF ${ }^{-}$Copy 1

ATCC29473 Ilumi

1540

1340

Ilumi 907

CSF007-82_Ilumi 620

NVH_3758._PacBi 1640

DARVTDAHSNPVAGOSVSFTATNGATVTTVI GTTGADGIATATLTNTAAGHSVVTATVNG

strain150

BigCreek74

CSF Copy2

$\mathrm{CSF}^{-} \mathrm{COPY} 1$

ATCC29473 Ilumi

1572

1400

1900

CSF007-82 Ilumi 620

NVH 3758. PacBi 1700

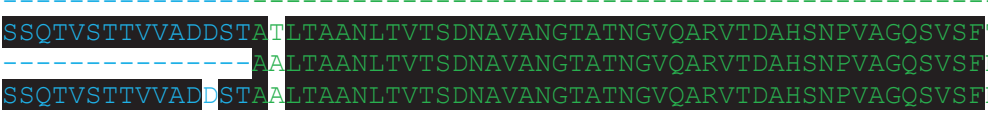

strain150

BigCreek74

CSF copy2

$\mathrm{CSF}^{-}$COPy 1

ATCC29473 Ilumi

1572

1460

1960

CSF007-82 Ilumi 620

NVH_3758._PacBi 1760

SSQTVSTTVVAD STA ILTAANETVTSDNAVANGTATNGVQARVTDAHSNPVAGQSVSA

strain150

BigCreek74

CSF_Copy2

1620

$\mathrm{CSF}^{-} \mathrm{COPY} 1$

1520

NLTVTS DNAVANGTATNGVQARVTDAHSNPVAGQ
ANLTVTSDNAVANGTATNGVQARVTDAHSNPVAGQ

ALTAANLTVTSDNAVANGTATNGV

LTAANLTVTSDNAVANGTATNGV

TATLTNTAAG HSVTATVNGSSQTVSTTVVADDSTAILTAANLTVTS DNAVANGTATNGV

ARVTDAHSNPVAGQSVSFTATNGATVTTVIGTTDADGIATATLTNTAAG SVVTA VNG ARVTDAHSNPVAGQSVSFTATNGATVTTVIGTTGADGIATATLTNTAAGHSVVTAKVNG

TNGATVTTVIGTTGADGIATATLTNTAAGHSVVTAKVNGSSQTVSTTVVADDSTATLTA
TNGATVTTVIGTTGADGIATATLTNTAAGHSVVTATVNGSSQTVSTTVVADDSTATLTA TNGATVTTVIGTTGADGIATATLTNTAAGHSVVTATVNGSSQTVSTTVVADDSTATLTA ATNGATVTTVIGTTGADGIATATLTNTAAGHSVVTATVNGSSQTVSTTVVADDSTATLTA
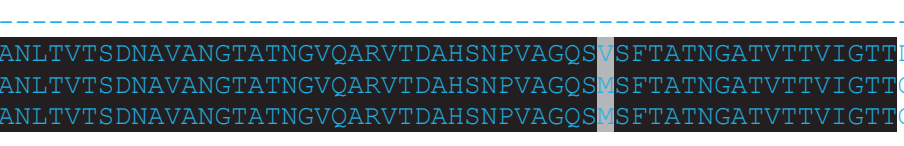

SFTATNGATVTTVIGT 
strain 150

BigCreek74

CSF copy2

CSF Copy 1
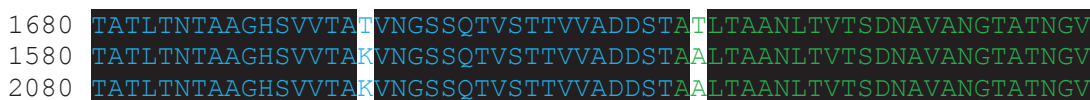

CSE 907

CSF007-82-Ilumi 620

NVH_3758._PaCBi 1880

[RATLTNTAAGHSVVTA UNGSSOTVSTTVVAD STIA LTAANLTVTSDNAVANGTATNGV

strain 150

BigCreek 74

CSF copy2

CSF_COPY1

Tlumi

CSF007-82-Ilumi 620

NVH_3758._PacBi 1940

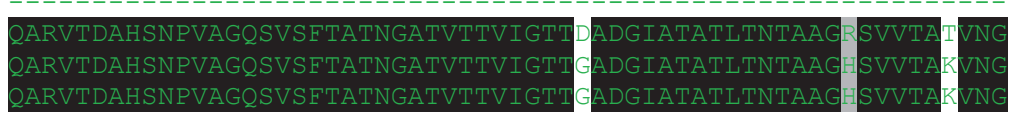

strain 150

BigCreek74

CSF copy2

$\mathrm{CSF}^{-}$Copy 1

ATCC29473 Ilumi

1800

1700

CSF007-82-Ilumi 620

NVH_3758._PacBi 2000

DARVTDAHSNPVAGQSVSFTATNGATVTTVIGTI MDDGIATATLINTAAG SVVTA IVNG

strain 150

BigCreek74

CSF copy2

CSF Copy 1

ATCC29473 Ilumi

1860
1760

1760
2260

CSF007-82-Ilumi 620

NVH_3758._PacBi 2060

strain 150

BigCreek74

CSF copy2

CSF_copy1

CSF007-82 Ilumi 620

NVH_3758._PacBi 2120
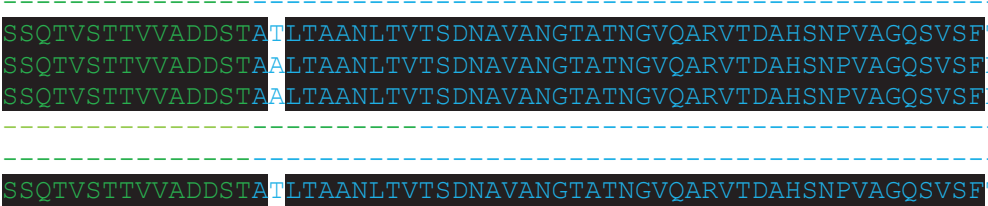

strain 150

BigCreek74

CSF copy2

CSF COpy 1

CSF007-82-Ilumi 620

NVH_3758._PacBi 2180

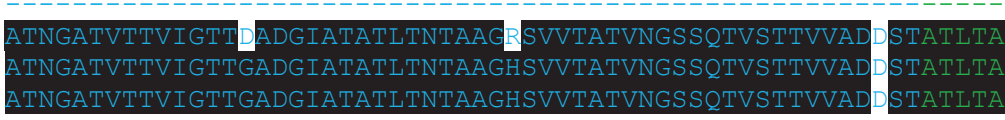

strain 150

BigCreek74

CSF_copy2

$\mathrm{CSF}^{-} \mathrm{Copy} 1$

ATCC29473 Ilumi

2040

1940

2440

CSF007-82 Ilumi 620

NVH_3758._PacBi 2240

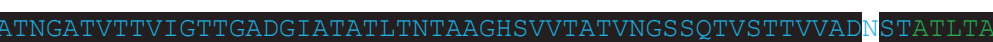

strain 150

BigCreek74

CSF copy2

CSF ${ }^{-}$Copy 1

CSF007-82 Ilumi 620

NVH 3758. PacBi 2300

strain 150

BigCreek74

CSF_copy2

CSF copy 1

2100

2000

2500

CSF007-82 Ilumi 660

NVH 3758. PacBi 2360

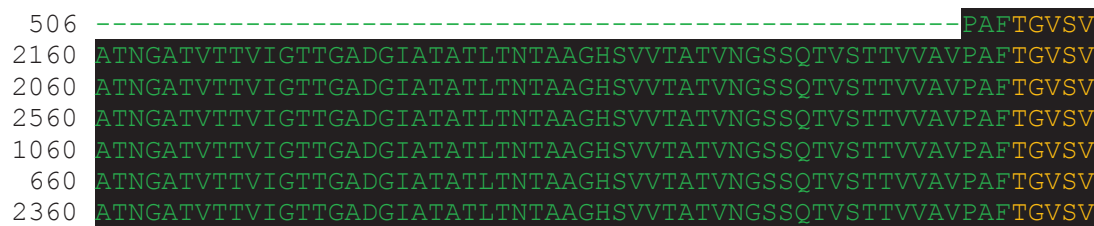




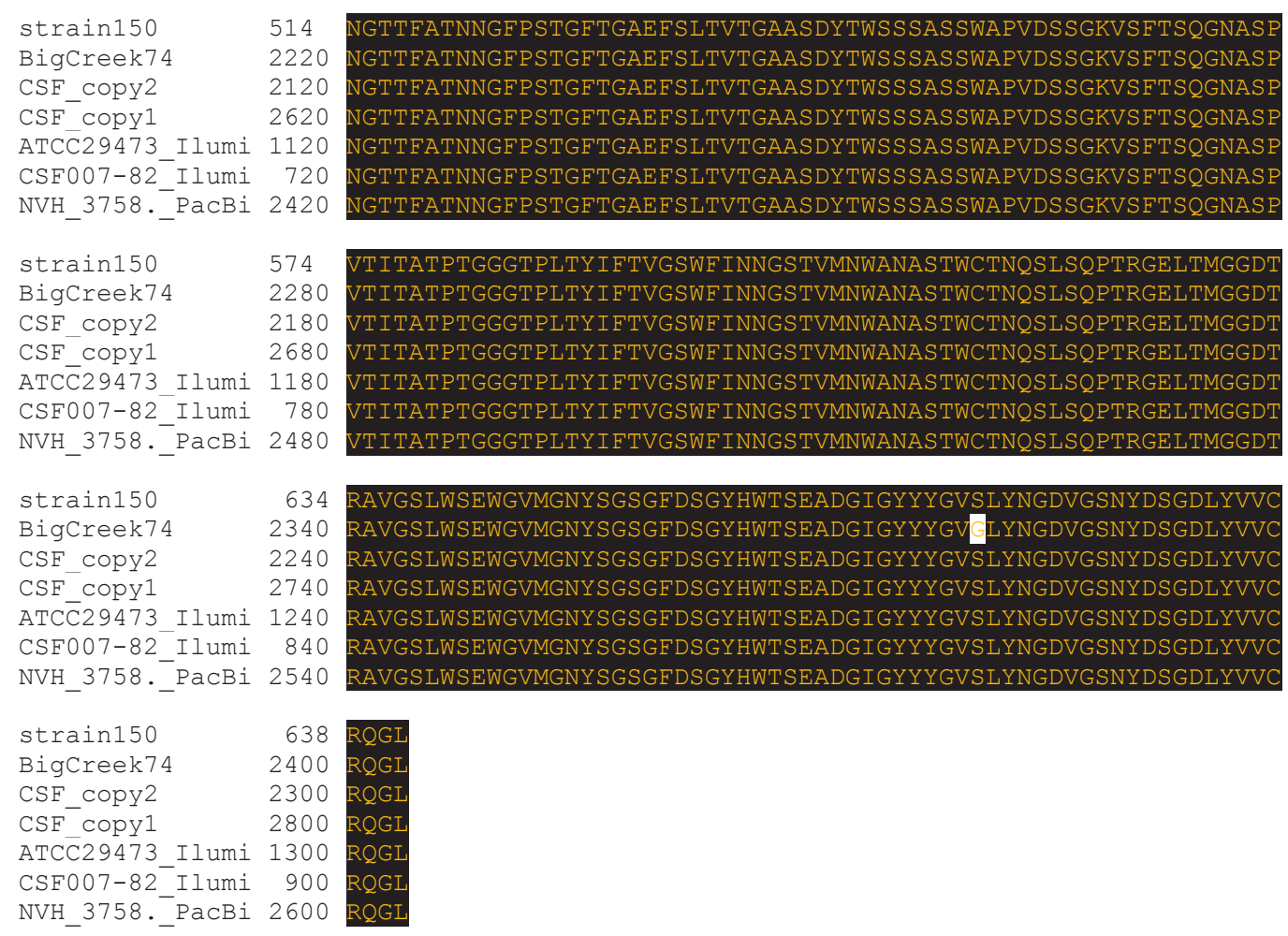

Figure S7. Sequence alignment and domain prediction of invasin from Edwardsiella piscicida C07087 (GenBank: WP_069579258.1) and YrInv. Invasin consists of an N-terminal signal peptide (shown in dark green), a transmembrane region shown in red, and an extracellular region. The extracellular region is composed of 3 Ig-like domains, each depicted in different color (in green, blue and grey). The passenger is capped by a C-type lectin domain depicted in orange. The sequence alignment was performed using Clustal Omega (Thompson et al., 1994), whereas shading of multiple-alignments was done with BoxShade (http://sourceforge.net/projects/boxshade/). The domain predictions were made using HHpred (Homology detection \& structure prediction by HMM-HMM comparison) at the Max Planck Institute for Developmental Biology toolkit server (Söding et al., 2005)

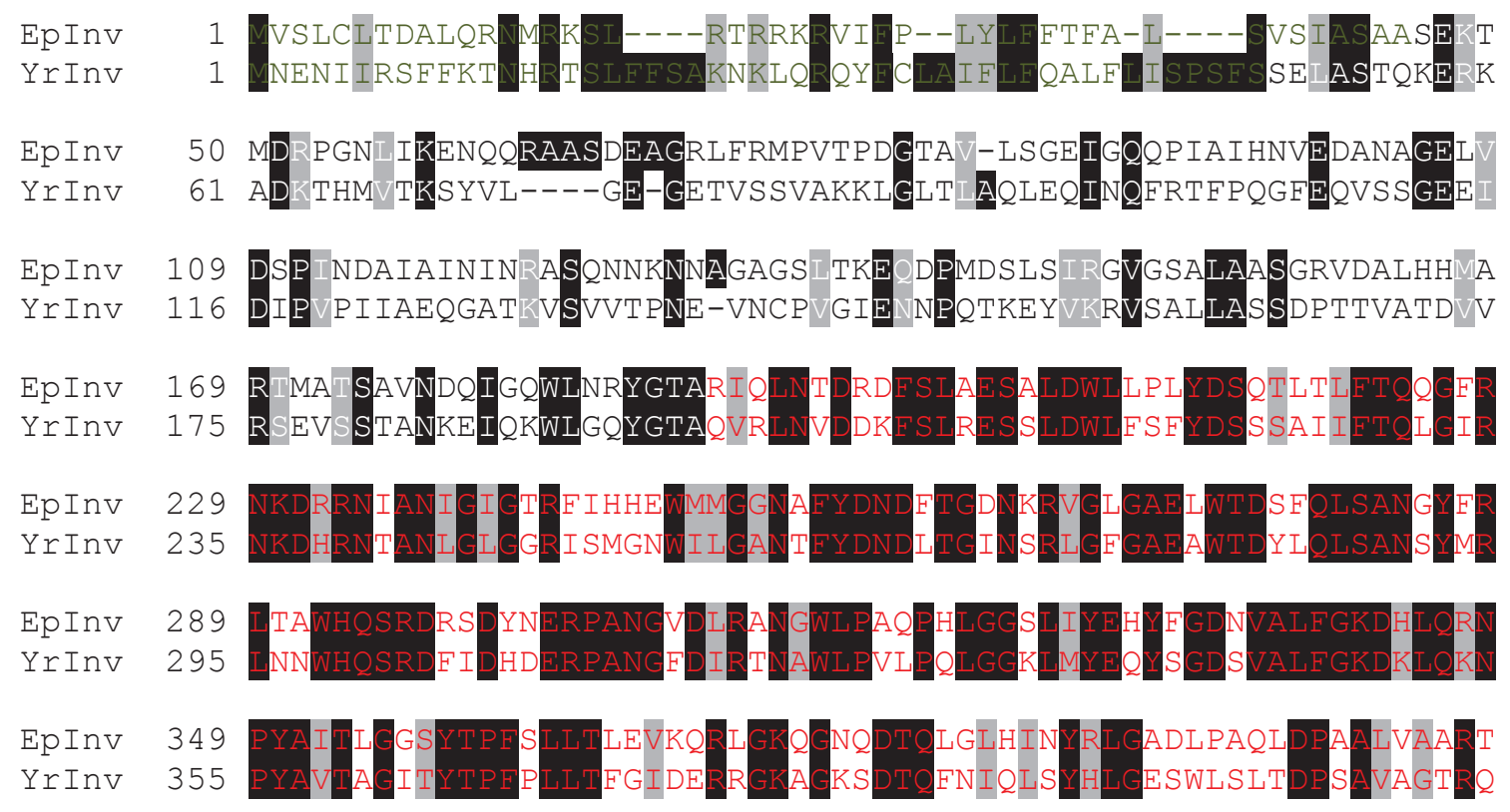




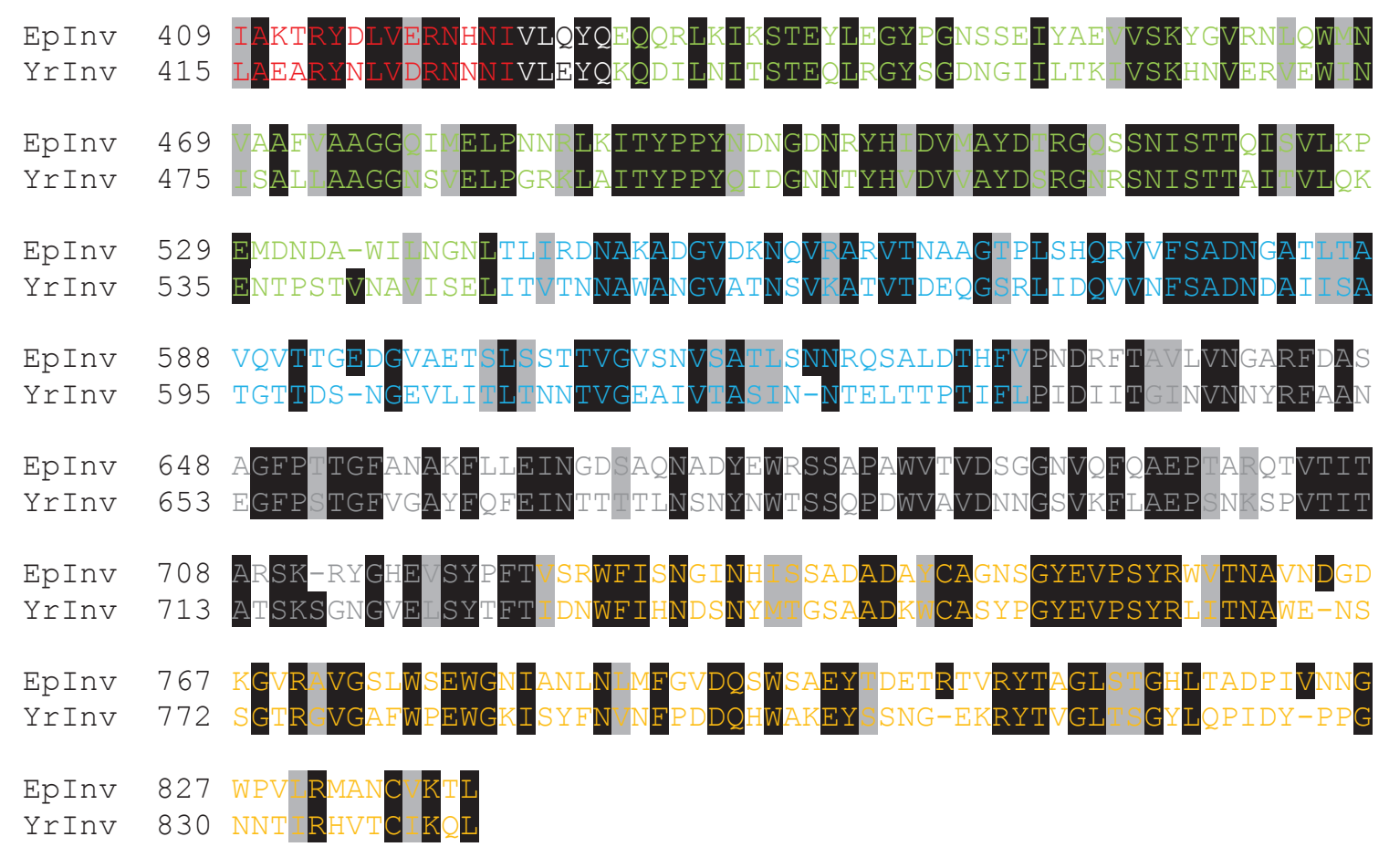


Figure S8. Sequence alignment and domain prediction of inverse autotransporter beta-barrel domaincontaining protein from Enterobacter cloacae (EcIlm) (Gen Bank: WP_023310354.1), and YrIlm. EcIlm consists of an N-terminal signal peptide (in blue), a transmembrane region (in red), and an extracellular region. The extracellular region is composed of 18 Ig-like domains. The D0 domain is depicted in brown, followed by D1-D17 depicted in purple and in green. The Ig-like domain contains from 70 residues to 104 residues, so they vary in size. Some of the Ig-like domains are almost identical in sequence. The passenger is capped by a C-type lectin domain depicted in orange. The sequence alignment was performed using Clustal Omega (Thompson et al., 1994), whereas shading of multiplealignments was done with BoxShade (http://sourceforge.net/projects/boxshade/).The domain predictions were made using HHpred (Homology detection \& structure prediction by HMM-HMM comparison) at the Max Planck Institute for Developmental Biology toolkit server (Söding et al., 2005)

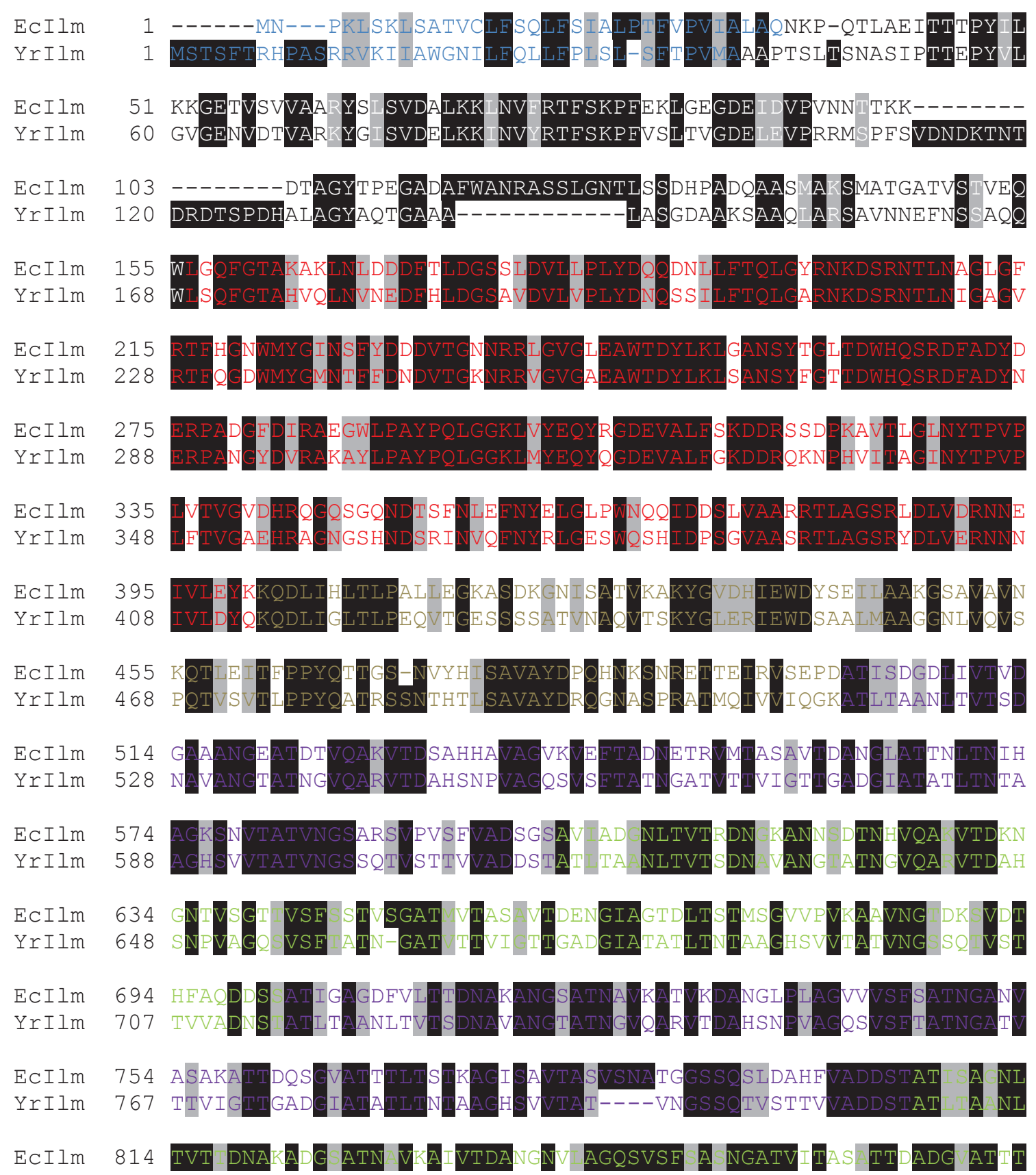




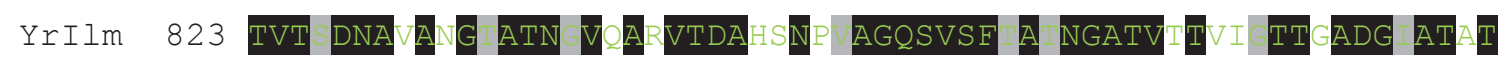

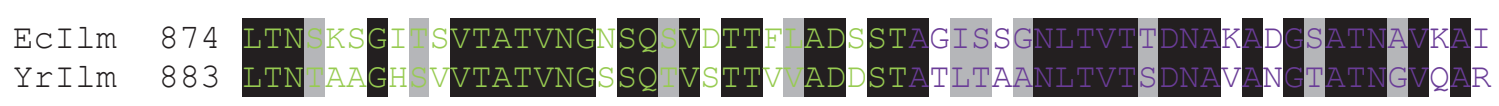

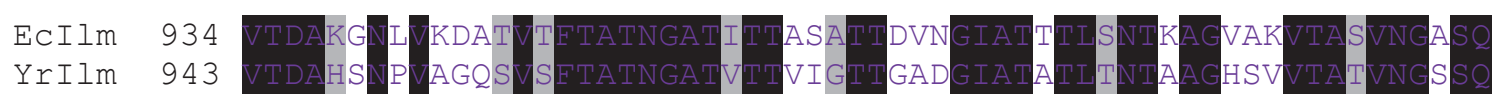

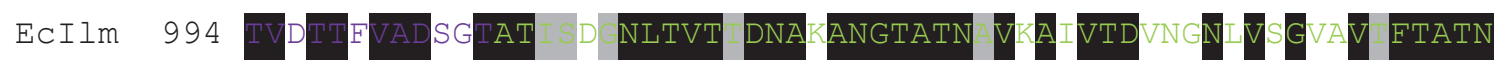

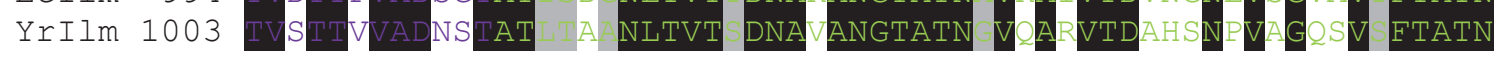

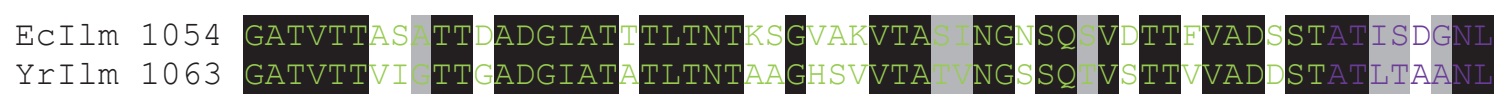

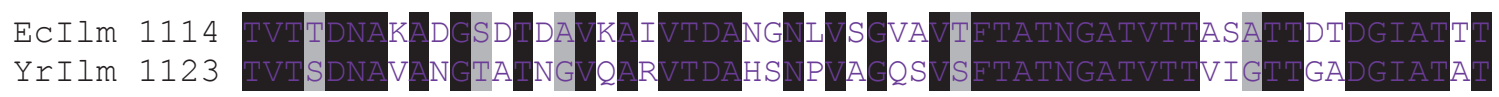

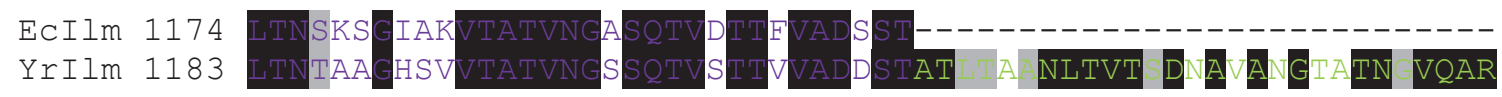
ECIlm 1230 YrIlm 1243

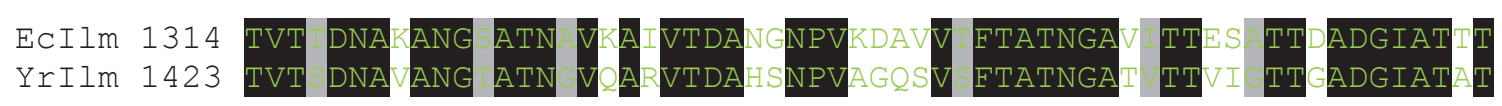

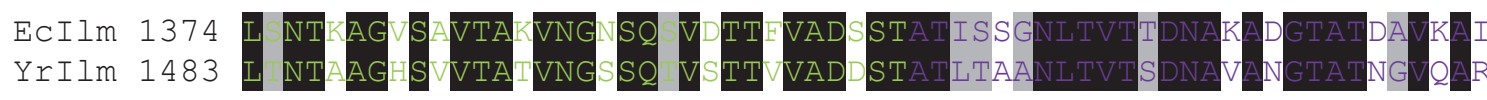




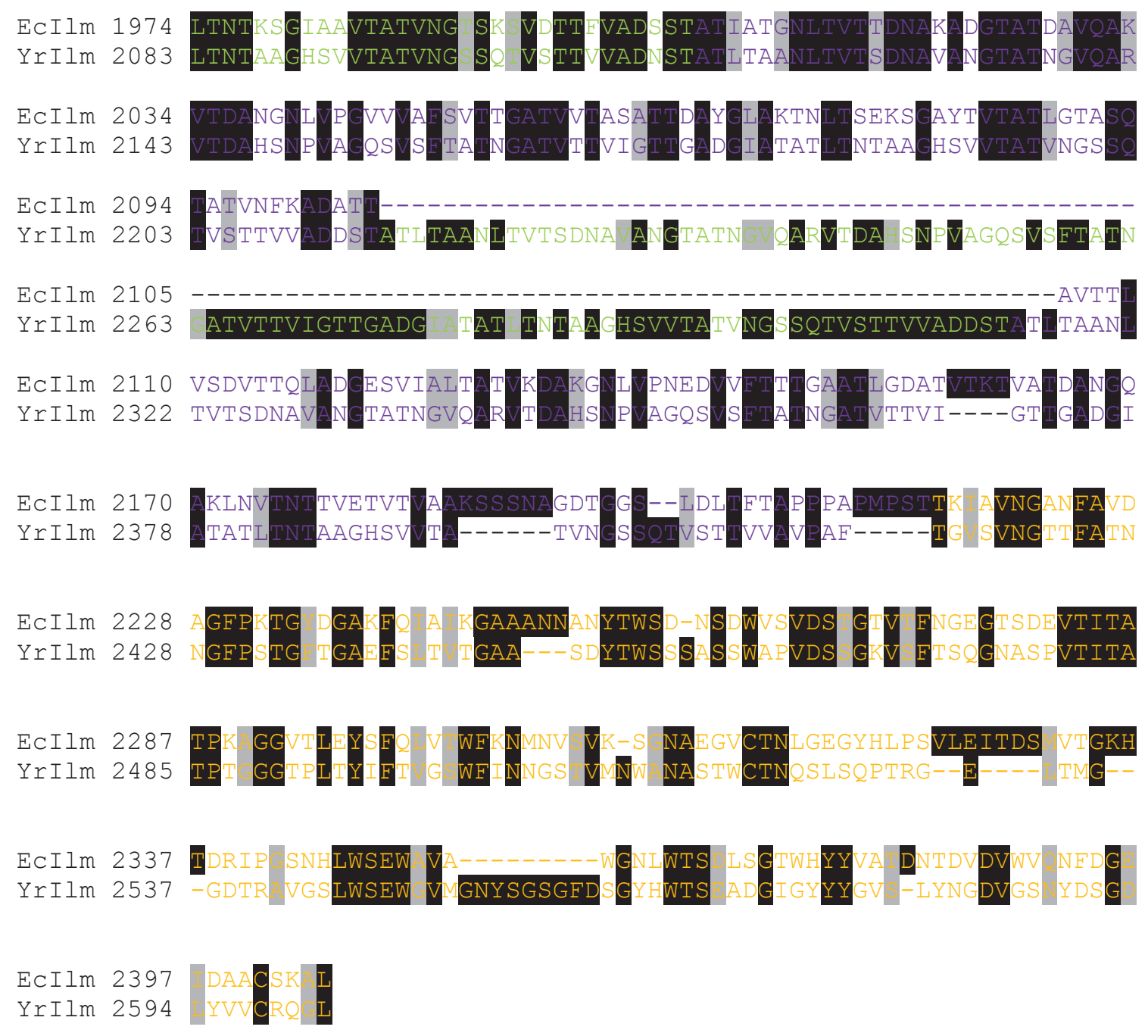


Biegert, A., Mayer, C., Remmert, M., Söding, J., Lupas, A.N., 2006. The MPI Bioinformatics Toolkit for protein sequence analysis. Nucleic Acids Res. 34. doi:10.1093/nar/gkl217

http://sourceforge.net/projects/boxshade/ [WWW Document], n.d. URL http://sourceforge.net/projects/boxshade/

Söding, J., Biegert, A., Lupas, A.N., 2005. The HHpred interactive server for protein homology detection and structure prediction. Nucleic Acids Res. 33. doi:10.1093/nar/gki408

Thompson, J.D., Higgins, D.G., Gibson, T.J., 1994. CLUSTAL W: Improving the sensitivity of progressive multiple sequence alignment through sequence weighting, position-specific gap penalties and weight matrix choice. Nucleic Acids Res. 22, 4673-4680. doi:10.1093/nar/22.22.4673 


\section{PAPER II}





\section{OPEN ACCESS}

Edited by:

Victoria Auerbuch,

University of California, Santa Cruz,

United States

Reviewed by:

Hanh N. Lam,

University of California, Santa Cruz,

United States

Gokhlesh Kumar

Veterinärmedizinische Universität

Wien, Austria

*Correspondence:

Dirk Linke

dirk.linke@ibv.uio.no

Specialty section:

This article was submitted to Molecular Bacterial Pathogenesis,

a section of the journal

Frontiers in Cellular and Infection

Microbiology

Received: 06 July 2018

Accepted: 04 October 2018

Published: 30 October 2018

Citation:

Wrobel A, Ottoni C, Leo JC and

Linke D (2018) pYR4 From a

Norwegian Isolate of Yersinia ruckeri Is a Putative Virulence Plasmid Encoding

Both a Type IV Pilus and a Type IV

Secretion System.

Front. Cell. Infect. Microbiol. 8:373.

doi: 10.3389/fcimb.2018.00373
pYR4 From a Norwegian Isolate of Yersinia ruckeri Is a Putative Virulence Plasmid Encoding Both a Type IV Pilus and a Type IV Secretion System

\author{
Agnieszka Wrobel ${ }^{1}$, Claudio Ottoni ${ }^{2}$, Jack C. Leo ${ }^{1}$ and Dirk Linke ${ }^{1 *}$ \\ ${ }^{1}$ Department of Biosciences, University of Oslo, Oslo, Norway, ${ }^{2}$ Centre for Ecological and Evolutionary Synthesis, University \\ of Oslo, Oslo, Norway
}

Enteric redmouth disease caused by the pathogen Yersinia ruckeri is a significant problem for fish farming around the world. Despite its importance, only a few virulence factors of $Y$. ruckeri have been identified and studied in detail. Here, we report and analyze the complete DNA sequence of pYR4, a plasmid from a highly pathogenic Norwegian Y. ruckeri isolate, sequenced using PacBio SMRT technology. Like the well-known pYV plasmid of human pathogenic Yersiniae, pYR4 is a member of the IncFIl family. Thirty-one percent of the PYR4 sequence is unique compared to other Y. ruckeri plasmids. The unique regions contain, among others genes, a large number of mobile genetic elements and two partitioning systems. The $\mathrm{G}+\mathrm{C}$ content of pYR4 is higher than that of the Y. ruckeri NVH_3758 genome, indicating its relatively recent horizontal acquisition. pYR4, as well as the related plasmid pYR3, comprises operons that encode for type IV pili and for a conjugation system (tra). In contrast to other Yersinia plasmids, pYR4 cannot be cured at elevated temperatures. Our study highlights the power of PacBio sequencing technology for identifying mis-assembled segments of genomic sequences. Comparative analysis of pYR4 and other Y. ruckeri plasmids and genomes, which were sequenced by second and the third generation sequencing technologies, showed errors in second generation sequencing assemblies. Specifically, in the Y. ruckeri 150 and Y. ruckeri ATCC29473 genome assemblies, we mapped the entire pYR3 plasmid sequence. Placing plasmid sequences on the chromosome can result in erroneous biological conclusions. Thus, PacBio sequencing or similar long-read methods should always be preferred for de novo genome sequencing. As the tra operons of pYR3, although misplaced on the chromosome during the genome assembly process, were demonstrated to have an effect on virulence, and type IV pili are virulence factors in many bacteria, we suggest that pYR4 directly contributes to Y. ruckeri virulence.

Keywords: tra operon, pil operon, conjugative plasmid, Yersinia ruckeri, type IV secretion system 


\section{INTRODUCTION}

The genus Yersinia consists of 17 different species (Reuter et al., 2014; Savin et al., 2014). Although the human pathogens within the genus are closely related to each other, they cause diverse diseases. Y. pestis, the causative agent of bubonic and pneumonic plague, is one of the most virulent organisms known (Chauhan et al., 2016). In addition, this genus includes Y. enterocolitica and $Y$. pseudotuberculosis, well-known human enteropathogens. $Y$. pestis spreads through fleabites or aerosols, whereas $Y$. enterocolitica and $Y$. pseudotuberculosis are transmitted via ingestion of contaminated food or water (Bottone, 1997; Perry and Fetherston, 1997; Jalava et al., 2006). Y. enterocolitica and Y. pseudotuberculosis are responsible for a broad range of diseases ranging from mild gastroenteritis to life-threatening septicemia (Bottone, 1997).

$Y$. ruckeri is a fish pathogen causing enteric redmouth disease (ERM), mainly in salmonids (Bullock et al., 1978; Busch, 1978). This bacterium contributes to enormous economic losses in aquaculture throughout the world. Y. ruckeri is mostly transmitted through contact with carrier fish (Busch, 1978; Stevenson and Airdrie, 1984). Despite the availability of vaccines, yersiniosis outbreaks still occur in fish farms (Ormsby et al., 2016). The majority of the ERM outbreaks are caused by the highly pathogenic Y. ruckeri serotype 1 belonging to biotype 1 , characterized as motile with phospholipase activity (Romalde and Toranzo, 1993). For a long time, ERM has played a minor role in Norway, with only a few outbreaks per year (Hjeltnes et al., 2017). The first report of a disease outbreak caused by Y. ruckeri among Atlantic salmon was described in Norway in 1985 , and this was successfully treated with antibiotics (Sparboe et al., 1986). In recent years, the number of outbreaks in the farmed Atlantic salmon population has substantially increased. The reasons for the most recent outbreaks remain unclear, and $Y$. ruckeri infections are nowadays a major challenge facing the Norwegian aquaculture industry, similar to other countries such as Australia (Barnes et al., 2016), Chile (Avendaño-Herrera et al., 2017), and Scotland (Ormsby et al., 2016).

Each of the human Yersinia pathogens harbors chromosomally and plasmid-encoded virulence determinants (Chauhan et al., 2016). Y. pestis usually carries two speciesspecific plasmids, pPCP1 and pMT1, and one highly conserved plasmid shared among the three human pathogenic Yersiniae, pYV (also called pCD1) (Ben-Gurion and Shafferman, 1981; Ferber and Brubaker, 1981; Haiko et al., 2009). This large 70-kb plasmid carries a type III secretion system (T3SS), Ysc. T3SS system encodes structural proteins, chaperones as well as effector proteins called Yops (Yersinia outer proteins) required for Yersinia extracellular survival. The effector proteins and the machinery for their delivery are required for infection and manipulation of host responses to overcome the action of phagocytes (Cornelis et al., 1998). Moreover, the plasmid encodes a major virulence factor, the Yersinia adhesin A (YadA) (Mühlenkamp et al., 2015).

Despite the economic importance, the pathogenicity of $Y$. ruckeri has not been studied in detail. Only few virulence factors are known, and to date all of these are encoded on the chromosome. These include bacterial adhesins important in establishing a successful colonization (Romalde and Toranzo, 1993). In particular, the chromosomally encoded adhesins YrInv and YrIlm might play a role in virulence (Wrobel et al., 2017). They belong to the intimin-invasin family of adhesins, which includes also InvA, the adhesin responsible for the initial bacterial attachment and colonization of host tissues in Y. enterocolitica and Y. pseudotuberculosis (Isberg and Leong, 1990; Wrobel et al., 2017). Other virulence factors described in Y. ruckeri include cytotoxins and haemolysins (Romalde and Toranzo, 1993), the metalloprotease Yrp1 (Secades and Guijarro, 1999), the haemolysin/cytolysin YhlA (Fernández et al., 2007), the iron uptake system ruckerbactin (Fernández et al., 2004), and a chromosomal T3SS (Liu et al., 2016). Recently, a large proteomic study of $Y$. ruckeri strains was performed under standard (Kumar et al., 2017) and iron-limited conditions (Kumar et al., 2016). In total, 1395 proteins were identified in the whole cell lysate of $Y$. ruckeri under standard culture conditions. Among them, several proteins were predicted to be virulence factors, including, among others, HtrA protease, TolB, the lipoprotein NlpD and a LuxR family transcriptional regulator. This global proteomic analysis will help in understanding the biology of the pathogen, as well as in development of new effective treatments against the ERM disease (Kumar et al., 2017).

Plasmid-borne virulence factors have been found in other fish pathogens, including Vibrio anguillarium (Crosa, 1980) and Edwardsiella tarda (Yu et al., 2012), but not in Y. ruckeri. Plasmids in Y. ruckeri strains were studied previously due to their possible involvement in virulence in analogy to the human pathogenic Yersiniae (De Grandis and Stevenson, 1982). Many authors expected to find the same virulence traits as those described for the human pathogens, such as the plasmid-encoded T3SS. However, none of the plasmid-associated virulence factors of the human-enteropathogenic Yersiniae were found in these plasmids. In general, $Y$. ruckeri plasmids have not yet been properly characterized and further research is required to understand their role in bacterial virulence. A study including 183 Y. ruckeri strains from different geographical locations reported 8 different plasmid profiles (Garcia et al., 1998). In this study, the most virulent sorbitol-negative Y. ruckeri strains of serotype $\mathrm{O} 1$ contained a large $75 \mathrm{MDa}$ plasmid $(\sim 113 \mathrm{~kb})$, in agreement with earlier studies (Guilvout et al., 1988; Romalde et al., 1993). In addition, smaller plasmids (12.7 MDa; $\sim 19 \mathrm{~kb})$ have been found in most of the strains (Garcia et al., 1998).

More recent studies showed that multidrug resistance plasmids in Y. ruckeri strains are a serious aquaculture concern (Toranzo et al., 1983; De Grandis and Stevenson, 1985; Carattoli et al., 2012; Huang et al., 2014). Welch et al. (2007) showed that Y. ruckeri strain YR71 carries a multidrug resistance plasmid called pYR1, which has 99\% nucleotide identity with the IncA/C (incompatibility $\mathrm{A} / \mathrm{C}$ ) plasmid backbone of the $Y$. pestis isolate IP275, plasmid pIP1202. The IncA/C group comprises a large, low-copy number, multidrug resistance plasmid family within Enterobacteriaceae such as Escherichia coli, Salmonella enterica, Y. pestis, and Klebsiella pneumoniae, as well as more distantly related species such as Vibrio cholerae. Plasmids of this family are unique with regard to their structure and gene content. 
They contain putative transfer regions [type IV secretion system (T4SS)], regions involved in integration of mobile genetic elements, as well as regions involved in transcription (Johnson and Lang, 2012). T4SSs are widely distributed in prokaryotes as well as in some archaea. T4SSs are large macromolecular complexes typically composed of a cell-envelope spanning mating channel and an extracellular pilus structure. T4SSs are classified into two major groups type IVA (T4ASSs) and type IVB (T4BSSs). T4ASS resemble the VirB/VirD system of Agrobacterium tumefaciens while T4BSSs are related to the conjugation system of IncI plasmids. Typical examples of T4ASSs are found on conjugative plasmids, such as F, RP4 and pKM101, as well as the prototypical VirB system of A. tumefaciens. These T4ASSs export nucleoprotein complexes during conjugation. T4BSS is represented by the Legionella pneumophila icm/dot system involved in protein translocation into host cells thus allowing the pathogen to replicate intracellularly (Wallden et al., 2010).

In this work, we sequenced a plasmid-which we named pYR4-from the highly pathogenic Norwegian Y. ruckeri isolate NVH_3758 from the 1987 outbreak and performed a comparative bioinformatics analysis of the available Y. ruckeri plasmid sequences to evaluate their role in virulence.

\section{MATERIALS AND METHODS Plasmid DNA Sequencing Technology}

Genomic DNA as well as plasmid DNA was extracted from a locally important, highly pathogenic Norwegian Y. ruckeri isolate NVH_3758 (biotype 1, serotype 1) recovered from an outbreak of clinical yersiniosis in farmed Atlantic salmon, kindly provided by Prof. Duncan Colquhoun at the Norwegian Veterinary Institute in Oslo, Norway (Gulla et al., 2018). Whole genome sequencing of Y. ruckeri NVH_3758 was performed by the Norwegian Sequencing Centre (Oslo, Norway) using the Single Molecule Real Time (SMRT) sequencing technology of Pacific Biosciences. Sample preparation, reads assembly and consensus polishing were done as previously described (Wrobel et al., 2017). The final assembly yielded two contigs of circularized length of $\sim 3.8 \mathrm{Mb}$, representing the chromosomal genome (Wrobel et al., 2017), and $\sim 81 \mathrm{~kb}$, corresponding to a new plasmid that we named pYR4. The DNA sequence of pYR4 has been deposited in the National Centre for Biotechnology Information (NCBI) database under the accession number CP032236.

\section{Plasmid Annotation}

The FASTA consensus of pYR4 from Y. ruckeri NVH_3758 was uploaded to RAST (Rapid Annotation using Subsystem Technology) for automatic annotation (Aziz et al., 2008; Seemann, 2014). After initial annotations, all open reading frames (ORFs) with initial annotations were checked using the interactive server HHpred available at the Max Planck Institute for Developmental Biology Toolkit (Söding et al., 2005) against two databases, the PDB and PFAM (Sonnhammer et al., 1998; Sussman et al., 1999). The functional annotations obtained from the HHpred server and RAST were compared and in some cases were corrected manually. Many uncharacterized proteins which were previously labeled as hypothetical by RAST were annotated based on similarity to characterized proteins. The protein sequences were uploaded into Geneious (Kearse et al., 2012). A circular representation of pYR4 showing the annotated features, the GC content and the GC skew within 50 bp-long genomic regions, was generated with Circos (Krzywinski et al., 2009). The identification of the promoter sequences of the pil and tra operons was performed with the online server BPROM (Solovyev and Salamov, 2011) as well as bTSSfinder (Shahmuradov et al., 2017) (see Table 1 and Supplementary Figure 1). The mfold Web server was used for RNA secondary structure prediction (Zuker, 2003).

\section{RepA Phylogeny}

The RepA protein sequence of pYR4 was annotated by RAST as "hypothetical." After the initial annotation, the protein was identified as RepA using HHpred. The protein sequence was then subjected to a search using BLASTP (Altschul et al., 1997). The BLASTP search returned 100 hits, from which the first 29 RepA protein sequences were selected, after excluding sequences of hypothetical proteins and multispecies proteins, and aligned using MUSCLE (Edgar, 2004). In the final alignment, we included RepA protein sequences from pYR1, pYR3, pYR4 in addition to eight RepA protein sequences belonging to the IncA/C plasmid family. The final alignment was then used to construct the phylogenetic tree using MEGA X software by applying the Maximum Likelihood method on the Poisson correction model (Zuckerkandl and Pauling, 1965; Felsenstein, 1985; Kumar et al., 2018) (see Supplementary Figure 2).

\section{Plasmid Comparative Analysis}

We compared the nucleotide sequence of Y. ruckeri NVH_3758 plasmid pYR4 with the nucleotide sequences of the plasmids of Y. ruckeri strains YR71 (pYR1), CSF007-82 (pYR2, pYR3) and SC09 (pLT, pWKY) (Table 2) deposited in the NCBI database. To keep the same annotation system as for the pYR4 plasmid, the nucleotide sequences of the Y. ruckeri plasmids were reannotated with RAST (see also Supplementary Figure 3 for pYR4, Supplementary Figure 4). Details of the annotation can be found in Supplementary Tables 1 and 2.

Plasmid comparisons were also done with sequences of other species containing the tra and pil operons described in literature, including Erwina amylovora (pEL60, pEA68, pEA72, pEA78), Serratia entomophila (pADAP), Citrobacter freundii (pCTX-M3), and Salmonella enterica subsp. enterica serovar Typhimurium (R64) (see Supplementary Figure 5). The nucleotide sequence of Y. ruckeri NVH_3758 pYR4 plasmid was also compared to PacBio-sequenced genomic data of Y. ruckeri CSF007-82, Big Creek 74, QMA0440, SC09, and Illumina-sequenced genomes of Y. ruckeri ATCC29473 and YRB (see Supplementary Figure 5). In the comparative survey, we also included the $\sim 57 \mathrm{~kb}$-long scaffold 20 of the Y. ruckeri 150 assembly, which contains the tra and pil operons.

Finally, pYR4 was compared to the Illumina-sequenced genomes of human pathogens $Y$. pestis CO92, $Y$. pseudotuberculosis YPIII, and Y. enterocolitica 8081 (see Supplementary Figure 5). Pairwise comparisons were 
TABLE 1 | pYR4 promoter predictions by bTSSfinder (Shahmuradov et al., 2017) and BPROM (Solovyev and Salamov, 2011) used in the present study.

\begin{tabular}{|c|c|c|c|c|c|c|}
\hline \multirow{2}{*}{$\begin{array}{l}\text { Name of } \\
\text { operon }\end{array}$} & \multirow{2}{*}{$\begin{array}{l}\text { Predicted } \sigma \\
\text { factor }\end{array}$} & \multicolumn{2}{|c|}{ Sequence of predicted promoter } & \multirow{2}{*}{$\begin{array}{l}\text { Location on the pYR4 } \\
\text { sequence (nt position) }\end{array}$} & \multirow[t]{2}{*}{ Score ${ }^{a}$} & \multirow[t]{2}{*}{ Software used } \\
\hline & & -10 & -35 & & & \\
\hline \multirow[t]{2}{*}{ pil operon } & $\sigma^{24}$ & TCTGT & TCATT & $14,351-14,374$ & 1.77 & bTSSfinder \\
\hline & $\sigma^{38}$ & ТАТТСС & TाTACC & $14,339-14,368$ & 1.52 & \\
\hline \multirow[t]{2}{*}{ tra2 operon } & $\sigma^{24}$ & GCGAT & CCACTG & $35,014-35,038$ & 0.30 & bTSSfinder \\
\hline & $\sigma^{32}$ & CСССССАСТG & CTCCAGA & $34,989-35,019$ & 1.91 & \\
\hline \multirow[t]{3}{*}{ mob operon } & $\sigma^{70}$ & TATAAT & TTGATT & $60,335-60,306$ & 1.91 & bTSSfinder \\
\hline & $\sigma^{38}$ & TATAAT & TTGATT & $60,335-60,306$ & 1.80 & \\
\hline & $\sigma^{32}$ & TACGCCAGAT & CGATITT & $60,289-60,259$ & 1.86 & \\
\hline \multirow[t]{5}{*}{ stbA operon } & $\sigma^{32}$ & ATCACTATTA & TGATTGA & $72,064-72,035$ & 1.95 & bTSSfinder \\
\hline & $\sigma^{38}$ & TACACA & CGTGAG & $72,030-72,002$ & 1.94 & \\
\hline & $\sigma^{28}$ & TGAGATAA & AAAATCAA & $72,011-71,939$ & 1.97 & \\
\hline & $\sigma^{70}$ & CAATAT & ТTТAТT & $71,981-71,961$ & 1.97 & \\
\hline & $\sigma^{24}$ & TCAAT & TAATAT & $71,992-71,978$ & 1.97 & \\
\hline \multirow[t]{5}{*}{ parA operon } & $\sigma^{32}$ & АТСАСТАТTA & TGATTGA & $72,035-72,064$ & 1.95 & bTSSfinder \\
\hline & $\sigma^{38}$ & TACACA & CGTGAG & $72,002-72,030$ & 1.94 & \\
\hline & $\sigma^{28}$ & TGAGATAA & AAAATCAA & $71,939-72,011$ & 1.97 & \\
\hline & $\sigma^{70}$ & CAATAT & ТТАAT & $71,963-71,981$ & 1.97 & \\
\hline & $\sigma^{24}$ & TCAAT & TAATAT & $71,978-71,993$ & 1.97 & \\
\hline pil operon & $\sigma^{70}$ & GCGTATTC & TTACCG & $14,340-14,367$ & $15 ; 55$ & BPROM \\
\hline tra2 operon & $\sigma^{70}$ & ATGAAAAAT & TाTAC & $34,792-34,817$ & $39 ; 42$ & BPROM \\
\hline tra3 operon & $\sigma^{70}$ & TCGCAAAAT & TTCAG & $47,970-48,003$ & $30 ; 47$ & BPROM \\
\hline mob operon & $\sigma^{70}$ & GGGTATAAT & TTGATT & $60,327-60,311$ & $53 ; 91$ & BPROM \\
\hline stbA operon & $\sigma^{70}$ & САСТАТТАТ & TTGACA & $72,065-72,038$ & $56 ; 66$ & BPROM \\
\hline parA operon & $\sigma^{70}$ & САСТАТТАТ & TTGACA & $72,038-72,065$ & $56 ; 66$ & BPROM \\
\hline
\end{tabular}

${ }^{a}$ A score of 0.81 or higher is considered significant for bTSSfinder, and a score of 0.2 or higher is considered significant for BPROM (Solovyev and Salamov, 2011; Shahmuradov et al., 2017). Two score values provided in the table were predicted for BPROM which correspond to the Pribnow box at the -10 position and at the -35 position, respectively.

TABLE 2 | Y. ruckeri plasmid sequences deposited in GenBank used in the present study.

\begin{tabular}{|c|c|c|c|c|c|c|c|}
\hline Plasmid & Strain & $\begin{array}{l}\text { Sequencing } \\
\text { technology }\end{array}$ & Size (bp) & $\mathrm{G}+\mathrm{C}$ content $(\%)$ & $\begin{array}{c}\text { CDS } \\
\text { (predicted by RAST) }\end{array}$ & GenBank & References \\
\hline pYR1 & YR71 & AB 3730xI & 158.038 & 50.9 & 200 & CP000602.1 & Welch et al., 2007 \\
\hline pYR2 & CSF007-82 & PacBio & 16.923 & 41.5 & 25 & LN681229.1 & Nelson et al., 2015 \\
\hline pYR3 & CSF007-82 & PacBio & 103.917 & 48.4 & 107 & LN681230.1 & Nelson et al., 2015 \\
\hline pYR4 & NVH_3758 & PacBio & 80.843 & 49.4 & 92 & PRJNA401093 & This study \\
\hline pLT & SC09 & Illumina & 57.905 & 44.3 & 65 & СР025802.1 & Liu et al., 2016 \\
\hline pWKY & SC09 & Illumina & 73.051 & 40.2 & 95 & СР025801.1 & Liu et al., 2016 \\
\hline
\end{tabular}

performed with Progressive Mauve (Darling et al., 2010) using default options and the "seed family" option to increase sensitivity. The output backbone file was then used to plot the Locally Collinear Blocks (LCB) in a circular representation with Circos.

\section{RESULTS}

\section{pYR4 Is a Novel Plasmid Isolated From Y. ruckeri NHV3758}

In order to define the relationship between the plasmid sequenced in this study and those described in literature, we performed a comparative analysis of pYR4 with plasmid sequences generated previously by Illumina and PacBio sequencing technologies. The comparative survey with Mauve indicated no obvious similarity between pYR4 and the Y. ruckeri plasmids pYR1, pYR2, pLT, and pWKY, as no LCBs (locally collinear blocks) were detected (data not shown). On the other hand, a $\sim 55 \mathrm{~kb}$-long LCB (sequence identity $>99 \%$ ) that included the pil and the tra operons was present in pYR4 (from nucleotide position 9,100 to 64,005) and in the PacBio-sequenced plasmid pYR3 (Figures 1, 3, Table 2). By re-annotating pYR3 and comparing it with the higher-resolution annotation of 

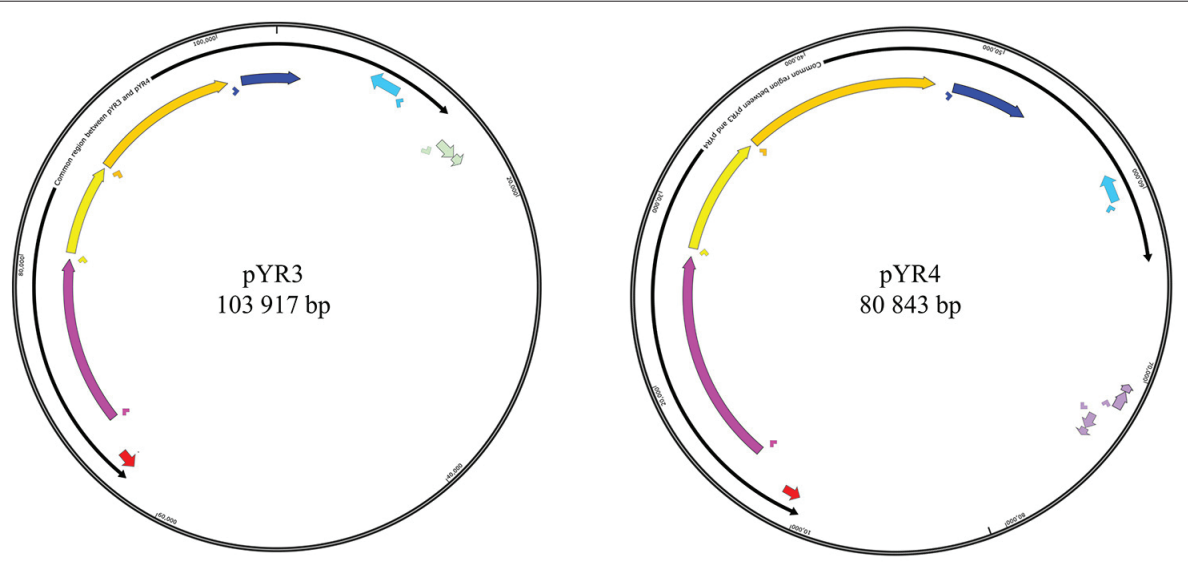

Legend:

- Replication control RepA

- Pil operon

$\square$ Tral operon

Tra2 operon

- Tra3 operon

$\square$ Mobilization system

$\square$ Partitioning system - pYR3

$\square$ Partitioning system - pYR4

Predicted promoters depicted in different colors

$\leftrightarrow$ Common region between pYR3 and pYR4

FIGURE 1 | Schematic representation of plasmid maps of pYR3 and pYR4. Gene clusters are depicted in different colors: light blue (mobilization gene cluster), yellow (tra1 gene cluster), orange (tra2 gene cluster), dark blue (tra3 gene cluster), magenta (pil gene cluster), purple (partitioning gene cluster). Approximate locations of the promoters based on the prediction of sigma factors with BPROM and bTSSfinder is reported as arrows below each operon. Replication initiation protein is indicated in red. Common regions for pYR3 and pYR4 are represented by bidirectional arrows. Partitioning system for pYR3 and pYR4 are depicted in light green and light purple, respectively. pYR4 contains 2 partitioning systems oriented in two different directions.

pYR4 obtained through HHPred, we could provide a more in depth characterization of the plasmids under analysis (Nelson et al., 2015) (see Materials and Methods section, Supplementary Figure 3 for pYR4 and Supplementary Figure 4 for pYR3).

The remaining portion of the plasmid sequence ( $>25 \mathrm{~kb}, 31 \%$ of the sequence length) appears to be unique, as no LCB was found in any of the plasmids of Y. ruckeri deposited in GenBank so far. This region contains mostly hypothetical proteins $(n=10)$ and mobile genetic elements $(n=10)$. In addition, we found a partial toxin-antitoxin system, a restriction system including both a type I restriction enzyme and a corresponding ArdA-like anti-restriction protein, and a small cluster of genes coding for two alcohol dehydrogenase enzymes and a transcription factor with high similarity to FrmR from Salmonella, a formaldehyde-sensitive regulator (Supplementary Figure 3). pYR4 contains two potential partitioning systems (ParAG and $\mathrm{Stb} A B$ ) (Figure 1). These two partitioning systems are represented by two operons oriented in opposite directions. No obvious sequence similarity with the partitioning system of pYR3 was found. Interestingly, the presence of alternative partitioning systems have already been described before for pYV from Yersinia species (Pilla and Tang, 2018). The high abundance of mobile elements may suggest that this plasmid is likely subject to structural rearrangements and that the unique $\sim 25 \mathrm{~kb}$ region of pYR4 may be the result of recent horizontal gene transfer. This is also supported by the difference in $\mathrm{G}+\mathrm{C}$ content between the $\sim 55 \mathrm{~kb}$ region (50.4\%) and the remaining portion of the plasmid (47.1\%). It is worth noting that in pYR3, this complete region is replaced by a different $\sim 45 \mathrm{~kb}$ region (Figure 1). These major differences suggest that $Y$. ruckeri NHV3758 contains a plasmid with significant differences to pYR3, which we named pYR4.

\section{Sequence Analysis of pYR4}

The nucleotide sequence of the circular pYR4 plasmid contains 80,842 base pairs $(\sim 53 \mathrm{MDa})$. The $\mathrm{G}+\mathrm{C}$ content of pYR4 is $49.4 \%$, which is around $2 \%$ less than the $\mathrm{G}+\mathrm{C}$ content of the Y. ruckeri NVH_3758 genome (47.6\%), suggesting acquisition by horizontal gene transfer (Figure 2) (Nishida, 2012; Hayek, 2013). The annotation of pYR4 with RAST showed 92 putative coding sequences along the entire plasmid sequence. The RAST server could annotate functions for 52 ORFs and we were able to expand this list to 71 ORFs manually, using the HHpred server (Söding et al., 2005) (see Supplementary Figure 3), leaving 21 ORFs without putative function. Fifty-five genes are encoded on the positive strand while the remaining 37 are encoded on the negative strand. The entire plasmid sequence can be divided into several gene clusters, including clusters for partitioning ( $\operatorname{par} A$, parG, and $s t b A B$ ), a T4SS (tra), and a type IV pilus (TFP) gene cluster (pil). 


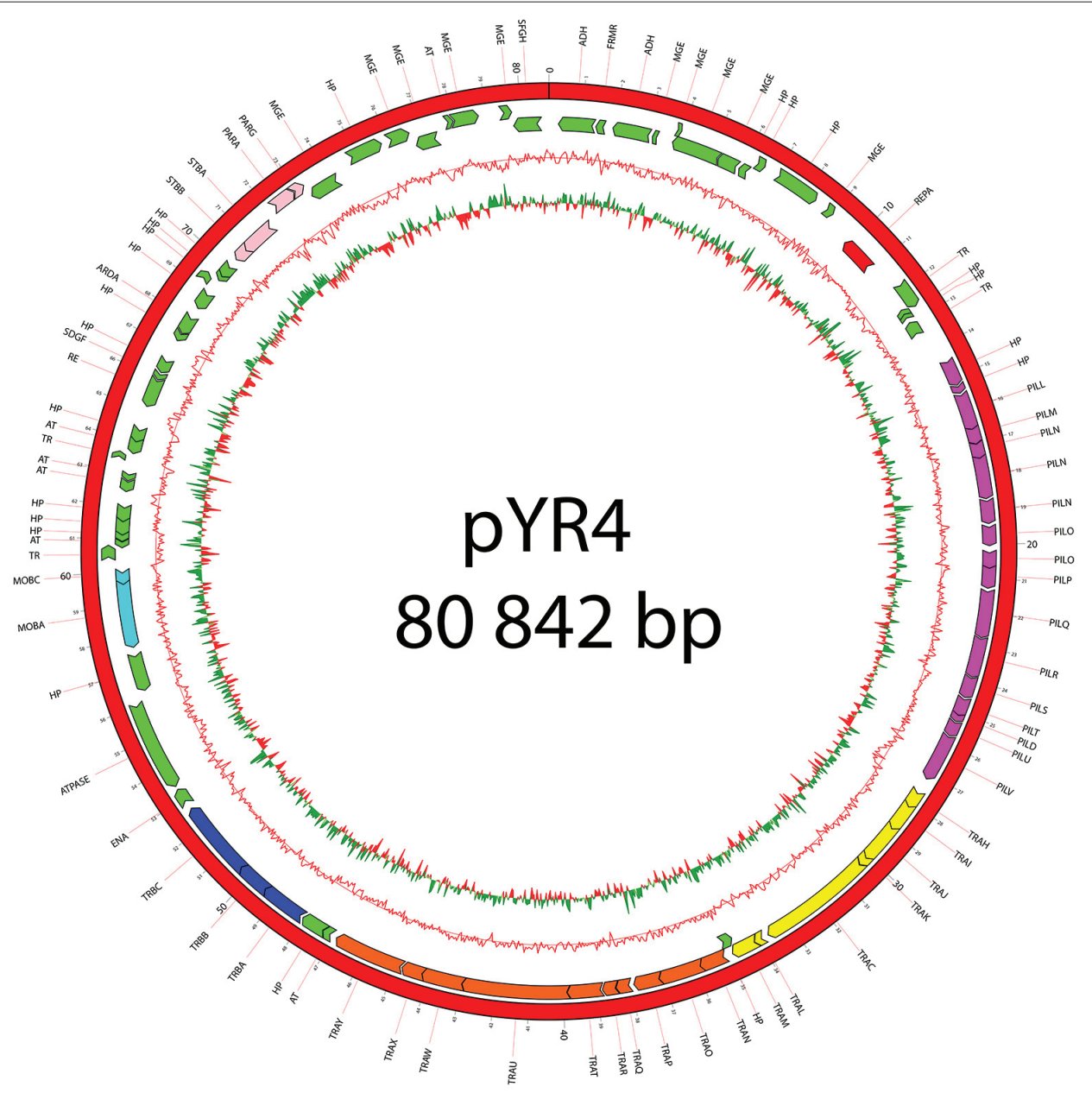

FIGURE 2 | Plasmid map of pYR4 isolated from Y. ruckeri NVH_3758. The sequence annotations were generated with RAST (Rapid Annotation using Subsystem Technology) and further analyzed with HHpred. The rings show from inside to outside (1) the GC skew, (2) the G+C content, (3) the position of predicted ORFs in the reverse strand, and (4) the position of ORFs in the forward strand. The gene annotations are positioned in the middle of each gene on the plasmid map. Gene clusters are indicated in different colors: light blue (mobilization gene cluster), yellow (tra1 gene cluster), orange (tra2 gene cluster), dark blue (tra3 gene cluster), magenta (pil gene cluster), pink (partitioning gene cluster). Replication initiation protein is indicated in red. Hypothetical proteins (HP) and mobile genetic elements are indicated in green.

In order to understand the pYR4 plasmid physiology as well as to follow its evolution and spread, we classified pYR4 into a plasmid family. A classical method of plasmid classification is based on incompatibility (Inc) groups. In general, plasmids with the same replication system are incompatible while plasmids with different replication system are compatible. In other words, two plasmids of the same Inc group cannot be propagated in the same bacterial cell (Couturier et al., 1988). A set of 30 RepA protein sequences from IncFII plasmid family, together with 9 RepA protein sequences previously characterized as belonging to IncA/C, were aligned in order to classify pYR4. Evaluation of the RepA phylogeny showed that the pYR4 RepA protein is closely related to IncFII plasmids found in other Yersiniae species (see Supplementary Figure 2). A BLASTP search of pYR4 RepA protein returned over 100 hits of homologs found in different species. The closest RepA homologs were found in Illumina-sequenced genomes of $Y$. frederiksenii and $Y$. enterocolitica with 91 and $90 \%$ similarity over the whole protein sequence, respectively. These RepA homologs presumably are part of unnamed plasmids that were incorrectly assigned to chromosomes, since they share only $19 \%$ similarity to RepA of the well-described virulence plasmid pYV from Y. enterocolitica 8081 (Table 3). Thus, pYR4 was classified as a member of the IncFII plasmid family, in contrast to pYR1 which belongs to the IncA/C family and is represented as an outgroup in Supplementary Figure 2 (Carattoli, 2009). The IncFII plasmid family includes low-copy number plasmids mostly related to virulence, such as pYV, as well as to the dissemination of antimicrobial resistance determinants. Plasmids from this family usually carry the FII replicon alone or in association with 
extra replicons such as repFIA and repFIB (Carattoli, 2009; Yang et al., 2015) and are common in Yersiniae (Villa et al., 2010).

\section{Comparative Analysis of Y. ruckeri Plasmid Sequences Demonstrates Errors in Assemblies of Second Generation Genome Sequencing}

Our comparative survey showed that no significant LCBs were found between $\mathrm{pYR} 4$ and the chromosomal genomes of $Y$. ruckeri CSF007-82, Big Creek 74, QMA0440, SC09, or YRB (data not shown). However, we found that the $\sim 100 \mathrm{~kb}$-long scaffold 2 of the Y. ruckeri ATCC29473 Illumina assembly matched pYR3, except for a mobile element of pYR3 (Figure 3 and Supplementary Figures 4-6). Furthermore, the higher quality of PacBio sequenced plasmids (pYR3 of CSF007-82 and pYR4 of NHV-3758) made it possible in our comparative survey to place scaffolds of previous $Y$. ruckeri assemblies into plasmid locations. In fact, the $\sim 57 \mathrm{~kb}-$ long Y. ruckeri 150 scaffold 20 that contained the tra and the pil operons could be mapped entirely to pYR3 (see Supplementary Figure 7). This scaffold included the $\sim 55 \mathrm{~kb}$-long region containing the pil and the tra operons detected in pYR4 and pYR3. Furthermore, by aligning other unplaced scaffolds of the Y. ruckeri 150 assembly, we found that four more scaffolds $(23,31,32,34)$ could be placed within pYR3 (Figure 3 and Supplementary Figures 5, 6). (An unplaced scaffold is a sequence found in an assembly that is not associated with any chromosome). Taken together, the evidence presented here suggests that the pil and tra operons are localized on plasmids pYR3 and pYR4 and that Y. ruckeri 150 and Y. ruckeri ATCC29473 contain the plasmid pYR3. In Y. ruckeri 150, the presence of plasmid- and chromosomally-borne tra clusters has been suggested based on Southern blot hybridization evidence (Méndez et al., 2009). When searching for tra genes in the assembly, we could not find copies of tra genes other than those matching pYR3 in the scaffold 20 of Y. ruckeri 150. Based on our data, chromosomal localization of the tra cluster seems very unlikely. However, resequencing or a higher quality assembly of the genome of $Y$. ruckeri 150 could clarify this unambiguously in the future.

Finally, no significant LCBs were found when comparing pYR4 or pYR3 to Yersinia human pathogenic species, including the well-studied pYV plasmid from $Y$. enterocolitica. This suggests a very different strategy for host infection in Y. ruckeri, as the pYV plasmid is essential for virulence in Y. enterocolitica.

\section{Sequence Analysis of pil Operon and Its Potential Involvement in Virulence}

Analysis of the pYR4 nucleotide sequence of a putative pil operon showed that this region spans a $12.6 \mathrm{~kb}$ locus containing 17 ORFs that encode a TFP. TFPs, not to be confused with T4SSs, are surface appendages expressed by many Gramnegative bacterial species. TFPs span both bacterial membranes and they are evolutionary and structurally related to type II secretion systems. TFPs are involved in bacterial adhesion, biofilm formation, horizontal gene transfer, and pathogenesis, and in addition they mediate cell movement such as gliding motility in Myxococcus xanthus and twitching motility in Pseudomonas and Neisseria species (Shi and Sun, 2002). In the enteropathogenic Y. pseudotuberculosis, the TFP gene cluster is composed of 11 open reading frames and contributes to Y. pseudotuberculosis pathogenicity (Collyn et al., 2002). The arrangement of the pYR4 pil cluster (Figure 2; see also Table 1 and Supplementary Figure 1) resembles the pil cluster from the plasmid pADAP, which was described in S. entomophila (Hurst et al., 2011), and in plasmid R64 from S. enterica serovar Typhimurium (Kim and Komano, 1997). By analogy with the pil operon from S. entomophila, we adopted the same names for the putative proteins as described there, and designated them as PilLMNNNOOPQRSTDUV [(with the exception of the first two hypothetical proteins, designated as $\mathrm{HP}(\mathrm{H}-$ for hypothetical and $\mathrm{P}$ - for proteins)]. It is worth mentioning that the pil operon in S. enterica includes only 14 genes (pilIJKLMNOPQRSTUV) in contrast to pYR4 (17 genes). The number of genes for pil clusters can vary, as described by Zhang et al. for S. enterica serovar Typhi, where the pil operon lacks the pilI, pilJ, and pilK genes (Zhang et al., 2000) of S. entomophila. The overall G+C content of the pil cluster is $51.7 \%$, and thus higher than that of the Y. ruckeri NVH_3758 genome (47.6\%) and the average of pYR4 (49.4\%). The $\mathrm{G}+\mathrm{C}$ content of the individual genes in the pil locus varies between $55.1 \%$ (pilP) and $46.8 \%$ (pilN). The ORFs of the pil cluster are encoded on the same strand and the length of the intercistronic region between each ORF ranges from 20 to $205 \mathrm{bp}$. In the region up to $333 \mathrm{bp}$ upstream of the first hypothetical protein of the pil cluster, we could identify binding sites for three sigma factors $(\sigma 70, \sigma 24$, and $\sigma 38)$ using BPROM and bTSSfinder, indicating the presence of putative promoters sequences in that region. In fact, no putative promoter sequence was identified between the pil genes suggesting that this region may function as an operon (Figure 2) (see Table 1 and Supplementary Figure 1). Additionally, analysis of the downstream region of pilV showed the presence of a palindromic sequence (5'CTAGACAGAATAGCCTAGTC AATATTATCTATGGCATTAAGATTCTGTCAG- $3^{\prime}$ ) that could serve as a transcription terminator. The analysis of the secondary structure of this region showed a steam-loop like fold with the $\Delta \mathrm{G}=-15 \mathrm{kcal} / \mathrm{mol}$ using the mfold Web server (Zuker, 2003).

The comparison of the protein sequences encoded by the pil operon, for example PilO and PilT, of pYR4 with database sequences using BLASTP showed from 64 to $86 \%$ identity to PilO and PilT proteins found in the IncI1 plasmid family from Serratia species. Accession numbers for the proteins, together with their functions, are given in Table 4.

The biogenesis of TFPs involves a number of proteins. These are all present in the pil operon of pYR4, suggesting that the locus is intact and functional. The pYR4 PilS protein encodes a major pilin, which is synthesized as a prePilS. In the prePilS protein sequence we identified a hydrophilic signal peptide comprising 15 residues. A predicted cleavage site lies between the 15th (glycine) and 16th (tryptophan) residues of prePils, which is recognized by the specific peptidase PilD (Kim and Komano, 1997). The mature Pils contains an N-terminal hydrophobic region (first 23 residues in the mature protein sequence), while 
TABLE 3 | pYR4 RepA homologs detected using BLASTP.

\begin{tabular}{|c|c|c|c|c|}
\hline Strain name & Name of the protein & Size (amino acids) & Degree of similarity & Accession number \\
\hline Y. frederiksenii & Replication protein & 316 & 280/308 (91\%) & WP_088130752.1 \\
\hline Y. enterocolitica & Replication protein & 316 & 276/308 (90\%) & WP_075339110.1 \\
\hline Y. massiliensis & Replication protein & 316 & 274/308 (89\%) & WP_099462805.1 \\
\hline Y. kristensenii & Replication protein & 316 & 270/308 (88\%) & WP_087768868.1 \\
\hline $\begin{array}{l}\text { Photorhabdus temperata } \\
\text { subsp. temperata M1021 }\end{array}$ & Sea7 & 314 & 229/308 (74\%) & EQB98986.1 \\
\hline S. fonticola AU-P3(3) & Sea7 & 362 & $217 / 308$ (70\%) & ERK05611.1 \\
\hline S entomophila & Sea7 & 362 & 208/306 (68\%) & WP_010895766.1 \\
\hline S. marcescens & Replication protein & 312 & 208/308 (68\%) & WP_089197752.1 \\
\hline S. fonticola & Replication protein & 312 & 204/306 (67\%) & WP_074032170.1 \\
\hline E. tarda & Replication protein & 311 & 194/303 (64\%) & WP_097364799.1 \\
\hline
\end{tabular}

the C-terminal region is rich in cysteine residues, a common feature of TFP pilins (Hurst et al., 2011). Beside the prepilins, we identified two copies of PilO and three copies of PilN, which seems to be a unique feature among plasmids from the same family. PilO and PilN are integral membrane proteins and usually exist only in one copy. An ATPase required for the assembly (PilQ) and an inner membrane protein (PilR) that we identified are also necessary for the assembly of the pili on the bacterial surface.

\section{Sequence Analysis of the tra Regions in pYR4}

Annotations of pYR4 by HHpred (Söding et al., 2005) showed the presence of the tra region that we presume encodes a T4SS and is involved in conjugation. In fact, the presence of a chromosomally-borne tra clusters in Y. ruckeri 150 was previously described (Méndez et al., 2009). In our analysis, in addition to the tra cluster identified by Méndez et al. (tra1) that is probably also plasmid-borne (see above), we could identify another two tra clusters, which we named tra2 and tra3. The tra 2 cluster comprises 10 genes with the gene order TraNOPQRTUWXY and an average G+C content of 53.5\%, while the tra3 cluster is composed of 3 genes with a $\mathrm{G}+\mathrm{C}$ content of $52.6 \%$. These two tra clusters are preceded by two putative promoter sequences with one located upstream from the traN gene while another one is located upstream from the $\operatorname{trb} A$ gene. The identification of the putative promoters sequences were based on the prediction of sigma factor binding sites using BPROM and bTSSfinder (see Table 1 and Supplementary Figure 1). The presence of the two identified putative promoter sequences and the small intercistronic region between the genes suggests that these genes might function as two operons, in addition to the tral operon (Figures 1, 2 ). The genetic organization of the tra 2 and tra3 operons resembles the gene order of the tra operon found in the pADAP plasmid of S. entomophila, the R64 plasmid of S. enterica serovar Typhimurium, pCTX-M3 of C. freundii, pEL60, pEA68, pEA72, and pEA78 of E. amylovora (see Supplementary Figure 5), as previously suggested for the tra1 operon (Méndez et al., 2009).
The G+C content of the tra 2 and tra3 operons (around 53\%) differs from the $\mathrm{G}+\mathrm{C}$ content of the chromosomes of $Y$. ruckeri NVH_3758 (47.6\%), Y. ruckeri Big Creek 74 (47.6\%), and Y. ruckeri CSF007-82 (47.5\%). Additionally, the tra region was is not present in the chromosome of the Y. ruckeri strains mentioned above, indicating that the tra region may originate from another species. Méndez et al. suggested that $S$. entomophila, the causative agent of amber disease of the New Zealand grass grub, could be the source of the tral region. The G+C content of the $S$. entomophila pADAP tra region (tra 1, tra2, tra 3 ) is around $52 \%$, which is close to the $\mathrm{G}+\mathrm{C}$ content of pYR4. In addition, the gene order of that region is very similar. We suggest that the whole tra region encompassing tra1, tra2, and tra 3 could have been acquired from this or a closely related Serratia species.

The amino acid sequences of TraH, TraI, TraJ, and TraK showed 29-34\% similarity to the L. pneumophila T4BSS proteins such as DotD (for "defect in organelle trafficking"), DotC, DotB, and IcmT (for "intracellular multiplication") (Wallden et al., 2010). The $\mathrm{icm} /$ dot genes are required for virulence, including intracellular growth and host cell killing (Sadosky et al., 1993; Swanson and Isberg, 1996). The pYR4 Tra proteins and their Tra homologs from L. pneumophila are similar in size, ranging from 87 residues (for TraK) to 385 residues (for TraJ). Interestingly, it has been shown before that a traI mutant strain of Y. ruckeri 150 was attenuated in an in vivo assay in rainbow trout and showed difficulty growing inside the fish (Méndez et al., 2009).

\section{Plasmid Curing Study of pYR4 in Yersinia ruckeri NVH_3758}

In order to understand the function of pYR4 and its involvement in pathogenesis, it is desirable to obtain a plasmid-cured strain. There is a wide number of plasmid curing procedures which have been successfully used to remove plasmids in Yersiniae. They for example include treatments with high temperatures or introduction of an incompatible plasmid (Sheridan et al., 1998; Ni et al., 2008). The genetic stability of the pYR4 plasmid was tested by treating $Y$. ruckeri cells with high temperature. Y. ruckeri $\mathrm{NVH}$ _3758 was grown in LB medium for 10 consecutive days at $37^{\circ} \mathrm{C}$ with dilutions each day (Trevors, 1986). After 10 days, colony PCR was performed on 10 clones using pil 


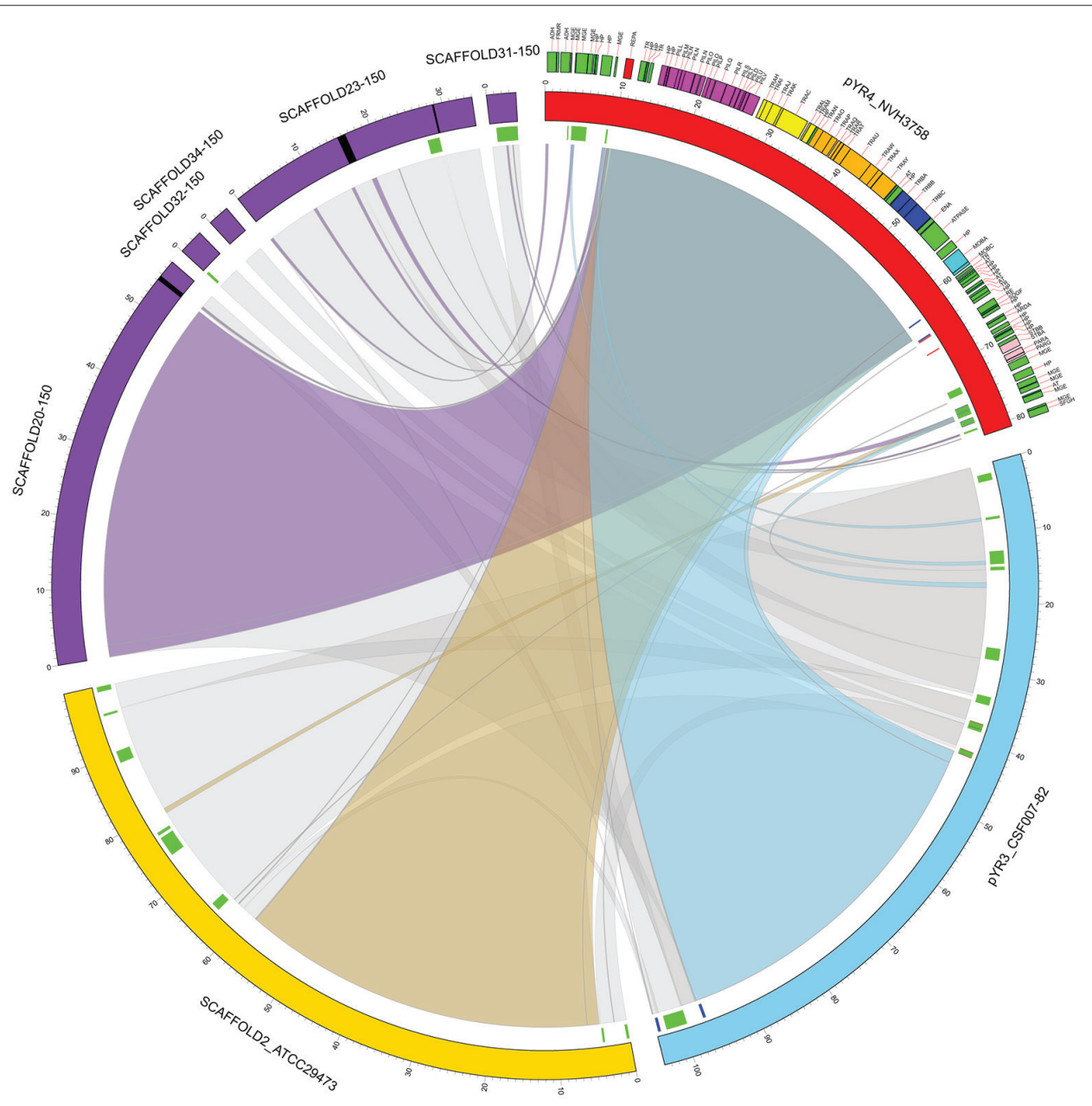

FIGURE 3 | Circular representation of a comparative analysis of pYR4 from Y. ruckeri NVH_3758 to pYR3 and scaffolds of genomic assemblies from Y. ruckeri ATCC29473 (scaffold 2) and Y. ruckeri 150 (scaffolds 20, 23, 31, 32, 34). The pYR4 plasmid is depicted in red, pYR3 in blue, Y. ruckeri ATCC29473 scaffold 2 in yellow, and Y. ruckeri 150 scaffolds in purple. Sequence gaps (stretches of Ns) within ATCC29473 scaffolds are reported in black. Annotated features in pYR4 are shown and colored as in Figure 2. Repetitive DNA regions in pYR3 and pYR4 are colored red and blue, and mobile genetic elements are colored in green (lines in inner ring). Pairwise Locally Collinear Blocks (LCBs) as found in Mauve DNA alignments, are represented as ribbon links colored as follows: pYR4-pYR3 in light blue, pYR4-ATCC29473 in yellow, pYR4-150 in purple, pYR3-ATCC29473, and pYR3-150 in gray. Ribbon links of the ATCC29473 and 150 scaffolds with pYR3 and pYR4 are represented separately in Supplementary Figures 6, 7.

primers that could only bind to the plasmid sequence. All tested clones were PCR-positive for the pYR4 plasmid (data not shown). Based on our high quality genomic assembly, the pil operon is found only on the pYR4 plasmid and is absent from the chromosome. The results obtained from this analysis indicate that pYR4 is a very stable plasmid. The conjugative ability of the plasmid may maintain it in the population and determine its stability, so that even if individual cells lose it, they get it back from their neighbors. This suggests that the plasmid cannot be cured easily in a short time frame such, as the one that we tested. As we were unable to cure pYR4 within a reasonable amount of time, this precluded performing virulence assays to check the involvement of the plasmid in pathogenesis.

\section{DISCUSSION}

\section{Higher Quality of pYR4 Assembly and Identification of Unplaced Scaffolds}

Comparative analysis of the pil region of pYR4 plasmid with other Y. ruckeri plasmids revealed that the pil region is not a common feature among Y. ruckeri strains. Even though we could identify different pil regions in some of the Y. ruckeri plasmids such as pWKY, we did not detect any significant sequence similarity with the pil region described here. Literature suggests that the pil operon can be encoded both on plasmids (pADAP of S. entomophila) (Hurst et al., 2011) and the chromosome (in Y. pseudotuberculosis 32777) (Collyn et al., 2002). Our data shows that in Y. ruckeri NVH_3758, the 
TABLE 4 | The main characteristic features of in pil operon identified in the pYR4 plasmid from Y. ruckeri NVH_3758.

\begin{tabular}{|c|c|c|c|c|}
\hline CDS & Homolog found by BLASTP & Organism & $\begin{array}{l}\text { No. of similar amino acids/total } \\
\text { no. of amino acids (similarity \%) }\end{array}$ & Accession number \\
\hline Pill & Lipoprotein PilL unknown function & Y. pseudotuberculosis & 234/356 (66\%) & WP_012606417.1 \\
\hline PilM & Lipoprotein PilM unknown function & S. marcescens & $109 / 141(77 \%)$ & CVH07391.1 \\
\hline PilN & $\begin{array}{l}\text { TFP formation outer membrane } \\
\text { protein, R64 PilN family }\end{array}$ & S. liquefaciens & 106/133 (80\%) & OKP16072.1 \\
\hline PilN & $\begin{array}{l}\text { PilN family TFP formation outer } \\
\text { membrane protein }\end{array}$ & S. marcescens & 338/404 (84\%) & WP_089197779.1 \\
\hline PilN & Putative TFP operon lipoprotein & Y. intermedia & $151 / 217(70 \%)$ & CNI92757.1 \\
\hline $\mathrm{PilO}$ & $\begin{array}{l}\text { Incl1 plasmid pilus assembly protein } \\
\text { PilO }\end{array}$ & S. fonticola & $103 / 160(64 \%)$ & WP_021807907.1 \\
\hline PilO & $\begin{array}{l}\text { Incl1 plasmid pilus assembly protein } \\
\text { PilO }\end{array}$ & S. fonticola & $126 / 153(82 \%)$ & WP_021807907.1 \\
\hline PilP & TFP biogenesis protein PilP & Serratia sp. 14-2641 & $142 / 195$ (73\%) & WP_065685464.1 \\
\hline PilQ & $\begin{array}{l}\text { Incl1 plasmid conjugative transfer } \\
\text { ATPase PilQ }\end{array}$ & S. fonticola & $334 / 424$ (79\%) & WP_021807909.1 \\
\hline PilR & $\begin{array}{l}\text { General secretion pathway protein } \\
\text { GspF }\end{array}$ & S. marcescens & 298/380 (78\%) & WP_060442021.1 \\
\hline Pils & Prepilin & Serratia sp. S4 & 167/197 (85\%) & WP_017891024.1 \\
\hline PilT & Lytic transglycosylase & Serratia sp. S4 & $138 / 161(86 \%)$ & WP_017891023.1 \\
\hline PilD & Prepilin peptidase & S. marcescens & $22 / 40$ (55\%) & ASL85991.1 \\
\hline PilV & $\begin{array}{l}\text { Shufflon system plasmid conjugative } \\
\text { transfer pilus tip adhesin PilV }\end{array}$ & Y. pekkanenii & 297/446 (67\%) & CNI31753.1 \\
\hline PilU & Prepilin peptidase & S. fonticola AU-AP2C & $101 / 135$ (75\%) & ERK05998.1 \\
\hline
\end{tabular}

TFP gene cluster is plasmid-encoded and no other TFP gene cluster was detected on the chromosome. In fact, our genomic comparative survey indicates that previously deposited Illuminasequenced genomic assemblies containing the tra and the pil operons-five scaffolds from a Y. ruckeri 150 assembly and a scaffold from Y. ruckeri ATCC29743-correspond to the plasmid pYR3. In particular for the 150 strain, failure in placing the genomic scaffolds may have occurred due to the presence of repetitive DNA sequences and of mobile elements in the flanking regions, e.g., the repetitive mobile element at positions 37,63338,328 and 41,885-42,850 of pYR3 (Figure 3). This might also explain the presence of sequence gaps in the scaffolds 20 and 23 of ATCC29743 (Figure 3). These results show the power of the PacBio SMRT technology in producing higher-quality genomic assemblies, thanks to the longer average read lengths available.

Our study highlights the problem related to incorrect assemblies when using second generation sequencing (SGS) technologies. Short-read sequencing is often not enough to properly assemble plasmid sequences. Plasmids often contain many mobile repeat structures whose DNA length exceeds that provided by limitations of SGS technology (ranging 100-600 bp), thus generating unplaced scaffolds and misassemblies. The longer average read length provided by the PacBio SMRT sequencing can address some of the limitations of the SGS technologies, making it possible to correctly place genomic scaffolds even when containing repetitive regions and obtain higher quality assemblies. Sequencing the NVH_3758 genome using the PacBio technology yielded two contigs representing the chromosomal genome of $\sim 3.8 \mathrm{Mb}$ and the $\sim 81 \mathrm{~kb}$ plasmid pYR4. Thanks to the PacBio platform, we could correctly determine the plasmid location of both the tra and the pil operons. The presence of the tra operon on the pYR4 plasmid, not on the chromosome, is reasonable as the tra operon encodes genes involved in bacterial conjugation and DNA transfer. We re-emphasize that these two systems, despite having similar names, are very distinct structurally and mechanistically. The T4SS is a secretion system that translocates nucleoprotein complexes or effector proteins into target cells, whereas TFP are contractile appendages mainly mediating adhesion and certain types of motility (Shi and Sun, 2002).

\section{TFPs in pYR4 And Their Potential Role in Virulence and Conjugation}

In the human pathogenic Yersiniae, pathogenicity is mainly related to the presence of the 70-kb virulence plasmid pYV. This plasmid encodes the Yop proteins and T3SS, which enable the bacteria to survive and multiply in the host tissues (Viboud and Bliska, 2005). Plasmids described so far in Y. ruckeri have recently gained more and more attention due to their potential association with virulence, although in-depth knowledge regarding their function is lacking.

Annotations of pYR4 showed 92 open reading frames. We could identify three different functional regions responsible for plasmid partitioning, a T4SS and a TFP. The present study strongly suggests that the pYR4 pil cluster belongs to the TFP family. In addition to attachment and motility, TFPs can be 
involved in DNA uptake as shown in N. gonorrhoeae (Wolfgang et al., 1998). Interestingly, there are examples of TFPs being involved in bacterial conjugation. For example, the PAPI-1 pathogenicity island of $P$. aeruginosa can be transferred to a recipient strain lacking this island. The mobilization of PAPI1 was dependent on a TFP (Carter et al., 2010). The fact that the pil operon clusters together with the tra operon suggests that the two are functionally coupled and that the TFPs are involved in conjugative transfer of pYR4. However, it is also possible that the TFP is a virulence factor. We speculate that the pil proteins in pYR4, apart from being involved in virulence, can also be responsible for thin pilus formation required for liquid mating (Kim and Komano, 1997). Experiments carried out by Collyn et al. showed that the TFP gene cluster present in Y. pseudotuberculosis is not only involved in synthesis of TFPs, but also contributes to its virulence (Collyn et al., 2002). Based on these findings, we speculate that the pil operon present in $Y$. ruckeri could play a similarly important role in fish disease.

The difference between the $\mathrm{G}+\mathrm{C}$ content of the pil operon (51.7\%) and the average G+C content of the pYR4 plasmid (49.4\%) suggests that the pil operon could have been acquired relatively recently by horizontal gene transfer. Likewise, the difference in $\mathrm{G}+\mathrm{C}$ content compared to the $Y$. ruckeri NVH_3758 chromosome (47.6\%) suggests that the plasmid has been acquired from a different species. Previous studies show that for a plasmid to be horizontally transferred, the difference in the $\mathrm{G}+\mathrm{C}$ composition between the genome and the plasmid should be in the range from 1 to 5\% (Hurst et al., 2011). The $\mathrm{G}+\mathrm{C}$ content of the plasmid pADAP of S. entomophila is $53 \%$. Most of the pil proteins from pYR4 (PilL, PilN, PilO, PilP, PilQ, PilR, PilS, PilT, PilD) are highly similar to pil proteins found in TFPs in Serratia species, whereas others (PilL, PilU, PilN) are more similar to those found in other Yersiniae. These findings, in addition to the same gene organization of the pil cluster, suggest that the TFP locus in pYR4 may have been acquired from $S$. entomophila, which occupies a similar aquatic environment as $Y$. ruckeri (Grimont et al., 1988).

\section{T4SSs and the tra Operon}

Analysis of the pYR4 protein encoding sequences allowed us to identify a complete T4SS, which we named tra. The corresponding coding region consists of three operons. The genetic organization of the tra operons (tra1, tra2, tra3) is very similar to that found in pADAP of S. entomophila, pCTXM3 of C. freundii and pEL60, pEA67, pEA72, and pEA78 of E. amylovora, as previously described for tral (Méndez et al., 2009). Comparative analysis of the pYR4 tra operons to the pYR3 tra operons from Y. ruckeri CSF007-82 showed 99.9\% nucleotide sequence similarity, in contrast to tra operons from other Y. ruckeri strains, where we did not detect any strong sequence similarity. In 2007, Welch et al. showed the presence of multidrug resistance of the plasmid pYR1 in Y. ruckeri YR71. pYR1 also contains a T4SS for conjugative transfer. However, the T4SS of pYR1 does not show high levels of sequence similarity-and no LCB was found in the Mauve alignment-to the tra operons described here (Welch et al., 2007).

Interestingly, similarities between the pYR4 Tra and $L$. pneumophila $\mathrm{Icm} /$ Dot proteins implicate a role in Y. ruckeri virulence. L. pneumophila is the causative agent of Legionnaires' disease. As an intracellular pathogen, L. pneumophila is able to grow and multiply within human macrophages, leading to their killing. In L. pneumophila, many virulence genes located in icm ("for intracellular multiplication") and dot ("defect in organelle trafficking") locus have been identified. Some of the Dot/Icm proteins are homologous to the Tra proteins found in plasmid R64 (Komano et al., 2000). pYR4 Tra proteins display amino acid sequence similarity to $\mathrm{Icm} /$ Dot proteins ranging from 29 to $34 \%$. They are similar in size and their predicted functions are similar. However, as we could not identify any genes encoding putative effector proteins in pYR4 of NVH_3758, it is possible that the tra locus is purely conjugative. Nevertheless, we cannot conclusively rule out a role for the tra locus in virulence. Interestingly, Méndez et al. generated the traI mutant strain of $Y$. ruckeri 150 in which the traI gene was disrupted. In the in vivo competition assays in rainbow trout, the virulence of the traI mutant strain was reported to be attenuated when compared to the WT strain, suggesting that TraI is involved in virulence of this bacterium.

\section{CONCLUSIONS}

In conclusion, the results presented here suggest that pYR4 from the 1987 outbreak strain Y. ruckeri NVH_3758 is a conjugative plasmid that encodes a T4SS and a TFP that might contribute to $Y$. ruckeri virulence. The $55 \mathrm{kDa}$ plasmid backbone is identical to that of pYR3 and has presumably been acquired by horizontal gene transfer through conjugation from a Serratia species that occupies the same biological niche, as previously suggested (Méndez et al., 2009). In addition, pYR4 contains a a previously undescribed $\sim 25 \mathrm{kDa}$ region with a partitioning system completely different from that of pYR3. This region contains a set of mobile elements, several hydrogenase enzymes with a corresponding transcription factor, and additional hypothetical genes that need further investigation.

The plasmid could contribute to the dissemination of $Y$. ruckeri virulence by spreading the TFP-encoding pil locus among non-virulent strains. Further experiments are required to elucidate the function of the pil and tra regions and to clarify their role in virulence. However, we would like to highlight that based on $100 \%$ sequence similarity between TraI of pYR4 and TraI of Y. ruckeri 150 that we now know is located on pYR3 based on our re-assembly of the Y. ruckeri 150 genome, we assume that at least the tra region is directly involved in virulence. traI deletion in $Y$. ruckeri 150 lead to a significant decrease in virulence (Méndez et al., 2009). Additionally, our study demonstrates the power of PacBio SMRT sequencing technology in producing assemblies of high quality and accuracy, compared to sequencing technologies based on shorter read lengths such as Illumina and 454 . The latter methods failed to show the plasmid localization of the pil and tra regions in multiple cases. 


\section{DATA AVAILABILITY}

The sequence of pYR4 described herein has been deposited in GenBank with the accession number CP032236.

\section{AUTHOR CONTRIBUTIONS}

$\mathrm{AW}$ and $\mathrm{CO}$ conceived, planned, and carried out the experiments. AW, CO, JL, and $\mathrm{DL}$ contributed to the discussion and interpretation of the results, and wrote the manuscript. All authors provided critical feedback and contributed to the final shape of the manuscript.

\section{FUNDING}

This work by supported by Departmental funds of the Department of Biosciences, University of Oslo (COMPI), by Research Council of Norway Young Investigator grant 249793

\section{REFERENCES}

Altschul, S., Madden, T., Schäffer, A., Zhang, J., Zhang, Z., Miller, W., et al (1997). Gapped BLAST and PSI-BLAST: a new generation of protein database search programs. Nucleic Acids Res. 25, 3389-3402. doi: 10.1093/nar/25.17. 3389

Avendaño-Herrera, R., Tapia-Cammas, D., Aedo, A., Saldivia, P., Ortega, C., and Irgang, R. (2017). Disease caused by Yersinia ruckeri serotype O2b found in chilean-farmed coho salmon, Oncorhynchus kisutch. J. Fish Dis. 40, 279-285. doi: $10.1111 /$ jfd.12502

Aziz, R., Bartels, D., Best, A., DeJongh, M., Disz, T., Edwards, R., et al. (2008). The RAST server: rapid annotations using subsystems technology. BMC Genomics 9:75. doi: 10.1186/1471-2164-9-75

Barnes, A., Delamare-Deboutteville, J., Gudkovs, N., Brosnahan, C., Morrison, R, and Carson, J. (2016). Whole genome analysis of Yersinia ruckeri isolated over 27 years in Australia and New Zealand reveals geographical endemism over multiple lineages and recent evolution under host selection. Microb. Genomics 2:e000095. doi: 10.1099/mgen.0.000095

Ben-Gurion, R., and Shafferman, A. (1981). Essential virulence determinants of different Yersinia are carried on a common plasmid. Plasmid 5, 183-187. doi: 10.1016/0147-619X(81)90019-6

Bottone, E. (1997). Yersinia enterocolitica: the charisma continues. Clin. Microbiol. Rev. 10, 257-276.

Bullock, G., Stuckey, H., and Shotts, J. R. E. (1978). Enteric redmouth bacterium: comparison of isolates from different geographic areas. J. Fish Dis. 1, 351-356. doi: 10.1111/j.1365-2761.1978.tb0 0039.x

Busch, R. (1978). Enteric redmouth disease. Mar. Fish. Rev. 40, 42-51.

Carattoli, A. (2009). Resistance plasmid families in Enterobacteriaceae. Antimicrob. Agents Chemother. 53, 2227-2238. doi: 10.1128/AAC.01707-08

Carattoli, A., Villa, L., Poirel, L., Bonnin, R., and Nordmann, P. (2012) Evolution of IncA /C bla CMY-2 -carrying plasmids by acquisition of the bla NDM-1 carbapenemase gene. Antimicrob. Agents Chemother. 56, 783-786. doi: 10.1128/AAC.05116-11

Carter, M., Chen, J., and Lory, S. (2010). The Pseudomonas aeruginosa pathogenicity island PAPI-1 is transferred via a novel type IV pilus. J. Bacteriol. 192, 3249-3258. doi: 10.1128/JB.00041-10

Chauhan, N., Wrobel, A., Skurnik, M., and Leo, J. (2016). Yersinia adhesins: an arsenal for infection. Proteomics-Clin. Appl. 10, 949-963. doi: $10.1002 /$ prca.201600012

Collyn, F., Léty, M., Nair, S., Escuyer, V., Younes, A., Simonet, M., et al. (2002). Yersinia pseudotuberculosis harbors a type IV pilus gene (to JL), and by Research Council of Norway FriMedBio grant 240483 (to DL).

\section{ACKNOWLEDGMENTS}

We would like to thank the sequencing service provided by the Norwegian Sequencing Centre (www.sequencing.uio. no), a national technology platform hosted by the University of Oslo and supported by the Functional Genomics and Infrastructure programs of the Research Council of Norway and the Southeastern Regional Health Authorities. We express gratitude to Prof. Duncan Colquhoun (Norwegian Veterinary Institute) for providing Y.ruckeri NVH_3758.

\section{SUPPLEMENTARY MATERIAL}

The Supplementary Material for this article can be found online at: https://www.frontiersin.org/articles/10.3389/fcimb. 2018.00373/full\#supplementary-material cluster that contributes to pathogenicity. Infect. Immun. 70, 6196-6205. doi: 10.1128/IAI.70.11.6196-6205.2002

Cornelis, G., Boland, A., Boyd, A., Geuijen, C., Iriarte, M., Neyt, C., et al. (1998). The virulence plasmid of Yersinia, an antihost genome. Microbiol. Mol. Biol. Rev. 62, 1315-1352.

Couturier, M., Bex, F., Bergquist, P., and Maas, W. (1988). Identification and classification of bacterial plasmids. Microbiol. Rev. 52, 375-395.

Crosa, J. (1980). A plasmid associated with virulence in the marine fish pathogen Vibrio anguillarum specifies an iron sequestering system. Nature 284, 566-568. doi: $10.1038 / 284566 \mathrm{a} 0$

Darling, A., Mau, B., and Perna, N. (2010). Progressive mauve: multiple genome alignment with gene gain, loss and rearrangement. PLOS ONE 5:e11147. doi: 10.1371/journal.pone.0011147

De Grandis, S., and Stevenson, R. (1982). Variations in plasmid profiles and growth characteristics of Yersinia ruckeri strains. FEMS Microbiol. Lett. 15, 199-202. doi: 10.1111/j.1574-6968.1982.tb00067.x

De Grandis, S., and Stevenson, R. (1985). Antimicrobial susceptibility pattern and R plasmid-mediated resistance of the fish pathogen Yersinia ruckeri. Antimicrob. Agents Chemother. 27, 938-942. doi: 10.1128/AAC.27.6.938

Edgar, R. (2004). MUSCLE: multiple sequence alignment with high accuracy and high throughput. Nucleic Acids Res. 32, 1792-1797. doi: 10.1093/nar/gkh340

Felsenstein, J. (1985). Confidence limits on phylogenies: an approach using the bootstrap. Evolution 39, 783-791. doi: 10.1111/j.1558-5646.1985.tb00420.x

Ferber, D., and Brubaker, R. (1981). Plasmids in Yersinia pestis. Infect. Immun. 31, 839-841.

Fernández, L., Marquez, I., and Guijarro, J. (2004). Identification of specific in vivo-induced (ivi) genes in Yersinia ruckeri and analysis of ruckerbactin, a catecholate siderophore iron acquisition system. Appl. Environ. Microbiol. 70 5199-5207. doi: 10.1128/AEM.70.9.5199-5207.2004

Fernández, L., Prieto, M., and Guijaro, J. (2007). The iron- and temperatureregulated haemolysin YhlA is a virulence factor of Yersinia ruckeri. Microbiology 153, 483-489. doi: 10.1099/mic.0.29284-0

Garcia, J., Dominguez, L., Larsen, J., and Pedersen, K. (1998). Ribotyping and plasmid profiling of Yersinia ruckeri. J. Appl. Microbiol. 85, 949-955. doi: 10.1111/j.1365-2672.1998.tb05258x

Grimont, P., Jackson, T., Ageron, E., and Noonan, M. (1988). Serratia entomophile sp. nov. associated with amber disease in the New Zealand grass grub Costelytra zealandica. Int. J. Syst. Bacteriol. 38, 1-6. doi: 10.1099/00207713-38-1-1

Guilvout, I., Quilici, M., Rabot, S., Lesel, R., and Mazigh, D. (1988). BamHI restriction endonuclease analysis of Yersinia ruckeri plasmids and their relatedness to the genus Yersinia 42- to 47-megadalton plasmid. Appl. Environ Microbiol. 54, 2594-2597. 
Gulla, S., Barnes, A., Welch, T., Romalde, J., Ryder, D., Ormsby, M., et al. (2018). Multi-locus variable number of tandem repeat Analysis (MLVA) of Yersinia ruckeri confirms the existence of host-specificity, geographic endemism and anthropogenic dissemination of virulent clones. Appl. Environ. Microbiol. 84:e00730-18. doi: 10.1128/AEM.00730-18

Haiko, J., Suomalainen, M., Ojala, T., Lähteenmäki, K., and Korhonen, T. (2009) Invited review: breaking barriers - attack on innate immune defences by omptin surface proteases of enterobacterial pathogens. Innate Immun. 15 67-80. doi: 10.1177/1753425909102559

Hayek, N. (2013). Lateral transfer and GC content of bacterial resistance genes. Front. Microbiol. 4:41. doi: 10.3389/fmicb.2013.00041

Hjeltnes, B., Bornø, G., Jansen, M., Haukaas, A., and Walde, C. (2017). The Health Situation in Norwegian Aquaculture 2016. Norwegian Veterinary Institute 2017

Huang, Y., Michael, G., Becker, R., Kaspar, H., Mankertz, J., Schwarz, S. et al. (2014). Pheno- and genotypic analysis of antimicrobial resistance properties of Yersinia ruckeri from fish. Vet. Microbiol. 171, 406-412. doi: 10.1016/j.vetmic.2013.10.026

Hurst, M., Becher, S., and O'Callaghan, M. (2011). Nucleotide sequence of the Serratia entomophila plasmid pADAP and the Serratia proteamaculans pU143 plasmid virulence associated region. Plasmid 65, 32-41. doi: 10.1016/j.plasmid.2010.10.001

Isberg, R., and Leong, J. (1990). Multiple $\beta 1$ chain integrins are receptors fo invasin, a protein that promotes bacterial penetration into mammalian cells. Cell 60, 861-871. doi: 10.1016/0092-8674(90)90099-Z

Jalava, K., Hakkinen, M., Valkonen, M., Nakari, U., Palo, T., Hallanvuo, S., et al. (2006). An outbreak of gastrointestinal illness and erythema nodosum from grated carrots contaminated with Yersinia pseudotuberculosis. J. Infect. Dis. 194 1209-1216. doi: 10.1086/508191

Johnson, T., and Lang, K. (2012). IncA/C plasmids: an emerging threat to human and animal health? Mob. Genet. Elements 2, 55-58. doi: 10.4161/mge. 19626

Kearse, M., Moir, R., Wilson, A., Stones-Havas, S., Cheung, M., Sturrock, S., et al. (2012). Geneious basic: an integrated and extendable desktop software platform for the organization and analysis of sequence data. Bioinformatics 28 , 1647-1649. doi: 10.1093/bioinformatics/bts199

Kim, S., and Komano, T. (1997). The plasmid R64 thin pilus identified as type IV pilus. J. Bacteriol. 179, 3594-3603. doi: 10.1128/jb.179.11.3594-3603. 1997

Komano, T., Yoshida, T., Narahara, K., and Furuya, N. (2000). The transfer region of IncI1 plasmid R64: similarities between R64 tra and Legionella icm/dot genes. Mol. Microbiol. 35, 1348-1359. doi: 10.1046/j.1365-2958.2000. 01769.x

Krzywinski, M., Schein, J., Birol, I., Connors, J., Gascoyne, R., Horsman, D., et al. (2009). Circos: an information aesthetic for comparative genomics. Genome Res. 18, 1639-1645. doi: 10.1101/gr.092759.109

Kumar, G., Hummel, K., Ahrens, M., Menanteau-Ledouble, S., Welch, T., Eisenacher, M., et al. (2016). Shotgun proteomic analysis of Yersinia ruckeri strains under normal and iron-limited conditions. Vet. Res. 47:100 doi: 10.1186/s13567-016-0384-3

Kumar, G., Hummel, K., Welch, T., Razzazi-Fazeli, E., and El-Matbouli, M. (2017). Global proteomic profiling of Yersinia ruckeri strains. Vet. Res. 48:55. doi: 10.1186/s13567-017-0460-3

Kumar, S., Stecher, G., Li, M., Knyaz, C., and Tamura, K. (2018). MEGA X: molecular evolutionary genetics analysis across computing platforms. Mol. Biol. Evol. 35, 1547-1549. doi: 10.1093/molbev/msy096

Liu, T., Wang, K., Wang, J., Chen, D., Huang, X., Ouyang, P., et al. (2016) Genome sequence of the fish pathogen Yersinia ruckeri SC09 provides insight into niche adaptation and pathogenic mechanism. Int. J. Mol. Sci. 17:557 doi: 10.3390/ijms 17040557

Méndez, J., Fernández, L., Ménendez, A., Reimundo, P., Pérez-Pascual, D., Navais, R., et al. (2009). A chromosomally located traHIJKCLMN operon encoding a putative type IV secretion system is involved in the virulence of Yersinia ruckeri. Appl. Environ. Microbiol. 75, 937-945. doi: 10.1128/AEM.01377-08

Mühlenkamp, M., Oberhettinger, P., Leo, J., Linke, D., and Schütz, M. (2015) Yersinia adhesin A (YadA) - Beauty \& beast. Int. J. Med. Microbiol. 305, 252-258. doi: 10.1016/j.ijmm.2014.12.008
Nelson, M., Lapatra, S., Welch, T. (2015). Complete genome sequence of Yersinia ruckeri strain CSF007-82, etiologic agent of red mouth disease in salmonid fish Genome Announc. 3:e01491-14. doi: 10.1128/genomeA.01491-14

Ni, B., Du, Z., Guo, Z., Zhang, Y., and Yang, R. (2008). Curing of four different plasmids in Yersinia pestis using plasmid incompatibility. Lett. Appl. Microbiol. 47, 235-240. doi: 10.1111/j.1472-765X.2008.02426.x

Nishida, H. (2012). Comparative analyses of base compositions, DNA sizes, and dinucleotide frequency profiles in archaeal and bacterial chromosomes and plasmids. Int. J. Evol. Biol. 2012:342482. doi: 10.1155/2012/342482

Ormsby, M., Caws, T., Burchmore, R., Wallis, T., Verner-Jeffreys, D., and Davies, R. (2016). Yersinia ruckeri isolates recovered from diseased atlantic salmon (Salmo salar) in scotland are more diverse than those from rainbow trout (Oncorhynchus mykiss) and represent distinct subpopulations. Appl. Environ. Microbiol. 82, 5785-5794. doi: 10.1128/AEM.01173-16

Perry, R., and Fetherston, J. (1997). Yersinia pestis - etiologic agent of plague. Clin. Microbiol. Rev. 10, 35-66.

Pilla, G., and Tang, C. M. (2018). Going around in circles: virulence plasmids in enteric pathogens. Nat. Rev. Microbiol. 16, 484-95. doi: 10.1038/s41579-018-0031-2

Reuter, S., Connor, T., Barquist, L., Walker, D., Feltwell, T., Harris, S., et al. (2014) Parallel independent evolution of pathogenicity within the genus Yersinia.Proc. Natl. Acad. Sci. U.S.A. 111, 6768-6773. doi: 10.1073/pnas.1317161111

Romalde, J., MagariÑos, B., Barja, J., and Toranzo, A. (1993). Antigenic and molecular characterization of Yersinia ruckeri proposal for new intraspecies classification. Syst. Appl. Microbiol. 16, 411-419. doi: 10.1016/S0723-2020(11)80274-2

Romalde, J. L., and Toranzo, A. E. (1993). Pathological activities of Yersinia ruckeri, the enteric redmouth (ERM) bacterium. FEMS Microbiol. Lett. 112, 291-299. doi: 10.1111/j.1574-6968.1993.tb06465.x

Sadosky, A. B., Wiater, L. A., and Shuman, H. A. (1993). Identification of Legionella pneumophila genes required for growth within and killing of human macrophages. Infect. Immun. 61, 5361-5373.

Savin, C., Martin, L., Bouchier, C., Filali, S., Chenau, J., Zhou, Z., et al. (2014) The Yersinia pseudotuberculosis complex: characterization and delineation of a new species, Yersinia wautersii. Int. J. Med. Microbiol. 304, 452-463. doi: 10.1016/j.ijmm.2014.02.002

Secades, P., and Guijarro, J. A. (1999). Purification and characterization of an extracellular protease from the fish pathogen Yersinia ruckeri and effect of culture condition on production. Appl. Environ. Microbiol. 65, 3969-3975.

Seemann, T. (2014). Prokka: rapid prokaryotic genome annotation. Bioinformatics 30, 2068-2069. doi: 10.1093/bioinformatics/btu153

Shahmuradov, I., Mohamad Razali, R., Bougouffa, S., Radovanovic, A and Bajic, V. (2017). bTSSfinder: a novel tool for the prediction of promoters in cyanobacteria and Escherichia coli. Bioinformatics 33, 334-340. doi: 10.1093/bioinformatics/btw629

Sheridan, J. J., Logue, C. M., McDowell, D. A., Blair, I. S., and Hegarty, T. (1998). A study of the growth kinetics of Yersinia enterocolitica serotype O:3 in pure and meat culture systems. J. Appl. Microbiol. 85, 293-301. doi: 10.1046/j.1365-2672.1998.00504.x

Shi, W., and Sun, H. (2002). Type IV pilus-dependent motility and its possible role in bacterial pathogenesis. Infect. Immun. 70, 1-4. doi: 10.1128/IAI.70.1.1-4.2002

Söding, J., Biegert, A., and Lupas, A. N. (2005). The HHpred interactive server for protein homology detection and structure prediction. Nucleic Acids Res. 33 , 244-248. doi: 10.1093/nar/gki408

Solovyev, V., and Salamov, A. (2011). "Automatic annotation of microbia genomes and metagenomic sequences," in Metagenomics and its Applications in Agriculture, Biomedicine and Environmental Studies, ed R. W. Li (New York, NY: Nova Science Publishers), 61-78.

Sonnhammer, E., Eddy, S., Birney, E., Bateman, A., and Durbin, R. (1998). Pfam: multiple sequence alignments and HMM-profiles of protein domains. Nucleic Acids Res. 26, 320-322. doi: 10.1093/nar/26.1.320

Sparboe, O., Koren, C., Hastein, T., Poppe, T., and Stenwig, H. (1986). The first isolation of Yersinia ruckeri from farmed Norwegian salmon. Bull. Eur. Assoc. Fish Pathol. 6, 41-42.

Stevenson, R., and Airdrie, R. (1984). Serological variation among Yersinia ruckeri strains. J. Fish Dis. 7, 247-254. doi: 10.1111/j.1365-2761.1984.tb00930.x 
Sussman, J. L., Abola, E. E., Lin, D., Jiang, J., Manning, N. O., and Prilusky, J. (1999). The protein data bank. Bridging the gap between the sequence and 3D structure world. Genetica 1062, 149-158. doi: 10.1023/A:10037535 17358

Swanson, M. S., and Isberg, R. R. (1996). Identification of Legionella pneumophila mutants that have aberrant intracellular fates. Infect. Immun. 64, 2585-2594.

Toranzo, A. E., Barja, J. L., Colwell, R. R., and Hetrick, F. M. (1983). Characterization of plasmids in bacterial fish pathogens. Infect. Immun. 39 184-192.

Trevors, J. T. (1986). Plasmid curing in bacteria. FEMS Microbiol. Lett. 32, 149-157. doi: 10.1111/j.1574-6968.1986.tb01189.x

Viboud, G. I., and Bliska, J. B. (2005). Yersinia outer proteins: role in modulation of host cell signaling responses and pathogenesis. Anпu. Rev. Microbiol. 59, 69-89. doi: 10.1146/annurev.micro.59.030804.121320

Villa, L., García-Fernández, A., Fortini, D., and Carattoli, A. (2010). Replicon sequence typing of IncF plasmids carrying virulence and resistance determinants. J. Antimicrob. Chemother. 65, 2518-2529. doi: $10.1093 / \mathrm{jac} / \mathrm{dkq} 347$

Wallden, K., Rivera-Calzada, A., and Waksman, G. (2010). Type IV secretion systems: versatility and diversity in function. Cell. Microbiol. 12, 1203-1212. doi: 10.1111/j.1462-5822.2010.01499.x

Welch, T. J., Fricke, W. F., Mcdermott, P. F., White, D. G., Rosso, M., Rasko, D. A., et al. (2007). Multiple antimicrobial resistance in plague: an emerging public health risk. PLoS ONE 2:e309. doi: 10.1371/journal.pone.00 00309

Wolfgang, M., Lauer, P., Park, H., Brossay, L., Hebert, J., and Koomey, M. (1998). PilT mutations lead to simultaneous defects in competence for natural transformation and twitching motility in piliated Neisseria gonorrhoeae. Mol. Microbiol. 29, 321-330. doi: 10.1046/j.1365-2958.1998. 00935.x

Wrobel, A., Ottoni, C., Leo, J. C., Gulla, S., and Linke, D. (2017). The repea structure of two paralogous genes, Yersinia ruckeri Invasin (yrInv) and a "Y. ruckeri Invasin-like molecule", (yrllm) sheds light on the evolution of adhesive capacities of a fish pathogen. J. Struct. Biol. 201, 171-183. doi: $10.1016 /$ j.jsb.2017.08.008

Yang, Q., Sun, J., Li, L., Deng, H., Liu, B., Fang, L., et al. (2015). IncF plasmid diversity in multi-drug resistant Escherichia coli strains from animals in China. Front. Microbiol. 6:964. doi: 10.3389/fmicb.2015.00964

Yu, J., Cho, M., Kim, J., and Kang, H. (2012). Large antibiotic-resistance plasmid of Edwardsiella tarda contributes to virulence in fish. Microb. Pathog. 52, 259-266. doi: 10.1016/j.micpath.2012.01.006

Zhang, X.-L., Tsui, I. S. M., Yip, C. M. C., Fung, A. W. Y., Wong, D. K. H., Dai, X., et al. (2000). Salmonella enterica Serovar typhi uses type IVB Pili to enter human intestinal epithelial cells. Infect. Immun. 68, 3067-3073. doi: 10.1128/IAI.68.6.3067-3073.2000

Zuckerkandl, E., and Pauling, L. (1965). "Evolutionary divergence and convergence in proteins," in Evolving Genes and Proteins, eds V. Bryson and H. J. Vogel (New York, NY: Academic Press), 97-166.

Zuker, M. (2003). Mfold web server for nucleic acid folding and hybridization prediction. Nucleic Acids Res. 31, 3406-3415. doi: 10.1093/nar/gkg595

Conflict of Interest Statement: The authors declare that the research was conducted in the absence of any commercial or financial relationships that could be construed as a potential conflict of interest.

The reviewer HL and handling Editor declared their shared affiliation.

Copyright (c) 2018 Wrobel, Ottoni, Leo and Linke. This is an open-access article distributed under the terms of the Creative Commons Attribution License (CC BY). The use, distribution or reproduction in other forums is permitted, provided the original author(s) and the copyright owner(s) are credited and that the original publication in this journal is cited, in accordance with accepted academic practice. No use, distribution or reproduction is permitted which does not comply with these terms. 


\title{
Supplementary Material
}

\section{pYR4 from a Norwegian isolate of Yersinia ruckeri is a putative virulence plasmid encoding a type IV pilus}

\author{
Agnieszka Wrobel*, Claudio Ottoni, Jack C. Leo, Dirk Linke
}

*Correspondence: Dirk Linke: dirk.linke@ibv.uio.no

\section{Supplementary figure 1 .}

Putative promoters prediction for pYR4 operons using bTSSfinder (1) (Shahmuradov et al., 2017) and BPROM (2) (Solovyev and Salamov, 2011) using default parameters. Raw data is included. bTSSfinder predicts putative promoters for five classes of $\sigma$ factors in Cyanobacteria $\left(\sigma^{\mathrm{A}}, \sigma^{\mathrm{C}}, \sigma^{\mathrm{H}}\right.$, $\sigma^{\mathrm{G}}$ and $\left.\sigma^{\mathrm{F}}\right)$ and for five classes of sigma factors in E. coli $\left(\sigma^{70}, \sigma^{38}, \sigma^{32}, \sigma^{28}\right.$ and $\left.\sigma^{24}\right)$ while BPROM predicts putative promoters for one class of $\sigma$ factors, namely $\sigma^{70}$.

\section{1) Putative promoters prediction using bTSSfinder (Shahmuradov et al., 2017)}

a) Putative promoter prediction upstream from hypothetical protein (pil operon)

Input sequence:

CTTGTCTTCGAACCTAGTTTGCTGGGGTTCTAATTACACTCCCGGCATTTAGCAGTTAACCCGGCCTTGTGTC GGGCTCTTTTCCCCCAGATGCGTTACTACAACACTGGATGCCGGCAATGGTGTCTGAGCTGGTCCTGCCATG GACATCCCTATCCCTTTACCGGCTGGTCATTTATGGCGTATTCCTTCTGTTGGAGGGTGATACAGACACCAT TGCCGGCATTCGATACACCAACTCAATTAAAAGGAGATAGCCT

Search for sigma 70, 24, 32, 28 and 38 promoters

Input sequence file with query sequence(s): /var/www/btssfinder/cgi-bin/userdata/928.fasta

Search parameters: for $E$. coli

TSSs of different Sigma classes are processed separately

Search only on Positive Strand

Total scoring threshold for

$$
\begin{array}{ll}
\text { sigma70: } & 0.06 \\
\text { sigma24: } & 0.00 \\
\text { sigma32: } & 1.01 \\
\text { sigma28: } & 1.24 \\
\text { sigma38: } & 0.31
\end{array}
$$

Length of Query sequence: 260

sigma24(+): 202 Score $1.77 \quad-35$ (172) tcattt $>>>$ tctgt -10 (195)

sigma38(+): 201 Score $1.52 \quad-35(160)$ tttacc $>>>$ tattcc -10 (189)

Total: 2 promoter(s) predicted

b) No putative promoters were found upstream from pilL

Input sequence:

CTCCTCTCGTCACCCTAGCAATATCGTCCCCATATACATCAATCGATATGGCTATTCCATTACCTGATGAAA CCTAT

c) Putative promoter prediction upstream from $\operatorname{traN}$

Input sequence:

TCAATCATCACCCGCGATGCCCGCTAATTTTACTCAGGTACTCTCATGAAAAATCTCACTCTCACTGCAGTG GTTATGCTGCTGTCAGCAGTCCCGGCACTCGCGACAGATTGGGTACCAGCCCGCACGGGTAATACACCAAC 
CACCGAGATCCCAGCGGCACCGAAACCTACAGCACCTCAAAACGAACCTGTAGTCCCTCAAACAGATATCA CTGCCCTGATGCTCCAGACACCACCGCCCACCCCCCCCACTGCAGCCCAAGCATGGGCGATGAGCCAGGCC AACCCTCTGGATAATCGCCAGGGTGTTGAAATGGTAGGCAAAGTGATG

Search for sigma 70, 24, 32, 28 and 38 promoters

Input sequence file with query sequence(s): /var/www/btssfinder/cgi-bin/userdata/812.fasta

Search parameters: for E. coli

TSSs of different Sigma classes are processed separately

Search on Positive Strand

Total scoring threshold for

$$
\begin{array}{ll}
\text { sigma70: } & 0.06 \\
\text { sigma24: } & 0.00 \\
\text { sigma32: } & 1.01 \\
\text { sigma28: } & 1.24 \\
\text { sigma38: } & 0.31
\end{array}
$$

Length of Query sequence: 333

sigma24(+): 282 Score $0.30 \quad-35(251)$ ccactg $\gg>$ gegat $-10(275)$

sigma32(+): 261 Score $1.91 \quad-35$ (226) ctccaga $>>>$ cccccactg $-10(256)$

Total: 2 promoter(s) predicted

d) No putative promoters were found upstream of $\operatorname{trb} \mathrm{A}$

Input sequence:

ACGTATCGCCGACGAGCAGGGGCTTAACCTGATCCTGCCGCCAAACTAATTCCCCTTCTGCAGTAACCCAC AGTACCGACTCTGGGGCACCCTTTTCAGGGTGCCTCTTCTTTTGCATTCGCAAAATATTTATAGGTCTCCTCT ATGGCGCAACCCATTCGCAAT

e) No putative promoters were found upstream of ena

Input sequence:

GATGATTTTGATAACACAACCGAACATCTTACCTACTGAAATAAATACTTCCCCGCCAGCTCCTCCAACCGT TGACTAAACCATTAGCTCAATAAGCTCAATTTTTTAATCATTAAGGAATGAAAATGACTATCCGTACATTAC GGTCAATTACTTTGGCCGGCGTTCTAC

f) Putative promoter prediction upstream of $m o b C$

Input sequence:

TGGCGTTTTTCACTCTTGCTCATCTTCAATCCTGCTTAACCGCTGAGGCGGACACTGCAAGTAGGGTGTCGG GACGGAGTCCTGACCAGGTCGTTTTGTGGGACCGACTGCGTGCAGGCGGTGCTACAAAACATACCCTGTCC CACGTTTTACTTCAGTATTCGCTATTATGGCCGATTTTCTTTATAAAGTCATTACGCCAGATGTGGAATGGG GTACCTTTGATTCATGAGTGAATACAAGGGTATAATTGGAAAGTTAACTCTGCACAAAGCACAGAAGGATA TGAGGATGGCCGCAAACAGT

Search for sigma 70, 24, 32, 28 and 38 promoters

Input sequence file with query sequence(s): /var/www/btssfinder/cgi-bin/userdata/820.fasta

Search parameters: for $E$. coli

TSSs of different Sigma classes are processed separately

Search on Positive Strand

Total scoring threshold for

$$
\begin{array}{ll}
\text { sigma70: } & 0.06 \\
\text { sigma24: } & 0.00 \\
\text { sigma32: } & 1.01 \\
\text { sigma28: } & 1.24 \\
\text { sigma38: } & 0.31
\end{array}
$$

Length of Query sequence: 306

sigma70(+): 256 Score $1.91 \quad-35(222)$ ttgatt $>>>$ tataat $-10(251)$

sigma38(+): 255 Score $1.80 \quad-35(222)$ ttgatt $\gg \gg$ tataat $-10(251)$

sigma32(+): 210 Score $1.86 \quad-35(175)$ cgatttt $\gg>$ tacgccagat $-10(205)$

Total: 3 promoter(s) predicted 
g) Putative promoter prediction upstream of $s t b A$

Input sequence:

CAAAATACATTCATCATTTTGAACCTCATCAATACTCAAACTGAGTGGTTGAAGTGCACCCAAGAAATGCA GCTCACAATTTAGGCGATTCCCCATAATCTATGTCCGGTCAGTTACTCAAATTGGGGTGTAATCATATTAAT ATCATTACGCAATCAAAATCAACCTAAAATGATATTGTTTTAATATTAAAACAATATTAAAAAATCAATATT CAACCCGTGAGATAAAAGAGAAGGTGCGTACACAGTAATGATTGACAATCAATAGTTAATCACTATTATCT TAATATTATTTTAATATTAAAAGGACTAACTATGATACTTACAGTTGGTAATACAA

Search for sigma $70,24,32,28$ and 38 promoters

Input sequence file with query sequence(s): /var/www/btssfinder/cgi-bin/userdata/826.fasta

Search parameters: for $E$. coli

TSSs of different Sigma classes are processed separately

Search on Positive Strand

Total scoring threshold for

$$
\begin{array}{ll}
\text { sigma70: } & 0.06 \\
\text { sigma24: } & 0.00 \\
\text { sigma32: } & 1.01 \\
\text { sigma28: } & 1.24 \\
\text { sigma38: } & 0.31
\end{array}
$$

Length of Query sequence: 342

sigma32(+): 288 Score $1.95 \quad-35(254)$ tgattga $>>>$ atcactatta $-10(283)$

sigma38(+): 257 Score $1.94 \quad-35(221)$ cgtgag $>>>$ tacaca $-10(249)$

sigma28(+): 237 Score $1.97 \quad-35(204)$ aaaatcaa $\gg>>$ tgagataa $-10(230)$

sigma70(+): 221 Score $1.97 \quad-35(182)$ tttaat $>>>$ caatat $-10(214)$

sigma24(+): 219 Score $1.97 \quad-35(184)$ taatat $\gg>$ tcaat $-10(212)$

Total: 5 promoter(s) predicted

h) Putative promoter prediction upstream of parA

Input sequence:

CAAAATACATTCATCATTTTGAACCTCATCAATACTCAAACTGAGTGGTTGAAGTGCACCCAAGAAATGCA GCTCACAATTTAGGCGATTCCCCATAATCTATGTCCGGTCAGTTACTCAAATTGGGGTGTAATCATATTAAT ATCATTACGCAATCAAAATCAACCTAAAATGATATTGTTTTAATATTAAAACAATATTAAAAAATCAATATT CAACCCGTGAGATAAAAGAGAAGGTGCGTACACAGTAATGATTGACAATCAATAGTTAATCACTATTATCT TAATATTATTTTAATATTAAAAGGACTAACTATGATACTTACAGTTGGTAATACAA

Search for sigma 70, 24, 32, 28 and 38 promoters

Input sequence file with query sequence(s): /var/www/btssfinder/cgi-bin/userdata/823.fasta

Search parameters: for $E$. coli

TSSs of different Sigma classes are processed separately

Search on Positive Strand

Total scoring threshold for

$$
\begin{array}{ll}
\text { sigma70: } & 0.06 \\
\text { sigma24: } & 0.00 \\
\text { sigma32: } & 1.01 \\
\text { sigma28: } & 1.24 \\
\text { sigma38: } & 0.31
\end{array}
$$

Length of Query sequence: 342

sigma32(+): 288 Score $1.95 \quad-35(254)$ tgattga $\gg>>$ atcactatta $-10(283)$

sigma38(+): 257 Score $1.94 \quad-35(221)$ cgtgag $>>>$ tacaca -10 (249)

sigma28(+): 237 Score $1.97 \quad-35(204)$ aaaatcaa $\gg>$ tgagataa $-10(230)$

sigma70(+): 221 Score $1.97 \quad-35(182)$ tttaat $>>>$ caatat $-10(214)$

sigma24(+): 219 Score $1.97 \quad-35(184)$ taatat $>>>$ tcaat $-10(212)$

Total: 5 promoter(s) predicted 


\section{2) Putative promoters prediction using BPROM (Solovyev and Salamov, 2011)}

a) Putative promoter prediction upstream from hypothetical protein (pil operon)

Input sequence:

CTTGTCTTCGAACCTAGTTTGCTGGGGTTCTAATTACACTCCCGGCATTTAGCAGTTAACCCGGCCTTGTGTC GGGCTCTTTTCCCCCAGATGCGTTACTACAACACTGGATGCCGGCAATGGTGTCTGAGCTGGTCCTGCCATG GACATCCCTATCCCTTTACCGGCTGGTCATTTATGGCGTATTCCTTCTGTTGGAGGGTGATACAGACACCAT TGCCGGCATTCGATACACCAACTCAATTAAAAGGAGATAGCCT

\section{Length of sequence- 260}

Threshold for promoters - 0.20

Number of predicted promoters - 1

Promoter Pos: 196 LDF- 1.43

-10 box at pos. 181 GCGTATTC Score 15

-35 box at pos. 16 TTACCG Score 32

Oligonucleotides from known TF binding sites:

For promoter at 196:

rpoS17: GGAGGGTG at position 197 Score - 12

b) No putative promoters were found upstream from pilL

Input sequence:

CTCCTCTCGTCACCCTAGCAATATCGTCCCCATATACATCAATCGATATGGCTATTCCATTACCTGATGAAA CCTAT

c) Putative promoter prediction upstream from $\operatorname{traN}$

Input sequence:

TCAATCATCACCCGCGATGCCCGCTAATTTTACTCAGGTACTCTCATGAAAAATCTCACTCTCACTGCAGTG GTTATGCTGCTGTCAGCAGTCCCGGCACTCGCGACAGATTGGGTACCAGCCCGCACGGGTAATACACCAAC CACCGAGATCCCAGCGGCACCGAAACCTACAGCACCTCAAAACGAACCTGTAGTCCCTCAAACAGATATCA CTGCCCTGATGCTCCAGACACCACCGCCCACCCCCCCCACTGCAGCCCAAGCATGGGCGATGAGCCAGGCC AACCCTCTGGATAATCGCCAGGGTGTTGAAATGGTAGGCAAAGTGATG

Length of sequence- 333

Threshold for promoters - 0.20

Number of predicted promoters - 1

Promoter Pos: 61 LDF- 1.52

-10 box at pos. 46 ATGAAAAAT Score 39

-35 box at pos. 29 TTTACT Score 42

Oligonucleotides from known TF binding sites:

No such sites for promoter at 61

d) Putative promoter predicted upstream of $\operatorname{trb} A$

Input sequence:

ACGTATCGCCGACGAGCAGGGGCTTAACCTGATCCTGCCGCCAAACTAATTCCCCTTCTGCAGTAACCCAC AGTACCGACTCTGGGGCACCCTTTTCAGGGTGCCTCTTCTTTTGCATTCGCAAAATATTTATAGGTCTCCTCT ATGGCGCAACCCATTCGCAAT

Length of sequence- 165

Threshold for promoters - 0.20

Number of predicted promoters - 1

Promoter Pos: 134 LDF- 1.65

-10 box at pos. 119 TCGCAAAAT Score 47

-35 box at pos. 94 TTTCAG Score 30

Oligonucleotides from known TF binding sites:

No such sites for promoter at 134 
e) Predicted putative promoters were found downstream of $t r b C$

Input sequence:

AACACAACCGAACATCTTACCTACTGAAATAAATACTTCCCCGCCAGCTCCTCCAACCGTTGACTAAACCA TTAGCTCAATAAGCTCAATTTTTTAATCATTAAGGAATGAAAATGACTATCCGTACATTACGGTCAATTACT TTGGCCGGCGTTCTACTTTTGGCTGTCAGTTCTGCCGTTGCAGCCCCGACG

Length of sequence- 194

Threshold for promoters - 0.20

Number of predicted promoters - 1

Promoter Pos: 93 LDF- 2.55

-10 box at pos. 78 CAATAAGCT Score 31

-35 box at pos. 60 TTGACT Score 61

Oligonucleotides from known TF binding sites:

For promoter at 93:

rpoD17: CTAAACCA at position 64 Score - 6

f) Putative promoter prediction upstream of $m o b C$

Input sequence:

TGGCGTTTTTCACTCTTGCTCATCTTCAATCCTGCTTAACCGCTGAGGCGGACACTGCAAGTAGGGTGTCGG GACGGAGTCCTGACCAGGTCGTTTTGTGGGACCGACTGCGTGCAGGCGGTGCTACAAAACATACCCTGTCC CACGTTTTACTTCAGTATTCGCTATTATGGCCGATTTTCTTTATAAAGTCATTACGCCAGATGTGGAATGGG GTACCTTTGATTCATGAGTGAATACAAGGGTATAATTGGAAAGTTAACTCTGCACAAAGCACAGAAGGATA TGAGGATGGCCGCAAACAGT

\section{Length of sequence- 306}

Threshold for promoters - 0.20

Number of predicted promoters - 1

Promoter Pos: 258 LDF- 5.32

-10 box at pos. 243 GGGTATAAT Score 91

-35 box at pos. 222 TTGATT Score 53

Oligonucleotides from known TF binding sites:

No such sites for promoter at 258

g) Putative promoter prediction downstream of $s t b B$

Input sequence:

AGAATTATTTGAGTAAGTTTGTGCATGAGAGTTACTCCAGTTATTCGCGGCACCATTGCCGTGCCGCCACGA CAGTCCTGCGGATAGTGGAGAAAACAAGGGCAGCGCCGCAAGCCGCAGCGCAGGCGTAAACGGGCTGAAT GCCCTGTTTACGGTGAGAACGGGTGAGGACGTTGGCGTCAGCGTTCCCCTTGTTTGTGAAACGGCAGGGCT ACAGTGAAGGCACGGCAAAAGGGGATATTCATACGTGAATAAATAGAACTCAGTTATCACCTAAAATTGT AGATGACTTTTCACTCCCCTTCCCTACCGGATTTTTGGCATGAGCTGTCAGGGCTAACGTATTGAGTAAGCA GCAAACACATTACATGAAGCCCGACATTTTCTT

Length of sequence- 388

Threshold for promoters - 0.20

Number of predicted promoters - 1

Promoter Pos: 287 LDF- 5.40

-10 box at pos. 272 ACCTAAAAT Score 62

-35 box at pos. 248 GTGAAT Score 22

Oligonucleotides from known TF binding sites:

For promoter at 287 :

argR: ATATTCAT at position 238 Score - 7

rpoD17: AATAAATA at position 251 Score - 11

cytR: ATAGAACT at position 256 Score - 7

rpoD19: CACCTAAA at position 271 Score - 6

rpoN: AAATTGTA at position 277 Score - 8

h) Putative promoter prediction upstream of $s t b A$

Input sequence: 
CAAAATACATTCATCATTTTGAACCTCATCAATACTCAAACTGAGTGGTTGAAGTGCACCCAAGAAATGCA GCTCACAATTTAGGCGATTCCCCATAATCTATGTCCGGTCAGTTACTCAAATTGGGGTGTAATCATATTAAT ATCATTACGCAATCAAAATCAACCTAAAATGATATTGTTTTAATATTAAAACAATATTAAAAAATCAATATT CAACCCGTGAGATAAAAGAGAAGGTGCGTACACAGTAATGATTGACAATCAATAGTTAATCACTATTATCT TAATATTATTTTAATATTAAAAGGACTAACTATGATACTTACAGTTGGTAATACAA

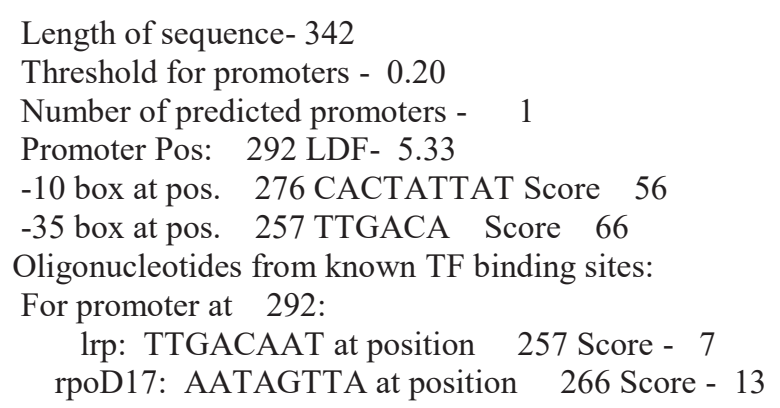

i) Putative promoter prediction upstream of parA Input sequence:

CAAAATACATTCATCATTTTGAACCTCATCAATACTCAAACTGAGTGGTTGAAGTGCACCCAAGAAATGCA GCTCACAATTTAGGCGATTCCCCATAATCTATGTCCGGTCAGTTACTCAAATTGGGGTGTAATCATATTAAT ATCATTACGCAATCAAAATCAACCTAAAATGATATTGTTTTAATATTAAAACAATATTAAAAAATCAATATT CAACCCGTGAGATAAAAGAGAAGGTGCGTACACAGTAATGATTGACAATCAATAGTTAATCACTATTATCT TAATATTATTTTAATATTAAAAGGACTAACTATGATACTTACAGTTGGTAATACAA

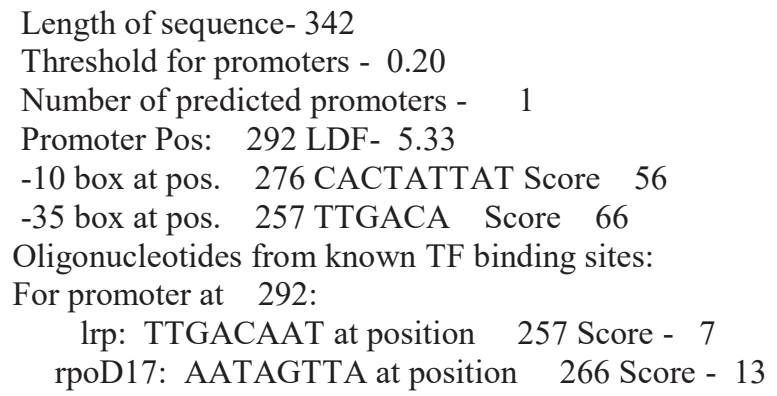

\section{Supplementary figure 2 .}

Molecular Phylogenetic analysis of pYR4 RepA protein to its closest homologs from different species within IncFII and IncA/C plasmid family. The tree shows two different clusters which resemble two different plasmid groups including IncFII (depicted in green) and IncA/C plasmid family (depicted in red). Note that the pYR4 RepA falls into the same cluster as other RepA Yersiniae protein sequences from the same plasmid family. The tree with the highest log likelihood $(-5236.58)$ is shown. The percentage of trees in which the associated taxa clustered together is shown next to the branches. Initial tree(s) for the heuristic search were obtained automatically by applying Neighbor-Join and BioNJ algorithms to a matrix of pairwise distances estimated using a JTT model, and then selecting the topology with superior log likelihood value. The tree is drawn to scale, with branch lengths measured in the number of substitutions per site. The analysis involved 40 amino acid sequences. All positions containing gaps and missing data were eliminated. There were a total of 210 positions in the final dataset. Evolutionary analyses were conducted in MEGA X. 


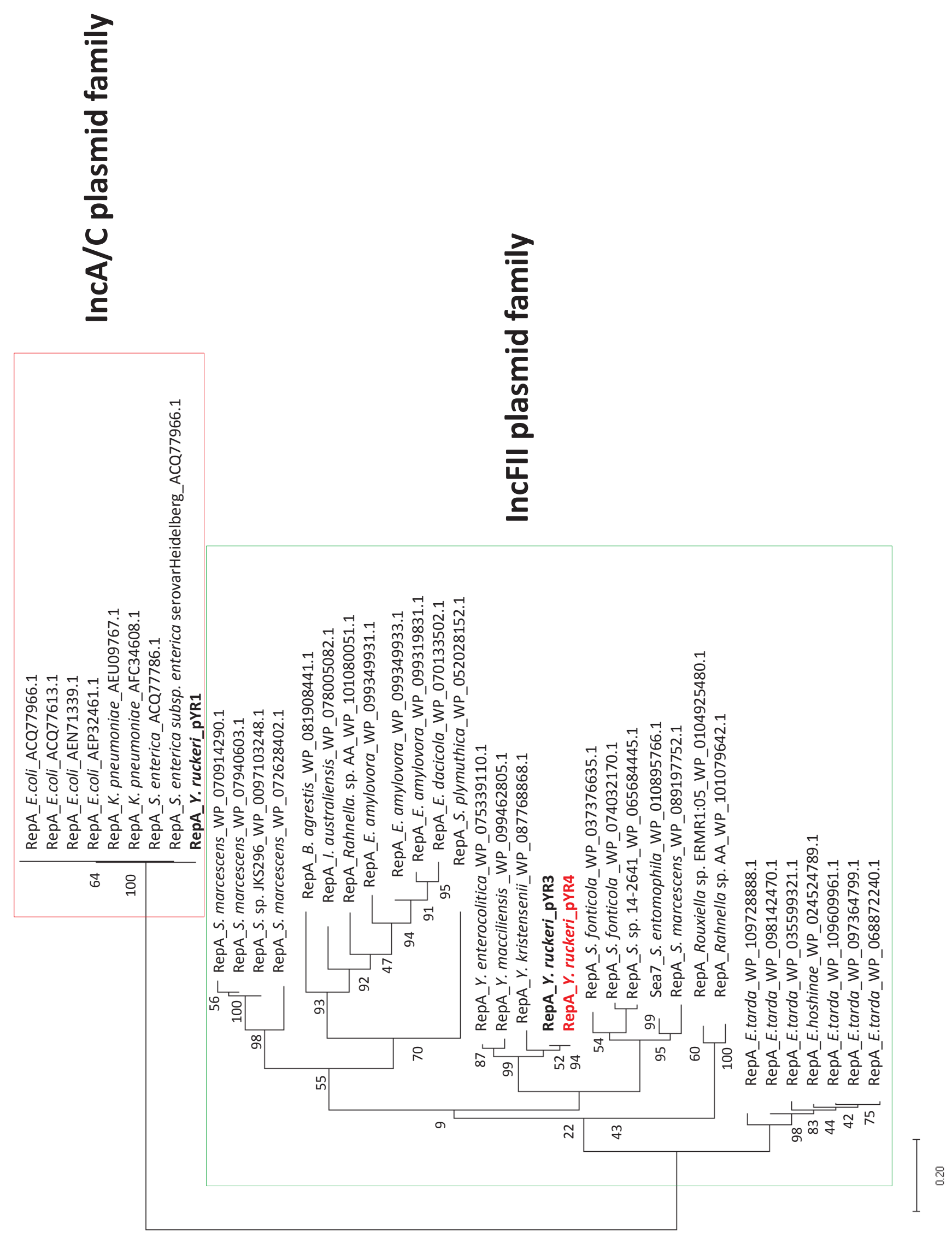




\section{Supplementary figure 3 .}

pYR4 plasmid annotations obtained by employing RAST (Rapid Annotation using Subsystem Technology)(Aziz et al., 2008) and HHpred available at the Max Planck Institute for Developmental Biology Toolkit (Söding et al., 2005)

\section{Supplementary figure 4.}

Y. ruckeri plasmids annotations obtained using RAST (Rapid Annotation using Subsystem Technology)(Aziz et al., 2008). The file contains 6 different $Y$. ruckeri plasmid sequences (nucleotide and protein) including pYR1, pYR2, pYR3, pYR4, pLT, pWKY together with their proposed functions.

\section{Supplementary figure 5 .}

Gen Bank Accession numbers for genome sequences (plasmid/chromosome) used in the study.

\begin{tabular}{|c|c|c|}
\hline Species & Genomic information & GenBank \\
\hline \multirow[t]{4}{*}{ E. amylovora } & pEL60 & AY422214 \\
\hline & pEA68 & HG813238 \\
\hline & pEA72 & NC_013973 \\
\hline & pEA78 & NC_023072 \\
\hline S. entomophila & pADAP & AF135182 \\
\hline C. freundii & pCTX-M3 & AF550415 \\
\hline $\begin{array}{l}\text { S. enterica subsp. enterica } \\
\text { serovar Typhimurium }\end{array}$ & R64 & NC_005014.1 \\
\hline Y. ruckeri CSF007-82 & Chromosome & LN681231 \\
\hline Y. ruckeri Big Creek 74 & Chromosome & NZ_CP011078.1 \\
\hline Y. ruckeri QMA0440 & Chromosome & СР017236.1 \\
\hline
\end{tabular}


Supplementary Material

\begin{tabular}{|c|c|c|}
\hline Y. ruckeri SC09 & Chromosome & CP025800.1 \\
\hline Y. ruckeri ATCC29473 & Chromosome & KN150747.1 \\
& & KN150748.1 \\
\hline Y.ruckeri YRB & Chromosome & CP009539.1 \\
\hline Y.ruckeri 150 & Chromosome & GCF_001750505.1 \\
\hline Y.pestis CO92 & Chromosome & AL590842 \\
\hline Y. pseudotuberculosis YPIII & Chromosome & CP000950.1 \\
\hline Y. enterocolitica 8081 & Chromosome & NC_008800.1 \\
\hline
\end{tabular}




\section{Supplementary figure 6.}

Circular representation of comparative analysis as in Figure 2 showing ribbon links of ATCC29473 with the two plasmids, pYR3 and pYR4. 


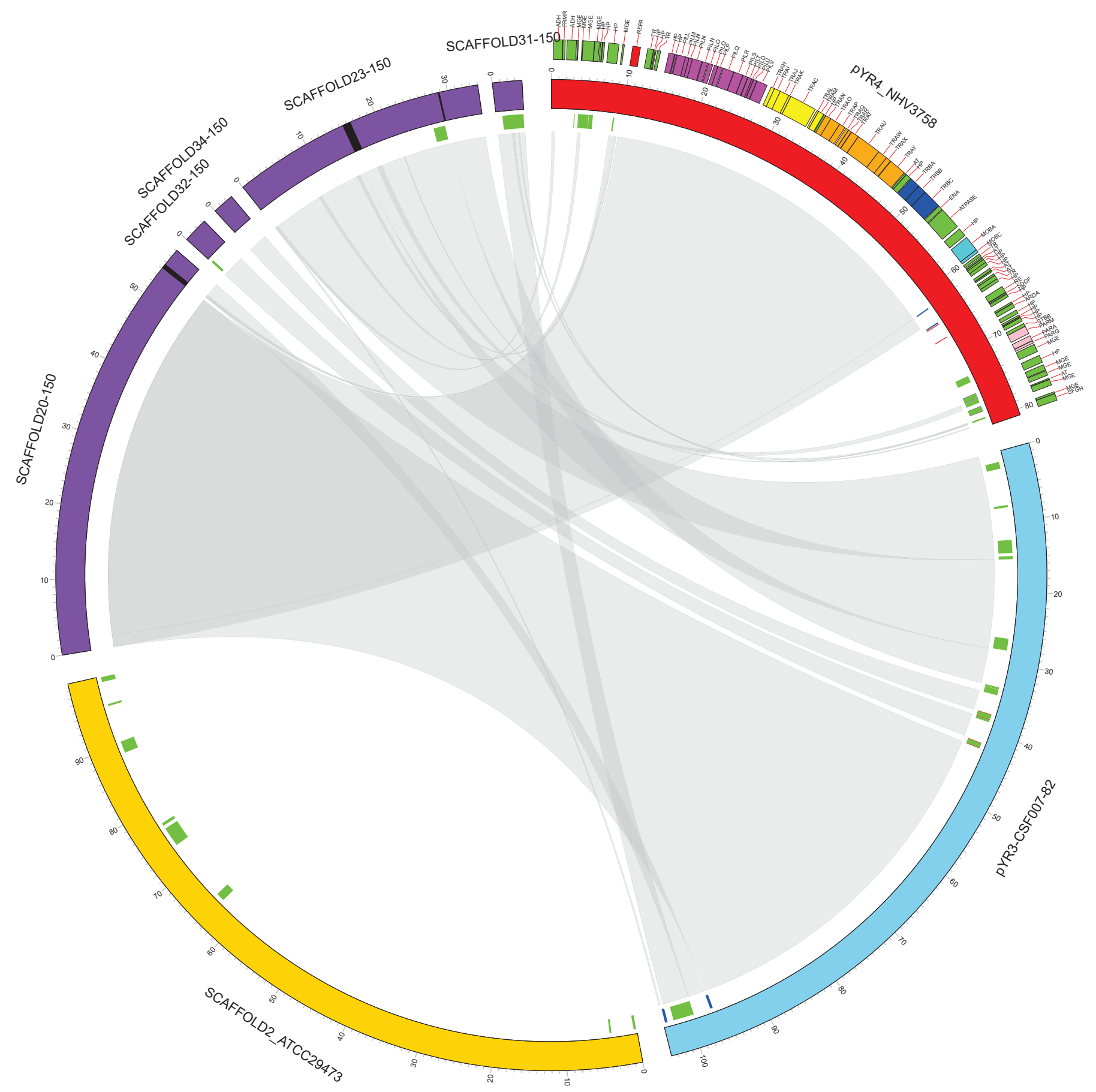


Supplementary Material

\section{Supplementary figure 7 .}

Circular representation of comparative analysis as in Figure 2 showing ribbon links of 150 with the two plasmids, pYR3 and pYR4. 


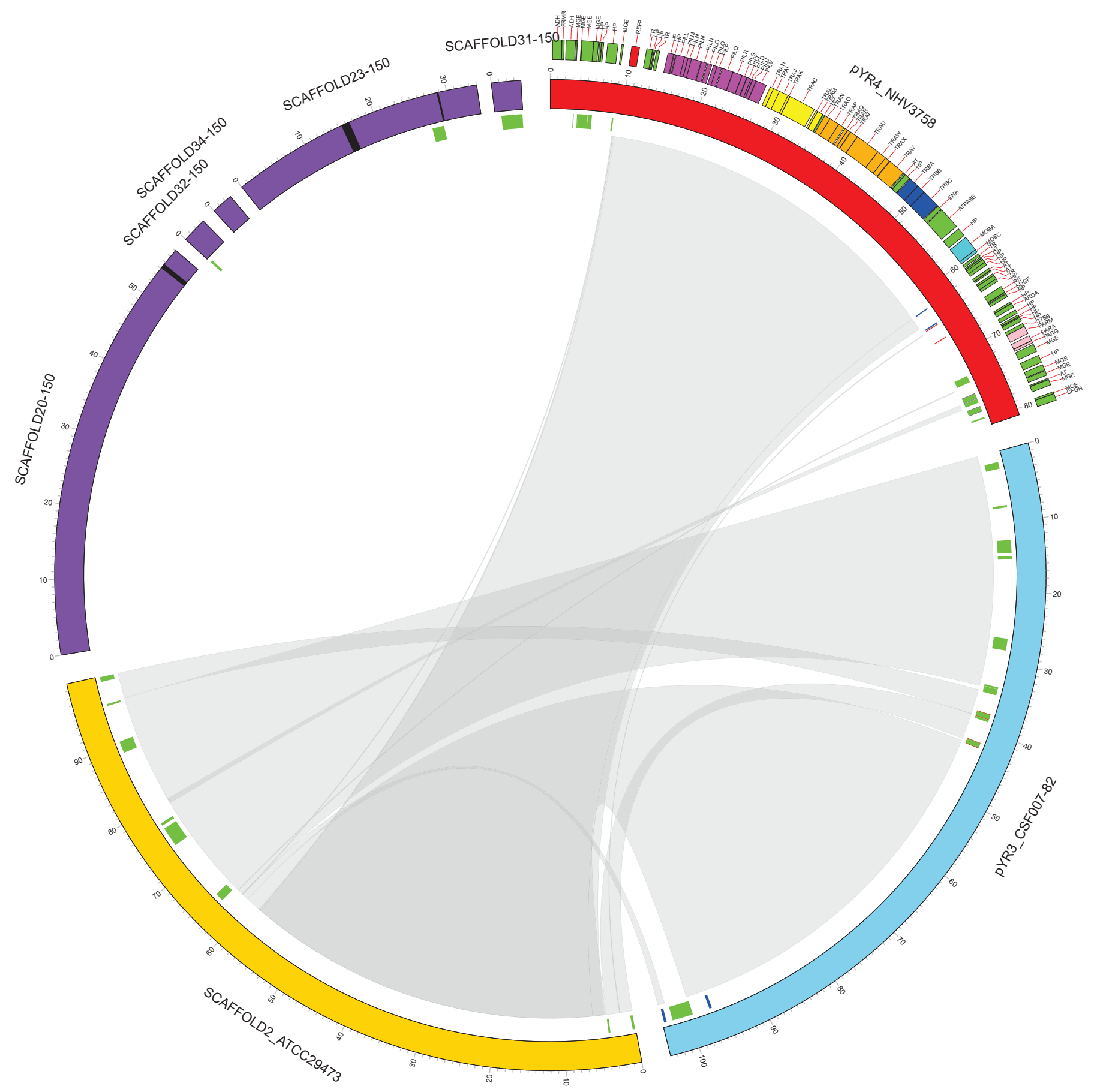


